\title{
A STUDY OF CYLINDER BORE DISTORTION IN V6 ALUMINUM ALLOY ENGINE BLOCKS
}

\author{
by \\ Anthony Lombardi \\ B. Eng., Ryerson University, 2009
}

\begin{abstract}
A thesis
presented to Ryerson University

in partial fulfillment of the

requirements for the degree of
\end{abstract}

Master of Applied Science

in the Program of

Mechanical Engineering

Toronto, Ontario, Canada, 2011

Copyright (C) Anthony Lombardi 2011 


\section{Author's Declaration}

I hereby declare that I am the sole author of this thesis.

I authorize Ryerson University to lend this thesis to other institutions or individuals for the purpose of scholarly research.

Anthony Lombardi

I further authorize Ryerson University to reproduce this thesis by photocopying or by other means, in total or in part, at the request of other institutions or individuals for the purpose of scholarly research.

Anthony Lombardi 


\title{
Abstract \\ A STUDY OF CYLINDER BORE DISTORTION IN V6 ALUMINUM ALLOY ENGINE BLOCKS
}

\author{
Master of Applied Science, 2011 \\ Anthony Lombardi \\ Mechanical Engineering \\ Ryerson University
}

This study investigates the potential factors which may cause cylinder bore distortion in V6 aluminum engine block with cast-in gray iron liners. In this research, the microstructure, mechanical properties and residual stress of 319 type aluminum alloy engine blocks were analyzed from top to bottom along the interbore regions in the TSR, T7 heat treated and service (dyno) tested conditions. The results suggest that the cooling rate increased significantly along the cylinder in the vicinity of the chill plate at the bottom of the engine block. This caused a significant refinement in the microstructure which increased the hardness and tensile strength at the bottom of the cylinder relative to the top. The increased strength at the bottom of the cylinder prevented the rapid relief of residual stress at elevated temperature, which suggests that the bottom of the cylinder is less susceptible to cylinder distortion. 


\section{Acknowledgements}

There are many people around me in my professional and personal life that deserve credit for the completion of this thesis. I would like to first express my deepest gratitude to Professor C. Ravindran for his constant guidance, support and advice. If not for his knowledge and motivation, this project would not have been completed as it was.

I would also like to thank Mr. Alan Machin and Mr. Francesco D'Elia for their technical knowledge, useful discussions, assistance with experiments and interpretation of results.

The author would also like to express his sincere gratitude to Dr. Robert MacKay and Dr. Glenn Byczynski from Nemak Canada for providing the engine block castings as well as in-kind contributions to the project.

The author is grateful for the assistance of Dr. Dimitry Sediako of the Canadian Neutron Beam

Centre in Chalk River, Canada and Professor B.S. Murty of the Indian Institute of Technology Madras for use of facilities, assistance with experiments and discussions regarding results.

Furthermore, the author thanks all the help provided by Dr. Sophie Lun Sin, Mr. Abdallah Elsayed and Mr. Mihai Vlasceanu from the Centre for Near-Net-Shape Processing of Materials at Ryerson University and the help of Mr. Papa Rao Mondi, Mr. Joseph Berkmans and Mr. Nikhil Charbhai at the Indian Institute of Technology Madras.

Finally, I am deeply grateful for the undying love and support I have received from my family and my wonderful girlfriend Allison during this project. Without them, completion of this work would not have been possible. 


\section{Table of Contents}

Author's Declaration.......................................................................................................................

Abstract ..................................................................................................................................ii

Acknowledgements ................................................................................................................................ iv

Table of Contents ................................................................................................................ v

List of Tables..............................................................................................................................

List of Figures....................................................................................................................................

List of Appendices ............................................................................................................................ $\mathrm{xV}$

Nomenclature.................................................................................................................................

Chapter 1: Introduction ............................................................................................................................ 1

Chapter 2: Literature Review ..............................................................................................................

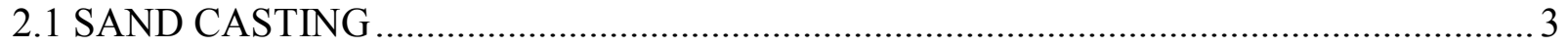

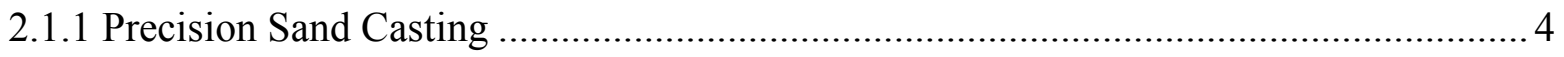

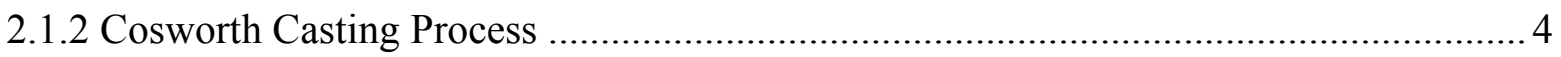

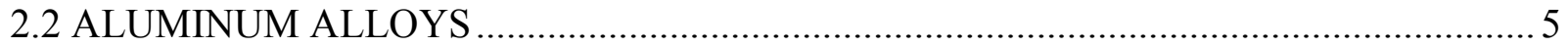

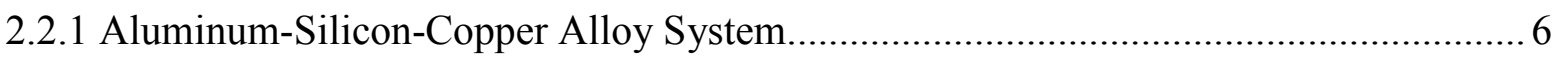

2.2.2 Microstructure of 319 Type Aluminum Alloys ........................................................... 6

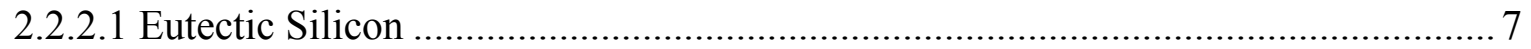

2.2.2.2 Iron Bearing Intermetallics....................................................................... 8

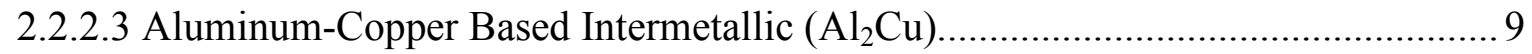

2.2.2.4 Magnesium Bearing Intermetallics ...................................................................... 10

2.2.3 Development of Microstructure in 319 Alloys ............................................................ 10

2.3 HEAT TREATMENT OF ALUMINUM ALLOYS ...................................................... 12

2.3.1 Solution Heat Treatment and Quenching................................................................ 12

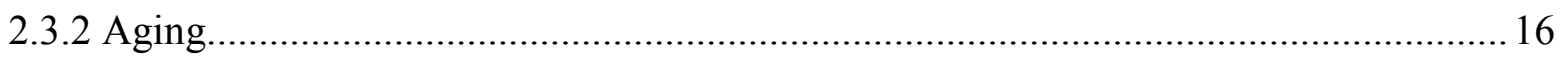

2.3.3 Influence of Heat Treatment on Mechanical Properties ................................................ 19

2.4 RESIDUAL STRESSES IN ENGINEERING COMPONENTS .......................................2

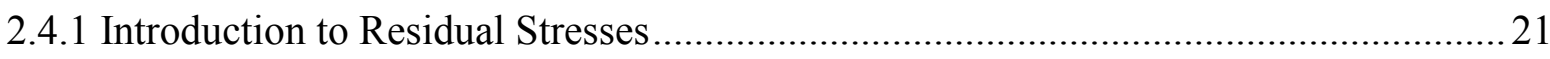

2.4.2 Development of Residual Stresses in Engineering Components .................................2 23

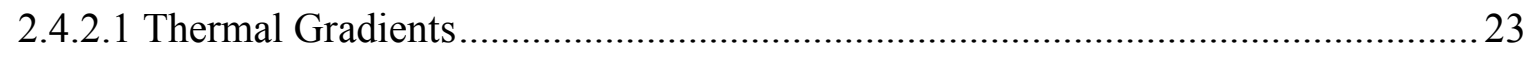


2.4.2.2 Mismatch of Thermal Expansion Coefficient ………………………………..... 24

2.4.2.3 Mechanical Loading .........................................................................................2 25

2.4.3 Residual Stresses in Aluminum Engine Blocks..........................................................26

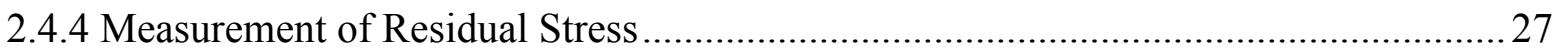

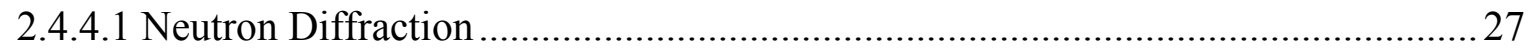

2.4.4.2 Comparison of Neutron Diffraction to X-ray Diffraction....................................... 30

2.5 MECHANISMS OF DIMENSIONAL DISTORTION IN ALUMINUM ALLOYS .......... 30

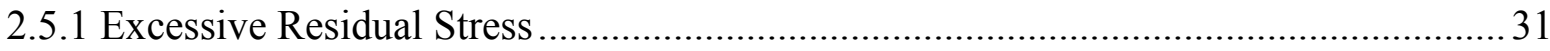

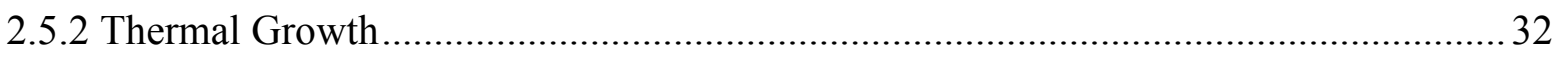

Chapter 3: Experimental Procedure ...........................................................................................................3 37

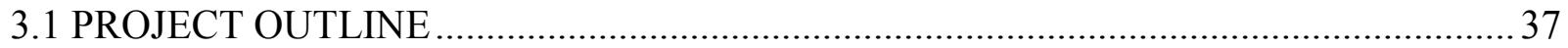

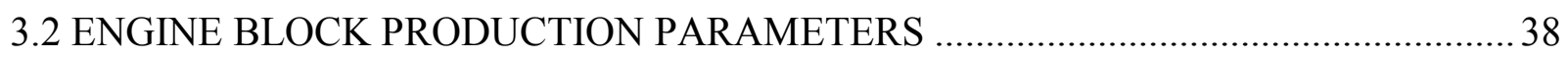

3.3 LOCATIONS ANALYZED IN ENGINE BLOCKS ...................................................... 40

3.4 OPTICAL AND SCANNING ELECTRON MICROSCOPY ………………….............. 42

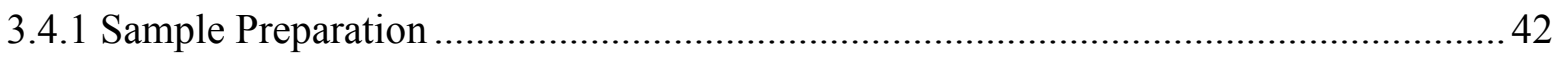

3.4.2 Measurement of Secondary Dendrite Arm Spacing (SDAS) ……………................. 43

3.4.3 Quantitative Image Analysis .................................................................................... 43

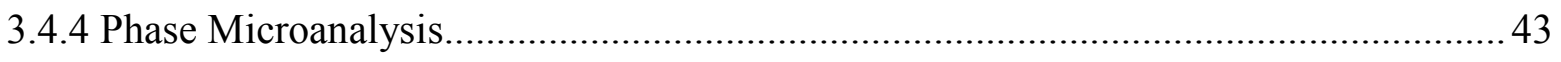

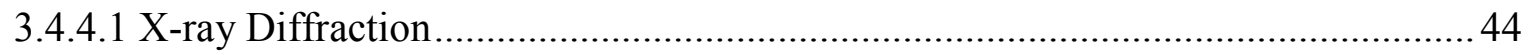

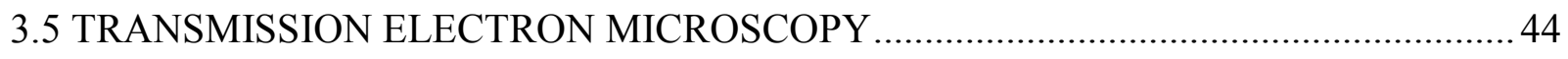

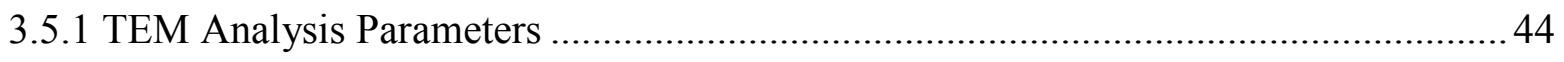

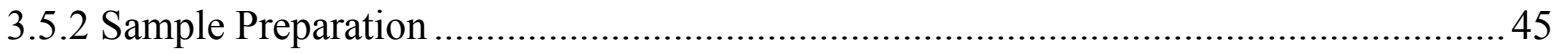

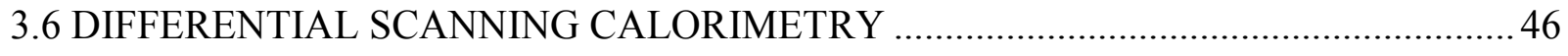

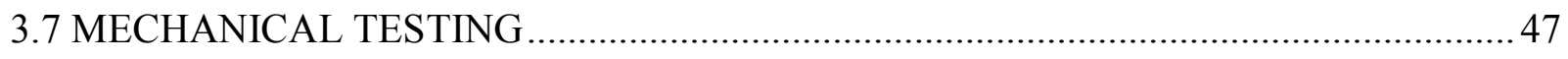

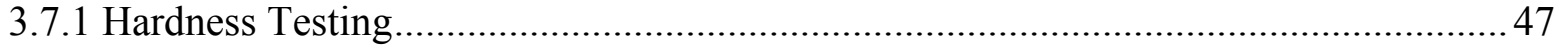

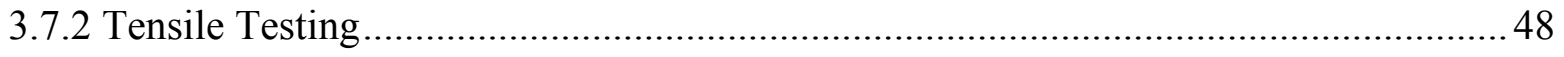

3.8 STRAIN MEASUREMENTS USING NEUTRON DIFFRACTION .............................. 48

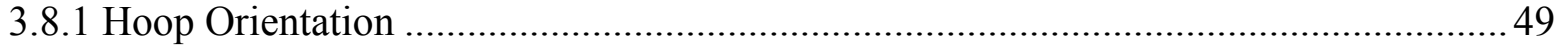

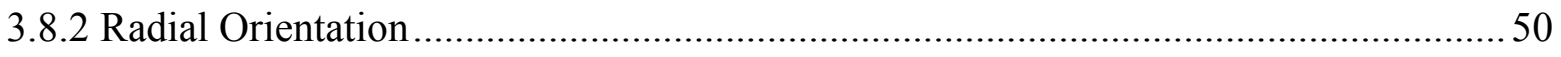

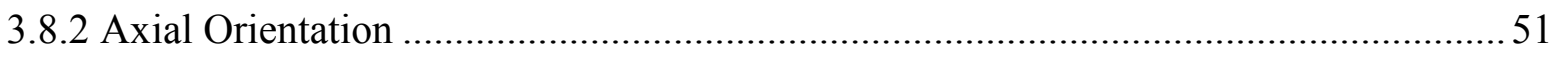

3.9 MEASUREMENT OF CYLINDER BORE DISTORTION .............................................51 
Chapter 4: Results and Discussion .............................................................................................52

4.1 ANALYSIS OF CYLINDER BORE DISTORTION …………...................................52

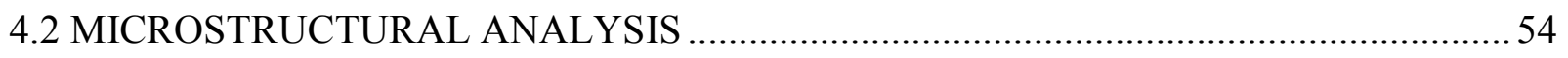

4.2.1 Dendritic Structure in the Aluminum Cylinder Bridge.................................................5 54

4.2.2 Secondary Phase Analysis in the Aluminum Cylinder Bridge .................................... 56

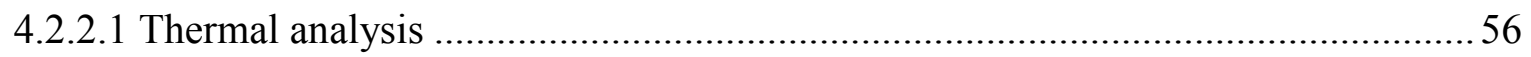

4.2.2.2 Secondary Phases in Interdendritic Regions …………......................................... 58

4.2.2.3 Secondary Phases at the Al-Fe Liner Interface ……………………………….... 63

4.2.2.4 Effect of Heat Treatment on Secondary Phase Distribution .................................. 65

4.2.2.5 Secondary Phases within Aluminum Dendrites .................................................... 67

4.2.3 Microstructure in the Gray Iron Cylinder Liners ......................................................... 72

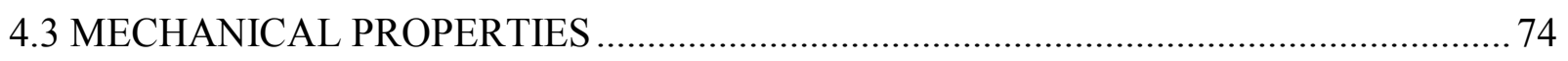

4.3.1 Hardness of Microstructural Constituents ................................................................ 74

4.3.1.1 Hardness at the Particle-Aluminum Dendrite Interface ......................................... 76

4.3.2 Macrohardness of the Aluminum Cylinder Bridge Region .......................................... 77

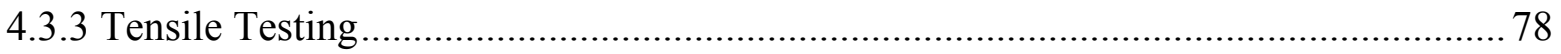

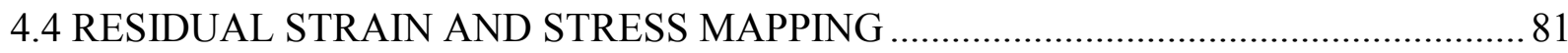

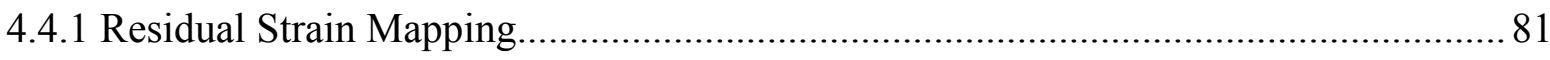

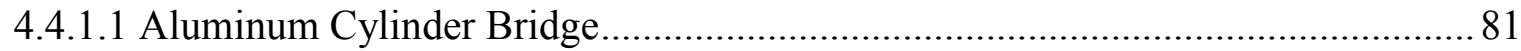

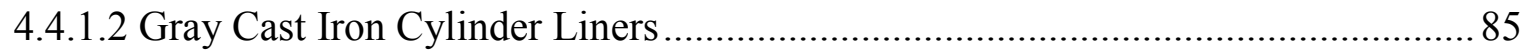

4.4.2 Residual Stress Mapping in the Aluminum Cylinder Bridge ……………………...... 88

Chapter 5: Conclusions.............................................................................................................93

Chapter 6: Recommendations for Future Work ................................................................................96

Back Matter ..............................................................................................................................................99

APPENDIX A: CALCULATIONS PERTAINING TO CONFIDENCE LIMITS OF

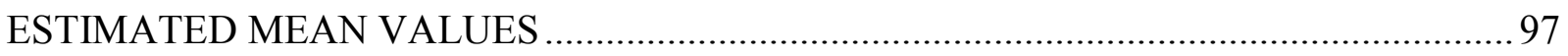

APPENDIX B: ANALYSIS OF VARIANCE ............................................................... 104

B.1 Secondary Dendrite Arm Spacing........................................................................... 104

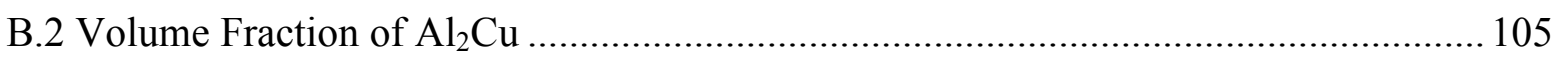

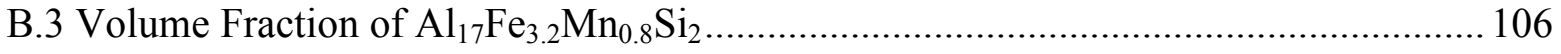

B.4 Volume Fraction of Eutectic Silic on .......................................................................... 107 
B.5 Copper Content within the Aluminum Dendrites ............................................... 108

B.6 Magnesium Content within the Aluminum Dendrites ........................................... 109

B.7 Hardness of the Aluminum Dendrites ................................................................... 110

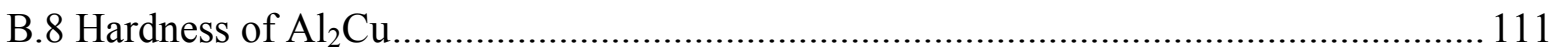

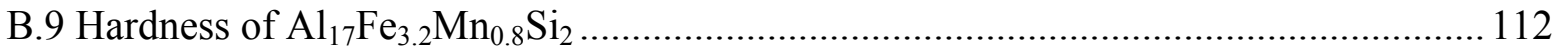

B.10 Hardness of Eutectic Silicon .................................................................................. 113

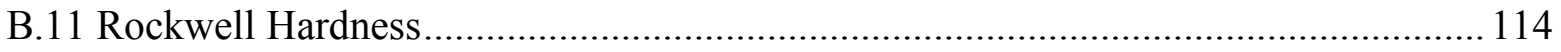

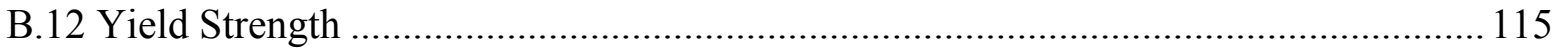

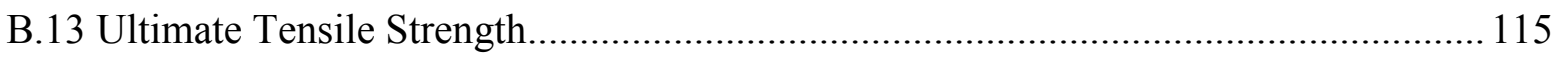

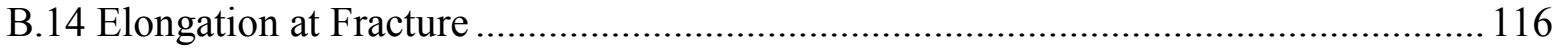

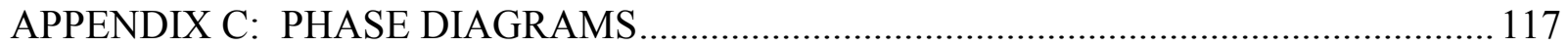

C.1 Aluminum-Silicon-Copper Ternary Phase Diagram............................................. 117

C.1 Aluminum-Silicon Binary Phase Diagram....................................................... 118

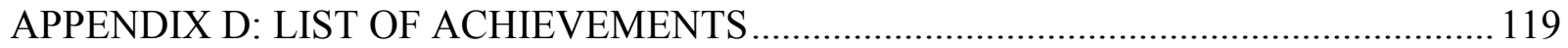

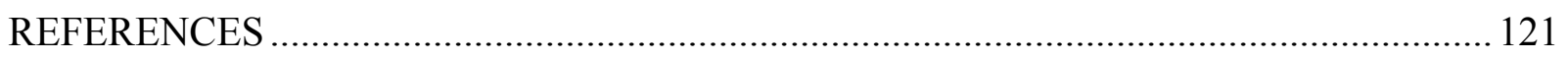




\section{List of Tables}

Table 1: Tensile properties of Al-6\%Si alloy, modified with additions of sodium, antimony and strontium [13].

Table 2: Description of phase formation reactions during solidification of Al-6Si-3.5Cu [19]... 11

Table 3: Composition of 319 type aluminum alloy engine block (wt.\%) from batch analysis..... 39

Table 4: Parameters used for heat treatment of the aluminum engine blocks............................. 40

Table 5: Metallographic polishing procedure ......................................................................... 42

Table 6: Abrasive grinding procedure used to produce thin plate samples for TEM analysis. .... 45

Table 7: Optimized parameters used in twin-jet electropolishing.......................................... 46

Table 8: Experimental parameters used for solidification and solution heat treatment

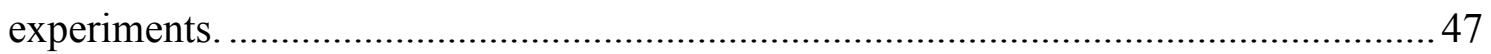

Table 9: Roundness values at various depths along the cylinder bores. .....................................53

Table 10: Comparison of phase formation temperatures during solidification of 319 aluminum alloys

Table A1: Calculated 95\% confidence intervals for SDAS measurements in cylinder (2-4) bridge. Calculations performed with $\mathrm{N}=25$.

Table A2: Calculated 95\% confidence intervals for $\mathrm{Al}_{2} \mathrm{Cu}$ volume fraction measurements in cylinder (2-4) bridge. Calculations performed with $\mathrm{N}=17$ for the top of the cylinder and $\mathrm{N}=25$ for the bottom

Table A3: Calculated 95\% confidence intervals for $\mathrm{Al}_{17} \mathrm{Fe}_{3.2} \mathrm{Mn}_{0.8} \mathrm{Si}_{2}$ volume fraction measurements in cylinder (2-4) bridge. Calculations performed with $\mathrm{N}=16$ for the top of the cylinder and $\mathrm{N}=25$ for the bottom.

Table A4: Calculated 95\% confidence intervals for eutectic silicon volume fraction measurements in cylinder (2-4) bridge. Calculations performed with $\mathrm{N}=21$. 99

Table A5: Calculated 95\% confidence intervals for composition of the aluminum dendrites for cylinder (2-4) bridge. Calculations performed with $\mathrm{N}=10$. 100

Table A6: Calculated 95\% confidence intervals for $\mathrm{Al}_{2} \mathrm{Cu}$ volume fraction measurements at the Al-Fe liner interface for the bottom of cylinder (2-4) and (4-6) bridge. Calculations performed with $\mathrm{N}=9$.

Table A7: Calculated 95\% confidence intervals for Rockwell hardness measurements of cylinder (2-4) bridge. Calculations performed with $\mathrm{N}=5$.

Table A8: Calculated 95\% confidence intervals for hardness of microstructural constituents in cylinder (2-4) bridge. Calculations performed with $\mathrm{N}=7$. 102

Table A9: Calculated 95\% confidence intervals for the yield strength in each treatment condition. Calculations performed with $\mathrm{N}_{\mathrm{TSR}}=10, \mathrm{~N}_{\mathrm{T} 7}=13, \mathrm{~N}_{\text {dyno }}=8$.. 103

Table A10: Calculated 95\% confidence intervals for the ultimate tensile strength in each treatment condition. Calculations performed with $\mathrm{N}_{\mathrm{TSR}}=10, \mathrm{~N}_{\mathrm{T} 7}=13, \mathrm{~N}_{\text {dyno }}=8 \ldots 103$ 
Table A11: Calculated 95\% confidence intervals for the fracture elongation in each treatment condition. Calculations performed with $\mathrm{N}_{\mathrm{TSR}}=5, \mathrm{~N}_{\mathrm{T} 7}=10, \mathrm{~N}_{\mathrm{dyno}}=5$.

Table B1: Results from 2-Factor ANOVA analysis of the SDAS at the cylinder bridge. 104

Table B2: Results from 2-Factor ANOVA analysis of the $\mathrm{Al}_{2} \mathrm{Cu}$ volume fraction at the cylinder bridge. 105

Table B3: Results from 2-Factor ANOVA analysis of the $\mathrm{Al}_{17} \mathrm{Fe}_{3.2} \mathrm{Mn}_{0.8} \mathrm{Si}_{2}$ volume fraction at the cylinder bridge. 106

Table B4: Results from 2-Factor ANOVA analysis of the eutectic silicon volume fraction at the cylinder bridge. 107

Table B5: Results from 2-Factor ANOVA analysis of the copper content within the aluminum dendrites. 108

Table B6: Results from 2-Factor ANOVA analysis of the magnesium content within the aluminum dendrites.

Table B7: Results from 2-Factor ANOVA analysis of the hardness of the aluminum dendrites.

Table B8: Results from 2-Factor ANOVA analysis of the hardness of $\mathrm{Al}_{2} \mathrm{Cu}$ 111

Table B9: Results from 2-Factor ANOVA analysis of the hardness of $\mathrm{Al}_{17} \mathrm{Fe}_{3.2} \mathrm{Mn}_{0.8} \mathrm{Si}_{2}$. 112

Table B10: Results from 2-Factor ANOVA analysis of the hardness of eutectic silicon. 113

Table B11: Results from 2-Factor ANOVA analysis of Rockwell hardness. 114

Table B12: Results from 1-Factor ANOVA analysis on the yield strength. 115

Table B13: Results from 1-Factor ANOVA analysis on the ultimate tensile strength. 115

Table B14: Results from 1-Factor ANOVA analysis on the elongation at fracture 116 


\section{List of Figures}

Figure 1: Schematic of the components in a typical sand mould [6] .......................................... 3

Figure 2: Schematic of an engine block mould utilized in the Nemak Cosworth process [8] ........5

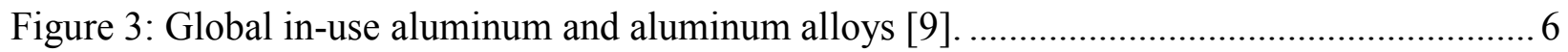

Figure 4: Optical micrographs of A319 in the as-cast condition with: (a) unmodified silicon eutectic, (b) strontium modified silicon eutectic [11] ................................................

Figure 5: Backscattered electron images for an Al-6.5Si-3.5Cu alloy with an Fe:Mn ratio of:

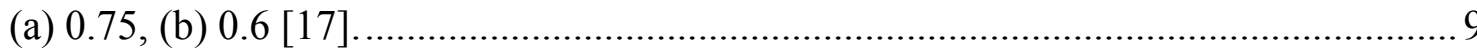

Figure 6: Tensile properties of a 319 alloy as a function of the Fe:Mn ratio showing: (a) ultimate tensile strength and yield strength in as-cast and T6 heat treated conditions, (b) percent elongation in the T6 condition [17] ...................................................................

Figure 7: Backscattered electron image of $\mathrm{A} 319$ in the as-cast condition showing: (a) eutectic $\mathrm{Al}_{2} \mathrm{Cu}$ morphology, (b) blocky $\mathrm{Al}_{2} \mathrm{Cu}$ morphology [11] ......................................... 10

Figure 8: Cooling curve and first derivative curve showing the formation of phases during solidification for an Al-6Si-3.5Cu-0.6Mg 319 type alloy [19] ..................................... 11

Figure 9: Aluminum rich portion of the Al-Cu binary phase diagram [22] ................................ 13

Figure 10: Graph showing the influence of solutionizing temperature and time on dissolution of

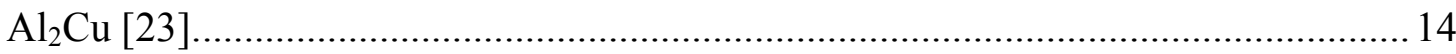

Figure 11: Graph showing influence of solidification time on dissolution of $\mathrm{Al}_{2} \mathrm{Cu}$ at a constant solutionizing temperature of $495^{\circ} \mathrm{C}$ and varying solutionizing time [27] ................. 15

Figure 12: Precipitation sequence and structure of each precipitate formed during the aging of

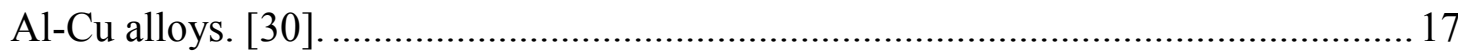

Figure 13: Bright field TEM image with corresponding selected area diffraction pattern along the [001] zone axis showing $\theta$ ' phase in the aluminum matrix [31]. 18

Figure 14: Variation in hardness with artificial aging time for: (a) $\mathrm{Al}-7 \mathrm{Si}-3 \mathrm{Cu}$ [33], (b) $\mathrm{Al}-7 \mathrm{Si}-0.45 \mathrm{Mg}-\mathrm{xCu}[34]$.

Figure 15: Mechanism of dislocations bypassing particles by: (a) particle shearing, (b) bending of dislocations [36].

Figure 16: Schematic of grain structure showing characteristic length for the three types of residual stress [41].

Figure 17: Qualitative stress distribution induced by thermal expansion mismatch between layers [44]. .25

Figure 18: Modeled residual stress distribution of an I-4 319 aluminum engine block with cast-in iron liners [46].

Figure 19: Schematic showing: (a) sampling volume formed from incident and diffracted beams, (b) direction of scattering vector with respect to the lattice planes, (c) magnitude of the scattering vector [47]. 28

Figure 20: Schematic of the combustion chamber (piston-cylinder assembly) within an engine showing the stresses experienced by the material while in-service [50]. 32 
Figure 21: Unit change in lattice parameter of the aluminum matrix with amount of dissolved alloying elements [53].

Figure 22: Observed dimensional changes due to the precipitation of age hardening precipitates during aging of Al-Cu alloys [53].

Figure 23: Dimensional growth of W319 aluminum alloy in the T4, T6 and T7 heat treatment condition while exposed to: (a) $180{ }^{\circ} \mathrm{C}$, (b) $250^{\circ} \mathrm{C}$ [54].... 35

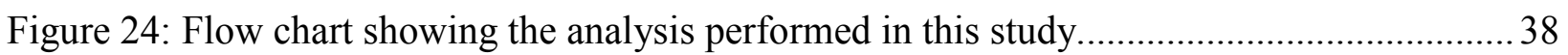

Figure 25: Schematic showing isometric view of an engine block casting with gating system (Courtesy Dr. Robert MacKay, Nemak of Canada Corporation).

Figure 26: Top view of the 319 aluminum engine block indicating analyzed locations and cylinder numbering.

Figure 27: (a) Cross-section of cylinder bridge showing sections analyzed along cylinder depth,

(b) sectioned cylinder bridge showing locations of extracted tensile samples.

Figure 28: Orientation of incident (labeled A) and scattering (labeled C) beams in the measurement of hoop component of strain in cylinder (4-6) bridge: (a) control system map; (b) actual positioning of the engine block on the spectrometer sample table...... 50

Figure 29: Orientation of incident (labeled A) and scattering (labeled C) beams in the measurement of radial component of strain in cylinder (4-6) bridge; (a) control system map; (b) actual positioning of the engine block on the spectrometer sample table......50

Figure 30: Orientation of incident (labeled A) and scattering (labeled C) beams in the measurement of radial component of strain in cylinder (4-6) bridge; (a) control system map; (b) actual positioning of the engine block on the spectrometer sample table......51

Figure 31: Measured radial deviation from the nominal cylinder diameter for: (a) cylinder 2, (b) cylinder 6 . .53

Figure 32: Optical micrographs showing the dendrite structure of: (a) cylinder (2-4) bridge top, (b) cylinder (2-4) bridge upper middle, (c) cylinder (2-4) bridge lower middle,

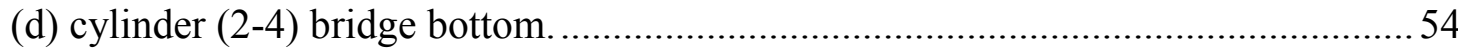

Figure 33: SDAS measurements for: (a) cylinder (2-4) bridge, (b) cylinder (4-6) bridge........... 55

Figure 34: Estimated cooling rate during solidification for each section of the cylinder bridge.. 56

Figure 35: Cooling curve generated using differential scanning calorimetry showing phase formation temperatures during solidification at a cooling rate of $1{ }^{\circ} \mathrm{C} / \mathrm{s}$. ...................57

Figure 36: Results of X-ray diffraction performed on extracted secondary phase particles.........58

Figure 37: Backscattered electron images and optical micrographs of: (a) and (b) cylinder (4-6) bridge TSR top, (c) and (d) cylinder (4-6) bridge TSR bottom.

Figure 38: Amount of $\mathrm{Al}_{2} \mathrm{Cu}$ at the top and bottom of the cylinder (2-4) and (4-6) bridge for various treatments.

Figure 39: Amount of $\mathrm{Al}_{17} \mathrm{Fe}_{3.2} \mathrm{Mn}_{0.8} \mathrm{Si}_{2}$ at the top and bottom of the cylinder (2-4) and (4-6) bridge for various treatments.

Figure 40: Amount of eutectic silicon at the top and bottom of the cylinder (2-4) and (4-6) bridge for various treatments. 
Figure 41: Backscattered electron image of the Al-Fe liner interface region for cylinder (4-6) T7 bottom.

Figure 42: Amount of $\mathrm{Al}_{2} \mathrm{Cu}$ at the $\mathrm{Al}-\mathrm{Fe}$ interface for the bottom of the cylinder for various treatments.

Figure 43: Results from isothermal hold experiment using DSC at $480{ }^{\circ} \mathrm{C}$ for 7.5 hours

Figure 44: Composition of the aluminum matrix for various treatments for cylinder (2-4) bridge.

Figure 45: (a) Bright field TEM image of Cylinder (2-4) TSR top (11500x), (b) selected area diffraction pattern of the matrix, (c) bright field TEM image of cylinder (2-4) TSR top (20000x) showing the location where EDX analysis was performed on the rod precipitates, (d) corresponding EDX spectrum for the rod-like precipitate. 68

Figure 46: Bright field TEM images of: (a) cylinder (2-4) T7 top (11500x), (b) EDX spectrum for Al-Cu platelet precipitates. (c) cylinder (2-4) Dyno bottom (11500x). . 70

Figure 47: Selected area diffraction patterns for an area encompasssing the matrix and a single cluster of age hardening precipitates for cylinder (2-4) T7 top. (a) [011] zone axis, (b) [011] zone axis with sample tilted. 70

Figure 48: Dark field TEM image corresponding to additional spots outlined by circles in Figure 47.

Figure 49: Optical micrographs of: (a) top section of the gray cast iron cylinder liner, (b) bottom section of the gray cast iron cylinder liner. 73

Figure 50: Load-displacement curves for each analyzed phase............................................ 74

Figure 51: Hardness of each phase for the top and bottom of cylinder (2-4) bridge in each treatment condition 75

Figure 52: (a) Hardness distribution across the particle-aluminum dendrite interface (Distance $=0$ ) for each analyzed phase, (b) and (c) AFM images showing the Al-Fe$\mathrm{Mn}-\mathrm{Si}$ and $\mathrm{Al}_{2} \mathrm{Cu}$ phases respectively. .76

Figure 53: Rockwell hardness for cylinder (2-4) and (4-6) bridge in each treatment condition... 78

Figure 54: Cylinder bridge tensile strength.................................................................... 79

Figure 55: Cylinder bridge fracture elongation............................................................. 80

Figure 56: Residual strain profiles along the aluminum cylinder bridge in the TSR condition. .. 81

Figure 57: Residual strain profiles along the aluminum cylinder bridge in the T7 condition. ..... 82

Figure 58: Residual strain profiles along the aluminum cylinder bridge in the service tested condition. 83

Figure 59: Residual strain profiles along the gray iron cylinder liners in the TSR condition. ..... 85

Figure 60: Residual strain profiles along the gray iron cylinder liners in the T7 condition. ........86

Figure 61: Residual strain profiles along the gray iron cylinder liners in the service tested condition. 87

Figure 62: Residual stress profiles along the aluminum cylinder bridge in the TSR condition. .. 88 Figure 63: Residual stress profiles along the aluminum cylinder bridge in the T7 condition. ..... 89 
Figure 64: Residual stress profiles along the aluminum cylinder bridge for the engine block in the service tested condition................................................................................... 90

Figure C1: Aluminum-silicon-copper ternary phase diagram [65].......................................... 117

Figure C2: Aluminum-silicon binary phase diagram [1] ........................................................ 118 


\section{List of Appendices}

Appendix A: Calculations Pertaining to Confidence Limits of Estimated Mean Values ........97

Appendix B: Analysis of Variance ............................................................................ 104

B.1 Secondary Dendrite Arm Spacing ................................................................... 104

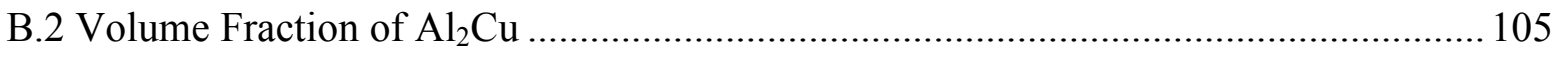

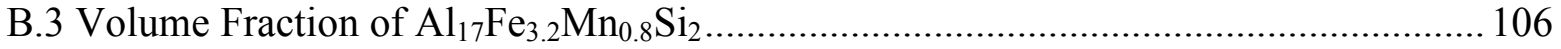

B.4 Volume Fraction of Eutectic Silicon ....................................................................... 107

B.5 Copper Content within the Aluminum Dendrites .................................................. 108

B.6 Magnesium Content within the Aluminum Dendrites ............................................. 109

B.7 Hardness of the Aluminum Dendrites ...................................................................... 110

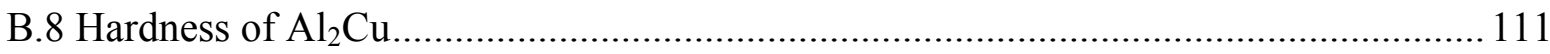

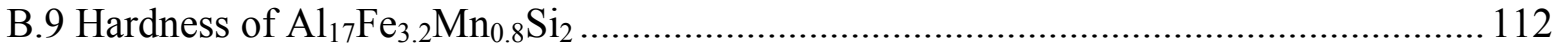

B.10 Hardness of Eutectic Silicon ............................................................................ 113

B.11 Rockwell Hardness...................................................................................... 114

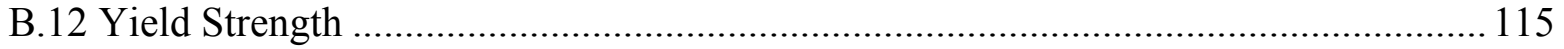

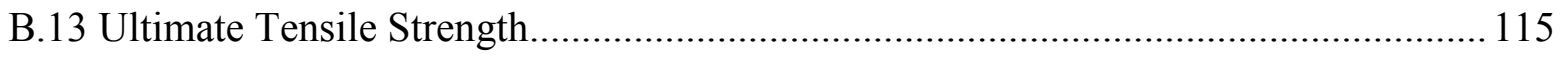

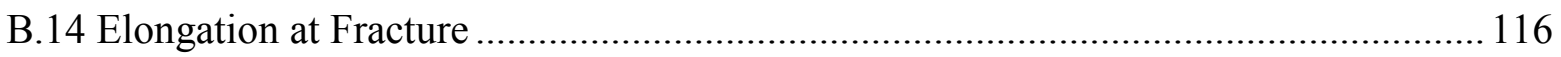

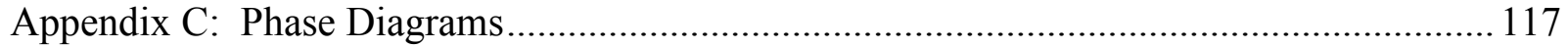

C.1 Aluminum-Silicon-Copper Ternary Phase Diagram.............................................. 117

C.1 Aluminum-Silicon Binary Phase Diagram........................................................... 118

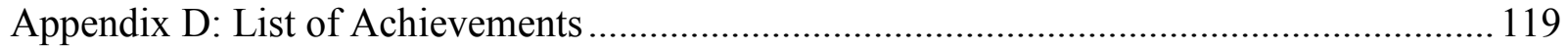




\section{Nomenclature}

\section{Greek}

Unit

$\theta$

$\theta^{\prime}$

$\theta "$

$\delta$

$\lambda$

$\varphi$

$\sigma^{\mathrm{I}}$

$\sigma^{\mathrm{II}}$

$\sigma^{\text {III }}$

$\sigma_{\mathrm{H}}$

$\sigma_{\mathrm{R}}$

$\sigma_{\mathrm{A}}$

$\varepsilon_{\mathrm{H}}$

$\varepsilon_{\mathrm{R}}$

$\varepsilon_{\mathrm{A}}$

$\alpha$

v

English

$\mathrm{d}_{\mathrm{hkl}}$

$\mathrm{d}_{0 \mathrm{hkl}}$

$\mathrm{d}_{\text {precipitate }}$

$\mathrm{d}_{\text {matrix }}$

E

$\mathrm{L}_{\mathrm{p}}$

$\mathrm{N}_{\mathrm{s}}$

$\mathrm{R}$

$\Delta \mathrm{T}$

Equilibrium age hardening precipitate in $\mathrm{Cu}$ containing $\mathrm{Al}$ alloys

Semi-coherent age hardening precipitate in $\mathrm{Cu}$ containing $\mathrm{Al}$ alloys

Coherent age hardening precipitate in $\mathrm{Cu}$ containing $\mathrm{Al}$ alloys

Misfit parameter

Wavelength

$\AA$

Diffraction angle

degree

Type I residual stress

$\mathrm{MPa}$

Type II residual stress

$\mathrm{MPa}$

Type III residual stress

MPa

Hoop stress component

$\mathrm{MPa}$

Radial Stress component

$\mathrm{MPa}$

Axial stress component

MPa

Hoop strain component

$\mathrm{mm} / \mathrm{mm}$

Radial strain component

$\mathrm{mm} / \mathrm{mm}$

Axial strain component

$\mathrm{mm} / \mathrm{mm}$

Coefficient of thermal expansion

$\mathrm{K}^{-1}$

Poisson's ratio

Units

Interplanar spacing

Interplanar spacing of stress free specimen

Interplanar spacing of the precipitate phases

Interplanar spacing of the matrix phase

Modulus of elasticity

Length of primary dendrite

Number of secondary dendrite arms

Cooling rate

${ }^{\circ} \mathrm{C} / \mathrm{s}$

${ }^{\circ} \mathrm{C}$ 


\section{Elements and Intermetallics}

Al

$\mathrm{Al}_{2} \mathrm{Cu}$

$\mathrm{Al}_{5} \mathrm{Mg}_{8} \mathrm{Cu}_{2} \mathrm{Si}_{6}$

$\mathrm{Al}_{15}(\mathrm{Fe}, \mathrm{Mn})_{3} \mathrm{Si}_{2}$

$\mathrm{Al}_{5} \mathrm{FeSi}$

$\mathrm{Al}_{17} \mathrm{Fe}_{3.2} \mathrm{Mn}_{0.8} \mathrm{Si}_{2}$

$\mathrm{Cr}$

$\mathrm{Cu}$

$\mathrm{Fe}$

$\mathrm{Mg}$

$\mathrm{Mg}_{2} \mathrm{Si}$

$\mathrm{Mn}$

$\mathrm{Ni}$

$\mathrm{Si}$

$\mathrm{Sn}$

$\mathrm{Sr}$

$\mathrm{Ti}$

\section{Abbreviations}

AFM

ANOVA

BSE

DSC

Dyno

EDX

FCC

G.P. Zones

HRE

HV

ND
Aluminum

Intermetallic in $\mathrm{Cu}$ containing $\mathrm{Al}$ alloys

Intermetallic in $319 \mathrm{Al}$ alloys

Intermetallic in $319 \mathrm{Al}$ alloys

Intermetallic in $319 \mathrm{Al}$ alloys

Intermetallic in $319 \mathrm{Al}$ alloys

Chromium

Copper

Iron

Magnesium

Intermetallic in $319 \mathrm{Al}$ alloys

Manganese

Nickel

Silicon

Tin

Strontium

Titanium

Atomic Force Microscopy

Analysis of Variance

Backscattered Electron

Differential Scanning Calorimetry

Dynamometer

Energy Dispersive X-ray Spectroscopy

Face Centred Cubic

Guinier-Preston Zones

Rockwell Hardness Number - E scale

Vickers Hardness Number

Neutron Diffraction 
$\mathrm{P}_{\alpha \max }$

RPM

SDAS

SEM

SSSS

T4

T6

T7

TEM

TSR

UTS

WDS

XRD

YS
Maximum confidence level for rejection of the null hypothesis

Revolutions per minute

Secondary Dendrite Arm Spacing

Scanning Electron Microscopy

Super Saturated Solid Solution

Solution Heat Treated

Solution Heat Treated and Aged to Optimal Condition

Solution Heat Treated and Stabilized by Overaging

Transmission Electron Microscopy

Thermal Sand Reclamation

Ultimate Tensile Strength

Wavelength Dispersive X-ray Spectroscopy

X-ray Diffraction

Yield Strength 


\section{Chapter 1: Introduction}

In recent years, there has been increased interest in the use of light alloys for automotive applications. Increased fuel costs and government legislation related to carbon emissions have encouraged the automotive industry to manufacture lighter and more fuel efficient automobiles. The use of aluminum (Al) alloys for automotive components, such as engine blocks, will result in reduced vehicle weight, thus making them more fuel efficient. Aluminum has a density of $2.7 \mathrm{~g} / \mathrm{cm}^{3}$ which is approximately one third of the density of steel or cast iron [1]. Furthermore, Al-Si-Cu based alloys, such as 319 , have good strength at ambient and elevated temperature $\left(\sim 200{ }^{\circ} \mathrm{C}\right)$. Thus, aluminum alloys are a suitable replacement to ferrous alloys in automotive powertrain applications. However, the use of 319 alloy for engine blocks is limited by the lack of adequate wear resistance, especially in the cylinder bore region.

The aluminum engine blocks require the insertion of gray cast iron cylinder liners for improved wear resistance. However, these cast iron cylinder liners may cause excessive residual stresses along the cylinder bores due to the large difference in thermal expansion coefficient between the 319 aluminum alloy $\left(2.4 \times 10^{-5} \mathrm{~K}^{-1}\right)$ and cast iron $\left(1.5 \times 10^{-5} \mathrm{~K}^{-1}\right)$ [2]. The cast iron liners may cause non-uniform cooling along its length, in its vicinity. This results in inhomogeneous microstructure and variation in strength characteristics. Subsequent heat treatment (solution heat treatment and aging) may exacerbate the situation. The large variation in mechanical properties, coupled with the residual stresses generated along the cylinders may lead to sections of the cylinder being prone to permanent dimensional distortion when the engine blocks are exposed to service conditions.

Dimensional distortion of the cylinder bores is a major problem affecting engine operating efficiency. Engine efficiency is greatly influenced by the thermodynamic efficiency of the engine cycle. Thermodynamic efficiency increases with increased compression ratio, which is the ratio of the volume of the air-fuel mixture prior to the compression stroke to the volume after the compression stroke [3]. Dimensional distortion of the cylinder bores, however, results in a loss in compression of the air-fuel mixture due to inadequate seal between the cylinder wall and the piston. This loss of seal causes a portion of the compressed air-fuel mixture to leak out of the combustion chamber by a process known as "blow-by". This process significantly reduces compression of the air-fuel mixture which results in a large reduction in thermodynamic 
efficiency. Cylinder bore distortion is detrimental to the engine operating efficiency, resulting in increased fuel consumption and carbon emissions. For this reason, there is a need to analyse or evaluate the relationship between microstructure, mechanical properties and residual stress along the cylinder bridge of the engine block in as-cast, heat treated and service tested conditions. This will help in determining the regions in the cylinder that are most prone to permanent dimensional distortion when exposed to elevated temperatures, and enable development of process parameters to eliminate them.

\section{Objective}

The main objective of this study is to determine the factors that contribute to cylinder bore distortion in 319 aluminum alloy engine blocks with cast-in gray iron liners, thus laying the foundation for optimization of production parameters to improve engine operating efficiency through the elimination of distortion. This research envisages a study of distortion in the 319 aluminum alloy cylinder block with cast iron inserts, in the as-cast, heat treated and dyno tested/customer returned conditions. The study will involve optical, scanning and transmission

electron microscopy for microstructural characterisation and neutron diffraction for residual stress analysis. 


\section{Chapter 2: Literature Review}

In this chapter, there are a general introduction to precision sand casting and an introduction to aluminum alloys. Phase formation during heat treatment of aluminum-silicon-copper alloys is explained and related to alloy strengthening and dimensional distortion. The development and measurement of residual stresses in engineering components are explained. Finally, the mechanisms contributing to dimensional distortion in aluminum alloys are discussed.

\subsection{Sand Casting}

Sand casting is a moulding process in which bonded sand is used to form the moulding cavity. A sand mould consists of top and bottom sections called the cope and drag, respectively. The cope and drag contain a portion of the casting cavity and gating system (downsprue, runners and in-gates). Prior to pouring, the cope and drag are assembled in order to obtain the complete mould cavity. For components which require complex internal features, cores of bonded sand or steel are inserted into the sand mould.

One of the most important considerations in mould design is the gating system. The gating system in the sand mould is used to control the flow of molten metal in order to prevent turbulence and subsequent entrainment of inclusions, such as oxides, within the casting [4]. A schematic of a typical sand mould is shown in Figure 1.

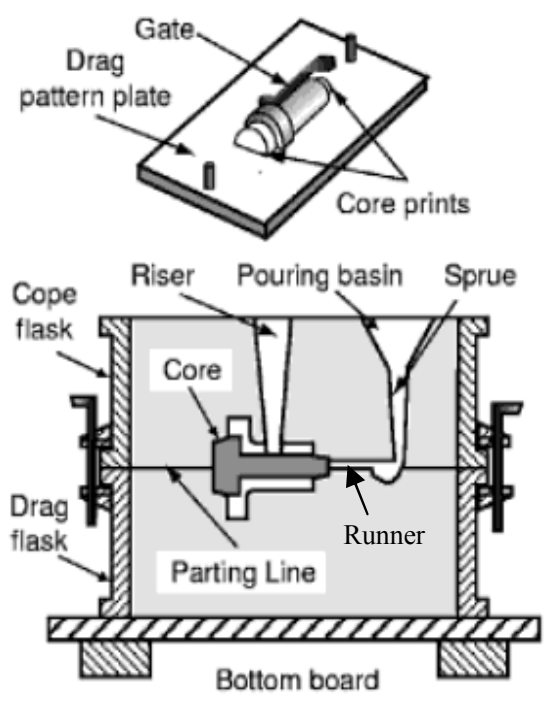

Bottom board

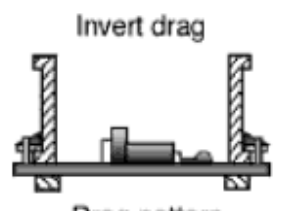

Drag pattern
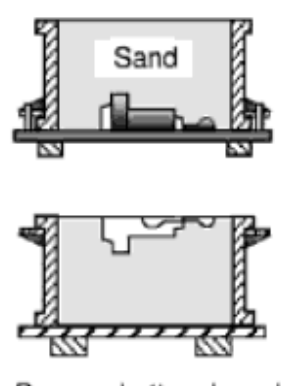

Drag on bottom board
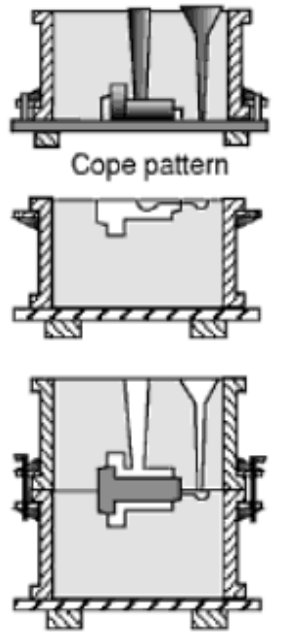

Ready for pouring

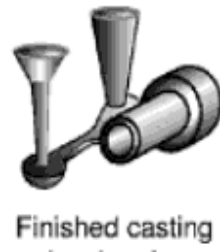

showing riser gate and sprue attached

Figure 1: Schematic of the components in a typical sand mould [6]. 
In order to construct the mould cavity of a sand mould, preconditioned sand is compacted around mahogany, composite or metal patterns, which represent the negative of the mould cavity. The sand is then bonded using a combination of clay and water (green sand moulding) or chemical binders (precision sand moulding) [5-7]. The internal patterns are subsequently removed once the sand has formed a rigid cavity

Strength and permeability are two main factors regarding mould quality. Sand moulds with high strength (typically chemically bonded) resist fracture and deformation during mould filling. This results in improved dimensional accuracy of the resulting casting. Conversely, moulds that are excessively rigid may increase the susceptibility for hot tearing, which are cracks that form in the casting during solidification. Permeable moulds allow gases in the mould cavity to escape resulting in reduced gas porosity. However, moulds with excessive permeability may cause metal penetration where sand becomes entrapped in the casting [6]. Optimization of the strength and permeability of the sand mould is of fundamental importance in ensuring that the casting meets the required dimensional tolerance values along with reduced casting defects.

\subsubsection{Precision Sand Casting}

Precision sand casting is a technique used when the dimensional accuracy of the component is critical. Unlike green sand moulds which use a combination of sand, clay and water, moulds prepared for precision sand casting use chemical binders such as phenolic urethane. The use of chemical binders results in sand moulds with improved rigidity and dimensional stability as compared to green sand moulds [7]. The increased rigidity of the mould also has benefits with regards to component quality and cost. Components produced by precision sand casting require less machining allowances, allowing thinner sections to be produced, and as a result in increased cooling rate and improved mechanical properties [7]. Furthermore, precision sand moulds use a more compact gating system, thereby improving casting yield and reducing the amount of energy used for remelt [6]. Therefore, precision sand casting is a cost effective technique in producing components with high dimensional accuracy.

\subsubsection{Cosworth Casting Process}

The Cosworth process has been recognized as a process that yields high quality, dimensionally accurate aluminum castings and has been used extensively in the production of engine blocks. 
The Cosworth process differs from other casting techniques in that the mould is rotated $180^{\circ}$ upon completion of filling. A schematic of the Cosworth casting process is shown in Figure 2.

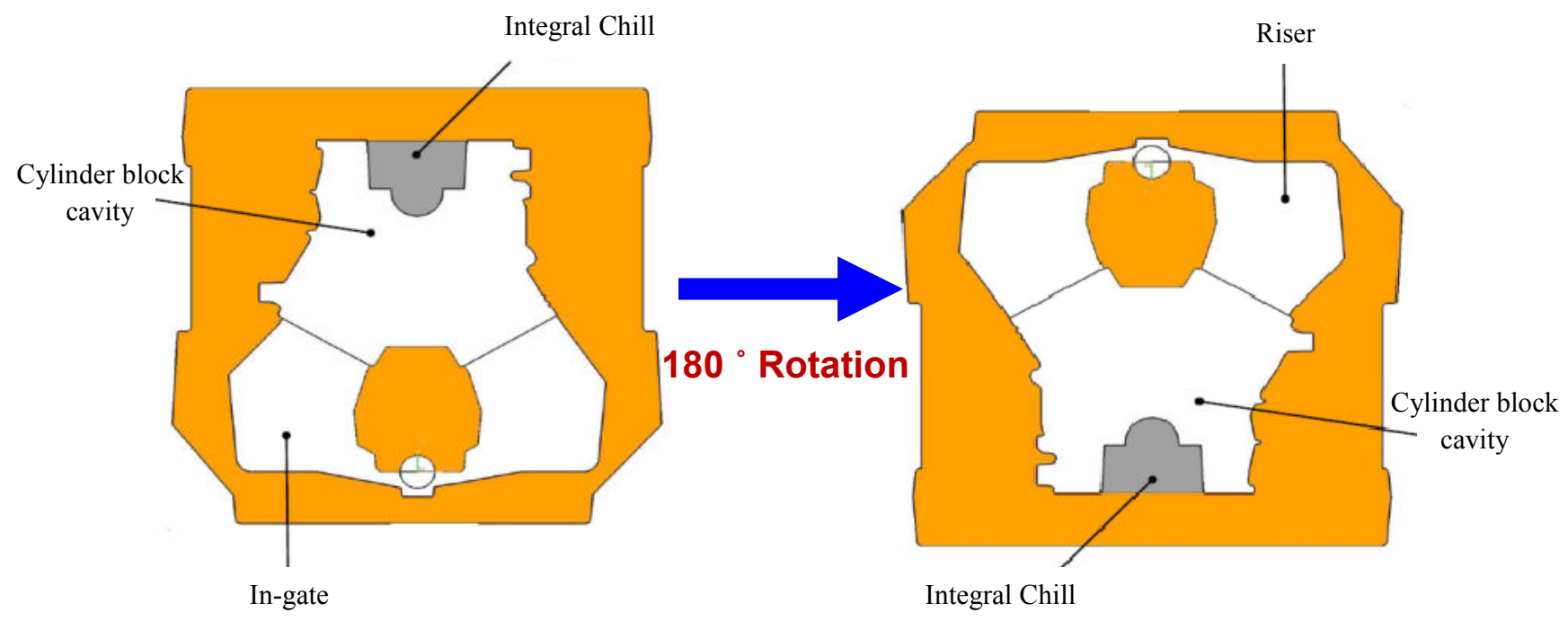

Figure 2: Schematic of an engine block mould utilized in the Nemak Cosworth process [8].

The procedure used in the Cosworth casting process allows for improved feeding of liquid metal into the casting. While bottom-gated moulds are essential to eliminate turbulence, the main draw-back with traditional casting techniques is that the hottest metal remains at the bottom of the mould. This prevents effective feeding from the gating system, resulting in casting defects such as shrinkage porosity. Therefore, separate reservoirs of liquid metal called risers are often required to reduce shrinkage porosity. The Cosworth process, however, due to the $180^{\circ}$ rotation after mould filling, utilizes the in-gates as risers which can effectively feed the shrinkage [8]. This eliminates the need for additional risers throughout the casting, which increases the casting yield, thereby reducing production cost.

\subsection{Aluminum Alloys}

In recent years, there has been increased interest in the use of light alloys for automotive applications. The global usage of aluminum and its alloys, including automotive applications, is shown in Figure 3. The data indicates that aluminum usage in other industries is more predominant than the automotive industry. However, the use of aluminum in automotive applications began in the 1970's and has steadily grown since [9]. The increased fuel costs and a need to reduce the impact of automobiles on the environment has been the main driving force for the increased use of aluminum in the automotive industry. 


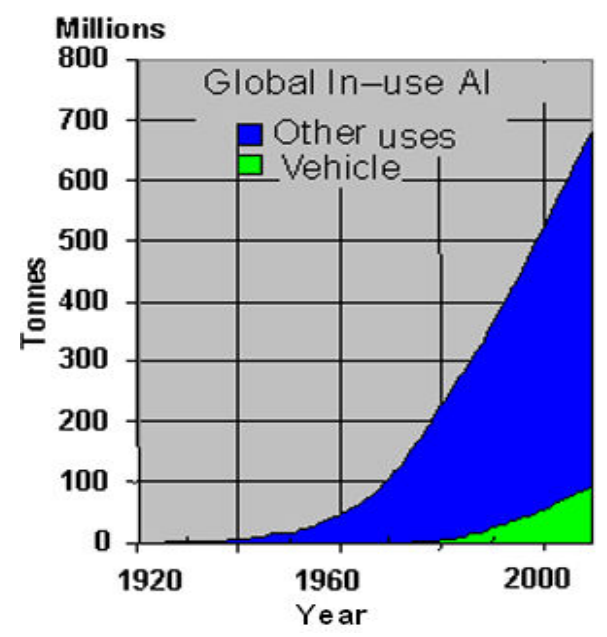

Figure 3: Global in-use aluminum and aluminum alloys [9].

\subsubsection{Aluminum-Silicon-Copper Alloy System}

The aluminum-silicon-copper ( $\mathrm{Al}-\mathrm{Si}-\mathrm{Cu}$ ) alloy system is used in the production of engineering components such as engine blocks and cylinder heads. This aluminum alloy system, known as the $3 \mathrm{xx}$ alloy series, has good mechanical properties at ambient and elevated temperatures $\left(\sim 200{ }^{\circ} \mathrm{C}\right)$ as well as good castability. Specifically, aluminum alloy 319 is a hypoeutectic $\mathrm{Al}-\mathrm{Si}$ based alloy that usually contains between 6 and $8 \mathrm{wt} \%$ Si along with additions of 3 to $4 \mathrm{wt} \% \mathrm{Cu}$. In most cases, iron $(\mathrm{Fe})$ is present as an impurity element introduced into the alloy during the handling and pouring of the molten aluminum and is considered very detrimental to the mechanical properties of Al-Si alloys due to the formation of brittle intermetallic compounds. Iron is also introduced into aluminum castings through the use of recycled aluminum [6]. In order to reduce the negative impact of iron impurities, manganese (Mn) is added into the alloy which forms less harmful iron and manganese bearing intermetallic compounds. Additions of magnesium are also made to 319 type aluminum alloys which results in the formation of phases that improve strength, machinability and increase the rate of age hardening [6].

\subsubsection{Microstructure of 319 Type Aluminum Alloys}

The 319 alloy microstructure usually consists of an $\alpha$-Al matrix, $\mathrm{Al}-\mathrm{Si}$ eutectic and $\mathrm{Al}_{2} \mathrm{Cu}$ intermetallic phase. Furthermore, in Al-Si alloys containing iron impurities $(\sim 0.35 \mathrm{wt} . \%)$, the $\beta-\mathrm{Al}_{5} \mathrm{FeSi}$ and $\alpha-\mathrm{Al}_{15}(\mathrm{Fe}, \mathrm{Mn})_{3} \mathrm{Si}_{2}$ phases are common in the microstructure. The following sub-sections discuss the phases present within the 319 alloy microstructure. 


\subsubsection{Eutectic Silicon}

Eutectic silicon is a phase consisting of nearly pure silicon surrounded by aluminum. During solidification of hypoeutectic Al-Si alloys, silicon particles nucleate along with eutectic aluminum following the formation of the primary aluminum dendrites. The eutectic silicon phase naturally appears in the microstructure as coarse acicular particles (Figure 4(a)) [10, 11]. Acicular silicon eutectic particles are typically detrimental to the mechanical properties due to the inherent brittleness of this phase as well as stress concentrations occurring at the tip of the silicon needles $[10,11]$. Modification of the eutectic silicon morphology into a fibrous structure by solution heat treatment and increased cooling rate (quench modification), or by additions of strontium, antimony or sodium may lead to an increase in the yield and ultimate tensile strength [10-12]. Fibrous eutectic silicon is characterized by clusters of small, globular silicon particles surrounded by the aluminum matrix (Figure 4(b)). The results from Fatahalla et al. [13], shown in Table 1, illustrates the influence of morphological modification of eutectic silicon on the tensile properties of Al-Si alloys. These results show that the addition of $0.015 \mathrm{wt} . \% \mathrm{Sr}$ increased in the yield strength, ultimate tensile strength and elongation from $37 \mathrm{MPa}, 74 \mathrm{MPa}$ and $1.4 \%$, respectively to $62 \mathrm{MPa}, 124 \mathrm{MPa}$ and $5 \%$, respectively [13]. Addition of strontium also caused the largest degree of eutectic silicon modification, which led to the largest improvement in tensile properties [13].
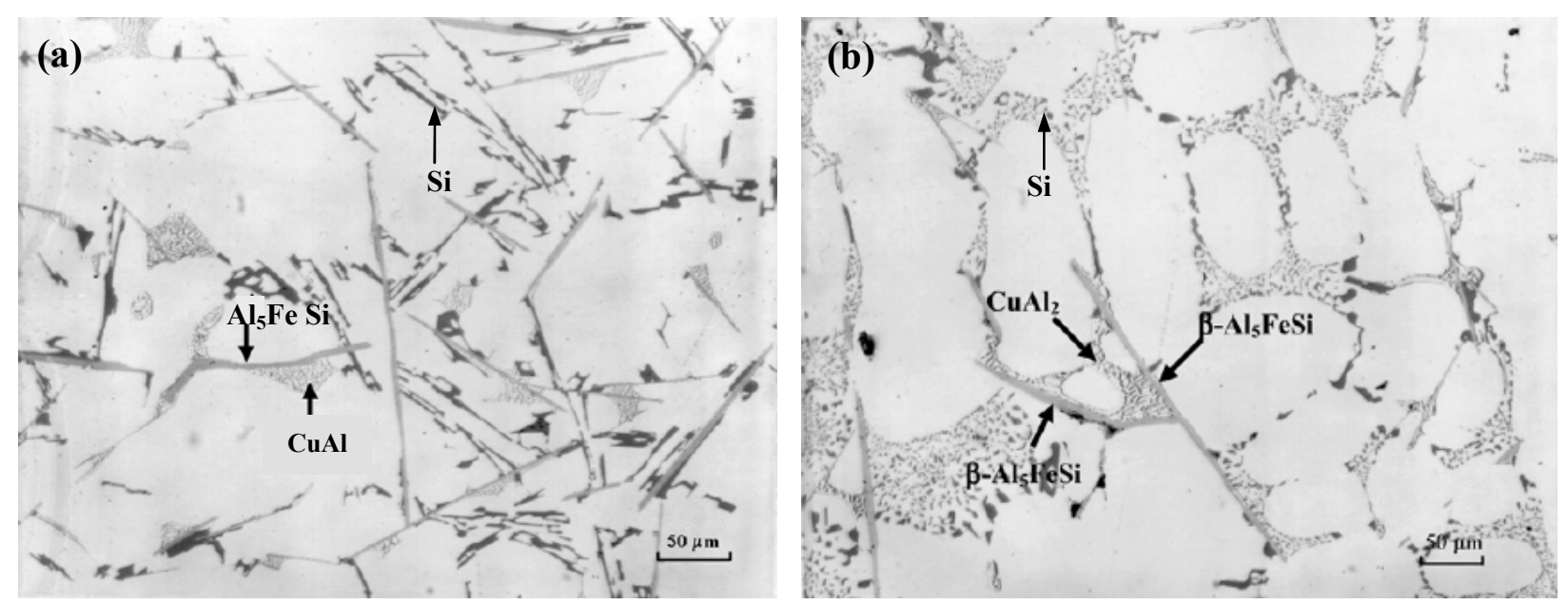

Figure 4: Optical micrographs of A319 in the as-cast condition with: (a) unmodified silicon eutectic, (b) strontium modified silicon eutectic [11]. 
Table 1: Tensile properties of Al-6\%Si alloy, modified with additions of sodium, antimony and strontium [13].

\begin{tabular}{cccc}
\hline & \multicolumn{3}{c}{ Tensile Properties } \\
\hline Alloy Condition & Yield Strength (MPa) & Ultimate Tensile Strength (MPa) & \% Elongation \\
Non-Modified & 37 & 74 & 1.4 \\
Na-Modified & 55 & 114 & 4.3 \\
$(1$ wt.\% Na addition) & & 109 & 3.7 \\
Sb-Modified & 50 & 124 & 5.0 \\
$(0.8$ wt.\% Sb addition) & 62 & & \\
Sr-Modified & & & \\
$(0.015$ wt.\% Sr addition) & &
\end{tabular}

\subsubsection{Iron Bearing Intermetallics}

Iron is an undesirable impurity in Al-Si alloys, usually found in commercial grade 319 aluminum alloys. Iron impurities typically lead to the formation of acicular $\beta-\mathrm{Al}_{5} \mathrm{FeSi}$ intermetallic, as shown in Figure 4. This iron bearing phase is hard, brittle and has poor bond strength with the aluminum matrix, making it highly deleterious to the mechanical properties of the alloy $[14,15]$.

In order to reduce the detrimental influence of the $\beta-\mathrm{Al}_{5} \mathrm{FeSi}$ phase on the mechanical properties of Al-Si alloys, manganese is added which to suppress the formation of $\beta-\mathrm{Al}_{5} \mathrm{FeSi}$ in favour of $\alpha$ $\mathrm{Al}_{15}(\mathrm{Fe}, \mathrm{Mn})_{3} \mathrm{Si}_{2}$. This phase has a more compact Chinese script morphology which is less harmful to the mechanical properties compared to $\mathrm{Al}_{5} \mathrm{FeSi}[14,16]$. Based on the results of Narayanan et al. [14], an Fe:Mn ratio of $1.5: 1$ at a cooling rate between 0.1 and $10{ }^{\circ} \mathrm{C} / \mathrm{s}$ is required to replace the majority of the $\beta-\mathrm{Al}_{5} \mathrm{FeSi}$ with $\alpha-\mathrm{Al}_{15}(\mathrm{Fe}, \mathrm{Mn})_{3} \mathrm{Si}_{2}$. Furthermore, Hwang et al. [17] observed that for an Fe:Mn ratio of approximately $0.75: 1$, the $\beta$ phase is completely suppressed. Larger manganese additions, however, caused the formation of a polyhedral $\alpha$-phase, referred to as sludge, along with the Chinese script $\alpha$-phase $[16,17]$. The morphology of the Chinese script and polyhedral $\alpha$-phases are shown in Figures 5(a) and (b) respectively.

The addition of manganese to iron bearing 319 aluminum alloy was observed by Hwang et al. [17] to improve the tensile strength and ductility with decreasing Fe:Mn ratio down to an Fe:Mn ratio of $0.75: 1$, as shown in Figure 6. The formation of the polyhedral $\alpha$-phase, for Fe:Mn ratios less than 0.75:1, was observed to be detrimental to the alloy ductility, as shown in Figure 6(b). This was attributed to the increased volume fraction of brittle iron bearing phases as well as 
increased porosity, which occurs due to the formation of the polyhedral $\alpha$-phase $[16,17]$. Therefore, for optimum mechanical properties, there should be only enough manganese to suppress the formation of $\beta-\mathrm{Al}_{5} \mathrm{FeSi}$.
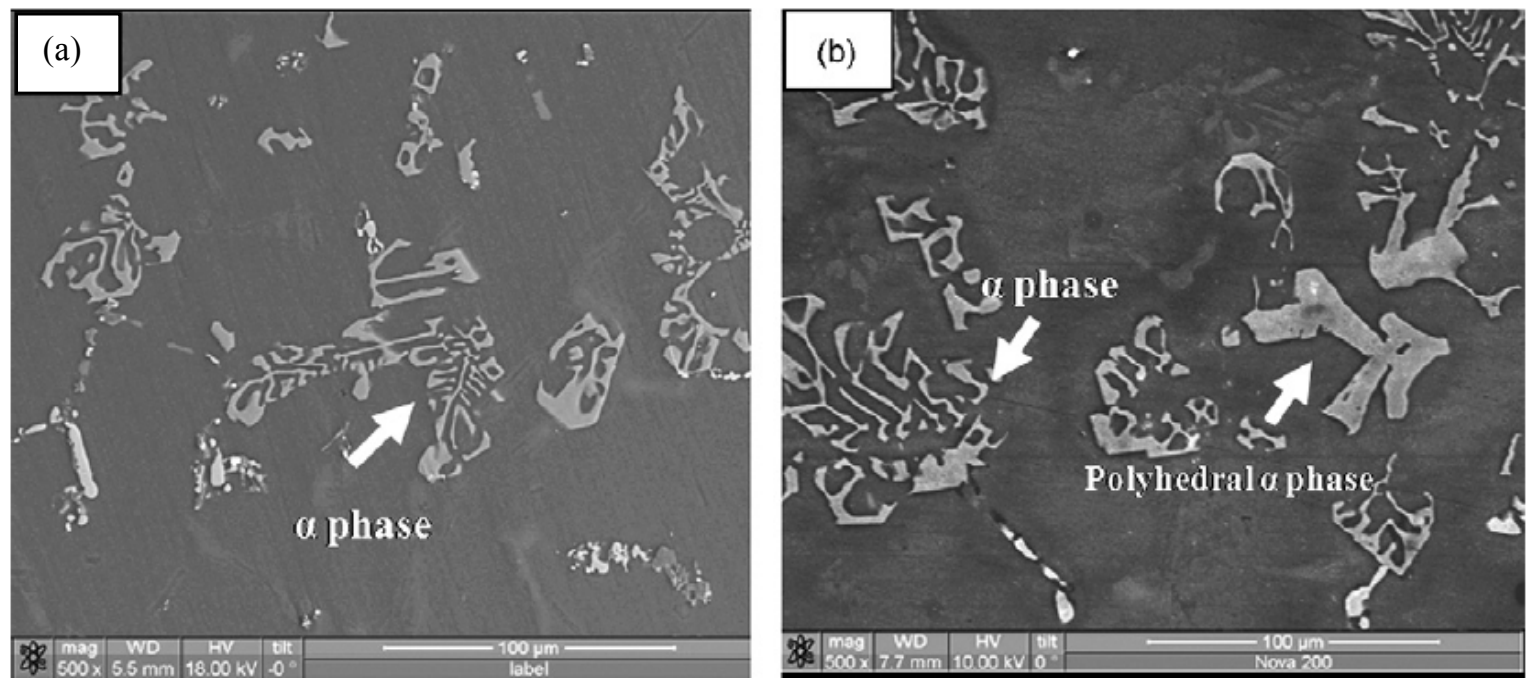

Figure 5: Backscattered electron images for an Al-6.5Si-3.5Cu alloy with an Fe:Mn ratio of: (a) 0.75, (b) 0.6 [17].
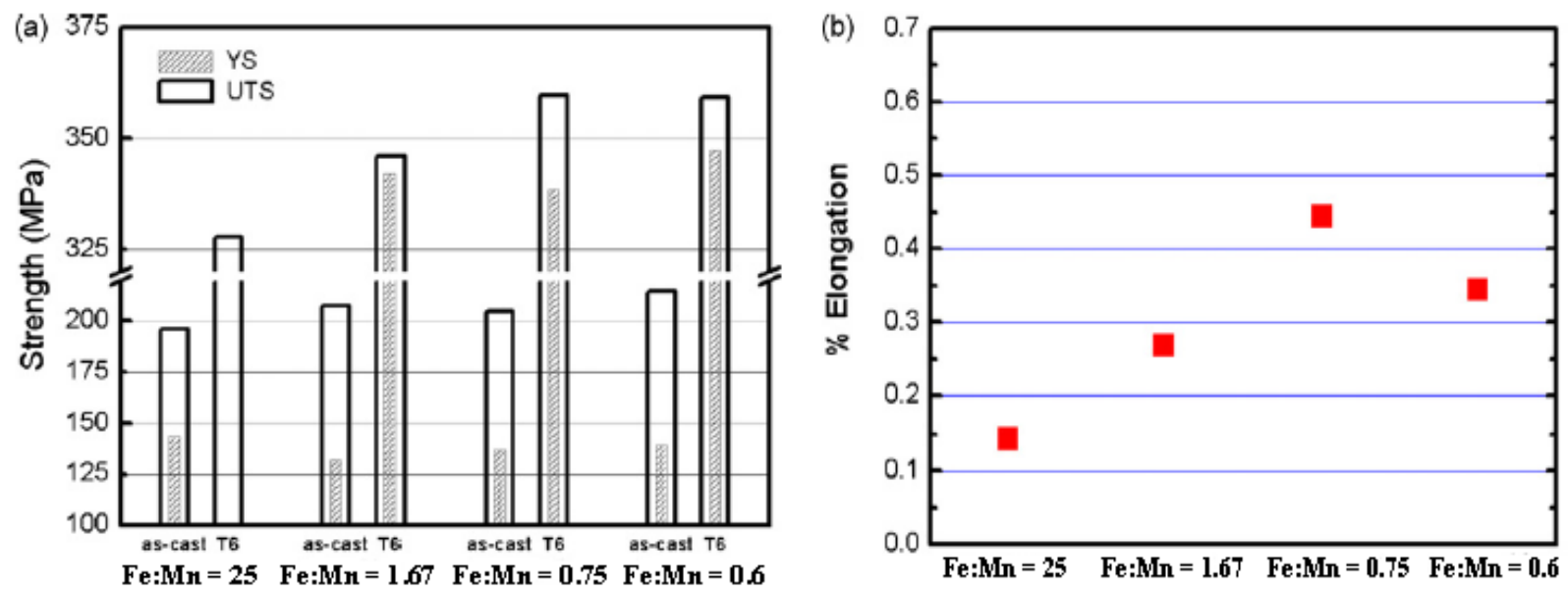

Figure 6: Tensile properties of a 319 alloy as a function of the Fe:Mn ratio showing: (a) ultimate tensile strength and yield strength in as-cast and T6 heat treated conditions, (b) percent elongation in the T6 condition [17].

\subsubsection{Aluminum-Copper Based Intermetallic $\left(\mathrm{Al}_{2} \underline{\underline{\mathrm{Cu}}}\right.$}

In the 319 aluminum alloy system, aluminum and copper form a strengthening phase, present in the interdendritic regions, with stoichiometry $\mathrm{Al}_{2} \mathrm{Cu}$. This intermetallic phase appears in the microstructure in two morphologies: eutectic and blocky. The eutectic $\mathrm{Al}_{2} \mathrm{Cu}$ morphology is 
characterized as a lamellar structure consisting of $\mathrm{Al}_{2} \mathrm{Cu}$ and $\alpha-\mathrm{Al}$ lamellae, as shown in Figure 7 (a). In contrast, the blocky morphology is characterized by clusters of larger $\mathrm{Al}_{2} \mathrm{Cu}$ particles $(20-40 \mu \mathrm{m})$ embedded in the aluminum matrix, as shown in Figure 7 (b). Although both morphologies of $\mathrm{Al}_{2} \mathrm{Cu}$ are usually present within the microstructure, $\mathrm{Sr}$ additions, used to modify the morphology of eutectic silicon, have been found to promote the formation of blocky $\mathrm{Al}_{2} \mathrm{Cu}$ [11]. However, since most engineering components are heat treated prior to use, the eutectic $\mathrm{Al}_{2} \mathrm{Cu}$ morphology is preferred in the as-cast state since less time is required to dissolve this phase during solution heat treatment.
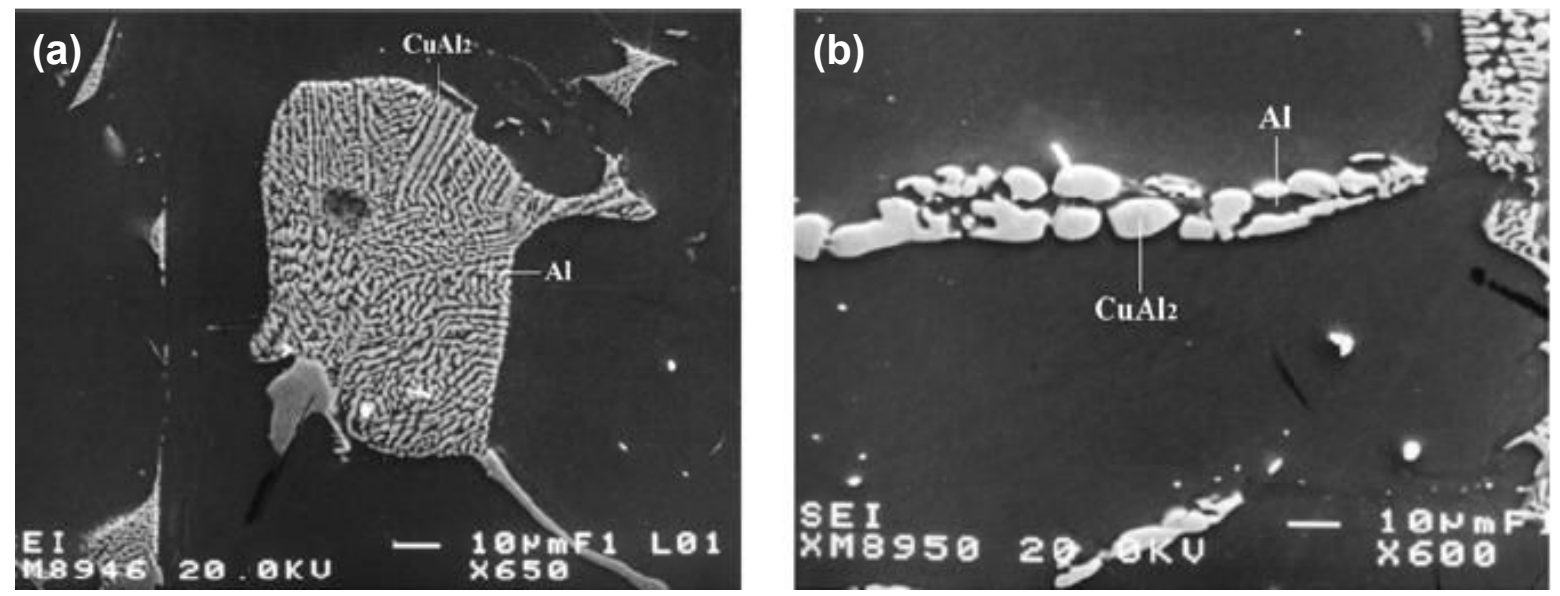

Figure 7: Backscattered electron image of $\mathrm{A319}$ in the as-cast condition showing: (a) eutectic $\mathrm{Al}_{2} \mathrm{Cu}$ morphology, (b) blocky $\mathrm{Al}_{2} \mathrm{Cu}$ morphology [11].

\subsubsection{Magnesium Bearing Intermetallics}

Magnesium bearing phases, such as $\mathrm{Mg}_{2} \mathrm{Si}$ or $\mathrm{Al}_{5} \mathrm{Mg}_{8} \mathrm{Cu}_{2} \mathrm{Si}_{6}$, are also present in 319 type alloys containing magnesium. Typically, in 319 alloys containing magnesium, the $\mathrm{Al}_{5} \mathrm{Mg}_{8} \mathrm{Cu}_{2} \mathrm{Si}_{6}$ intermetallic compound forms during solidification, although $\mathrm{Mg}_{2} \mathrm{Si}$ may also be present. The $\mathrm{Al}_{5} \mathrm{Mg}_{8} \mathrm{Cu}_{2} \mathrm{Si}_{6}$ phase precipitates in clusters with $\mathrm{Al}_{2} \mathrm{Cu}$ since both phases precipitate near the solidus point of the alloy. The magnesium bearing phases have been observed to improve the strength of 319 type alloys especially in the metastable state, obtained after solution heat treatment and aging [18].

\subsubsection{Development of Microstructure in 319 Alloys}

The development of microstructure in the Al-Si-Cu alloy system is highly dependent on the composition of the alloy and the cooling rate during solidification. Since there is a large range of 
compositional limits that are considered within the 319 alloy designation, the precipitation temperature of the phases may vary greatly in each alloy. However, the phase formation reactions maintain a specific sequence. An example is the formation of $\mathrm{Al}_{2} \mathrm{Cu}$ in commercial 319 aluminum alloys. This phase forms after the $\alpha$-Al dendrites, eutectic silicon and the iron bearing phases regardless of the alloy composition. Specifically, $\mathrm{Al}_{2} \mathrm{Cu}$ forms near the solidus point of the alloy [19]. A cooling curve and its first derivative, indicating the phase formation sequence for Al-6Si-3.5Cu-0.6Mg alloy, are shown in Figure 8. A list of phase formation reactions along with the formation temperature are given in Table 2.

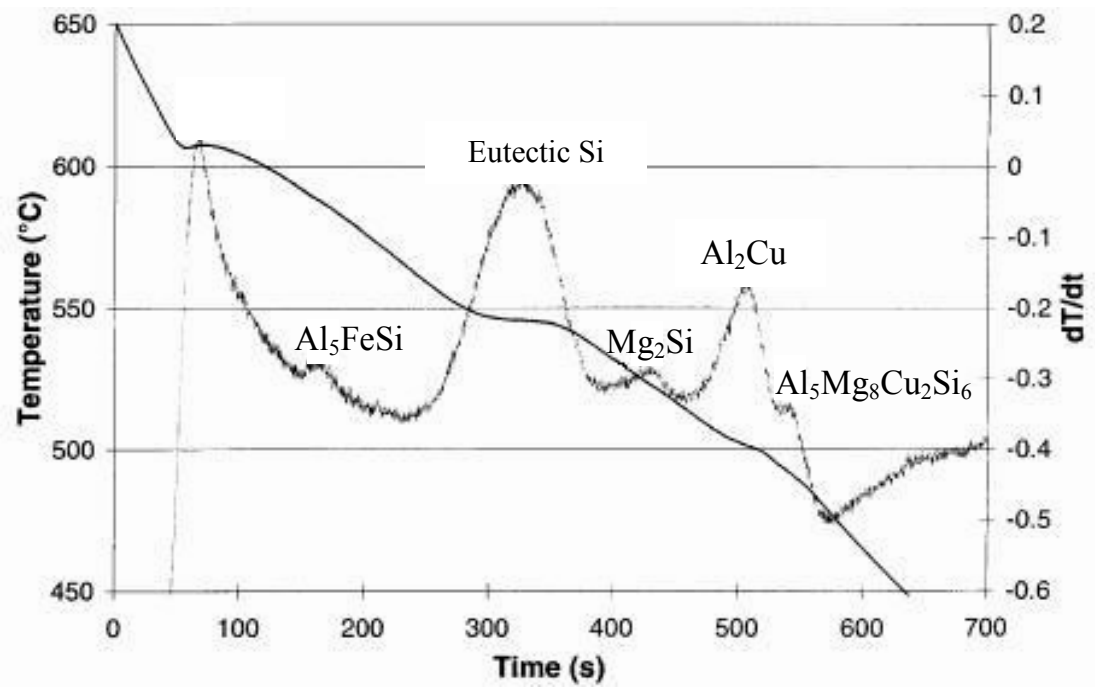

Figure 8: Cooling curve and first derivative curve showing the formation of phases during solidification for an $\mathrm{Al}-6 \mathrm{Si}-3.5 \mathrm{Cu}-0.6 \mathrm{Mg} 319$ type alloy [19].

Table 2: Description of phase formation reactions during solidification of Al-6Si-3.5Cu [19].

\begin{tabular}{ccc}
\hline Reaction Number & Temperature $\left({ }^{\circ} \mathbf{C}\right)$ & Type of Reaction \\
\hline 1 & 611.8 & Formation of $\alpha$-Al dendritic network \\
2 & 600 to 572.7 & Precipitation of pre-eutectic iron intermetallics \\
& & $\left(\alpha-\mathrm{Al}_{15}(\mathrm{Fe}, \mathrm{Mn})_{3} \mathrm{Si}_{2}\right.$ and $\left.\beta-\mathrm{Al}_{5} \mathrm{FeSi}\right)$ \\
3 & 561.8 & Precipitation of eutectic $\mathrm{Si}$ \\
4 & 550 to 541 & Precipitation of post-eutectic $\beta-\mathrm{Al}_{5} \mathrm{FeSi}$ \\
5 & 510 & Precipitation of $\mathrm{Al}_{2} \mathrm{Cu}$ \\
6 & 502.7 & Precipitation of $\mathrm{Al}_{5} \mathrm{Mg}_{8} \mathrm{Cu}_{2} \mathrm{Si}_{6}$ \\
\hline
\end{tabular}

The cooling curve (Figure 8) indicates that the $\alpha$-Al dendrites form at approximately $608{ }^{\circ} \mathrm{C}$. However, increased concentration of silicon reduces the phase formation temperature of the $\alpha$-Al 
dendrites down to $577^{\circ} \mathrm{C}$ at the eutectic composition [11]. For this reason, alloy composition dictates the type of phases that form, the quantity of each phase in the microstructure and the phase formation temperatures.

\subsection{Heat Treatment of Aluminum Alloys}

Engineering components are typically heat treated prior to being exposed to service conditions. Heat treatment, through the mechanism of atomic diffusion, is used to obtain a more uniform microstructure compared to the as-cast state, improve mechanical properties and reduce residual stresses that may have been generated during processing of the component. The following sections discuss the stages involved in precipitation hardening heat treatments that are typically used in engine block production.

\subsubsection{Solution Heat Treatment and Quenching}

The first stage of a precipitation hardening heat treatment is solution heat treatment. Solution heat treatment is carried out to dissolve coarse equilibrium phases that are present in the as-cast state to form a single phase, supersaturated solid solution (SSSS) $[4,20,21]$. In order to form a supersaturated solid solution, the alloy system must have a region where all of the alloying elements are soluble in the base material. Furthermore, the solid solubility of the alloying elements should decrease with decreasing temperature, indicated by a solvus line in the phase diagram. An example of the solubility trend required to effectively solutionize alloys is shown in the aluminum rich portion of the Al-Cu binary phase diagram in Figure 9.

In this section, the $\mathrm{Al}-\mathrm{Cu}$ binary system with approximately $3 \mathrm{wt} . \% \mathrm{Cu}$ is considered in the explanation of precipitation hardening of 319 aluminum alloys since these alloys are typically strengthened during heat treatment by the formation of $\mathrm{Al}-\mathrm{Cu}$ based precipitates. For $\mathrm{Al}-\mathrm{Cu}$ alloys, heating to a temperature above the solvus line results in the dissolution of the equilibrium $\theta-\mathrm{Al}_{2} \mathrm{Cu}$ phase, which forms a single phase microstructure.

Three main variables influence the material properties following heat treatment: temperature, time and cooling rate during quenching. 


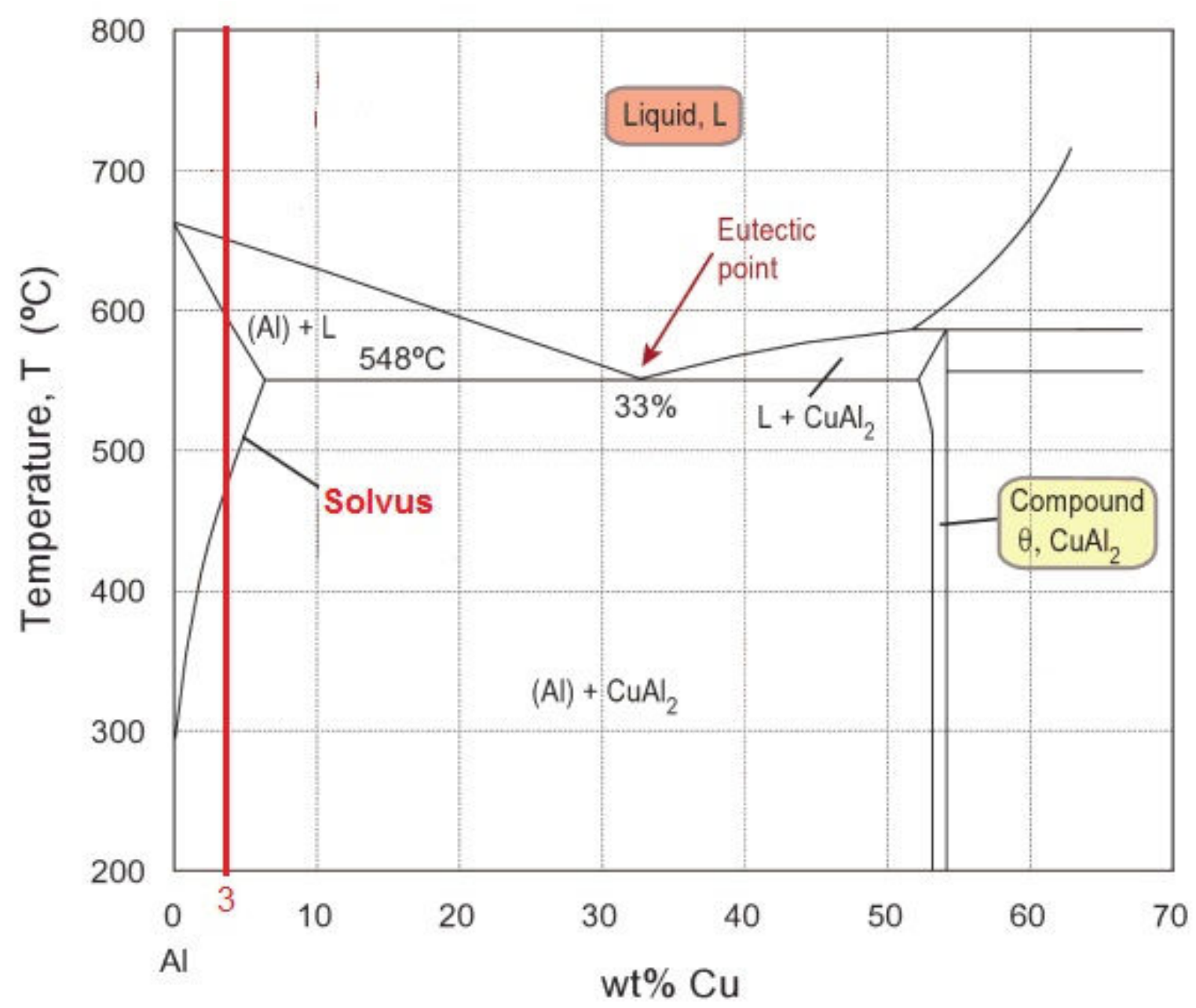

Figure 9: Aluminum rich portion of the Al-Cu binary phase diagram [22].

Solution temperature depends on the phases that are required to be dissolved. For instance, to effectively dissolve $\mathrm{Al}_{2} \mathrm{Cu}$ in 319 aluminum alloys (containing approximately $3 \mathrm{wt} \% \mathrm{Cu}$ ), solution treatment should be conducted between 505 and $540{ }^{\circ} \mathrm{C}$. Solution temperatures near the solvus point $\left(\sim 480{ }^{\circ} \mathrm{C}\right.$ for $\mathrm{Al}_{2} \mathrm{Cu}$ dissolution (Figure 9)) result in sluggish dissolution of $\mathrm{Al}_{2} \mathrm{Cu}$ $[20,21]$. These trends were illustrated by the results of Samuel et al. [23] (Figure 10).

The results in Figure 10 show that increasing the solutionizing temperature from $480{ }^{\circ} \mathrm{C}$ to above $500{ }^{\circ} \mathrm{C}$ reduced the amount of residual $\mathrm{Al}_{2} \mathrm{Cu}$ in the microstructure, suggesting more effective dissolution of $\mathrm{Al}_{2} \mathrm{Cu}$. The dissolution kinetics are greatly accelerated with increasing temperature due to increased diffusion rates which lowers the amount of time required to attain complete dissolution of equilibrium secondary phases [11, 23, 24]. However, the solutionizing temperature should be kept in an optimal range since too high a temperature causes incipient melting of the 
$\mathrm{Al}_{2} \mathrm{Cu}$ phases, leading to increased porosity, which severely deteriorates the mechanical properties of the alloy [23, 24]. Samuel et al. [23] determined that incipient melting of $\mathrm{Al}_{2} \mathrm{Cu}$ occurs for solution heat treatment temperatures above $540{ }^{\circ} \mathrm{C}$, which corresponds to the melting point of $\mathrm{Al}_{2} \mathrm{Cu}$ as shown in the Al-Si-Cu ternary phase diagram (Appendix $\mathrm{C} 1$ ).

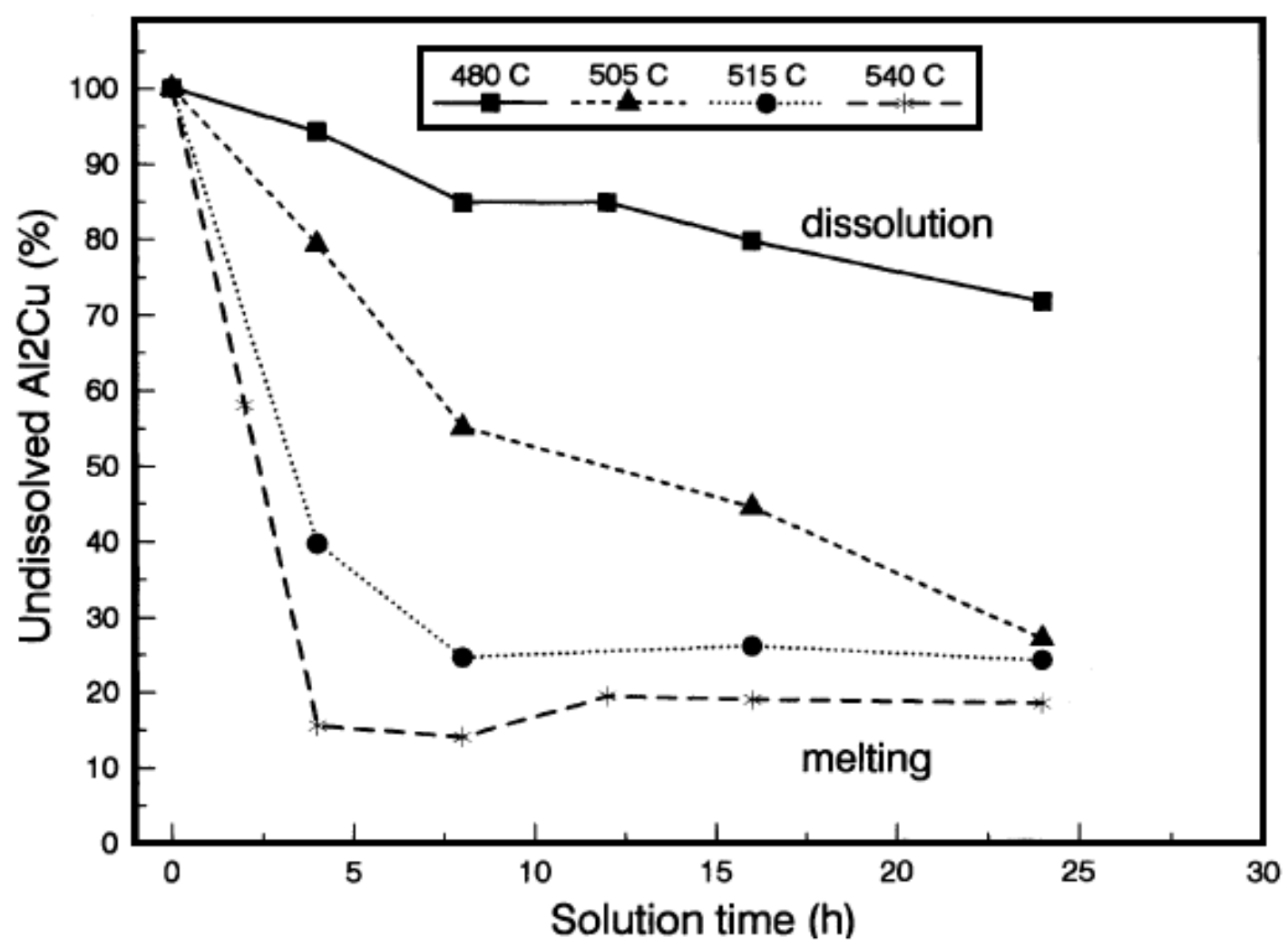

Figure 10: Graph showing the influence of solutionizing temperature and time on dissolution of $\mathrm{Al}_{2} \mathrm{Cu}$ [23].

In addition to temperature, alloying also influences the appropriate solutionizing temperature. For instance, additions of 0.3 to $0.6 \mathrm{wt} \% \mathrm{Mg}$ to $\mathrm{Al}-\mathrm{Si}-\mathrm{Cu}$ alloys lower the recommended optimum solution temperature range to $500-520{ }^{\circ} \mathrm{C}$. This was attributed to the presence of $\mathrm{Al}_{5} \mathrm{Mg}_{8} \mathrm{Si}_{6} \mathrm{Cu}_{2}$ which has a lower melting point than $\mathrm{Al}_{2} \mathrm{Cu}$ [23].

Solution heat treatment time, which depends on the selected solutionizing temperature, is mainly determined by considering the dissolution rate of the secondary phases which are to be dissolved. For example, the dissolution of the magnesium bearing phases in 319 aluminum alloys occurs rapidly due to their relatively low melting point. In contrast, the higher melting point of iron bearing phases results in a significantly lower dissolution rate. Iron bearing intermetallic 
particles typically fragment and gradually dissolve after prolonged solution heat treatment time [25].

Morphology and size of the constituents in the microstructure also influence the amount of time required for complete dissolution. With regards to $\mathrm{Al}_{2} \mathrm{Cu}$, the blocky morphology is more difficult to dissolve than the eutectic morphology [11]. The main reason is that the dissolution of eutectic $\mathrm{Al}_{2} \mathrm{Cu}$ occurs by fragmentation into smaller particles, which then spheroidize and dissolve into the matrix by atomic diffusion. In contrast, blocky $\mathrm{Al}_{2} \mathrm{Cu}$ particles do not fragment into smaller particles. Thus more time is required to attain complete dissolution of blocky $\mathrm{Al}_{2} \mathrm{Cu}$ since spheroidization and dissolution by diffusion occur on significantly larger particles [11, 23, 26]. The relationship between local solidification time, which indicates the coarseness of the microstructure, and the amount of undissolved $\mathrm{Al}_{2} \mathrm{Cu}$ following solution heat treatment is shown in Figure 11. Figure 11 indicates that at a constant solutionizing temperature, increased local solidification time results in more $\mathrm{Al}_{2} \mathrm{Cu}$ remaining in the microstructure following solution heat treatment which suggests that more time is required to dissolve coarse $\mathrm{Al}_{2} \mathrm{Cu}$ particles. Although this trend is shown for $\mathrm{Al}_{2} \mathrm{Cu}$, similar trends have been observed for other phases such as $\mathrm{Al}_{5} \mathrm{Mg}_{8} \mathrm{Cu}_{2} \mathrm{Si}_{6}$ and $\mathrm{Mg}_{2} \mathrm{Si}$.

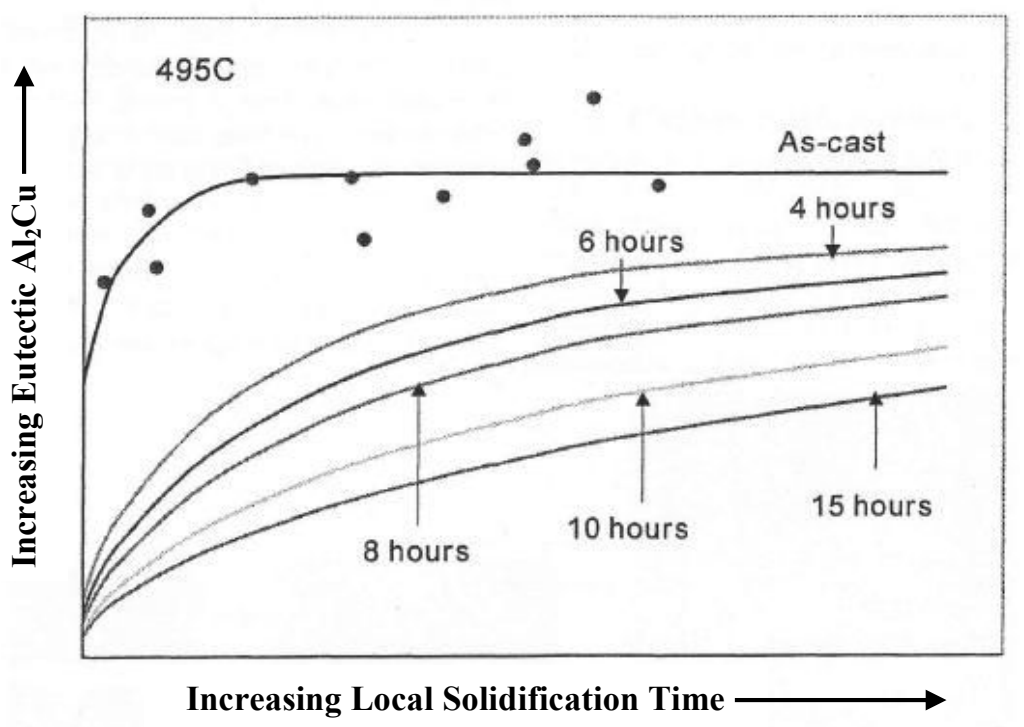

Figure 11: Graph showing influence of solidification time on dissolution of $\mathrm{Al}_{2} \mathrm{Cu}$ at a constant solutionizing temperature of $495{ }^{\circ} \mathrm{C}$ and varying solutionizing time [27].

The last aspect to consider in the solutionizing process is quench rate. The quenching stage involves rapid cooling to a specified temperature and is required at the end of the solutionizing 
process to preserve the metastable supersaturated solid solution. Although higher quench rates are desirable since the dissolved elements remain in supersaturated solid solution, higher quench rates also result in large thermal gradients between the surface and the interior of the component $[21,28,29]$. Thermal gradients in the material subsequently cause the generation of residual stresses, which can lead to premature failure of the component. Therefore, the quench rate must be optimized in order to prevent equilibrium phases from coming out of solution, while reducing the generated residual stress.

\subsubsection{Aging}

Solution heat treatment is followed by aging (precipitation of fine metastable particles from the supersaturated solid solution). Aging is carried out by holding the component at room temperature (natural aging) or at elevated temperature (artificial aging) for a specified period of time. Although aging is usually performed after solution heat treatment, there are standard aging schedules where aging is done following fabrication. Typically, the peak aging condition in aluminum alloys (T6 temper), which involves a solution heat treatment and artificial aging, is preferred due to the superior material strength (yield and ultimate tensile strength) in this condition. However, when dealing with high temperature applications that require precise dimensional tolerances, the component is usually overaged (T7 temper) following the solution heat treatment to improve the dimensional stability. The aging schedule to achieve a T7 temper requires a higher aging temperature and longer aging time compared to the T6 temper [1]. Therefore, the aging parameters, such as temperature and time, are not only dependant on the alloy system but also on the desired properties.

In order to describe the phase transformation during aging, the evolution of Al-Cu precipitates is considered. The aging process causes many stages of intermediate metastable phases to precipitate from the supersaturated solid solution (SSSS) rather than the direct precipitation of the equilibrium phase. The main reason for this is that metastable phases have lower strain energy due to the coherent or semi-coherent interface with the matrix. The preferential formation of metastable phases occurs to minimize free energy. Therefore, the lower strain energy allows metastable phases to precipitate prior to the incoherent equilibrium phases [21]. In the aging of $\mathrm{Al}-\mathrm{Cu}$ alloys, the supersaturated solid solution is followed by three metastable secondary phases prior to the formation of the equilibrium $\theta-\mathrm{Al}_{2} \mathrm{Cu}$. The precipitation sequence along with a model 
showing the crystal structure of each phase (white and shaded spheres represent copper and aluminum atoms respectively) is shown in Figure 12.

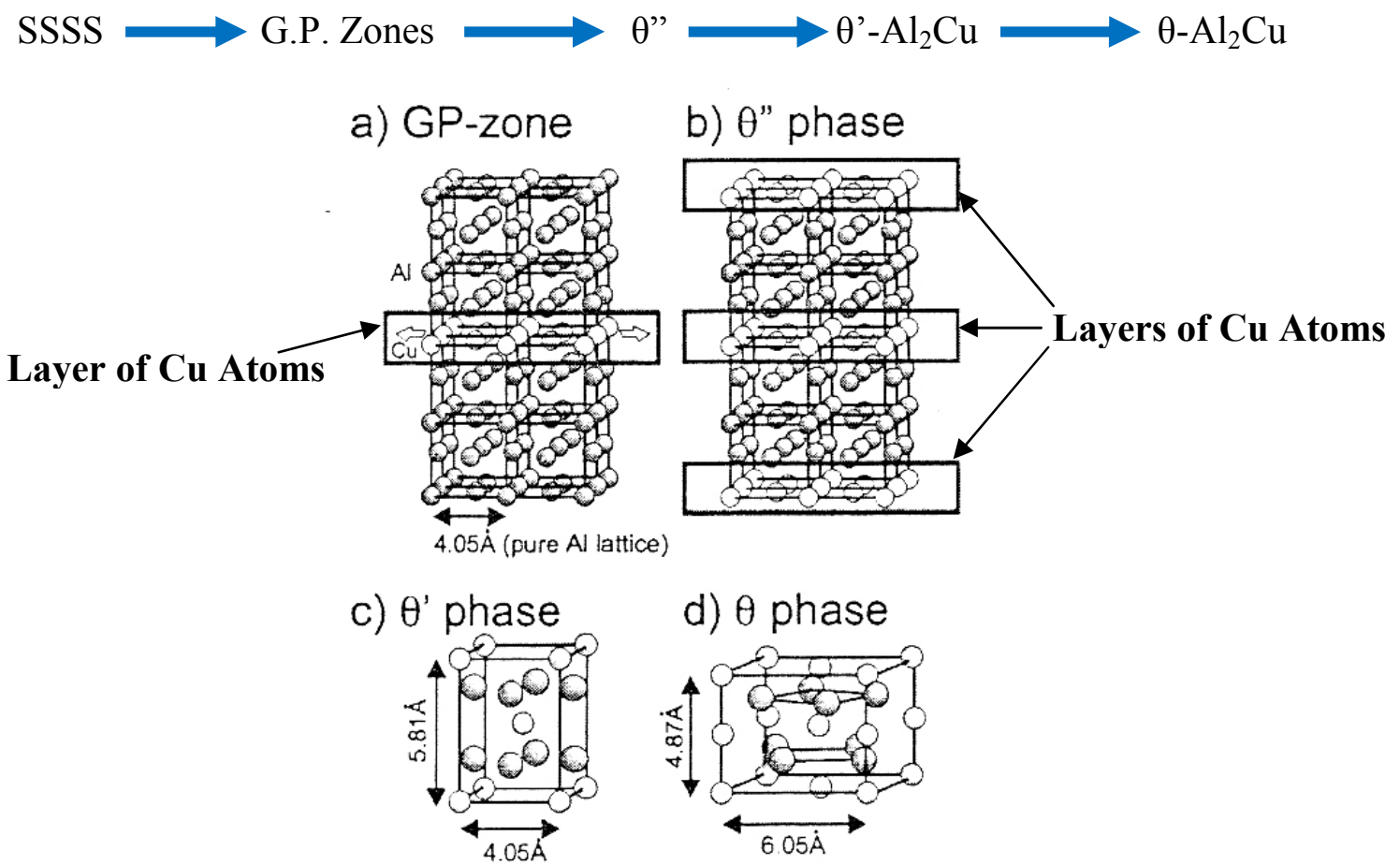

Figure 12: Precipitation sequence and structure of each precipitate formed during the aging of Al-Cu alloys. [30].

The first metastable phase to precipitate from the supersaturated solid solution is a phase consisting of Guinier-Preston (G.P.) zones. Guinier-Preston zones are clusters of alloying elements that come out of solution during aging. In the case of Al-Cu alloys, G.P. zones are clusters of copper atoms that form thin plates along the $\{100\}$ planes of the face centred cubic (FCC) aluminum lattice, as shown in Figure 12(a). Furthermore, the copper rich G.P. zones are approximately 2 atomic layers thick, 20 to 30 atoms in diameter and are coherent with the aluminum matrix $[20,21]$. The formation of G.P. zones in the thin plate morphology occurs to minimize strain energy due to the large difference in atomic size between aluminum and copper. Although copper rich G.P. zones are the most frequently documented, other elements, such as magnesium, can form G.P. zones within the aluminum matrix during aging. Furthermore, for alloy systems in which the atomic size of the precipitating alloying elements is closer to that of the matrix material, spherical G.P. zones form rather than the plate-like morphology observed in Al-Cu alloys [21]. 
Following the formation of G.P. zones, continued aging results in the precipitation of the $\theta$ " phase, which is also known as the GP-2 phase. The $\theta$ " phase, which has a platelet morphology, consists of alternating layers of aluminum and copper atoms along the $\{100\}$ planes as shown in Figure 12(b). The $\theta$ " phase replaces G.P. zones in the microstructure provided sufficient aging has been performed on the alloy [21]. The replacement of the G.P. zones with $\theta$ " is due to diffusion induced movement of atoms with time. Growth of $\theta$ " occurs to a thickness of approximately $2-3 \mathrm{~nm}$ and a diameter of $10-20 \mathrm{~nm}$, which is significantly larger than the G.P. zones [21]. Similar to the G.P. zones, the $\theta$ " phase is coherent with the aluminum matrix. The formation of $\theta$ " precipitates indicate that the peak aging condition has been achieved.

Continued aging past the peak aging condition results in the conversion of the $\theta$ " precipitates into $\theta^{\prime}$. The $\theta^{\prime}$ phase has a tetragonal crystal structure, as shown in Figure 12(c), and a similar stoichiometry to the equilibrium $\mathrm{Al}_{2} \mathrm{Cu}$. Similar to $\theta^{\prime \prime}$, the $\theta^{\prime}$ precipitates are characterized by a fine platelet morphology within the aluminum matrix, as shown in Figure 13.

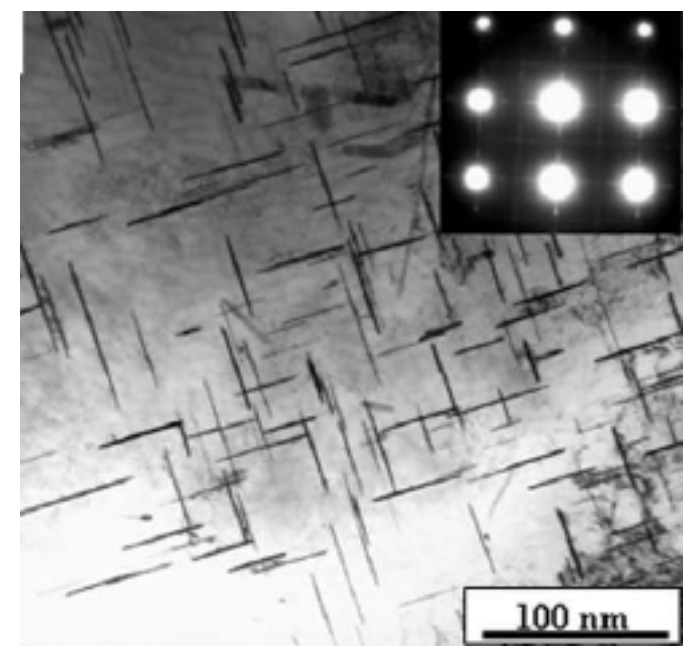

Figure 13: Bright field TEM image with corresponding selected area diffraction pattern along the [001] zone axis showing $\theta$ ' phase in the aluminum matrix [31].

The $\theta^{\prime}$ phase is a semi-coherent metastable precipitate since this phase is only coherent with the matrix in certain planar directions. Furthermore, coherency in these specific directions is gradually lost with particle growth since growth of $\theta^{\prime}$ causes the introduction of interfacial dislocations. The transformation of $\theta^{\prime}$ to equilibrium $\theta$ occurs when the interface between the matrix and the precipitates becomes incoherent $[20,21]$. A schematic showing the tetragonal crystal structure of equilibrium $\theta$ is shown in Figure 12(d). 
The evolution of the $\theta-\mathrm{Al}_{2} \mathrm{Cu}$ precipitates was used to illustrate the influence of heat treatment on the microstructure. However, similar results have been observed with other secondary phases in aluminum alloys. For instance, Al-Si-Cu-Mg alloys may form $\lambda-\mathrm{Al}_{5} \mathrm{Mg}_{8} \mathrm{Cu}_{2} \mathrm{Si}_{6}$ and $\beta-\mathrm{Mg}_{2} \mathrm{Si}$ phases during solidification in addition to $\theta-\mathrm{Al}_{2} \mathrm{Cu}$. Similar to $\mathrm{Al}_{2} \mathrm{Cu}, \lambda$ and $\beta$ phases are dissolved by solution heat treatment while subsequent aging leads to the formation of G.P. zones as well as metastable magnesium-rich age hardening precipitates. Furthermore, in multi-component aluminum alloys, solution heat treatment and aging leads to a combination of metastable phases (e.g. $\lambda^{\prime}$ and $\theta^{\prime}$ ) present within the aluminum grains [32].

\subsubsection{Influence of Heat Treatment on Mechanical Properties}

Solution heat treatment and aging are often performed on aluminum engineering components in order to improve the strength of the alloy as well as reduce residual stresses that may have been introduced during processing. The formation of metastable precipitates within the aluminummatrix during aging has been documented to increase the hardness of $\mathrm{Al}-\mathrm{Si}-\mathrm{Cu}$ and $\mathrm{Al}-\mathrm{Si}-\mathrm{Cu}-\mathrm{Mg}$ alloys, as shown in Figures 14(a) and (b), respectively [33, 34].
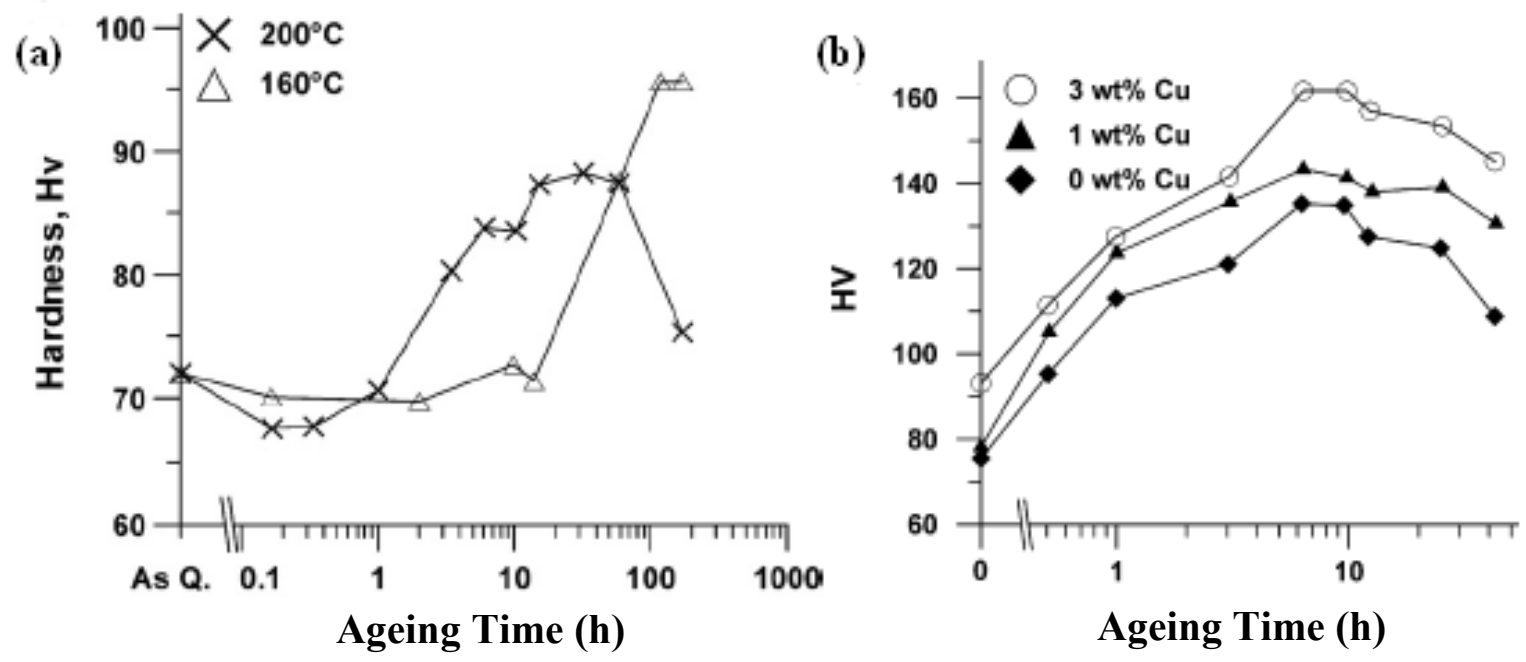

Figure 14: Variation in hardness with artificial aging time for: (a) Al-7Si-3Cu [33], (b) Al-7Si-0.45Mg-xCu $[34]$.

The results from Figures 14(a) and (b) demonstrate that hardness increases with increasing aging time until the peak hardness is reached, at which point further aging results in a reduction in hardness. Furthermore, by comparing the data shown in Figures 14(a) and (b), the addition of magnesium to $\mathrm{Al}-\mathrm{Si}-\mathrm{Cu}$ alloys not only increases the alloy hardness at the peak aging condition, but also reduces the time required to reach the peak aging condition. 
The main reason for the increase in hardness up to the peak aging condition is due to the formation of coherent metastable precipitates. Coherent precipitates introduce strain fields in the surrounding matrix which interact with mobile dislocations. This interaction increased the resistance to the movement of dislocations $[33,34,35]$. At the peak aged condition, the microstructure of $\mathrm{Al}-\mathrm{Si}-\mathrm{Cu}$ alloys contains coherent $\theta$ " precipitates while $\mathrm{Al}-\mathrm{Si}-\mathrm{Cu}-\mathrm{Mg}$ alloys may contain a combination of $\theta ", \lambda$ " and $\beta$ " depending on composition. Continued aging past the peak aging condition results in reduced hardness, mainly due to the replacement of coherent metastable precipitates with semi-coherent metastable precipitates. Since these precipitates are only coherent with the matrix in certain crystallographic directions, strain fields will only exist in these directions, thus reducing the resistance to dislocation motion [20, 21, 33, 34]. Further decrease in hardness with aging time is attributed to the formation of equilibrium phases where coherency is lost, thus strain fields are no longer present to resist the movement of dislocations.

Although strain fields provide a significant amount of strengthening, the interaction between mobile dislocations and second phase particles also result in increased strength provided that the particles are of the appropriate size and of sufficient hardness [21]. This is illustrated by the fact that a small amount of strengthening is observed compared to the as-fabricated condition even after equilibrium precipitates have completely replaced the metastable precipitates.

In order to explain the influence of second phase particles on alloy strength, the two dislocation bypass mechanisms (shearing of particles and bending of dislocations) are shown in Figure 15. The mechanism where the second phase particles are sheared by dislocations applies mainly to small particles (less than $100 \AA$ ) or particles that are not significantly harder than the matrix. Particles that are sheared by dislocations do not increase strength significantly since the particles are typically bypassed by dislocations without much resistance [21].

Conversely, particles of optimum size, typically in the order of $500 \AA$, cause dislocations to bypass the particles by the bending mechanism, provided the particle hardness is sufficient to make shearing difficult. The bending mechanism also leads to the multiplication of dislocations, as shown in Figure 15(b), which increases the strain hardening response of the alloy. Therefore, in addition to coherency strains, alloys in the peak aging condition contain precipitates with an appropriate size to allow dislocations to bypass the particles by the bending mechanism which 
also contributes to increased strength [37]. Additional aging beyond the peak aging condition results in not only a loss of coherency, but also coarsening of the precipitates. Coarsening of precipitates increases the interparticle spacing which allows the particles to be bypassed by dislocations at significantly lower stress levels compared to the required stress to bypass particles of optimum size [20, 21, 36, 37]. For this reason, overaging results in a significant loss of hardness and strength relative to the peak aging condition.

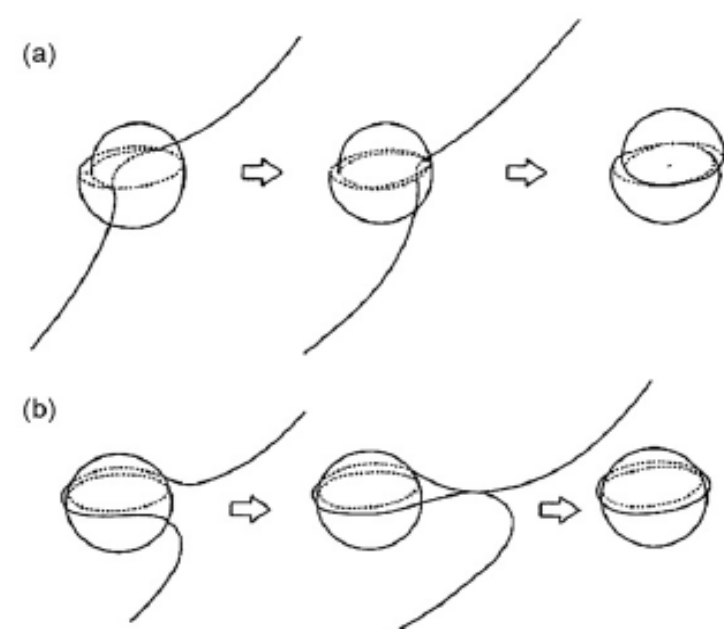

Figure 15: Mechanism of dislocations bypassing particles by: (a) particle shearing, (b) bending of dislocations [36].

\subsection{Residual Stresses in Engineering Components}

\subsubsection{Introduction to Residual Stresses}

The presence of residual stress is common in many engineering components as a result of manufacturing processes such as casting, forging, extrusion and heat treatment. By definition, a residual stress is a stress which exists in an elastic body without the application of an external load [38-40]. Therefore, in order for the component to remain in equilibrium state, different regions of the component contain residual stresses of opposite sign which balance to zero. The distance required for the residual stress to equilibrate is known as the characteristic length $\left(l_{0}\right)$ which determines the type of residual stress that is present within the system. Residual stresses are classified into three main groups as shown in Figure 16.

The first group refers to long range or macro residual stresses which are designated as type $\mathrm{I}\left(\sigma^{\mathrm{I}}\right)$. Type I residual stresses have a characteristic length in the order of the scale of the structure 
$[38,39]$. Models used to estimate type I residual stresses usually ignore the polycrystalline and multi-phase nature of engineering structural materials. The second class of residual stress, known as type II $\left(\sigma^{\mathrm{II}}\right)$, equilibrate over a distance between 3 to 10 times the grain size. Finally, type III $\left(\sigma^{\mathrm{III}}\right)$ residual stresses are those which exist over atomic dimensions and balance within grains. Type III residual stresses are usually associated with the presence of dislocations or point defects within grains [39].

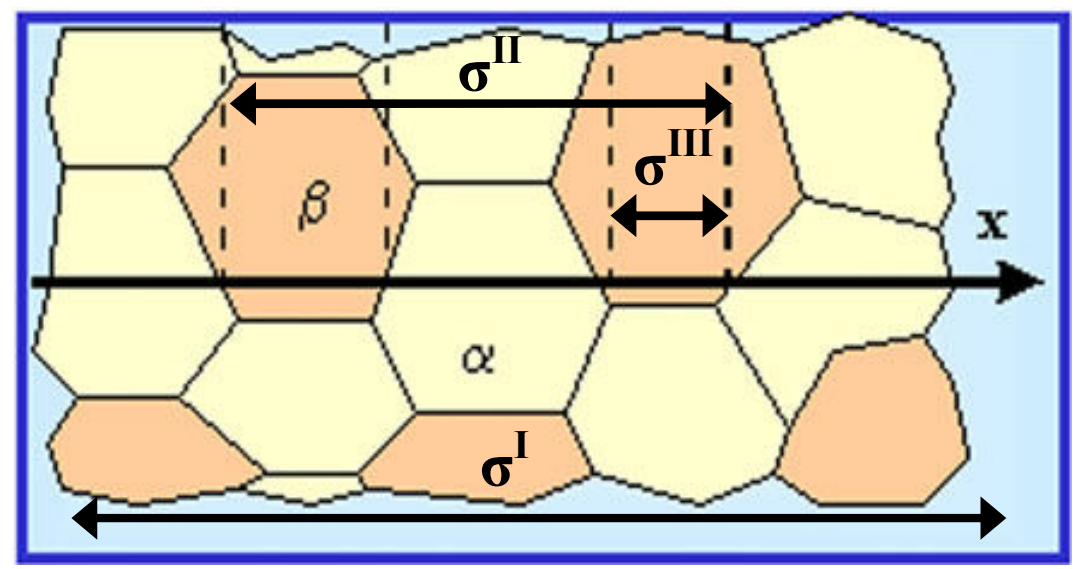

Figure 16: Schematic of grain structure showing characteristic length for the three types of residual stress [41].

It is important to recognize the type of residual stress present in the system, specifically when performing quantitative measurements. Since the three types of residual stress have different characteristic lengths, they will also have different characteristic volumes. With regards to the measurement of residual stress, if the characteristic volume is smaller than the sampling volume, the measured stress is equal to zero [38]. Therefore, in order to yield accurate measurements on the stress state of the system, the appropriate sampling volume is required.

Residual stresses can be favourable or detrimental to a system depending on the magnitude of the stress, the nature of the stress (tensile or compressive) and the application of the component. For example, the presence of tensile residual stress in components experiencing large tensile loads may lead to premature failure of the component since the residual stress is additive to the applied load. However, in the case of components which require a high cycle fatigue life, compressive residual stresses at the surface of the material reduces the amplitude of the applied cyclic stress, thereby extending the fatigue life of the component [38, 39]. 


\subsubsection{Development of Residual Stresses in Engineering Components}

Residual stresses are developed through many manufacturing processes. In general, the development of residual stress is mainly attributed to uneven loading (mechanical or thermal), resulting in non-uniform plastic deformation of neighbouring regions in a constrained material [42]. In the following sections, the development of residual stress due to thermal gradients, differences in thermal expansion coefficient in components containing dissimilar materials and mechanical loading is discussed.

\subsubsection{Thermal Gradients}

The formation of large thermal gradients during manufacturing is one of the most common ways to induce residual stress. In order to explain the influence of thermal gradients on induced stress, an externally unconstrained material, divided evenly into many cubical elements, is considered. If the material is heated or cooled uniformly, the individual elements in the material expand or contract freely by an equal amount, proportional to $\alpha \Delta \mathrm{T}$, where $\alpha$ is the coefficient of thermal expansion of the material and $\Delta \mathrm{T}$ is the change in temperature. In this case, there is no significant formation of residual stress. Conversely, an externally constrained material that is heated or cooled uniformly results in the generation of residual stress since the external constraint prevents certain sections of the material from freely changing dimensions.

In the case of non-uniform heating or cooling of an externally unconstrained material, the individual elements expand or contract by differing amounts, depending on the temperature at each specific region of the component, resulting in a misfit between neighbouring elements. However, since continuity must be maintained, dimensional changes of individual elements are constrained by neighbouring elements, resulting in the generation of an elastic strain field, provided that the resulting induced residual stress is lower than the yield strength of the material $[43,44]$. The magnitude of this strain field is dependent on the magnitude of the temperature gradient since the change in dimensions of each element is directly proportional to the variation in temperature and the coefficient of thermal expansion of the material.

In the production of engineering components, thermal gradients may arise due to high quench rates following heat treatment as well as non-uniform heating during component manufacturing or while in service. With regards to high quenching rates following heat treatment, thermal 
gradients are formed between the surface and the interior of the component. The surface of the component, due to direct contact with the quenchant, cools very rapidly to obtain an equilibrium temperature with the quenching medium. Rapid cooling at the surface results in the surface being compressed plastically. The interior of the component subsequently cools, but at a cooling rate that is significantly lower than at the surface, giving rise to a thermal gradient [28, 39]. Upon cooling, the interior of the component is restricted from contraction due to the rigid outer surface resulting in the interior remaining elastically in tension.

\subsubsection{Mismatch of Thermal Expansion Coefficient}

Thermally induced residual stress in a component can also occur when in scenarios where dissimilar materials are in direct contact with one another. The generated thermal stress is directly related to the difference in thermal expansion coefficient between the two materials. In order to illustrate the influence of thermo-mechanical mismatch on residual stress generation, a uniformly heated beam made of two dissimilar layers is considered [44]. In this system, it is assumed that the beam is initially stress free. The stress generated due to the uniform change in temperature of each constrained beam layer is given in Equations 1(a) and (b), respectively [45]. The relationships in Equation 1, utilize the force equilibrium condition on the entire system to derive the stress induced due to thermo-mechanical mismatch of the beam layers. Equation 1 relates residual stress $(\sigma)$ in each layer to the change in temperature $(\Delta T)$, the thermal expansion coefficient $(\alpha)$, the cross-sectional area (A) and the modulus of elasticity (E), for each layer of the component.

$$
\begin{gathered}
\sigma_{1}=\left(\alpha_{1}-\alpha_{2}\right) \Delta T \frac{E_{2} E_{1} A_{1}}{E_{2} A_{2}+E_{1} A_{1}} \\
\sigma_{2}=-\left(\alpha_{1}-\alpha_{2}\right) \Delta T \frac{E_{2} E_{1} A_{2}}{E_{2} A_{2}+E_{2} A_{1}}
\end{gathered}
$$

The resulting residual stress distribution for each dissimilar layer of the beam, with layer thicknesses $h_{1}$ and $h_{2}$, assuming that $\alpha_{1}>\alpha_{2}$ and $\Delta T>0$ (heating), is shown in Figure 17. 


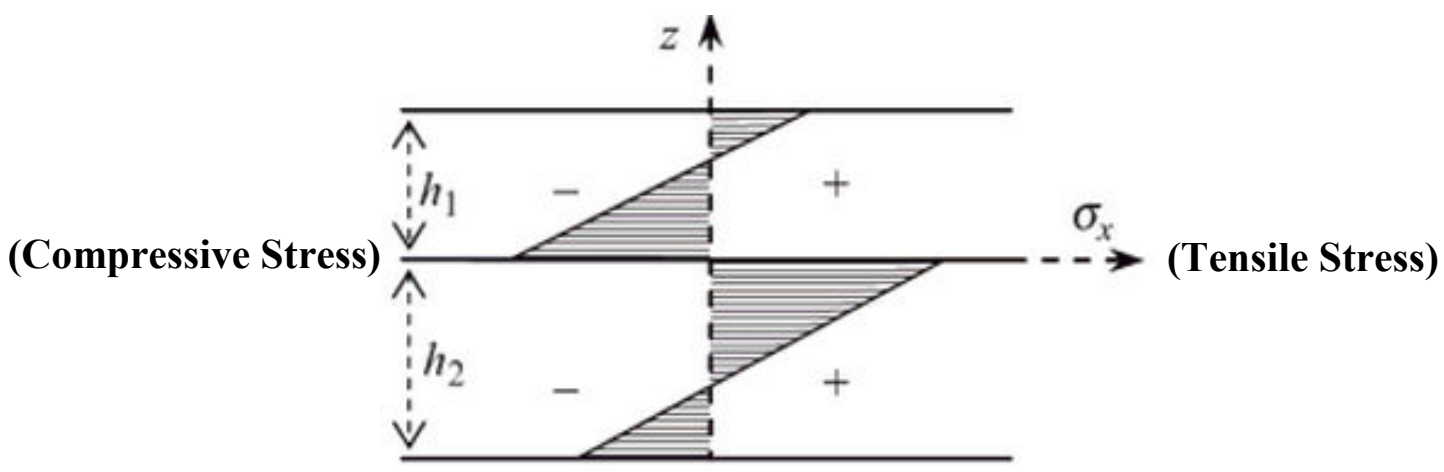

Figure 17: Qualitative stress distribution induced by thermal expansion mismatch between layers [44].

The stress distribution shows that the maximum induced residual stress occurs at the interface between the two dissimilar materials when the component is subjected to a uniform temperature change. The magnitude of the residual stress subsequently reduces with increased distance from the interface and eventually reaches zero before increasing in the opposite orientation compared to the interface. The mechanism of residual stress generation due to thermo-mechanical mismatch is similar to that of thermal gradients. During heating or cooling, the dissimilar materials change dimensions at different rates resulting in a mismatch in dimensional change between adjacent elements. However, to maintain continuity, adjacent elements restrict the dimensional change of each element resulting in the formation of strain fields. Therefore, thermo-mechanical mismatch causes the individual sections of the component to be constrained by the surrounding sections due to differences in the rate of expansion or contraction [44].

\subsubsection{Mechanical Loading}

Mechanical loading is another method of inducing residual stress during the production of engineering components. Similar to thermal loading, residual stress generated from mechanical loading is mainly due to localized plastic deformation of an externally constrained material preventing the material from uniform dimensional change [42]. Once again considering an initially stress free, externally unconstrained material divided into equally sized cubic elements, it can be deduced that uniform mechanical loading results in uniform dimensional change of each element. Thus, similar to the case with uniform thermal loading, no dimensional mismatch between elements forms, resulting in no residual stress formation. However, for non-uniform loading, such as shot peening where the load is concentrated toward the surface of the material, localized plastic strain of one region results in a misfit of elements. Therefore, due to the 
continuity requirement of the material, neighbouring elements constrain the deformation of the material, resulting in the formation of residual stress.

\subsubsection{Residual Stresses in Aluminum Engine Blocks}

Residual stresses typically develop in aluminum alloy engine block castings due to the formation of thermal gradients during quenching and a mismatch in thermal expansion coefficient between the aluminum alloy and the cylinder liner material [40, 46]. The development of residual stress at different sections of the cylinder bridge was modelled by Su et al. [46] using ABAQUS finite element software on an inline-4 (I-4) 319 aluminum engine block with cast-in iron liners. In this simulation, residual stresses formed during solidification were neglected since it was assumed that solution heat treatment relieved these residual stresses. Therefore, the model focussed on simulating residual stress formation due to quenching from the solution heat treatment temperature to ambient temperature. The simulated stress distribution of the engine block is shown in Figure 18. The results in Figure 18 show large tensile residual stresses at the cylinder bridge with a magnitude of approximately $150 \mathrm{MPa}$. The stress at the cylinder bridge was significantly larger in magnitude compared to other sections of the engine block. Su et al. [46] attributed the generation of residual stresses to the difference in thermal expansion coefficient between the aluminum alloy and the cast iron liners, which is compounded at the cylinder bridge due to the influence of two cast iron cylinder liners.

The modelled results were confirmed for the deck face of the cylinder bridge by using strain gauge rosettes to measure the resulting strain due to sectioning of the cylinder bridge. The experimentally measured strains were found to be within $5 \%$ of the modelled strains. Furthermore, the results of Carrera et al. [40] also confirmed the results of the finite element model. Using strain gauges, and applying Hooke's law, Carrera et al. [40] determined the residual stress at the cylinder bridge of an I-4 aluminum engine block with cast iron cylinder liners to be approximately $150 \mathrm{MPa}$. Therefore, based on the modelled and experimental results from $\mathrm{Su}$ et al. [46] and Carrera et al. [40], the critical location with respect to the residual stress magnitude of an aluminum engine block containing iron cylinder liners is the cylinder bridge. 


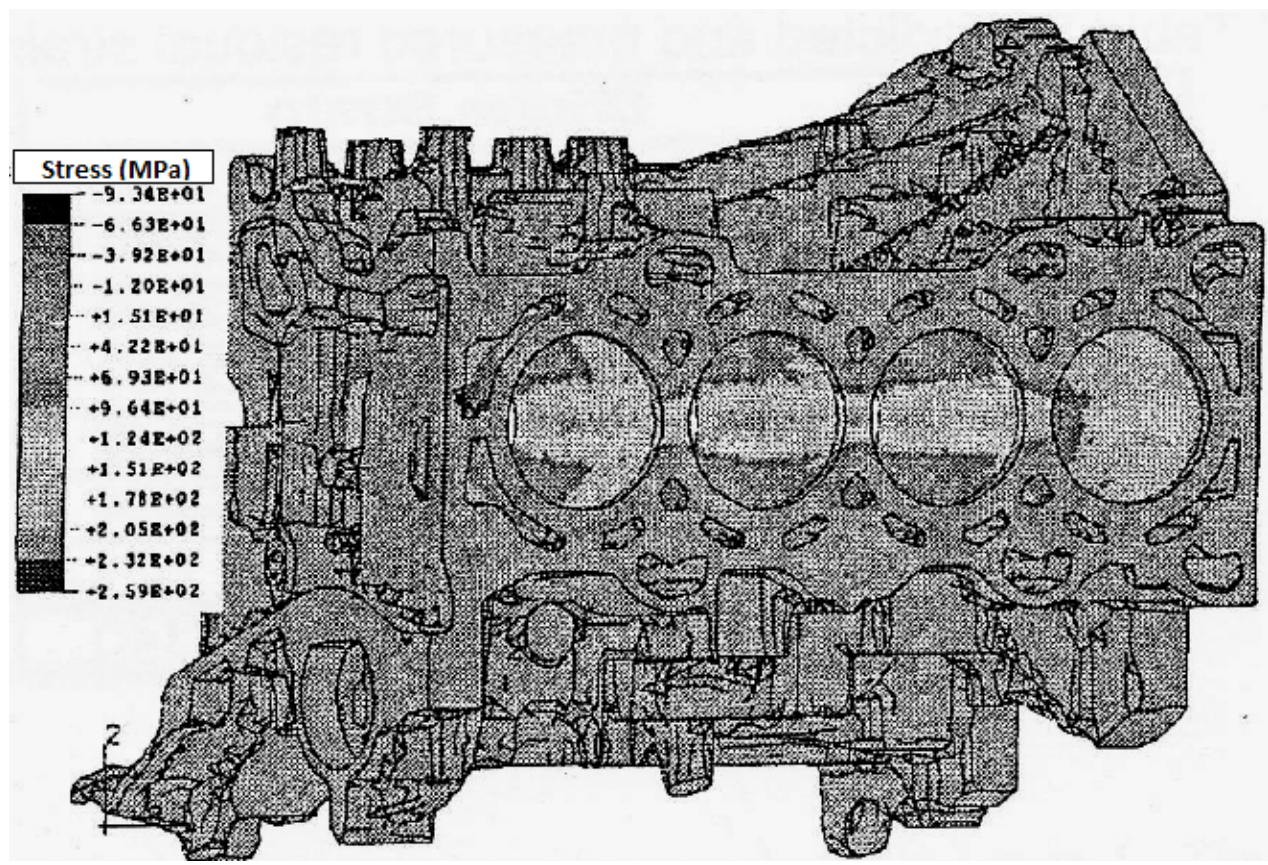

Figure 18: Modeled residual stress distribution of an I-4 319 aluminum engine block with cast-in iron liners [46].

\subsubsection{Measurement of Residual Stress}

Measurement of residual stress is usually accomplished through various destructive and non-destructive methods. Destructive methods of residual stress measurement include hole drilling and sectioning, where the residual stress is assessed using strain gauges by measuring the resultant plastic strain from the relief of residual stress [40]. The residual stress is then calculated using Hooke's law since residual stresses are elastic in nature. This method utilizes the concept that disrupting the continuity of the component results in the relief of residual stress thereby causing plastic deformation (strain). Non-destructive methods of residual stress measurement include X-ray diffraction and neutron diffraction, which observe structural changes in the crystalline lattice such as the interplanar spacing [47]. These non-destructive techniques are ideal for the measurement of residual stress without inadvertently altering the stress state due to sectioning.

\subsubsection{Neutron Diffraction}

Neutron diffraction experiments employ a high energy neutron beam which is focussed and directed towards the sample in the specified orientation. A schematic illustrating the neutron diffraction method of strain measurement is shown in Figure 19. 


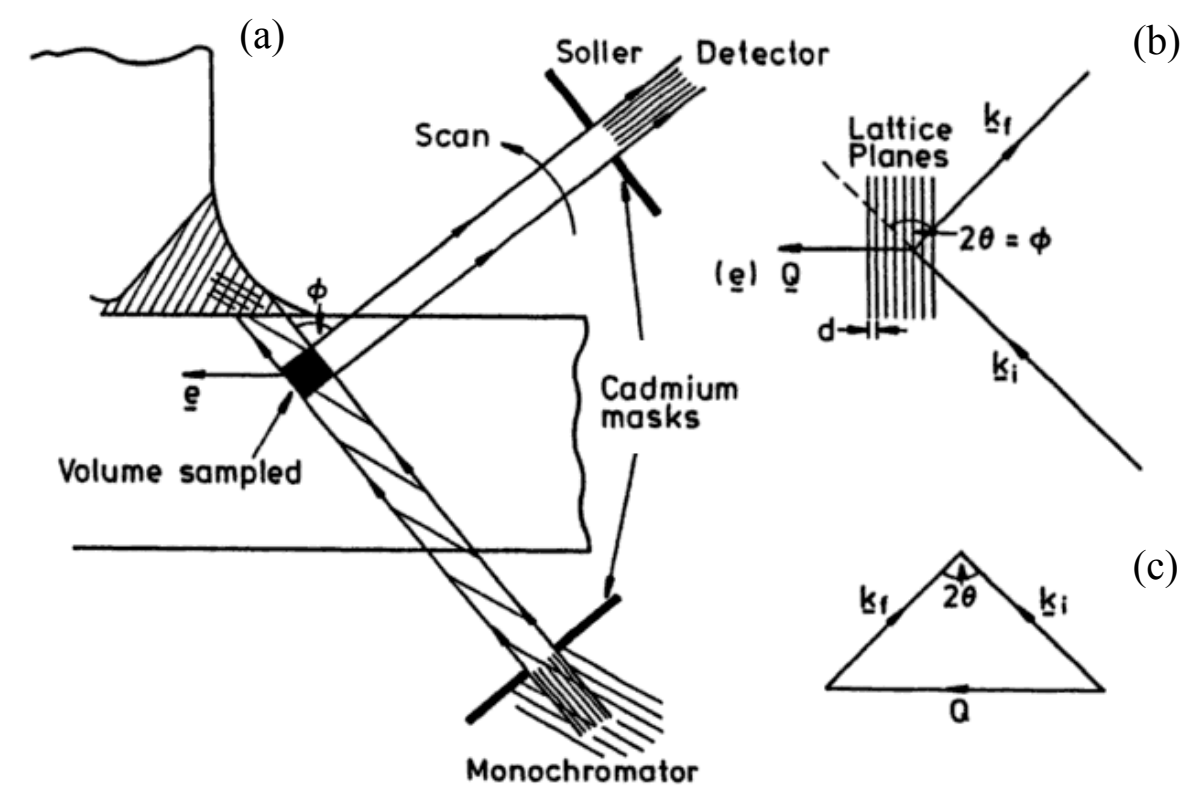

Figure 19: Schematic showing: (a) sampling volume formed from incident and diffracted beams, (b) direction of scattering vector with respect to the lattice planes, (c) magnitude of the scattering vector [47].

The first aspect that must be considered in a neutron diffraction experiment is the wavelength $(\lambda)$ of the neutron beam. In order to ensure that a single wavelength is used throughout the experiment, a monochromator filters the neutron beam and only allows neutrons of a specified wavelength to pass through it. The monochromated neutron beam is then defined in a specific direction by a soller slit collimator. The beam that emerges from the collimator is subsequently used as the incident beam in the experiment [47]. Once in contact with a crystalline specimen having an interplanar spacing of the order of the wavelength of the neutron beam, the incident beam scatters (or diffracts) if the Bragg condition is met. The Bragg condition states that constructive interference between adjacently scattered neutrons occurs if the scattered neutrons remain in phase. For the diffracted neutron beams to remain in phase the path difference between adjacent diffracted beams must be integer multiples of the wavelength. The path difference resulting in constructive interference between adjacent waves is given by Bragg's law as shown in Equation 2 for first order diffraction $(n=1)$, which relates the wavelength $(\lambda)$ to the interplanar spacing $\left(\mathrm{d}_{\mathrm{hkl}}\right)$ and the scattering angle $(\varphi)$ [47].

$$
\lambda=2 d_{h k l} \sin (\phi / 2)
$$

The diffracted beam that emerges from the crystalline specimen is then directed towards the detector using another soller slit collimator. The volume defined by the intersection of the 
incident and diffracted beam, as shown in Figure 19, is known as the sampling volume, which is the location of the specimen where crystallographic information is obtained.

The measurement of strain using neutron diffraction involves the measurement in the change in interplanar spacing $\left(\mathrm{d}_{\mathrm{hkl}}\right)$. The interplanar spacing is determined by first plotting the diffracted neutron intensity against angular position. By fitting a continuous statistical distribution to the data (i.e. Gaussian distribution), the diffraction angle is estimated, which by utilizing Bragg's law, allows the interplanar spacing to be estimated. Using the "peak shift" method shown in Equation 3, strain is calculated by relating the measured interplanar spacing to the interplanar spacing of a "strain free" sample $\left(\mathrm{d}_{0, \mathrm{hkl}}\right)$ of the same chemical composition.

$$
\varepsilon=\frac{d_{h k l}-d_{0, h k l}}{d_{0, h k l}}
$$

The accuracy of the calculated strain depends largely on the "strain free" sample. If this sample is indeed strain free, then the calculated strain at the sample location of interest is a relatively accurate estimation of the true strain within the specimen.

In most engineering applications where residual stress is a concern, strain measurements are performed along the three principal orientations to calculate the residual stress. Strain measurements in different orientations are performed using neutron diffraction by orientating the specimen perpendicular to the scattering vector $(\mathrm{Q})$. The scattering vector is a linear combination of the incident and diffracted neutron wave vectors, $K_{i}$ and $K_{d}$, respectively, as shown in Figure 19. Therefore, by measuring the interplanar spacing of the appropriate family of planes, the three principal strain components are determined. The residual stress in each orientation is then calculated using the measured strain and generalized Hooke's law, shown in Equations 4-6 [47].

$$
\begin{aligned}
& \sigma_{x}=\frac{E}{1+v}\left[\varepsilon_{x}+\frac{v}{1-2 v}\left(\varepsilon_{x}+\varepsilon_{y}+\varepsilon_{z}\right)\right] \\
& \sigma_{y}=\frac{E}{1+v}\left[\varepsilon_{y}+\frac{v}{1-2 v}\left(\varepsilon_{x}+\varepsilon_{y}+\varepsilon_{z}\right)\right] \\
& \sigma_{z}=\frac{E}{1+v}\left[\varepsilon_{z}+\frac{v}{1-2 v}\left(\varepsilon_{x}+\varepsilon_{y}+\varepsilon_{z}\right)\right]
\end{aligned}
$$


where, $E$ is the modulus of elasticity, $v$ is Poisson's ratio, $\sigma$ is the residual stress in the $\mathrm{x}, \mathrm{y}$ and $\mathrm{z}$ principal axes and $\varepsilon$ is the strain in the $\mathrm{x}, \mathrm{y}$ and $\mathrm{z}$ principal axes.

Although Hooke's law in Equations 4-6 is defined for the Cartesian co-ordinate system, for cylindrical specimens polar co-ordinates are typically used where the principal directions are the hoop, radial and axial orientations.

\subsubsection{Comparison of Neutron Diffraction to X-ray Diffraction}

Residual stress measurement using neutron diffraction and X-ray diffraction use similar principles. Both methods use Bragg's law to determine the interplanar spacing in order to calculate strain and subsequently the residual stress in the sample. However, the main difference between the two techniques lies in the way each wave is scattered by the crystalline specimen. Neutrons interact directly with the nucleus of the atoms while X-rays interact with the surrounding electron cloud [48]. Since the penetration depth of the incident beam is inversely proportional to the probability of interaction within the material, neutrons can penetrate further than X-rays prior to being scattered. This occurs since the probability of a scattering event between the incident beam and the nucleus of an atom is lower than the probability of a scattering event between the incident beam and the electron cloud. Furthermore, while the neutron beam has essentially the same penetration depth regardless of the atomic number of the specimen, the penetration depth for X-rays decreases with increasing atomic number. With a higher atomic number, the electron cloud becomes larger, increasing the probability of a scattering event [48]. For this reason, neutron diffraction can be applied to analyze the bulk material properties $(2-3 \mathrm{~cm}$ depth) of larger engineering components, while X-ray diffraction can only be used to analyze surface properties (100 $\mu \mathrm{m}$ depth). However, due to significantly higher cost and scarcity of neutron generators, X-ray diffraction is typically used in the measurement of residual stress.

\subsection{Mechanisms of Dimensional Distortion in Aluminum Alloys}

Dimensional distortion is one of the major considerations in engineering design regarding materials selection and heat treatment schedule used in the production of components. Similar to ferrous alloys, such as steel, heat treatable aluminum alloys are typically prone to distortion unless the proper precautions are taken during processing of the component. The two 
mechanisms associated with dimensional distortion of $\mathrm{Al}-\mathrm{Si}-\mathrm{Cu}$ alloy components are the presence of excessive tensile residual stress and a phase transformation based mechanism known as thermal growth. The following sections discuss the mechanisms of dimensional distortion in Al-Si-Cu alloy components.

\subsubsection{Excessive Residual Stress}

The formation of residual stresses during manufacturing of engineering components may cause significant distortion or premature failure while the component is in service. It is generally accepted that residual stress exceeding the yield strength of the material causes plastic deformation resulting in permanent dimensional distortion [49, 50]. Plastic flow subsequently results in the relief of the residual stress within the material since elastic stresses are relieved by plastic deformation.

Dimensional distortion is especially a concern in components which operate at elevated temperatures and require high dimensional accuracy. An example of this is the cylinder bore regions of hypoeutectic Al-Si alloy engine blocks. Large tensile residual stresses are induced along the cylinder bores due to a mismatch in the thermal expansion coefficient between the aluminum alloy $\left(2.4 \times 10^{-5} \mathrm{~K}^{-1}\right)$ and the gray cast iron cylinder liner $\left(1.5 \times 10^{-5} \mathrm{~K}^{-1}\right)[2,40,51]$. Moreover, during in-service conditions, the regions of the engine block nearest to the cylinder bores are heated to approximately $200{ }^{\circ} \mathrm{C}$ due to the combustion cycle. This reduces the yield strength of the aluminum alloy at the regions nearest to the cylinder bores, thereby increasing the susceptibility to distortion. Furthermore, while in service, external stresses are applied to the cylinder walls of the engine block. A schematic of the combustion chamber showing the external stresses arising during operation are shown in Figure 20.

The externally applied stresses (normal and shear stresses) arise during the power stroke of the engine cycle. The ignition of the compressed air-fuel mixture causes a rapid expansion of the air-fuel mixture within the combustion chamber [50]. This large change of pressure within the combustion chamber imparts a large amount of externally applied stress on the engine cylinder walls. For engine blocks containing large tensile residual stress prior to operation, the externally applied stress is added to the residual stress by superposition principles, making the engine 
blocks highly susceptible to dimensional distortion. Therefore, it is critical to minimize the residual stresses at the cylinder bore regions prior to in-service use.

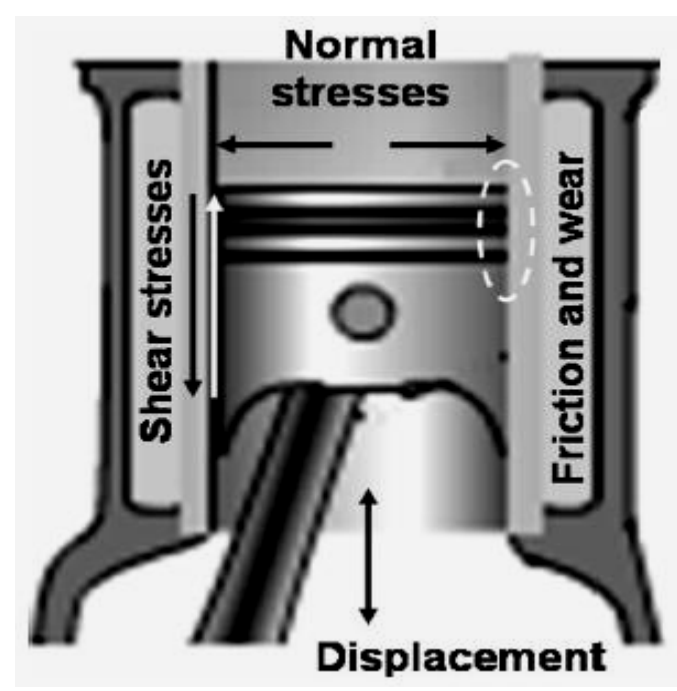

Figure 20: Schematic of the combustion chamber (piston-cylinder assembly) within an engine showing the stresses experienced by the material while in-service [50].

\subsubsection{Thermal Growth}

Permanent dimensional changes may also occur during heat treatment of Al-Si-Cu alloys by a mechanism known as thermal growth. Thermal growth is associated with a change in specific volume of the material due to the precipitation of age hardening precipitates [27, 52-54]. This mechanism influences the specific volume of the material in two ways $[53,54]$. The first deals with the change in lattice parameter of the matrix phase during precipitation of age hardening precipitates. Dissolution of equilibrium secondary phases into the aluminum matrix causes the lattice parameter of aluminum ( $\mathrm{a}=4.05 \AA$ for pure aluminum [30]) to change. However, during precipitation of age hardening precipitates, the lattice parameter of the matrix phase changes proportionally to the amount of alloying elements that precipitate out of solution. The magnitude of the change in lattice parameter for the dissolution of common alloying elements in aluminum alloys is shown in Figure 21. Considering the trends shown in Figure 21, it can be seen that precipitation of copper rich precipitates during aging causes an expansion in the lattice parameter of the matrix while magnesium rich precipitates cause contraction. 


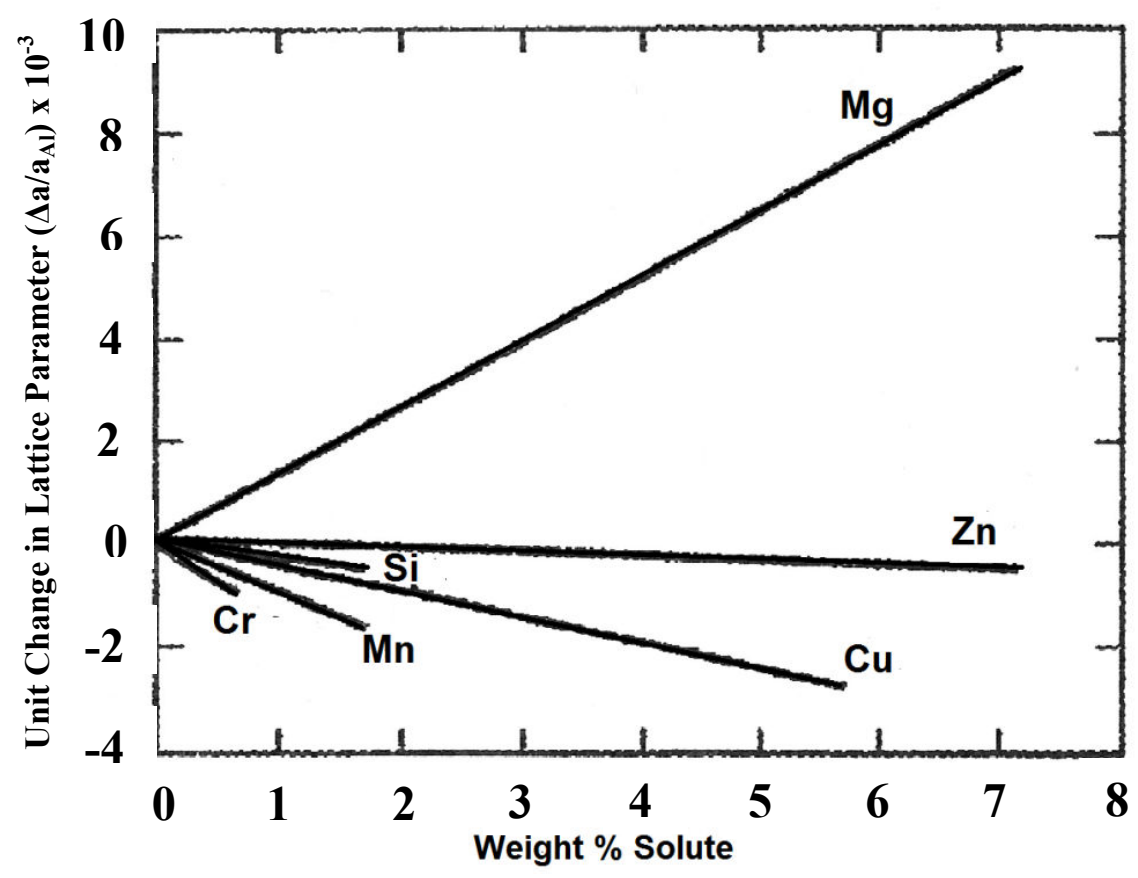

Figure 21: Unit change in lattice parameter of the aluminum matrix with amount of dissolved alloying elements [53].

The second aspect of thermal growth is associated with the difference in specific volume of the precipitates relative to the matrix phase. Prior to aging treatments, the microstructure of the material is composed mainly of a single phase supersaturated solid solution with a certain specific volume. However, the precipitation of secondary phases during aging may influence the overall specific volume of the material if secondary phases have a significantly different specific volume relative to the matrix. This phenomenon was illustrated in the work of Hunsicker (Figure 22) [53]. Figure 22 shows the linear dimensional change associated with the precipitation of $\theta^{\prime \prime}, \theta^{\prime}$ and equilibrium $\theta$ as a function of the amount of copper precipitated. The results suggest that during aging of $\mathrm{Al}-\mathrm{Cu}$ alloys, the precipitation of different metastable phases resulted in a different unit linear dimensional change of the alloy. For instance, the precipitation of the $\theta$ ' phase resulted in the largest change in specific volume, approximately three times larger than that associated to the precipitation of equilibrium $\theta$. 


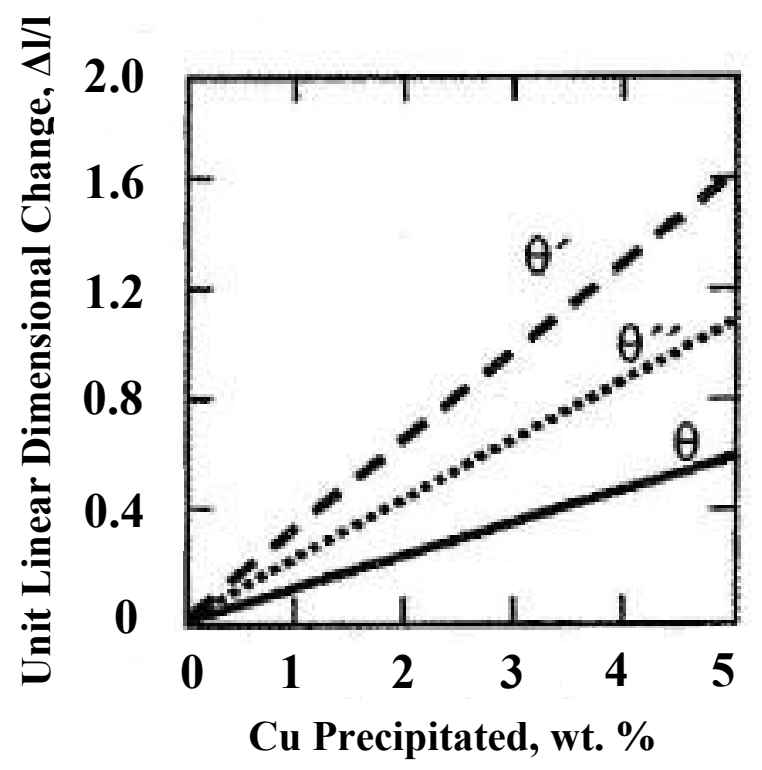

Figure 22: Observed dimensional changes due to the precipitation of age hardening precipitates during aging of Al-Cu alloys [53].

Components made from heat treated 319 aluminum alloys that operate at elevated temperature $\left(\sim 200{ }^{\circ} \mathrm{C}\right)$ may be dimensionally unstable due to phase transformation of metastable $\mathrm{Al}-\mathrm{Cu}$ precipitates. However, the magnitude of dimensional growth of a component while in service at elevated temperature is highly dependent on the heat treatment temper of the component prior to in-service use as well as the operating temperature. Boileau et al. [54] investigated the dimensional change of a 319 aluminum alloy that was heat treated to $\mathrm{T} 4$ (solution treated at $495{ }^{\circ} \mathrm{C}$ for 1 hour), T6 (solution treated at $495^{\circ} \mathrm{C}$ for 8 hours then aged at $190{ }^{\circ} \mathrm{C}$ for 5 hours) and T7 (solution treated at $495{ }^{\circ} \mathrm{C}$ for 8 hours then aged at $260{ }^{\circ} \mathrm{C}$ for 4 hours) tempers and subsequently exposed to temperatures of 180 and $250^{\circ} \mathrm{C}$. The variation in dimensional change for each treatment condition at exposure temperatures of 180 and $250{ }^{\circ} \mathrm{C}$ are shown in Figures 23(a) and (b), respectively.

The results from Boileau et al. [54] illustrated that components in the T4 temper were less dimensionally stable than components in the T6 or T7 tempers. Thermal growth of 319 aluminum alloy in the T4 treatment condition was attributed to the continued aging of the 319 alloy while exposed to elevated temperatures $\left(180\right.$ and $\left.250{ }^{\circ} \mathrm{C}\right)$. This likely resulted in the precipitation of $\theta^{\prime}$ precipitates from the supersaturated solid solution that is present for 319 alloys in the T4 temper [54]. 

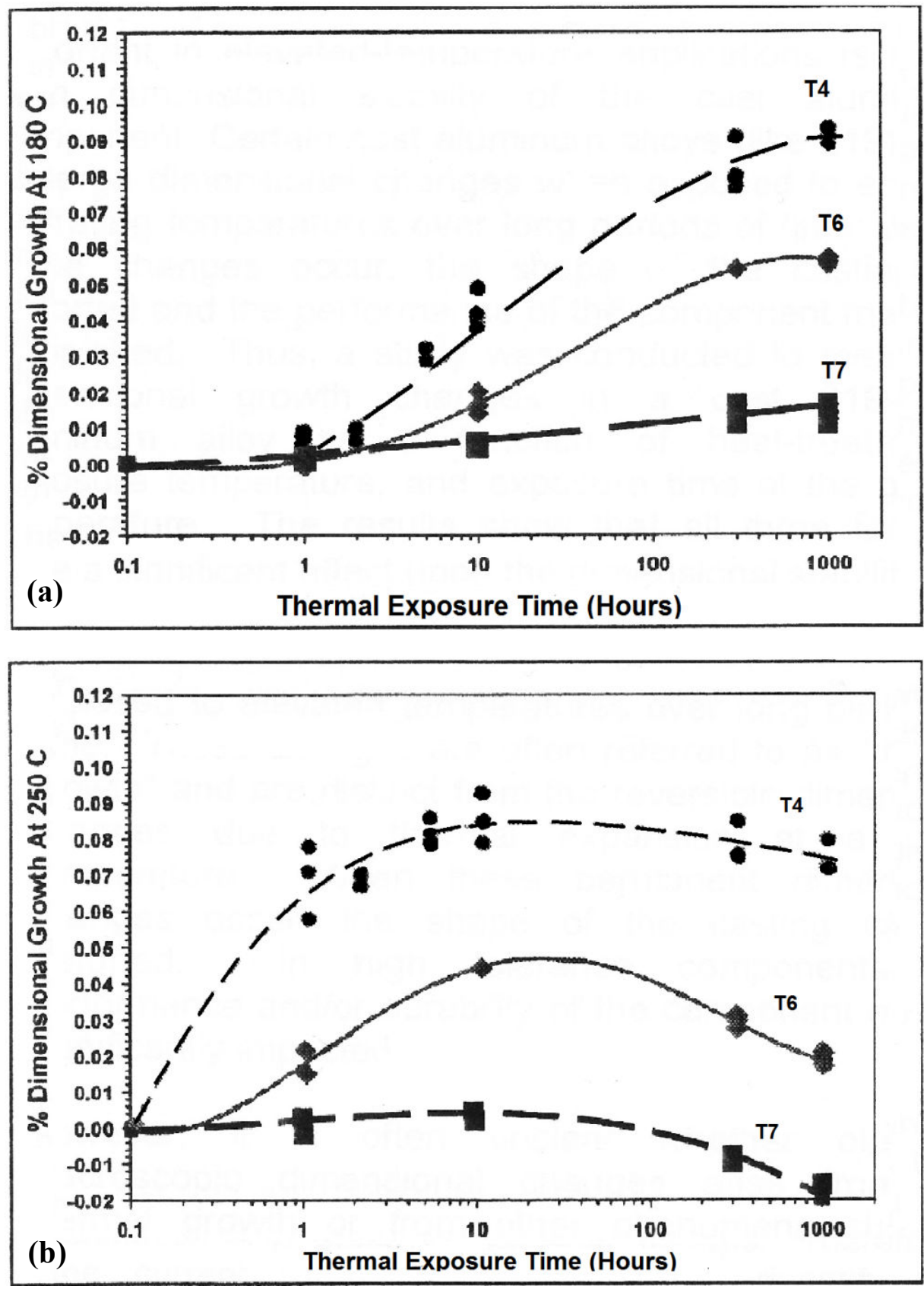

Figure 23: Dimensional growth of W319 aluminum alloy in the T4, T6 and T7 heat treatment condition while exposed to: (a) $180^{\circ} \mathrm{C}$, (b) $250{ }^{\circ} \mathrm{C}$ [54].

Exposure of T6 treated 319 aluminum alloy to elevated temperatures $\left(180\right.$ and $\left.250{ }^{\circ} \mathrm{C}\right)$ also led to thermal growth, albeit to a lesser degree than for the T4 temper. Thermal growth for the alloy in the T6 condition was attributed to the replacement of the $\theta$ " phase with $\theta$ ' due to continued aging [54]. The precipitation of the $\theta$ ' phase in place of $\theta$ " resulted in a dimensional expansion as shown in Figure 22 [53]. 
Conversely, Boileau et al. [54] found that the 319 alloy in the T7 temper exhibited a significantly lower degree of thermal growth as compared to the T4 and T6 tempers. The primary reason for this is that the microstructure of a 319 aluminum alloy in the T7 temper consisted of a combination of $\theta^{\prime}$ and equilibrium $\theta$. Since the $\theta^{\prime}$ phase was already present in the microstructure along with $\theta$, significant growth did not occur while in service. Thus the component was dimensionally stable at temperatures up to $250^{\circ} \mathrm{C}$.

Operating temperature is also an important factor regarding the dimensional stability of heat treated 319 aluminum alloy components. By comparing Figures 23 (a) and (b), it is apparent that higher operating temperatures result in accelerated aging which causes dimensional changes to occur in a shorter period of time. Furthermore, Figure 23 (b) illustrates that thermal exposure for more than approximately 50 hours at $250{ }^{\circ} \mathrm{C}$ causes dimensional contraction. Boileau et al. [54] attributed dimensional contraction to the replacement of $\theta^{\prime}$ with equilibrium $\theta$ phase. Since the $\theta$ phase results in a lower unit dimensional change compared to $\theta^{\prime}$, the replacement of $\theta$ ' with $\theta$ was believed to result in dimensional contraction.

\section{Chapter Summary}

This chapter provided a review of the $\mathrm{Al}-\mathrm{Si}-\mathrm{Cu}$ alloy system along with heat treatment of aluminum alloys and its effect on mechanical properties. Mechanisms associated to residual stress generation during component processing were also reviewed in detail. This chapter also discussed mechanisms that cause dimensional distortion in aluminum alloys. This discussion of mechanisms related to residual stress formation and dimensional distortion establishes the background for a thorough investigation of the potential causes of cylinder bore distortion in Al-Si-Cu alloy engine blocks with cast-in gray iron cylinder liners. 


\section{Chapter 3: Experimental Procedure}

This chapter outlines the experiment methods utilized in this study. Section 3.1 outlines the project structure and the analysis that was performed on the engine block castings. The relevant engine block production parameters are discussed in Section 3.2, while the analyzed cylinder locations in the engine blocks are shown in Section 3.3. Finally, this chapter shows the methodology of sample preparation for scanning and transmission electron microscopy, the set up required for the neutron diffraction experiments and the procedure used to measure the cylinder profiles using a co-ordinate measuring machine.

\subsection{Project Outline}

This project was a collaborative project between the Centre for Near-net-shape Processing of Materials (CNPM) at Ryerson University and the Nemak Centre of Engineering in Windsor, Canada. The project sought to determine the cause of dimensional distortion in aluminum engine blocks with cast-in gray iron cylinder liners and to develop a scientific explanation for distortion in order to prevent it in the future production of aluminum engine block castings.

In order to determine the cause of cylinder bore distortion, the following aspects were investigated for engine blocks following the thermal sand reclamation treatment (TSR), T7 heat treatment and service testing to determine the cause of cylinder distortion.

- Analysis of the cylinder profiles in service tested block

- Microstructure

- Thermal analysis

- Mechanical properties

- Residual stress/strain evolution

The flow chart shown in Figure 24 shows the analysis performed on several engine blocks in each treatment condition. The flow chart includes the specific aspects assessed in microstructural analysis, mechanical properties and thermal analysis as well as the orientations in which strain measurements were performed. 


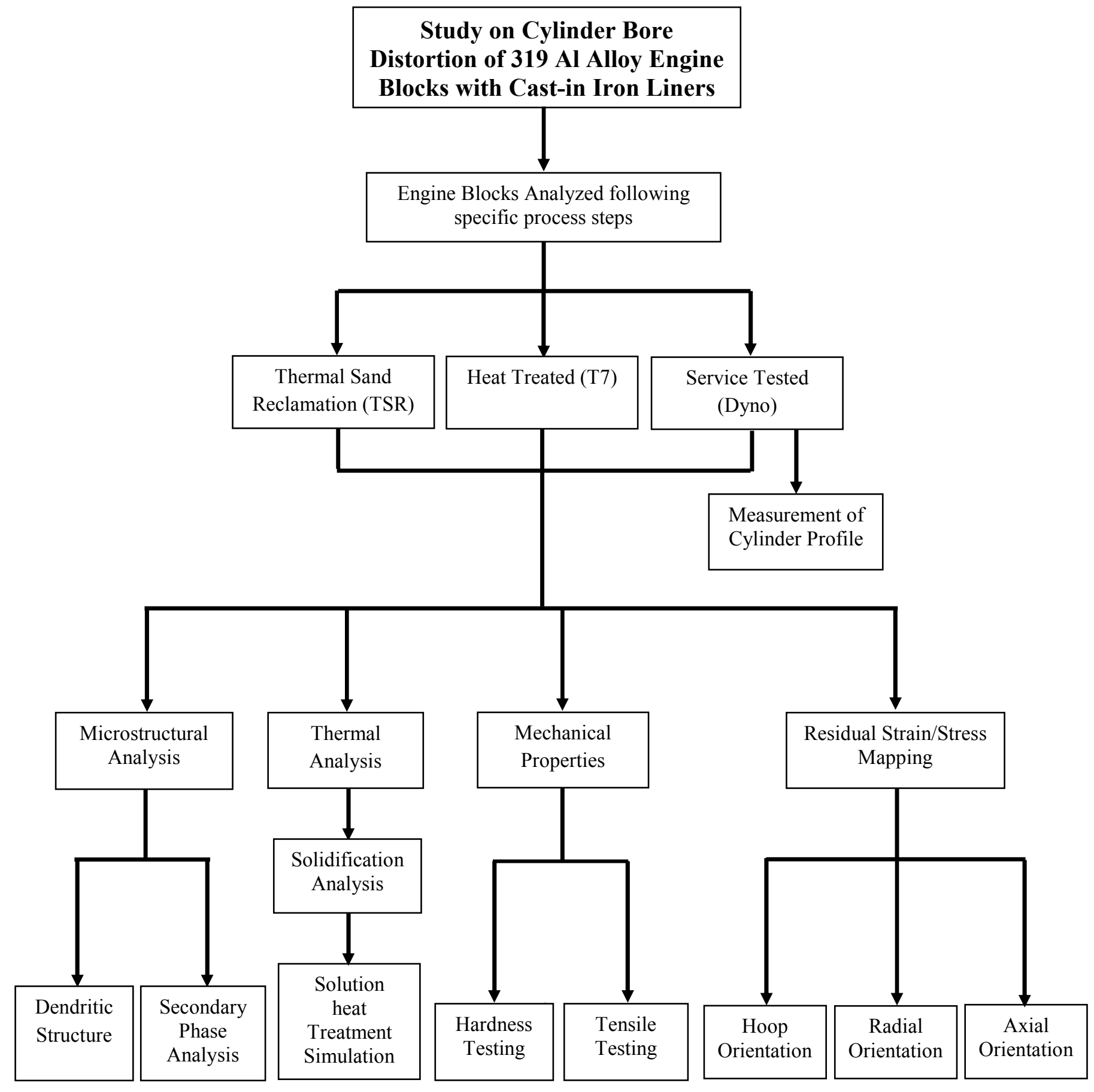

Figure 24: Flow chart showing the analysis performed in this study.

\subsection{Engine Block Production Parameters}

This investigation dealt with the analysis of production 319 type aluminum alloy engine blocks taken randomly from the production line at three stages in the production process. The three 
stages were: 1) following a thermal sand reclamation (TSR) treatment, 2) following a heat treatment to $\mathrm{T} 7$ temper and 3) after service (dyno) testing. The composition of the alloy used to manufacture the engine blocks is shown in Table 3.

Table 3: Composition of 319 type aluminum alloy engine block (wt.\%) from batch analysis.

\begin{tabular}{ccccccccccc}
\hline $\mathbf{S i}$ & $\mathbf{C u}$ & $\mathbf{F e}$ & $\mathbf{M n}$ & $\mathbf{M g}$ & $\mathbf{S n}$ & $\mathbf{T i}$ & $\mathbf{N i}$ & $\mathbf{C r}$ & $\mathbf{S r}$ & $\mathbf{A l}$ \\
\hline 8.5 & 2.8 & 0.45 & 0.35 & 0.35 & 0.25 & 0.15 & 0.04 & 0.03 & 0.005 & Bal. \\
\hline
\end{tabular}

The engine blocks were cast at the Nemak Centre of Engineering in Windsor, Canada using the Cosworth casting process with precision sand moulds to improve the dimensional accuracy of the casting. A schematic showing an engine block casting with the gating system attached is shown in Figure 25.

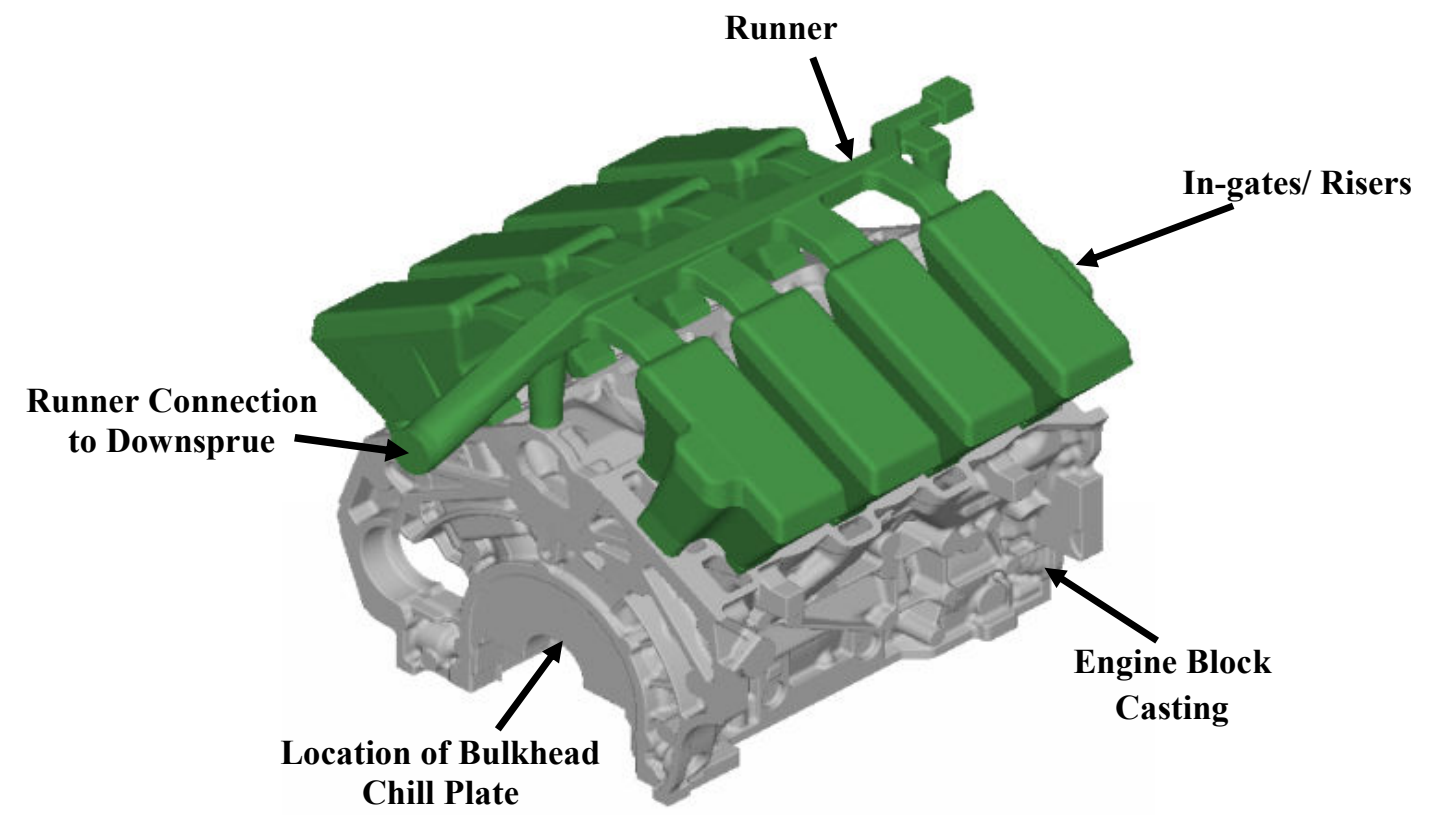

Figure 25: Schematic showing isometric view of an engine block casting with gating system (Courtesy Dr. Robert MacKay, Nemak of Canada Corporation).

In order to improve the in-service wear resistance of the engine block, gray cast iron cylinder liners were inserted into the mould cavity. The liners were preheated to $400{ }^{\circ} \mathrm{C}$ using induction coils prior to being inserted into the mould to promote a more uniform microstructure. The molten 319 aluminum alloy was then poured into the sand mould at a pouring temperature of $720^{\circ} \mathrm{C}$. Risers were placed near the top of the cylinder bores, as shown in Figure 25, while chills were inserted at the bulkhead region (near the bottom of the cylinder). 
Following solidification, the engine block castings were subjected to a thermal sand reclamation treatment (TSR) as well as solution heat treatment, forced air quench $\left(50-100{ }^{\circ} \mathrm{C} / \mathrm{minute}\right)$ and aging to a T7 temper. The details of the heat treatment parameters used in engine block production are shown in Table 4.

Table 4: Parameters used for heat treatment of the aluminum engine blocks.

\begin{tabular}{ccc}
\hline Treatment & Temperature $\left({ }^{\circ} \mathbf{C}\right)$ & Time (Hours) \\
\hline Thermal Sand Reclamation & 495 & 1 \\
Solution Heat Treatment & 480 & 7.5 \\
Aging to T7 Temper & 240 & 5.5 \\
\hline
\end{tabular}

In addition to analyzing as-cast and heat treated engine blocks, select engine blocks were studied after service testing in order to observe the effect of service testing on microstructure, mechanical properties and residual stress. Service testing was conducted by connecting the engine to an engine dynamometer for 20 hours. The combustion process subsequently heated the aluminum in the vicinity of the cylinder bores to the operating temperature of $180{ }^{\circ} \mathrm{C}$.

\subsection{Locations Analyzed in Engine Blocks}

The engine block castings were sectioned at the cylinder bridge in order to perform microstructural analysis and to evaluate the mechanical properties at this section. The cylinder bridge was selected for analysis since this location was designated as a critical location within the engine block due to the influence of two Al-Fe liner interfaces at this section [40, 46]. The sections of the engine block that were analyzed are indicated by the squares in Figure 26.

Microstructural analysis of various sections along the cylinder, including the top, upper middle, lower middle and bottom, was carried out as illustrated in Figure 27 (a). However, scanning electron microscopy (SEM), phase microanalysis, transmission electron microscopy (TEM) and hardness testing were only performed at the top and bottom sections since preliminary optical microscopy revealed that the largest variations in microstructure occurred at these sections. The analyzed sections were approximately $15 \mathrm{~mm}$ in length and $7 \mathrm{~mm}$ in width. The top and bottom sections were taken approximately $10 \mathrm{~mm}$ from the top and bottom respectively, corresponding 
to the location where the aluminum was in contact with the gray iron cylinder liner. Tensile samples were also extracted in three locations from the cylinder bridge, as shown by the lines in Figure 27(b). The extracted samples were machined in accordance to the ASTM B557 sub-sized standard [55].

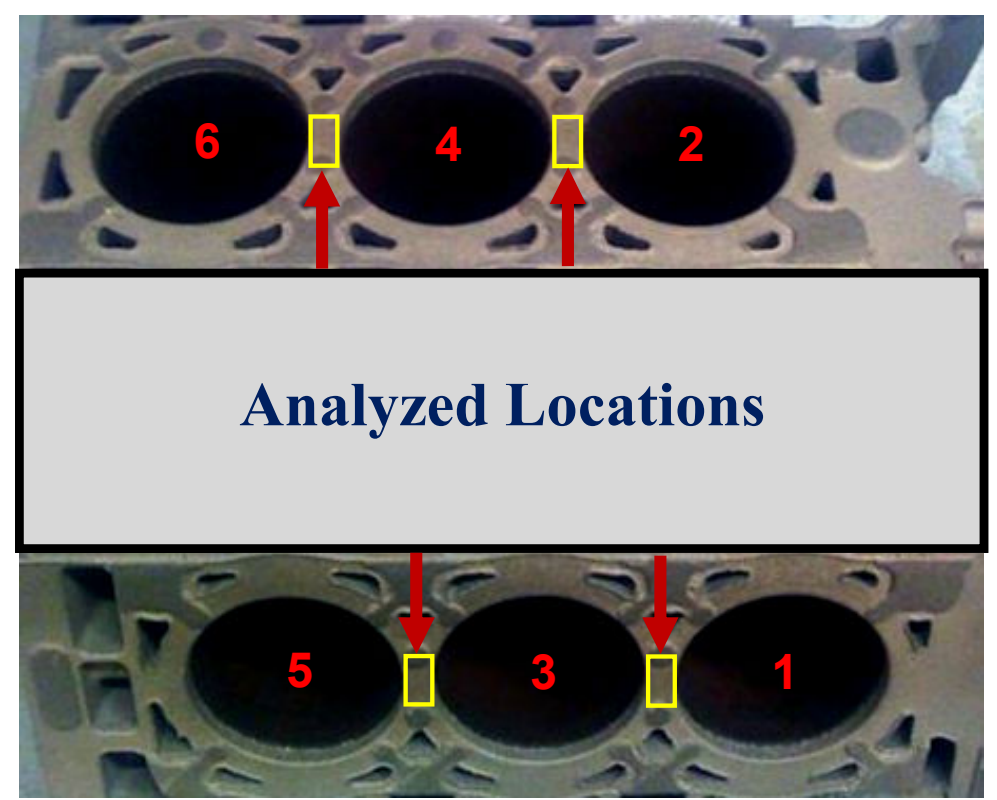

Figure 26: Top view of the 319 aluminum engine block indicating analyzed locations and cylinder numbering.
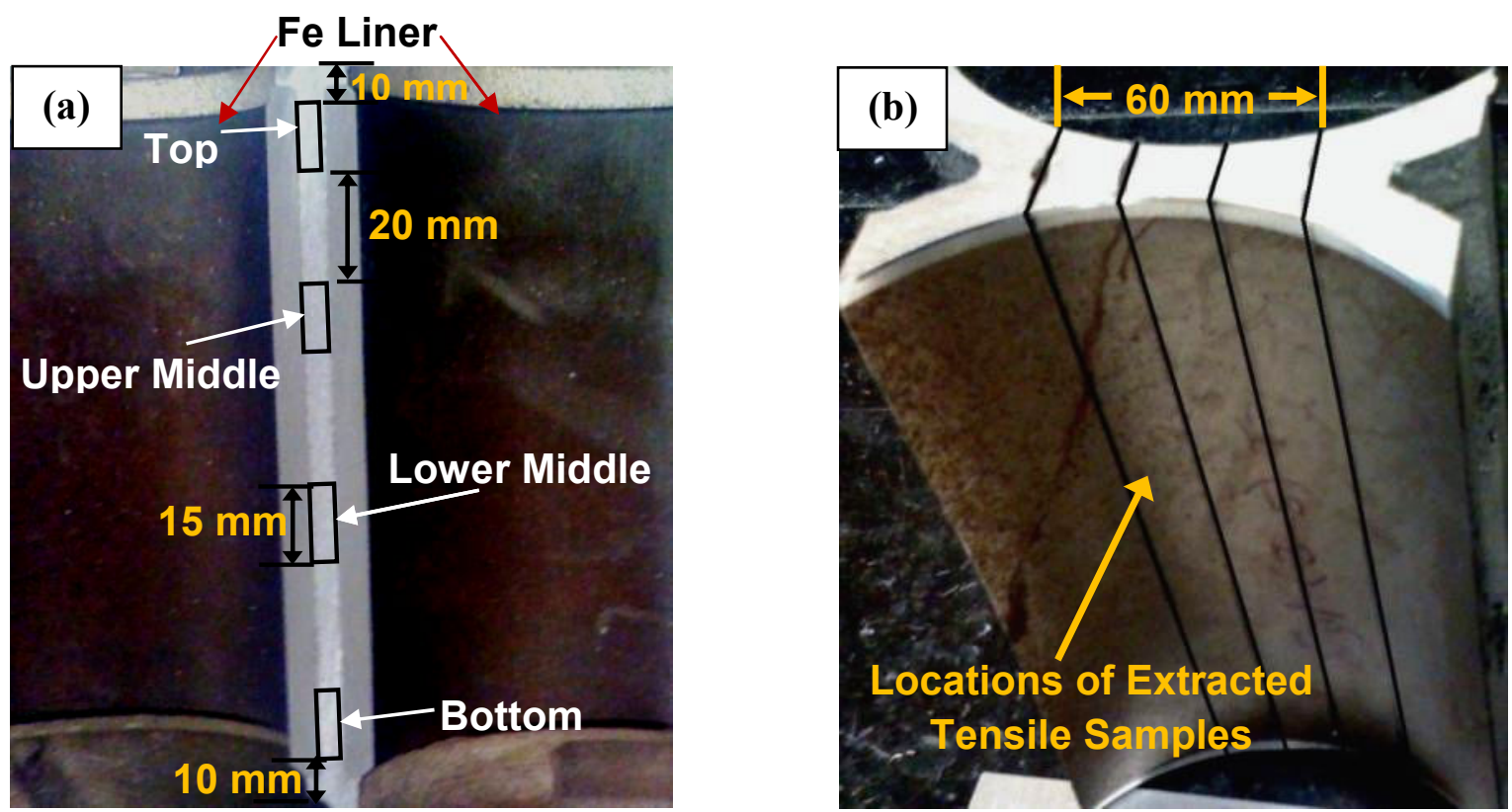

Figure 27: (a) Cross-section of cylinder bridge showing sections analyzed along cylinder depth, (b) sectioned cylinder bridge showing locations of extracted tensile samples. 


\subsection{Optical and Scanning Electron Microscopy}

Optical and scanning electron microscopy was performed at various locations along the cylinder in order to assess variations in microstructure for each treatment condition. Microstructural characterization included measurement of the secondary dendrite arm spacing (SDAS), quantitative image analysis of microstructural constituents and phase microanalysis. This section outlines the sample preparation and microstructural characterization procedure.

\subsubsection{Sample Preparation}

Samples for optical and scanning electron microscopy were taken from the cylinder bridge as shown in Figure 27 (a). In order to develop samples for optical and scanning electron microscopy, the cylinder bridge was sectioned using a horizontal bandsaw and subsequently cut into individual samples using a Buehler abrasive cut off wheel. Once sectioning was completed, the samples were subjected to metallographic polishing using a polishing wheel which rotated in the counter-clockwise direction. The details of the polishing procedure are shown in Table 5.

Table 5: Metallographic polishing procedure

\begin{tabular}{cccc}
\hline Step & Abrasive Grit/ Polishing Cloth & RPM & Time (minutes) \\
\hline 1 & $120 \mathrm{SiC}$ & 200 & Until plane \\
2 & $320 \mathrm{SiC}$ & 200 & 2 \\
3 & $1200 \mathrm{SiC}$ & 200 & 2 \\
4 & $5 \mu \mathrm{m} \mathrm{Al}{ }_{2} \mathrm{O}_{3}$, Lecloth & 150 & 5 \\
5 & $3 \mu \mathrm{m}$ diamond suspension, Lecloth & 150 & 5 \\
6 & $0.05 \mu \mathrm{m}$ colloidal silica, Chemomet & 100 & 5 \\
\hline
\end{tabular}

In the first three steps of the metallographic polishing procedure, the samples were cleaned using water and dried with compressed air following each step. For steps 4 and 5, an ultrasonic cleaner was used with water to remove excess $\mathrm{Al}_{2} \mathrm{O}_{3}$ or diamond particles that may have been stuck to the surface. In the final polishing step, the Chemomet cloth was flushed with water for 10 seconds prior to the completion of this step to remove the colloidal silica from the sample surface. This effectively prevented the formation of a surface film that commonly forms while using colloidal silica. Following the polishing procedure, the samples were thoroughly washed with ethanol and dried with compressed air. 


\subsubsection{Measurement of Secondary Dendrite Arm Spacing (SDAS)}

The measurement of the SDAS was performed along the cylinder bridge using a Buehler Viewmet optical microscope instrumented with a uEye CCD camera, which was connected to a personal computer. Buehler Omnimet image analysis software was used to perform all the required measurements. The average SDAS was estimated using the relationship shown in Equation 7, where $L_{p}$ is the length of the primary dendrite and the number of secondary dendrite $\operatorname{arms}\left(\mathrm{N}_{\mathrm{s}}\right)[56]$.

$$
S D A S=\frac{L_{p}}{N_{S}-1}
$$

The measurement of the average SDAS also allowed the cooling rate along the cylinder bridge to be estimated. The cooling rates $(\mathrm{R})$ were estimated using an empirical relationship developed by Vazquez-Lopez et al. [57] for Al-Si alloys, as shown in Equation 8.

$$
S D A S=36.1 R^{-0.34}
$$

\subsubsection{Quantitative Image Analysis}

In order to investigate the influence of cooling rate, heat treatment and service testing on the volume fraction of the secondary phases present in the microstructure, quantitative image analysis was employed. Image analysis was carried out at the top and bottom sections of the cylinder bridge for each analyzed treatment condition. Optical micrographs, taken at 200x magnification, were used to quantify the amount of eutectic silicon present in the microstructure. However, since $\mathrm{Al}_{2} \mathrm{Cu}$ intermetallics do not have sufficient contrast under an optical microscope, backscattered electron images taken in a JEOL JSM-6380LV scanning electron microscope at a magnification between 200 and $300 x$ were used to quantify the amount of $\mathrm{Al}_{2} \mathrm{Cu}$ and iron bearing intermetallics present in the microstructure. For both optical and SEM analysis, estimates on the area fraction of each intermetallic phase were made using a minimum of fifteen micrographs.

\subsubsection{Phase Microanalysis}

Phase microanalysis was conducted on the primary aluminum dendrites as well as the secondary phases to determine the composition of the phases present in the microstructure. Energy 
dispersive X-ray spectroscopy (EDX) was performed on the secondary phases to determine the composition of phases in the microstructure. A minimum of five particles of each secondary phase were analyzed using EDX. Energy dispersive X-ray spectroscopy was used to determine the elements present in each phase. This data was further utilized in determining the stoichiometry using other techniques such as X-ray diffraction (XRD).

The composition of the $\alpha$-Al dendrites was estimated using wavelength dispersive X-ray spectroscopy (WDS) using a minimum of 10 points in each section of the cylinder bridge. This

analysis was carried out on the TSR, T7 heat treated and service tested engine blocks to determine if thermal processing caused dissolution of phases into the aluminum dendrites. The equipment was calibrated using standard samples of similar composition to the 319 alloy in order to ensure accurate compositional measurements.

\subsubsection{X-ray Diffraction}

X-ray diffraction was undertaken using a Panalytical X'Pert Pro diffractometer to determine the stoichiometry of the secondary phases in the microstructure. This analysis was first conducted on the polished bulk sections that were used for optical and scanning electron microscopy. However, due to an insufficient volume fraction of certain secondary phases, XRD analysis was also performed on extracted secondary phase particles. To extract the secondary phase particles, the bulk samples were immersed in a solution containing $30 \mathrm{~g} \mathrm{NaOH}$ and $500 \mathrm{~mL}$ of distilled water for 48 hours, which resulted in a powder composed mainly of second phase particles. The extracted particles were then heated to $200{ }^{\circ} \mathrm{C}$ for 2 hours in order to decompose and remove any residual aluminum hydroxide that may have formed during the dissolution of the aluminum matrix [58].

\subsection{Transmission Electron Microscopy}

\subsubsection{TEM Analysis Parameters}

Transmission electron microscopy was performed on engine blocks in the TSR, T7 and dyno tested conditions using a Phillips CM20 transmission electron microscope, equipped with a $\mathrm{LaB}_{6}$ filament, at a voltage of $200 \mathrm{kV}$. This analysis was performed to observe any changes in the structure within the primary aluminum dendrites due to thermal processing. An energy dispersive 
X-ray (EDAX) spectrometer was also used in order to perform chemical analysis of the nano-precipitates observed within the aluminum dendrites.

\subsubsection{Sample Preparation}

Transmission electron microscopy samples were extracted from the cylinder bridge at the top and bottom sections. The first step involved obtaining a bulk section from the top and bottom of the cylinder, similar in dimensions to the samples used for optical and scanning electron microscopy. Once the bulk sections were obtained, they were cut into $1 \mathrm{~mm}$ thick plates using a low speed saw at a speed of $200 \mathrm{rpm}$. The plates were mounted on $20 \mathrm{~mm}$ diameter cylindrical sample holders using double sided tape and thinned with successively finer SiC papers on a polishing wheel which rotated in the counter clockwise direction. The samples were held with minimal applied pressure to prevent bending of the samples. The abrasive grinding procedure for obtaining the approximately $120 \mu \mathrm{m}$ thick plate samples is given in Table 6 .

Table 6: Abrasive grinding procedure used to produce thin plate samples for TEM analysis.

\begin{tabular}{cccc}
\hline Step & Abrasive Grit & RPM & Time (minutes) \\
\hline 1 & $320 \mathrm{SiC}$ & 150 & 4 \\
2 & $600 \mathrm{SiC}$ & 150 & 6 \\
3 & $1200 \mathrm{SiC}$ & 150 & Until sample thickness $<120 \mu \mathrm{m}$ \\
\hline
\end{tabular}

Following the thinning procedure, the samples were immersed in toluene for 12 hours to dissolve the double sided tape allowing the samples to be removed from the sample holder without risk of bending. Once removed, the sample thickness was measured using a digital vernier calliper to ensure the samples were thinned below $120 \mu \mathrm{m}$. For samples that did not meet the required thickness, the 1200 grit $\mathrm{SiC}$ step was repeated.

The thin samples were cut into $3 \mathrm{~mm}$ diameter disks using a punch and placed in a Struers TenuPol-5 twin-jet electropolisher. The electropolishing process was used to electrochemically attack the material, using an electrolyte under an applied voltage and stopped as soon as a small observable hole developed in the centre of the sample. A wedge-like gradual increase in thickness away from the hole subsequently formed for samples polished under optimal process parameters. The approximately $100 \mathrm{~nm}$ thick region nearest to the hole is called the transmission region, which was observed in the TEM. The temperature, flow rate and composition of the 
electrolyte control the material removal rate along with the applied voltage [59]. Initial trials were carried out to optimize the process parameters. The optimized parameters used to obtain the transmission region in the samples are outlined in Table 7.

Once electropolishing was completed, the samples were rinsed thoroughly with methanol and subsequently placed in a Gatan Solarus 950 plasma cleaner. The samples were plasma cleaned for 2 minutes using a mixture of oxygen and argon gas in order to remove oxide layers that may have formed on the sample surface.

Table 7: Optimized parameters used in twin-jet electropolishing.

\begin{tabular}{cc}
\hline Parameter & Description \\
\hline Electrolyte & $30 \% \mathrm{HNO}_{3}, 70 \%$ Methanol \\
Electrolyte Temperature & $-30{ }^{\circ} \mathrm{C}$ (Cooled with liquid nitrogen) \\
Electrolyte Flow Rate & 10 flow units (on a full scale of 50) \\
Electrolyte Flow Mode & Dual flow \\
Voltage & $12.5 \mathrm{~V}$ \\
Process Time & Varies depending on initial foil thickness \\
\hline
\end{tabular}

\subsection{Differential Scanning Calorimetry}

The Differential scanning calorimetry (DSC) analysis was carried out to determine the phase formation temperatures during solidification and during the laboratory simulation of the heat treatment process. Samples for DSC analysis were taken from the cylinder bridge at the top and bottom sections. Theses samples were developed by sectioning the cylinder bridge into $1 \mathrm{~mm}$ thick plates using a low speed saw at $200 \mathrm{rpm}$. The plates were then cut into 3 × $3 \mathrm{~mm}$ samples and weighed with a digital scale.

The DSC analysis was performed in a Perkin-Elmer Pyris Diamond differential scanning calorimeter. The parameters used in the DSC analysis are shown in Table 8. The cooling rates used in the solidification experiments were estimated using the SDAS measurements at the top and bottom of the cylinder. 
Table 8: Experimental parameters used for solidification and solution heat treatment experiments.

\section{Differential Scanning Calorimetry Experiments}

\begin{tabular}{|c|c|c|}
\hline & Solidification Experiments & $\begin{array}{c}\text { Simulation of Solution } \\
\text { Heat Treatment }\end{array}$ \\
\hline Crucible & $\mathrm{Al}_{2} \mathrm{O}_{3}$ & $\mathrm{Al}$ \\
\hline Heating Rate to Start Temperature & $100{ }^{\circ} \mathrm{C} /$ minute to $650{ }^{\circ} \mathrm{C}$ & $100^{\circ} \mathrm{C} /$ minute to $480{ }^{\circ} \mathrm{C}$ \\
\hline Isothermal hold time & - & 450 minutes \\
\hline Cooling Rate to End Temperature & $\begin{array}{l}\text { 1. Top of cylinder: } \\
60{ }^{\circ} \mathrm{C} / \text { minute to } 400{ }^{\circ} \mathrm{C} \\
\text { 2. Bottom of cylinder: } \\
300^{\circ} \mathrm{C} / \text { minute to } 400^{\circ} \mathrm{C}\end{array}$ & $100^{\circ} \mathrm{C} /$ minute to $25^{\circ} \mathrm{C}$ \\
\hline
\end{tabular}

\subsection{Mechanical Testing}

\subsubsection{Hardness Testing}

The hardness measurements were carried out using Rockwell hardness testing and Nanoindentation testing. The samples were taken from the top and bottom of the cylinder bridge. The dimensions of the samples used in hardness testing are similar to those of the samples analyzed for optical and scanning electron microscopy. Furthermore, since a polished surface was required, the metallographic polishing procedure outlined in Table 5 was used in the preparation of hardness samples.

Rockwell hardness testing (HRE) was carried out using a 1/8 inch ball indenter at a load of 100 $\mathrm{kg}$. This analysis was performed to observe the influence of microstructural variation (e.g. SDAS, morphology of secondary phases) and thermal processing (e.g. heat treatment, dyno testing) on the hardness and related to strength properties (yield and ultimate tensile strength) of the castings in the relevant regions.

Following Rockwell hardness testing, the nanoindentation technique was used to determine the hardness of each microstructural constituent for specific treatment conditions. Nanoindentation testing was carried out using a Hysitron TI 950 Triboindenter equipped with a triangular (Berkovich) tip indenter and atomic force microscopy (AFM) imaging probe. Similar to Rockwell hardness testing, nanoindentation testing was carried out at the top and bottom sections 
of the cylinder bridge. Furthermore, the hardness near the Al-Fe liner interface was also determined using nanoindentation. The load used to perform the indentation of each phase was $10 \mathrm{mN}$. Atomic force microscopy was used to measure the size and location of each indent to verify the precision of locating the indenter on the specific phase.

\subsubsection{Tensile Testing}

The final step in the assessment of the mechanical properties in the cylinder bridge region of the engine block was tensile testing at the ambient temperature. The samples were extracted from the cylinder bridge region as shown in Figure 27(b). Although size restrictions prevented the top and bottom of the cylinder bridge to be tested separately, the tensile gauge was placed in the centre of the cylinder to estimate the average strength of the cylinder bridge, while also determining the effect of heat treatment and service testing on tensile properties.

\subsection{Strain Measurements using Neutron Diffraction}

Strain within the engine blocks was measured using neutron diffraction (ND) at both the Oak Ridge National Laboratory in Oak Ridge, Tennessee and the Canadian Neutron Beam Centre in Chalk River, Ontario. The first stage of the neutron diffraction experiments involved obtaining a reference d-spacing value $\left(\mathrm{d}_{0}\right)$ using "strain free" samples of composition similar to that of to the specimen requiring strain analysis. The reference value of the $d$-spacing was determined from neutron scans of "match stick" samples cut from the cylinder bridge. Although the cylinder bridge is a high stress region in the engine block, it was assumed that any residual stress in the material would be relieved during machining of the relatively small (4 mm x $4 \mathrm{~mm}$ x $15 \mathrm{~mm}$ ) "strain free" samples. To further ensure strain free measurements of the reference, the match stick samples were rotated at $6 \mathrm{rpm}$ during the neutron scan in order to obtain an "averaged" d-spacing across many sections of the sample.

In order to measure the true in-service strain, the engine block was placed directly under the neutron beam without prior sectioning. The neutron beam wavelengths used in these experiments were $1.73 \AA$ and $1.55 \AA$. Neutron scans were completed using the $(311)\left(\varphi_{(311)}=78.73^{\circ}\right)$ and (331) $\left(\varphi_{(331)}=112.95^{\circ}\right)$ reflections from aluminum as well as the $(211)\left(\varphi_{(211)}=82.95^{\circ}\right)$ reflection from iron. These reflections were selected due to the strong diffraction intensity, resulting in a large peak-to-background ratio. The other consideration was the shape of the 
sampling volume. Generally it is desirable to have a rectangular sampling volume rather than trapezoidal. For this reason, the aluminum (311) was selected instead of aluminum (111) even though the (111) reflection has a stronger diffraction intensity. The rectangular sampling volume ensures that the only neutrons that reach the detector were the ones that were diffracted from the specified area of interest. The aluminum (331) reflection was used in cases where the sampling volume consisted of aluminum and the iron liners. The $\mathrm{Al}$ (331) reflection has a diffraction angle that is far from that of the strong iron reflections, reducing the background generated by neutrons diffracted from the iron liners.

The strain measurements were performed by determining the $\mathrm{d}$-spacing in the cylinder bridge region and relating it to the reference d-spacing (Equation 3). The d-spacing was determined from Bragg's law using a diffraction angle that was estimated by fitting a statistical distribution (i.e. Gaussian distribution) to a plot relating peak intensity to diffraction angle. The following sections outline the placement of the engine blocks required to achieve accurate strain measurements in the hoop, axial and radial directions. These strain measurements were then used in conjunction with generalized Hooke's law to calculate the residual stress profiles along the cylinder bridge of the engine blocks.

\subsubsection{Hoop Orientation}

The measurement of the hoop strain component involved aligning the engine block so that the incident and diffracted wave vectors formed a scattering vector $(\mathrm{Q})$ that was tangential to the cylinder bore and perpendicular to the planes shown in Figure 28(a). The actual positioning of the engine block on the spectrometer table is shown in Figure 28(b).

The monochromated incident beam penetrated through the bulk of the sample material (both aluminum and iron). The sampling volume was formed at the point of intersection (B) of the incident and diffracted beams allowing neutron data to be collected at that specific location within the cylinder bridge of the engine block. Once completed, the engine block was translated in $\mathrm{X}, \mathrm{Y}$ and $\mathrm{Z}$ directions to the next point-of-interest in order to reposition the location of the sampling volume. The neutron scan was then repeated for each subsequent point to obtain a distribution of strain measurements from top to bottom along the cylinder bridge. 

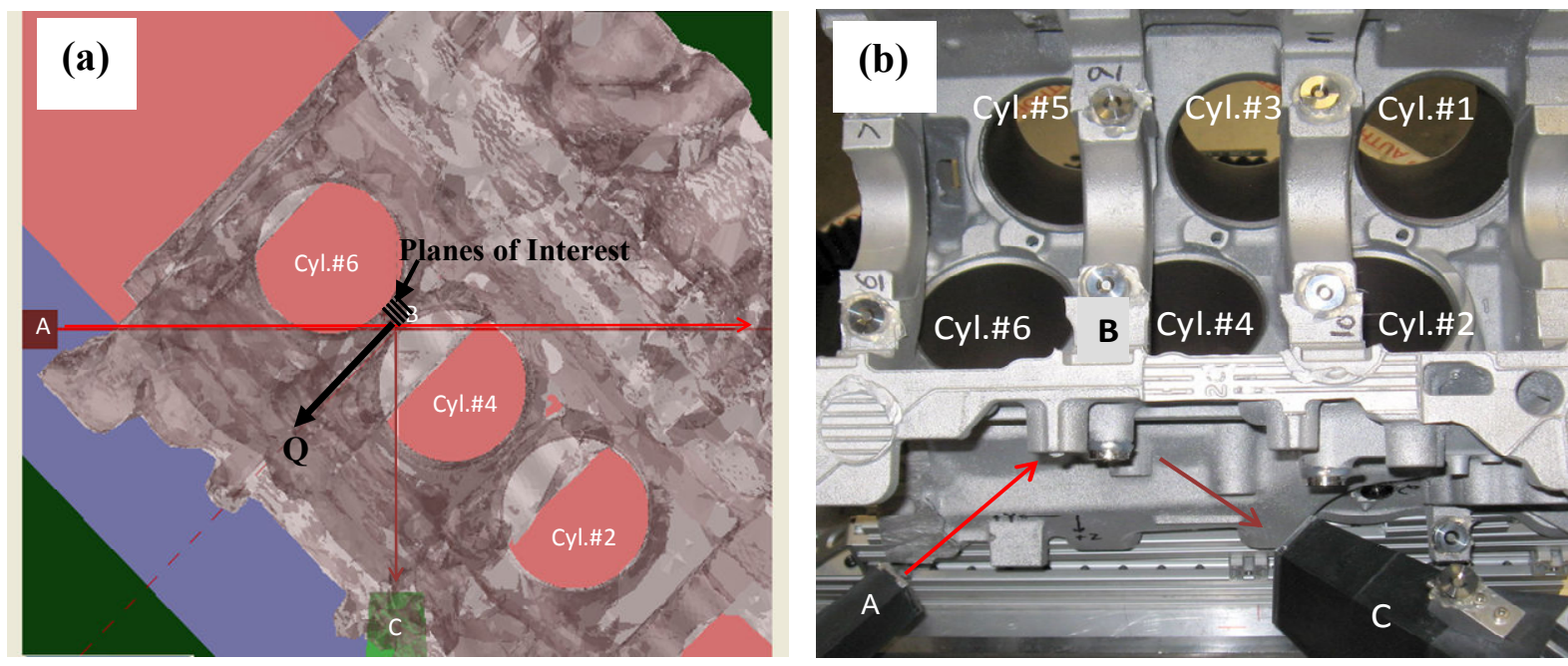

Figure 28: Orientation of incident (labeled $A$ ) and scattering (labeled C) beams in the measurement of hoop component of strain in cylinder (4-6) bridge: (a) control system map; (b) actual positioning of the engine block on the spectrometer sample table.

\subsubsection{Radial Orientation}

The radial component of the strain was measured using a similar methodology as that used for the measurement of the hoop strain component. The engine block was however repositioned to allow the scattering vector $(\mathrm{Q})$ to be in the radial direction relative to the cylinder bore and perpendicular to the planes shown in Figure 29(a). The actual positioning of the engine block on the spectrometer table is shown in Figure 29(b).
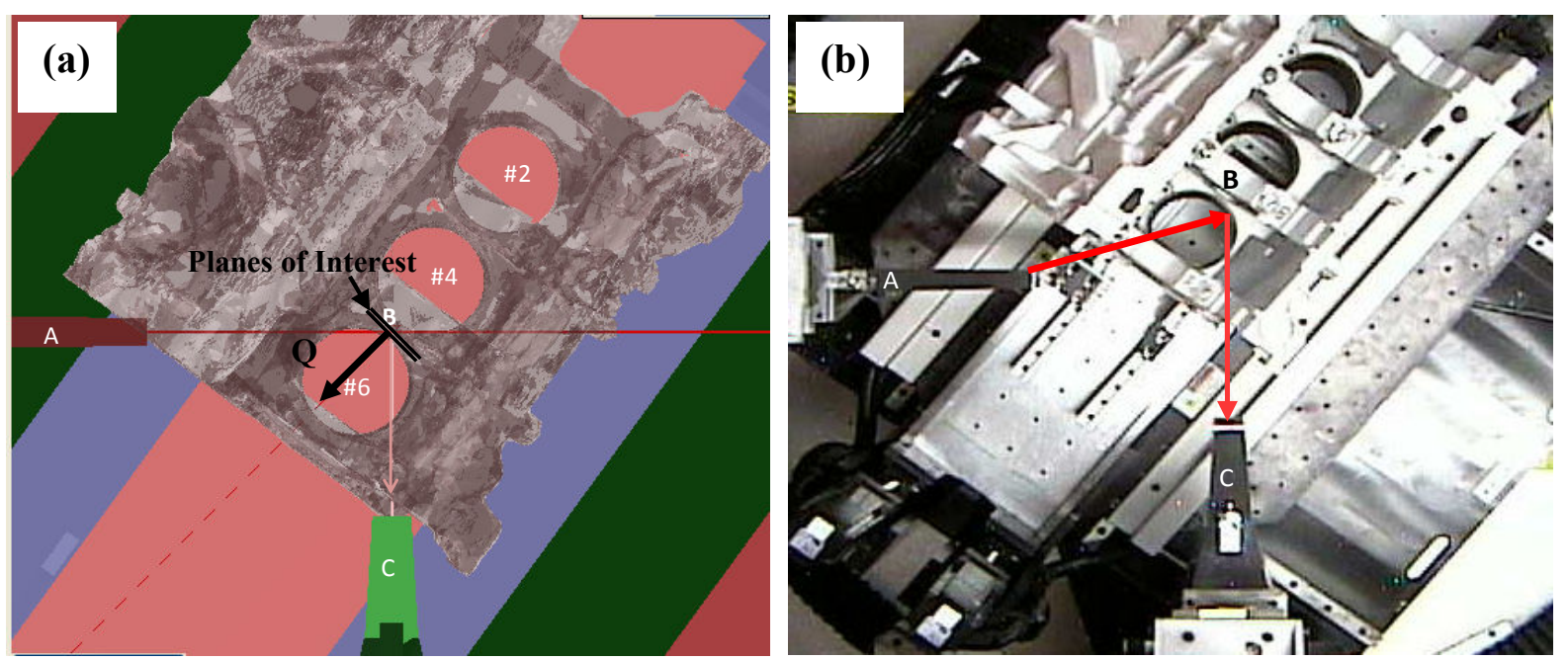

Figure 29: Orientation of incident (labeled $A$ ) and scattering (labeled $C$ ) beams in the measurement of radial component of strain in cylinder (4-6) bridge; (a) control system map; (b) actual positioning of the engine block on the spectrometer sample table. 


\subsubsection{Axial Orientation}

The final strain component measured using neutron diffraction was the axial component. The methodology employed was once again similar to that employed in the measurement of the hoop and radial strain components. For the axial strain component, the engine block was positioned so that the scattering vector $(\mathrm{Q})$ was in a direction parallel to the cylinder axis and perpendicular to the planes shown in Figure 30(a). The actual positioning of the engine block on the spectrometer table is shown in Figure 30(b).
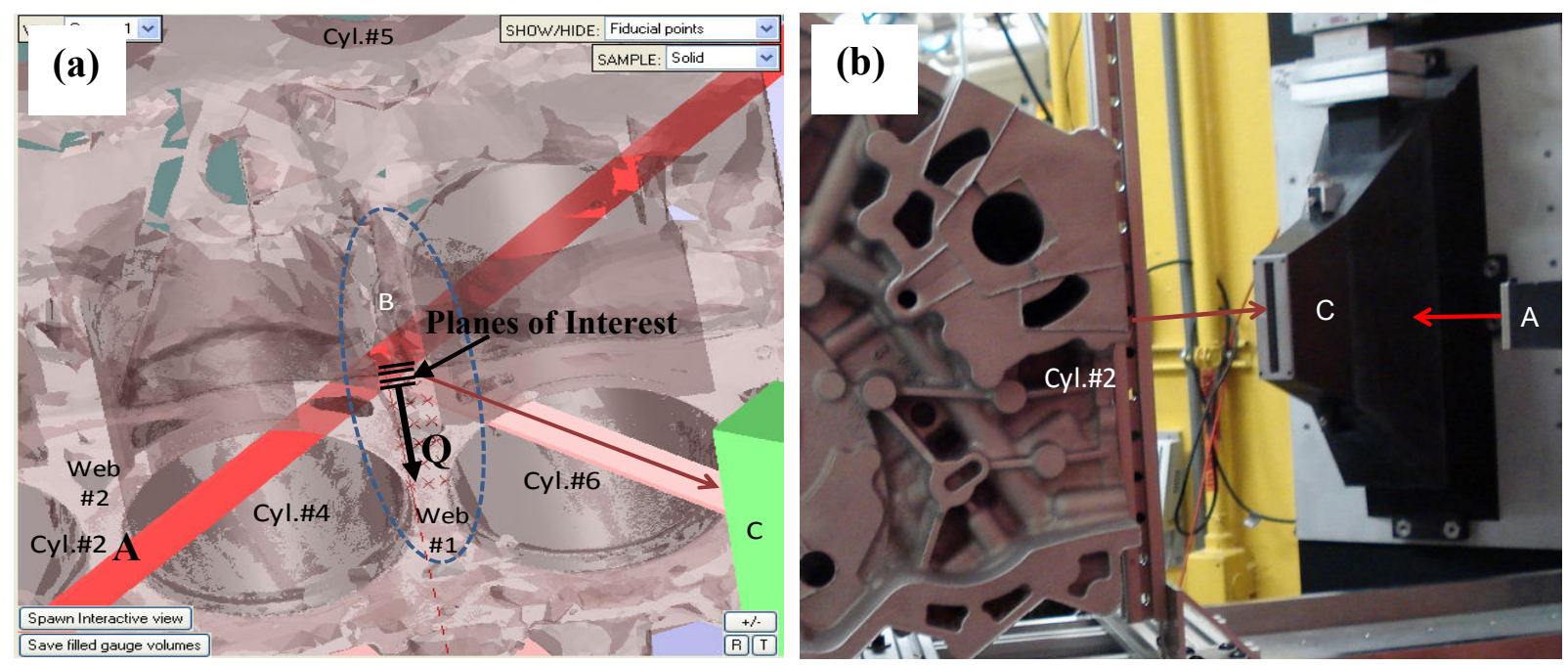

Figure 30: Orientation of incident (labeled A) and scattering (labeled C) beams in the measurement of radial component of strain in cylinder (4-6) bridge; (a) control system map; (b) actual positioning of the engine block on the spectrometer sample table.

\subsection{Measurement of Cylinder Bore Distortion}

Cylinder bore distortion was determined by measuring the cylinder bore profile of the service tested engine block using a co-ordinate measuring machine (CMM). The analyzed depths were 5, 25 and $48.5 \mathrm{~mm}$ relative to the top of the cylinder. Further depths could not be measured due to equipment constraints. Cylinder profiles were plotted against angular position at each measured depth within the cylinder (where the $0^{\circ}$ position represents the cylinder bridge) by determining the radial deviation from the nominal cylinder diameter $(94 \mathrm{~mm})$. Furthermore, roundness of the cylinder, which is a measure of deviation (non-circularity) compared to a nominal least squares circle, was also estimated using the data obtained from the CMM measurements and least squares regression analysis. 


\section{Chapter 4: Results and Discussion}

This chapter presents the results obtained from the analysis of 319 type aluminum engine blocks in the TSR, T7 heat treated and service (dyno) tested conditions. The cylinder profiles were measured to estimate the amount of distortion along the cylinder (Section 4.1). The dendrite arm spacing was used to estimate the cooling rate during solidification of the engine blocks (Section 4.2). The microstructural changes were related to the analyzed conditions. The microstructure-mechanical property relationships were explained in Section 4.3. Strain and residual stress measurements along the bridge between cylinders 4 and 6 are then discussed in Section 4.4. The experimental data and analysis were used to explain the cause of cylinder distortion.

\subsection{Analysis of Cylinder Bore Distortion}

Cylinder profiles were obtained for the service tested engine block, using a co-ordinate measuring machine (CMM) to quantify the bore distortion The results from the CMM measurements (Figure 31) indicated that the maximum deviation from the nominal cylinder diameter for cylinders 2 and 6 were approximately $30 \mu \mathrm{m}$ at depths (relative to the top of the cylinder) of 5 and $48.5 \mathrm{~mm}$, respectively. Furthermore, by performing least squares regression analysis on the data obtained from the CMM, the cylinder roundness was estimated at these three depths (Table 9). The maximum roundness was found to be between 35 and $45 \mu \mathrm{m}$ for both cylinders. Measurements of the other cylinders in the engine block revealed similar dimensional profiles and roundness values to those in Figure 31 and Table 9, respectively.

Engine blocks require extremely high dimensional tolerances to avoid loss of compression during operation. For this reason, Nemak of Canada determined the maximum tolerable cylinder distortion which does not significantly cause leakage of compressed air-fuel mixture ("blow-by"). This was done by simulating service conditions with an engine dynamometer. Dynamometer testing revealed that a significant loss of compression occurred when roundness values were greater than approximately $40 \mu \mathrm{m}$. Therefore, although the amount of measured distortion in the analyzed service tested engine block was relatively small, there was sufficient distortion to cause "blow-by", which reduced engine efficiency. The discussion in Sections 4.2-4.4 describes the variations in microstructure, mechanical properties and residual 
stress along the cylinder bridge with the aim to identify the cause of cylinder distortion of 319 aluminum alloy engine block with gray iron cylinder liners.
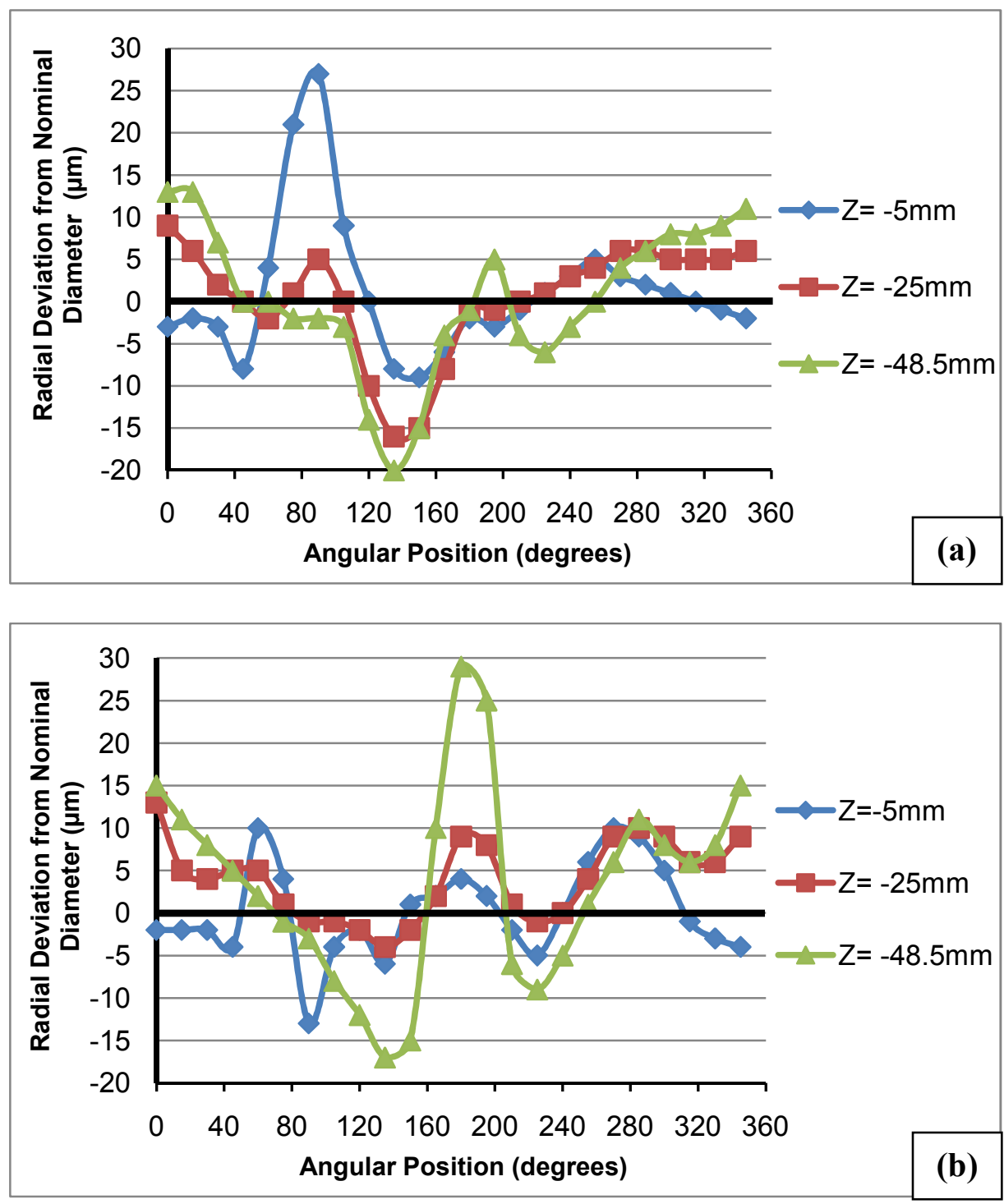

Figure 31: Measured radial deviation from the nominal cylinder diameter for: (a) cylinder 2, (b) cylinder 6.

Table 9: Roundness values at various depths along the cylinder bores.

\begin{tabular}{cccc}
\hline & \multicolumn{3}{c}{ Roundness $(\boldsymbol{\mu m})$} \\
\hline Cylinder Depth $(\mathbf{m m})$ & Cylinder 2 & Cylinder $\mathbf{4}$ & Cylinder 6 \\
5 & 35 & 31 & 24 \\
25 & 20 & 20 & 15 \\
48.5 & 23 & 33 & 44 \\
\hline
\end{tabular}




\subsection{Microstructural Analysis}

\subsubsection{Dendritic Structure in the Aluminum Cylinder Bridge}

Optical microscopy revealed a significant variation in the dendritic structure of the cylinder bridge. It was observed that the top of the cylinder bridge contained relatively coarse dendrites, while the bottom of the cylinder contained finer dendrites (Figure 32).
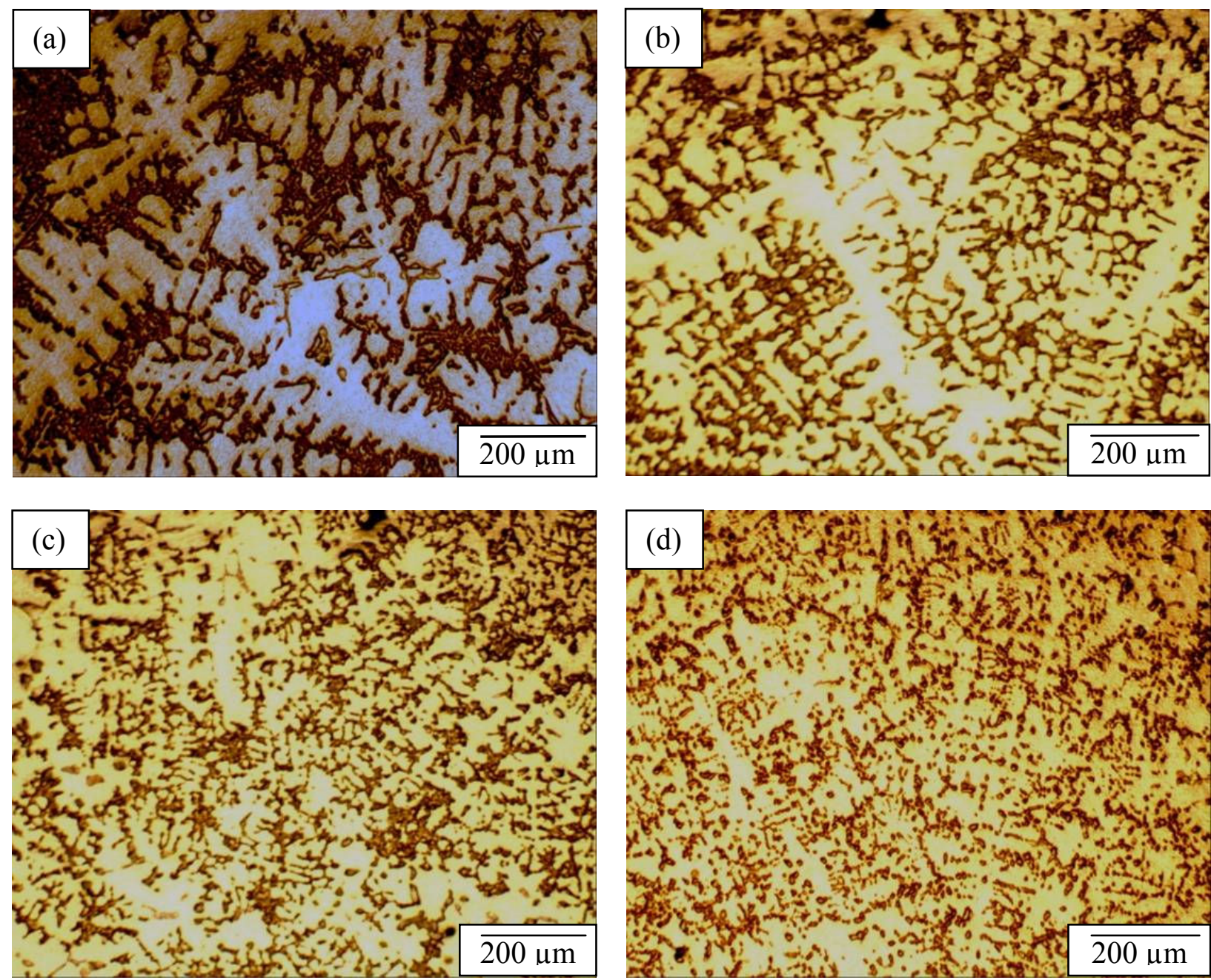

Figure 32: Optical micrographs showing the dendrite structure of: (a) cylinder (2-4) bridge top, (b) cylinder (2-4) bridge upper middle, (c) cylinder (2-4) bridge lower middle, (d) cylinder (2-4) bridge bottom.

The dendrite refinement was quantified by measuring the secondary dendrite arm spacing (SDAS). These measurements were carried out at the top, upper middle, lower middle and bottom sections of the cylinder bridge as shown in Figure 27. The results are shown in Figure 33, where the error bars represent the $95 \%$ confidence limits of the SDAS population mean. The 
average SDAS was found to continuously decrease from approximately $35 \mu \mathrm{m}$ at the top of the cylinder bridge to approximately $20 \mu \mathrm{m}$ at the bottom. Analysis of Variance (ANOVA) of the SDAS measurements (Appendix B1) confirmed that the gradual refinement in SDAS along the cylinder bridge was statistically significant with a $99.9 \%$ confidence level.

Heat treatment was not found to have a significant effect on the dendrites, as the size of the dendrites did not change during heat treatment or during in-service testing. This was confirmed by ANOVA analysis (Appendix B1). The SDAS was affected only by cooling rate, concentration of solute atoms and the temperature gradient in front of the solid-liquid interface during solidification.
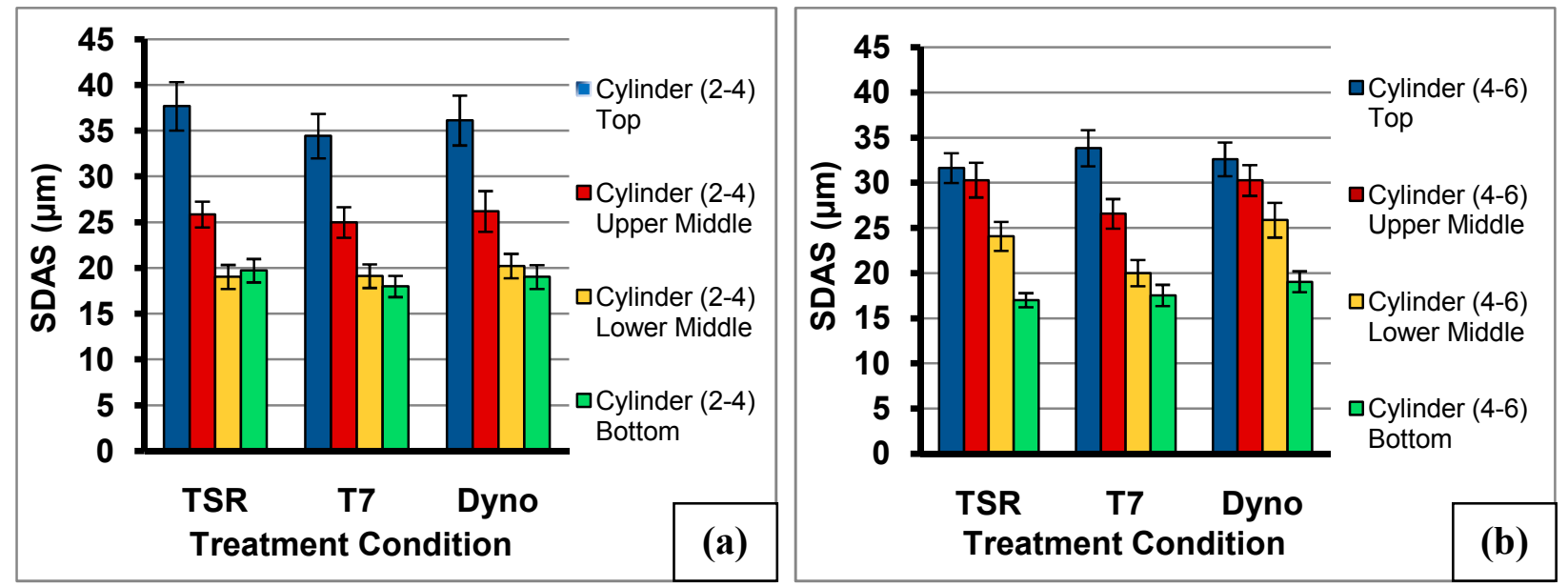

Figure 33: SDAS measurements for: (a) cylinder (2-4) bridge, (b) cylinder (4-6) bridge.

The refinement of dendrites at the bottom section of the cylinder bridge suggested a shorter local solidification time and faster cooling rate at the bottom of the cylinder compared to the top [2]. For this reason, the cooling rate was estimated using an empirical relationship developed by Vazquez-Lopez et al. [56] for Al-Si alloys as shown in Equation 8. The estimated cooling rates for each cylinder bridge are shown in Figure 34. The results show that the cooling rate during solidification at the cylinder bridge ranges between approximately 1 and $8{ }^{\circ} \mathrm{C} / \mathrm{s}$. The error bars in Figure 34 represent the $95 \%$ confidence limits of the cooling rate population mean.

This refinement in dendrite size at the bottom of the cylinder was caused mainly by the design of the sand mould. The bottom section of the cylinder was closer to the chill plate that was inserted into the bulkhead region of the sand mould prior to pouring. This resulted in an increased 
solidification rate. Conversely, the top section of the cylinder was near the risers and was required to solidify last in order to reduce shrinkage porosity [2]. Therefore, the top section of the cylinder likely had a longer local solidification time, resulting in significantly larger dendrites as compared to the bottom section of the cylinder bridge.

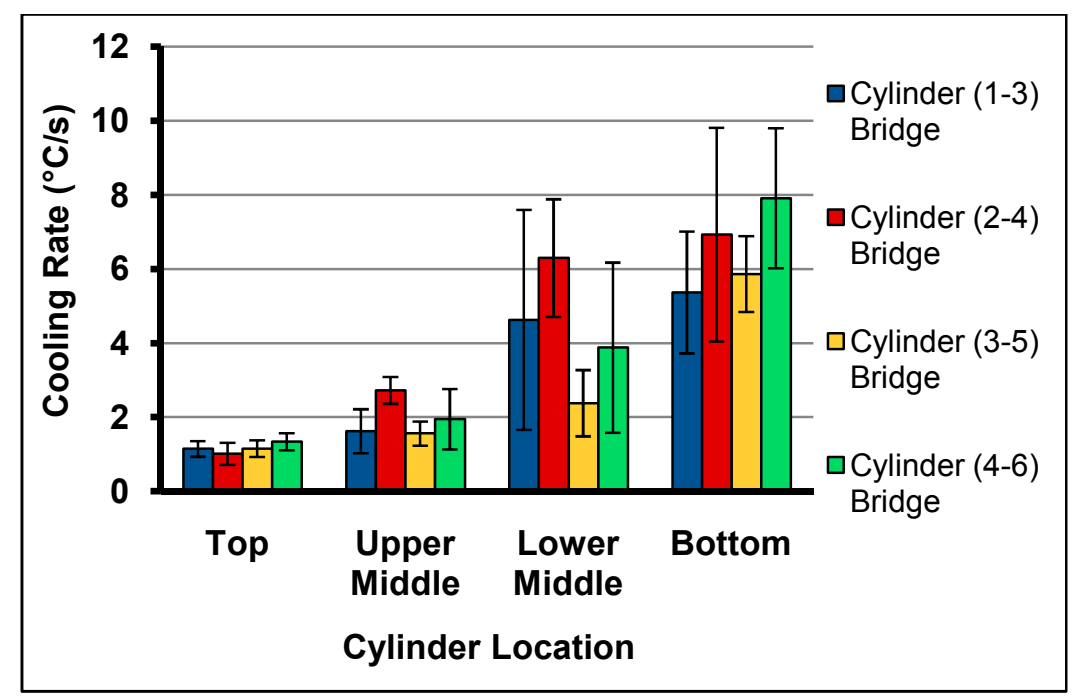

Figure 34: Estimated cooling rate during solidification for each section of the cylinder bridge.

\subsubsection{Secondary Phase Analysis in the Aluminum Cylinder Bridge}

\subsubsection{Thermal analysis}

Thermal analysis was performed at the top and bottom sections of the engine blocks in the TSR treatment condition. The estimated cooling rates obtained from the SDAS measurements were used to simulate solidification at individual sections along the cylinder bridge of the engine block. The simulation was carried out using differential scanning calorimetry (DSC). The resulting cooling curve, where endothermic heat flow is represented by upward peaks, for a cooling rate of $1{ }^{\circ} \mathrm{C} / \mathrm{s}$ is shown in Figure 35.

The DSC cooling curve in Figure 35 clearly shows the onset of exothermic reactions at 594, 568 and $496{ }^{\circ} \mathrm{C}$. These exothermic reactions approximately correspond to the formation of the $\alpha-\mathrm{Al}$ dendrite network, $\mathrm{Al}-\mathrm{Si}$ eutectic and $\mathrm{Al}-\mathrm{Al}_{2} \mathrm{Cu}-\mathrm{Al}_{5} \mathrm{Mg}_{8} \mathrm{Cu}_{2} \mathrm{Si}_{6}$ complex eutectic, respectively, as reported by Samuel et al. [19]. The results in this study are compared to those of Samuel et al. [19] in Table 10. 


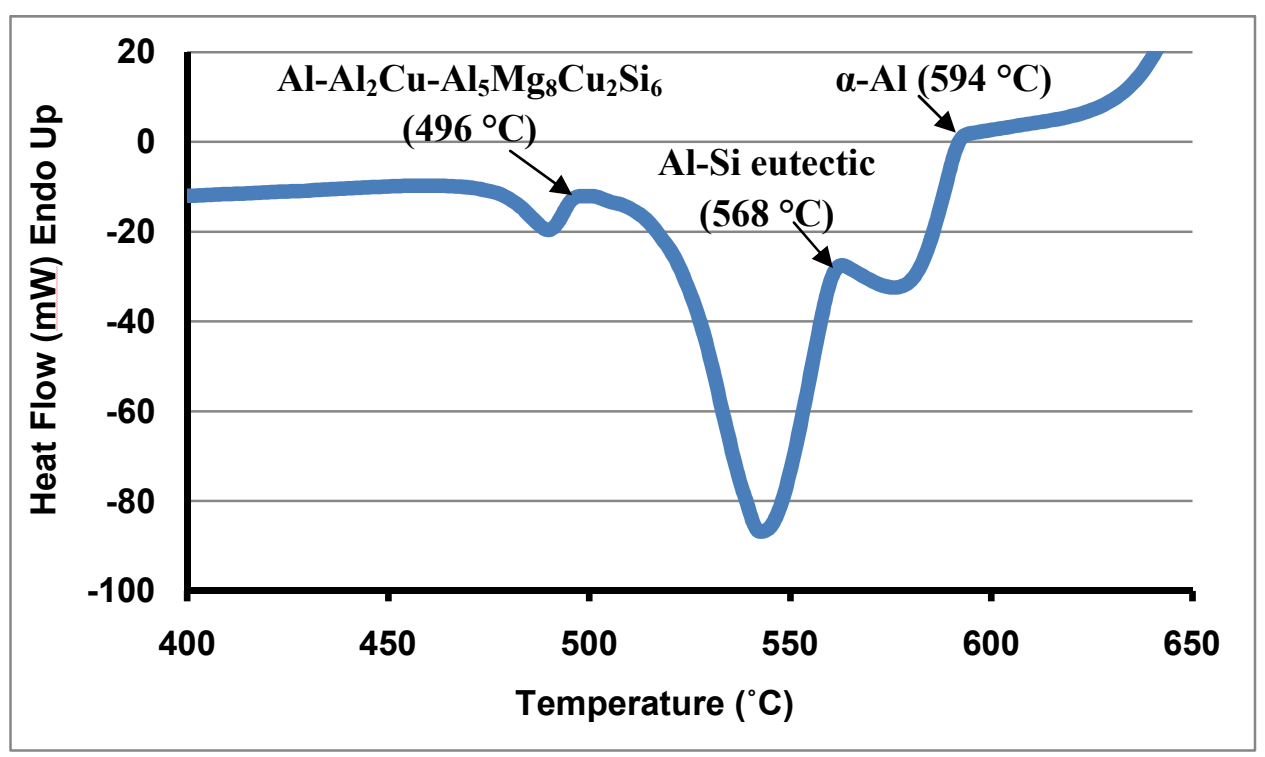

Figure 35: Cooling curve generated using differential scanning calorimetry showing phase formation temperatures during solidification at a cooling rate of $1^{\circ} \mathrm{C} / \mathrm{s}$.

Table 10: Comparison of phase formation temperatures during solidification of 319 aluminum alloys.

\begin{tabular}{ccc}
\hline Type of Reaction & \multicolumn{2}{c}{ Phase Formation Temperature $\left({ }^{\circ} \mathbf{C}\right)$} \\
\hline Formation of $\alpha-\mathrm{Al}$ dendritic network & Current Study & Samuel et al. [19] \\
\cline { 2 - 3 } Precipitation of pre-eutectic iron intermetallics & 594 & 611.8 \\
$\left(\alpha-\mathrm{Al}_{15}(\mathrm{Fe}, \mathrm{Mn})_{3} \mathrm{Si}_{2}\right.$ and $\left.\beta-\mathrm{Al}_{5} \mathrm{FeSi}\right)$ & 594 to 568 & 600 to 572.7 \\
Precipitation of $\mathrm{Al}-\mathrm{Si}$ eutectic & 568 & 561.8 \\
Precipitation of $\mathrm{Al}_{2} \mathrm{Cu}$ & 496 & 510 \\
Precipitation of $\mathrm{Al}_{5} \mathrm{Mg}_{8} \mathrm{Cu}_{2} \mathrm{Si}_{6}$ & 496 & 502.7 \\
\hline
\end{tabular}

The discrepancies in phase formation temperatures between what is observed in this study and those of Samuel et al. [19] are likely due to the difference in composition. The Al-Si-Cu ternary phase diagram (Appendix C1) indicates that the formation temperature for the $\alpha$-Al dendrites in Al-8.5Si-3Cu alloys is approximately $593^{\circ} \mathrm{C}$, which corresponds well with the results obtained in this study. In addition, the formation of the Al-Si eutectic occurred at temperatures below $577^{\circ} \mathrm{C}$ (eutectic temperature in Al-Si phase diagram (Appendix C2)) in both studies, indicating that the presence of impurity elements such as copper may have lowered the Al-Si eutectic temperature. It is also important to note that the peak corresponding to the iron bearing phases is not distinguishable in Figure 35. Samuel et al. [19] observed that the formation temperatures of the iron bearing phases and eutectic silicon are relatively close during the solidification of $\mathrm{Al}-\mathrm{Si}-\mathrm{Cu}$ 
alloys containing iron impurities. For this reason, it can be assumed that because of the high silicon content in the alloy, the precipitation of the Al-Si eutectic masks the exothermic peak associated with the iron bearing phases. In addition, thermal analysis using DSC was also done for cooling rates associated to the bottom of the cylinder $\left(\sim 8{ }^{\circ} \mathrm{C} / \mathrm{s}\right)$, however, due to the rapid cooling rate, the exothermic peaks corresponding to phase precipitation were not easily discernable.

\subsubsection{Secondary Phases in Interdendritic Regions}

Scanning electron microscopy in conjunction with energy dispersive X-ray spectroscopy (EDX) and X-ray diffraction (XRD) was performed to analyse the secondary phases present in the microstructure of the 319 aluminum engine blocks. The results suggest that the microstructure of the cylinder bridge was composed of an $\alpha-\mathrm{Al}$ matrix, eutectic silicon particles, as well as $\mathrm{Al}-\mathrm{Cu}$, $\mathrm{Al}-\mathrm{Fe}-\mathrm{Mn}-\mathrm{Si}$ and $\mathrm{Al}-\mathrm{Mg}-\mathrm{Si}-\mathrm{Cu}$ intermetallic phases. Furthermore, to determine the stoichiometry of the secondary phases, XRD analysis was carried out on the extracted second phase particles. The results (Figure 36) indicate that the secondary phases are $\mathrm{Al}_{2} \mathrm{Cu}$, $\mathrm{Al}_{17} \mathrm{Fe}_{3.2} \mathrm{Mn}_{0.8} \mathrm{Si}_{2}$ and eutectic silicon. The Al-Mg-Si-Cu phase, however, could not be analyzed using XRD because of its small volume fraction within the microstructure. However, this phase was identified by Lasa and Rodriguez-Ibabe [18] as $\mathrm{Al}_{5} \mathrm{Mg}_{8} \mathrm{Cu}_{2} \mathrm{Si}_{6}$.

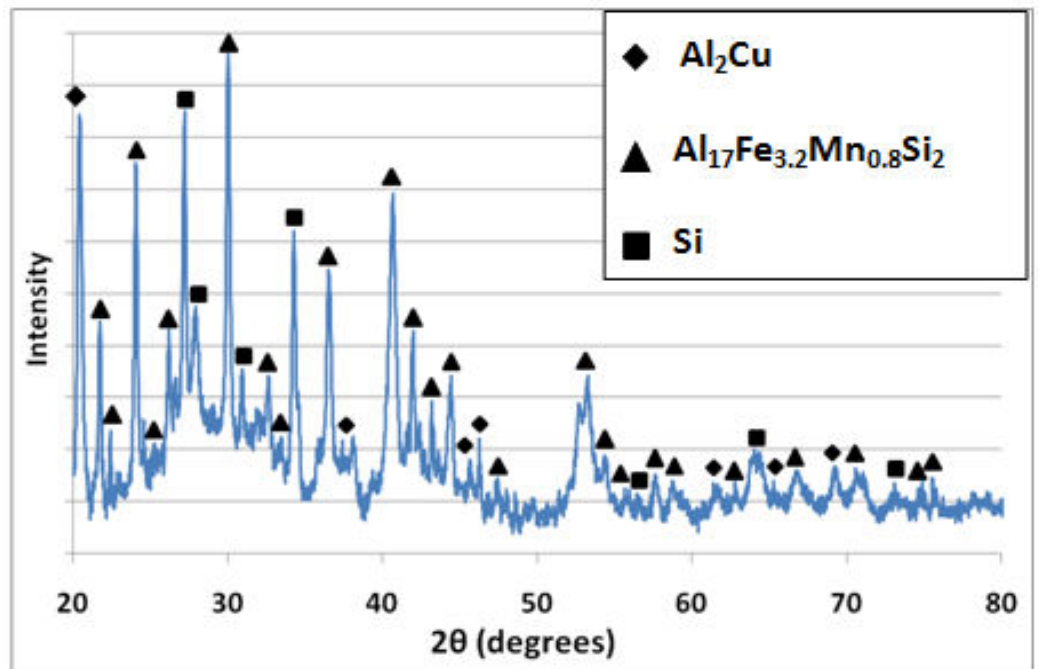

Figure 36: Results of X-ray diffraction performed on extracted secondary phase particles.

Analysis of the secondary phases in the microstructure resulted in the observation that the volume fraction of the $\beta-\mathrm{Al}_{5} \mathrm{FeSi}$ intermetallic phase was very low in comparison to the 
observations of $\mathrm{Li}$ et al. [11]. The majority of the iron-bearing phase particles were identified as $\alpha-\mathrm{Al}_{17} \mathrm{Fe}_{3.2} \mathrm{Mn}_{0.8} \mathrm{Si}_{2}$. The relatively low volume fraction of $\beta-\mathrm{Al}_{5} \mathrm{FeSi}$ is significant with regards to the mechanical properties, since this phase is hard, brittle and has poor bond strength with the aluminum matrix $[16,17]$. For this reason, the precipitation of $\beta-\mathrm{Al}_{5} \mathrm{FeSi}$ has a detrimental influence on the mechanical properties. The $\alpha-\mathrm{Al}_{17} \mathrm{Fe}_{3.2} \mathrm{Mn}_{0.8} \mathrm{Si}_{2}$, however, is less detrimental to the mechanical properties of Al-Si alloys, resulting in improved strength and ductility compared to an alloy containing a large volume fraction of $\beta-\mathrm{Al}_{5} \mathrm{FeSi}[16,17]$.

The Fe:Mn concentration ratio is important in explaining the precipitation of $\alpha-\mathrm{Al}_{17} \mathrm{Fe}_{3.2} \mathrm{Mn}_{0.8} \mathrm{Si}_{2}$ as opposed to $\beta-\mathrm{Al}_{5} \mathrm{FeSi}$. Narayanan et al. [14] observed that at a Fe:Mn ratio of 1.5:1, the majority of the iron bearing intermetallics were Chinese script $\alpha$-phase rather than $\beta$ - $\mathrm{Al}_{5} \mathrm{FeSi}$. In this study, the Fe:Mn ratio was found to be approximately 1.3:1. Therefore, the observation that the microstructure of the engine block was composed mainly of $\alpha-\mathrm{Al}_{17} \mathrm{Fe}_{3.2} \mathrm{Mn}_{0.8} \mathrm{Si}_{2}$ rather than $\beta-\mathrm{Al}_{5} \mathrm{FeSi}$ confirms the results of Narayanan et al. [14].

The variation in cooling rate and dendrite structure from the top to the bottom of the cylinder led to a significant modification in the morphology of the intermetallics. As shown in Figures 37(a) and (b), the microstructure at the top of the cylinder bridge was characterized by coarse clusters of eutectic silicon particles and coarse $\mathrm{Al}_{2} \mathrm{Cu}$ particles of mostly blocky morphology in clusters with $\mathrm{Al}_{5} \mathrm{Mg}_{8} \mathrm{Cu}_{2} \mathrm{Si}_{6}$. The $\mathrm{Al}_{17} \mathrm{Fe}_{3.2} \mathrm{Mn}_{0.8} \mathrm{Si}_{2}$ phase was present mainly in the Chinese script morphology and as coarse platelets.

Small clusters of eutectic silicon were seen dispersed along the microstructure, as shown in Figure $37(\mathrm{~b})$. This suggests that the eutectic silicon was partially modified by the addition of strontium [12]. The presence of strontium in the alloy may have also influenced the morphology of the $\mathrm{Al}_{2} \mathrm{Cu}$ phase, as strontium is known to promote the formation of blocky $\mathrm{Al}_{2} \mathrm{Cu}$, as opposed to eutectic $\mathrm{Al}_{2} \mathrm{Cu}[11,25]$.

The bottom of the cylinder bridge was characterized by a significant refinement of the secondary phases, as shown in Figures 37(c) and (d). Accompanying this refinement in particle size was a modification in the morphology of eutectic silicon (Figure 37(d)) and the intermetallic particles. Eutectic silicon, $\mathrm{Al}_{5} \mathrm{Mg}_{8} \mathrm{Cu}_{2} \mathrm{Si}_{6}$ and $\mathrm{Al}_{2} \mathrm{Cu}$ became finer and more globular, while $\mathrm{Al}_{17} \mathrm{Fe}_{3.2} \mathrm{Mn}_{0.8} \mathrm{Si}_{2}$ transformed from mainly coarse Chinese script to a finer particulate 
morphology. Furthermore, the backscattered electron images and optical micrographs show that the eutectic silicon and the intermetallic particles were more uniformly distributed in the aluminum matrix at the bottom of the cylinder bridge. From the observations of the dendrite structure and measurement of the SDAS, it can be deduced that the modification of the phase morphology was likely due to an increase in cooling rate experienced by the bottom of the cylinder bridge relative to the top.
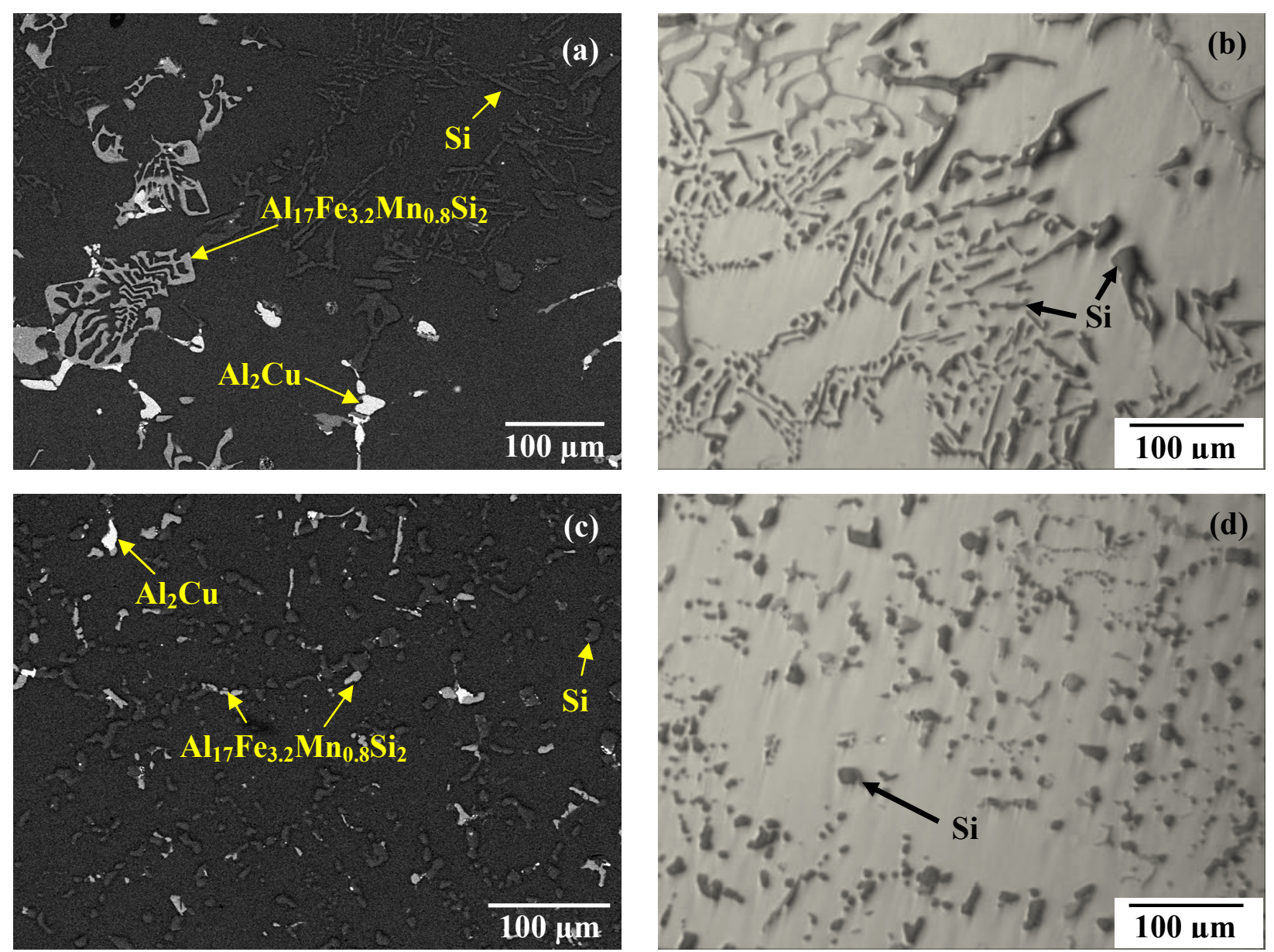

Figure 37: Backscattered electron images and optical micrographs of: (a) and (b) cylinder (4-6) bridge TSR top, (c) and (d) cylinder (4-6) bridge TSR bottom.

Scanning electron microscopy was used in conjunction with image analysis software to quantify the volume fraction of $\mathrm{Al}_{2} \mathrm{Cu}$ and $\mathrm{Al}_{17} \mathrm{Fe}_{3.2} \mathrm{Mn}_{0.8} \mathrm{Si}_{2}$. The analysis revealed that the increased cooling rate at the bottom of the cylinder influenced the amount and distribution of second phase particles. Quantitative phase analysis, shown in Figure 38, illustrated a reduction in the amount of $\mathrm{Al}_{2} \mathrm{Cu}$ at the bottom section of the cylinder relative to the top. The error bars in Figure 38 
represent the $95 \%$ confidence limits for the population mean of the $\mathrm{Al}_{2} \mathrm{Cu}$ volume fraction. Analysis of Variance (Appendix B2) confirmed that the reduction in the amount of $\mathrm{Al}_{2} \mathrm{Cu}$ at the bottom of the cylinder relative to the top was statistically significant with a $99.9 \%$ confidence level. The reduction in $\mathrm{Al}_{2} \mathrm{Cu}$ confirmed the observations of Li et al. [11], who showed that the amount of $\mathrm{Al}_{2} \mathrm{Cu}$ that forms during solidification was reduced with a shorter local solidification time. The results obtained using image analysis also revealed significant clustering of the $\mathrm{Al}_{2} \mathrm{Cu}$ intermetallic particles at the top section of the cylinder, as illustrated by the relatively large error bars in Figure 38. Conversely, the bottom section of the cylinder had a more uniform distribution of $\mathrm{Al}_{2} \mathrm{Cu}$, as shown by the relatively short error bars.

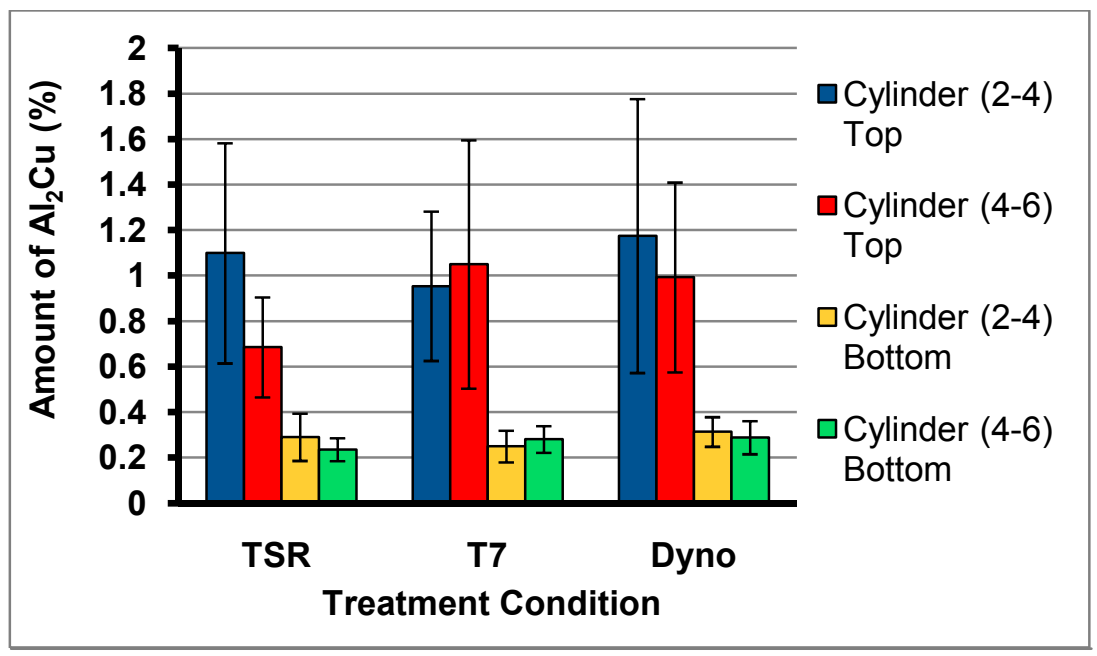

Figure 38: Amount of $\mathrm{Al}_{2} \mathrm{Cu}$ at the top and bottom of the cylinder (2-4) and (4-6) bridge for various treatments.

The volume fraction of the $\mathrm{Al}_{17} \mathrm{Fe}_{3.2} \mathrm{Mn}_{0.8} \mathrm{Si}_{2}$ phase changed slightly from top to bottom of the cylinder bridge as indicated by the $99.13 \%$ confidence level obtained from ANOVA analysis in Appendix B3. The area fraction of $\mathrm{Al}_{17} \mathrm{Fe}_{3.2} \mathrm{Mn}_{0.8} \mathrm{Si}_{2}$ for each condition is shown in Figure 39, where the error bars represent the $95 \%$ confidence limits for the population mean of the $\mathrm{Al}_{17} \mathrm{Fe}_{3.2} \mathrm{Mn}_{0.8} \mathrm{Si}_{2}$ area fraction. Although the change in the amount of $\mathrm{Al}_{17} \mathrm{Fe}_{3.2} \mathrm{Mn}_{0.8} \mathrm{Si}_{2}$ was small, as in the case of the $\mathrm{Al}_{2} \mathrm{Cu}$ phase, the $\mathrm{Al}_{17} \mathrm{Fe}_{3.2} \mathrm{Mn}_{0.8} \mathrm{Si}_{2}$ particles were more evenly distributed at the bottom of the cylinder bridge.

Quantitative phase analysis for eutectic silicon was performed using optical micrographs in conjunction with image analysis software. The analysis revealed no significant changes in volume fraction of eutectic silicon from top to bottom of the cylinder, as shown in Figure 40. 
This was confirmed by the overlapping of the error bars, which represent the $95 \%$ confidence limits for the population mean of the eutectic silicon volume fraction. Analysis of Variance (Appendix B4) further confirmed the insignificant change in the eutectic silicon volume fraction. However, the eutectic silicon particles were more uniformly distributed at the bottom relative to the top of the cylinder bridge.

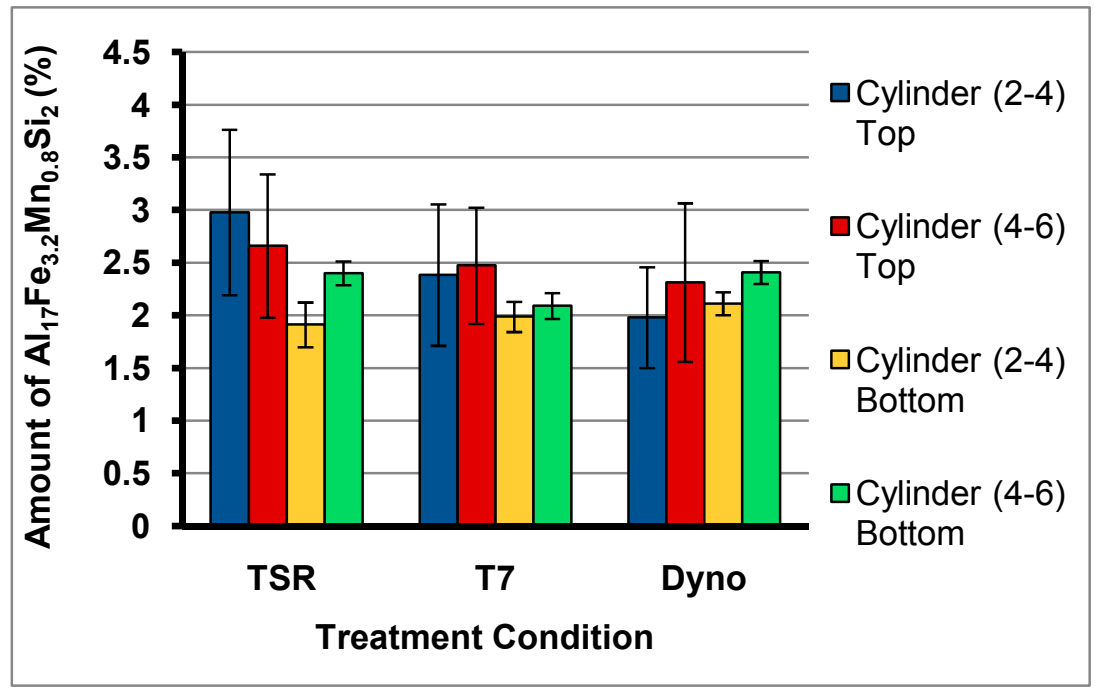

Figure 39: Amount of $\mathrm{Al}_{17} \mathrm{Fe}_{3.2} \mathrm{Mn}_{0.8} \mathrm{Si}_{2}$ at the top and bottom of the cylinder (2-4) and (4-6) bridge for various treatments.

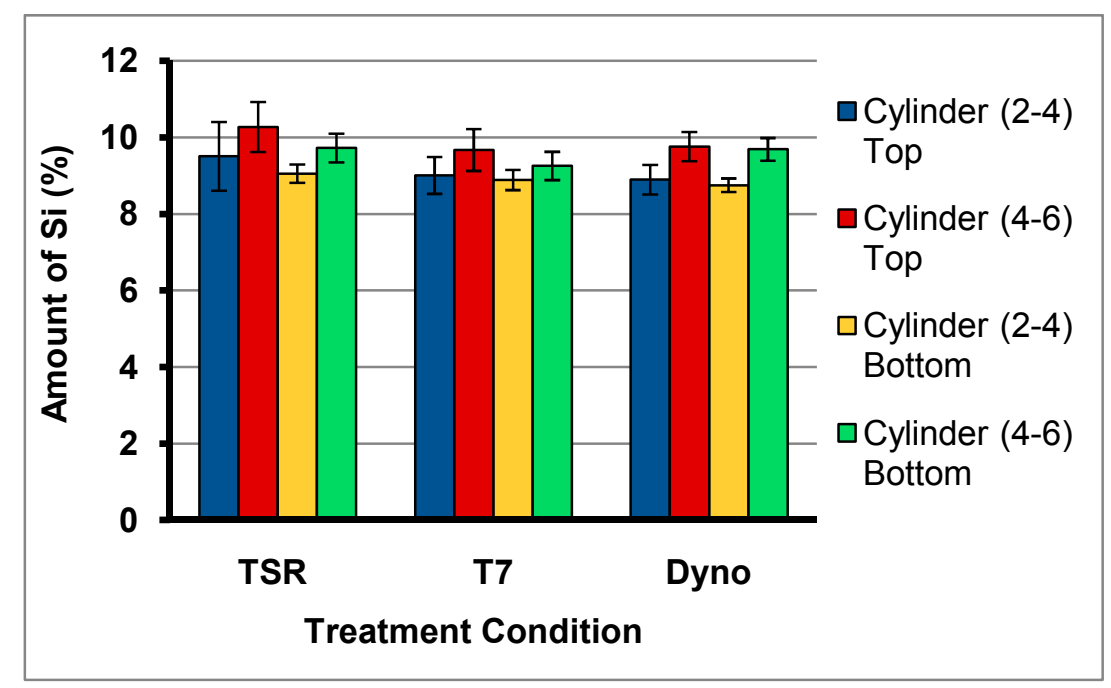

Figure 40: Amount of eutectic silicon at the top and bottom of the cylinder (2-4) and (4-6) bridge for various treatments.

Quantitative phase analysis could not be performed for $\mathrm{Al}_{5} \mathrm{Mg}_{8} \mathrm{Cu}_{2} \mathrm{Si}_{6}$ due to insufficient contrast relative to the other phases present in the microstructure. However, based on the results obtained 
from optical microscopy and SEM, it appeared that the volume fraction of $\mathrm{Al}_{5} \mathrm{Mg}_{8} \mathrm{Cu}_{2} \mathrm{Si}_{6}$ was reduced with increasing cooling rate.

\subsubsection{Secondary Phases at the Al-Fe Liner Interface}

Scanning electron microscopy was also used to characterize the microstructure near the Al-Fe liner interface. Backscattered electron images and EDX at the Al-Fe liner interface region for the bottom of the cylinder bridge revealed a $100 \mu \mathrm{m}$ band of segregated coarse second phase particles. This is shown in Figure 41. This band of coarse second phase particles was primarily composed of $\mathrm{Al}_{2} \mathrm{Cu}$ and only appeared at the bottom section of the cylinder. For the top section of the cylinder, the distribution of second phase particles at the Al-Fe liner interface was similar to that in the remainder of the section.

The segregation of coarse $\mathrm{Al}_{2} \mathrm{Cu}$ particles to the $\mathrm{Al}-\mathrm{Fe}$ liner interface was likely caused by a variation in cooling rate and concentration of solute between the $100 \mu \mathrm{m}$ band and the remainder of the cylinder section during solidification. Chills were inserted at the bulkhead of the engine block. These chills may have accelerated the cooling rate in the centre region of the bottom cylinder section, thereby leaving a thin region near the Al-Fe liner interface to solidify at a slower rate. The cast iron liners were also expected to act as a chill for the molten aluminum. However, the liners were preheated to approximately $400{ }^{\circ} \mathrm{C}$, which likely eliminated any chill effect and resulted in coarser intermetallics at the Al-Fe liner interface. On the other hand, despite the presence of cast iron cylinder liners at the top section of the cylinder as well, the $\mathrm{Al}_{2} \mathrm{Cu}$ phase did not segregate to the Al-Fe liner interface in this region of the cylinder. This suggests that the driving force for the segregation of $\mathrm{Al}_{2} \mathrm{Cu}$ to the $\mathrm{Al}-\mathrm{Fe}$ liner interface was the increased cooling rate in the centre region (caused by the chill plate) rather than the presence of the cast iron liners.

The variation in cooling rate between the Al-Fe liner interface region and the centre region of the section only partially explains the discrepancy in particle size. If cooling rate was the only factor influencing this phenomenon, a more gradual coarsening of intermetallics from the centre of the section to the Al-Fe liner interface would have taken place. However, the change in particle size occurred very suddenly, indicating that other factors may have also contributed to this segregation. During solidification, the rapid cooling rate of the centre section caused the 
aluminum dendrites to nucleate and grow more rapidly. In turn, this likely resulted in an enrichment of copper in the remaining liquid near the Al-Fe liner interface. This enrichment of copper, in conjunction with the slower cooling rates experienced at the Al-Fe liner interface, likely caused coarse $\mathrm{Al}_{2} \mathrm{Cu}$ particles to precipitate upon solidification.

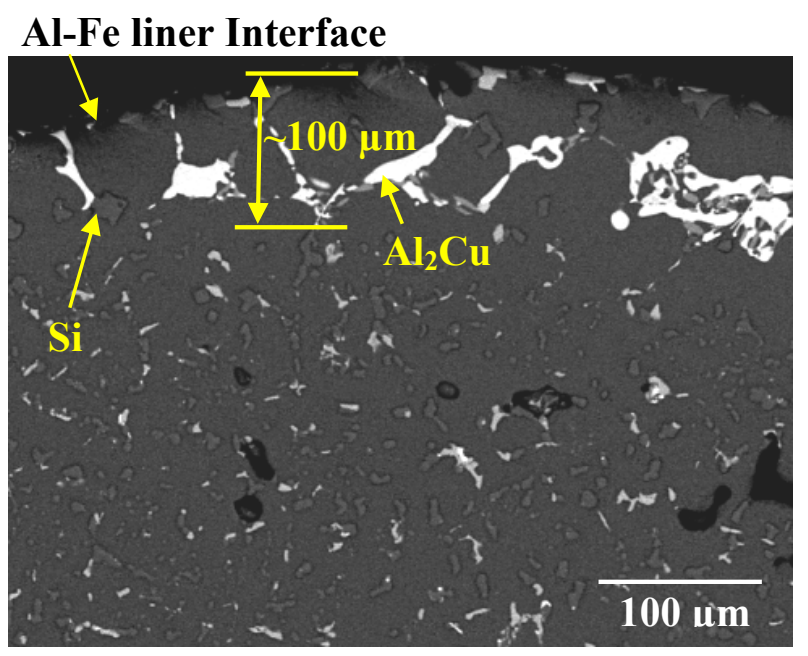

Figure 41: Backscattered electron image of the Al-Fe liner interface region for cylinder (4-6) T7 bottom.

The amount of $\mathrm{Al}_{2} \mathrm{Cu}$ was measured along the $100 \mu \mathrm{m}$ band across the Al-Fe liner interface using image analysis. The results, shown in Figure 42, confirmed the segregation of coarse $\mathrm{Al}_{2} \mathrm{Cu}$ particles to the Al-Fe liner interface. The error bars in Figure 42 represent the $95 \%$ confidence limits of the population mean for the $\mathrm{Al}_{2} \mathrm{Cu}$ volume fraction at the $\mathrm{Al}-\mathrm{Fe}$ liner interface. It was found that this region had approximately 6 area $\%$ of $\mathrm{Al}_{2} \mathrm{Cu}$, while the centre region of the bottom cylinder section had approximately 0.25 area $\%$ of $\mathrm{Al}_{2} \mathrm{Cu}$.

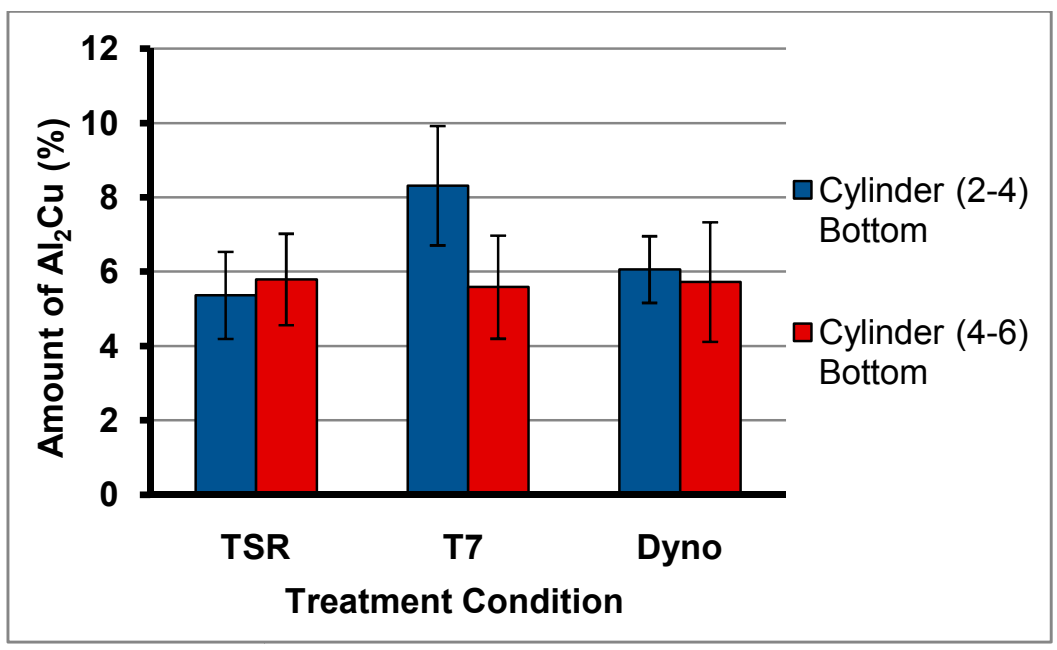

Figure 42: Amount of $\mathrm{Al}_{2} \mathrm{Cu}$ at the $\mathrm{Al}-\mathrm{Fe}$ interface for the bottom of the cylinder for various treatments. 


\subsubsection{Effect of Heat Treatment on Secondary Phase Distribution}

The influence of heat treatment on dissolution or precipitation of secondary phases was analyzed using SEM, DSC and WDS. Although the microstructure at the top of the cylinder bridge was significantly different from the bottom, heat treatment did not significantly influence the relative quantity of secondary phases in the interdendritic regions. The data collected from image analysis showed that the volume fraction of $\mathrm{Al}_{2} \mathrm{Cu}, \mathrm{Al}_{17} \mathrm{Fe}_{3.2} \mathrm{Mn}_{0.8} \mathrm{Si}_{2}$ and eutectic silicon was unaffected after $\mathrm{T} 7$ heat treatment and in-service testing. This was confirmed by ANOVA analysis (Appendices B2-B4). Heat treatment did not have a significant effect on the amount and morphology of the eutectic silicon particles, as the silicon particles were found to have the same morphology as in the TSR state. The iron rich phases were also unaffected by heat treatment. These phases, however, are known to dissolve solely with very high solution heat treatment time [25]. Therefore, the heat treatment time allotted for these engine blocks ( $\sim 7.5$ hours) may not have been long enough to cause significant dissolution of the iron rich phases. Furthermore, the size and distribution of $\mathrm{Al}_{2} \mathrm{Cu}$ also remained unchanged after heat treatment.

In order to confirm the effectiveness of the solution heat treatment parameters used in this study, the solution heat treatment schedule $\left(480{ }^{\circ} \mathrm{C}\right.$ for 7.5 hours) was simulated using DSC analysis. The results, where upward peaks represent endothermic heat flow, are shown in Figure 43.

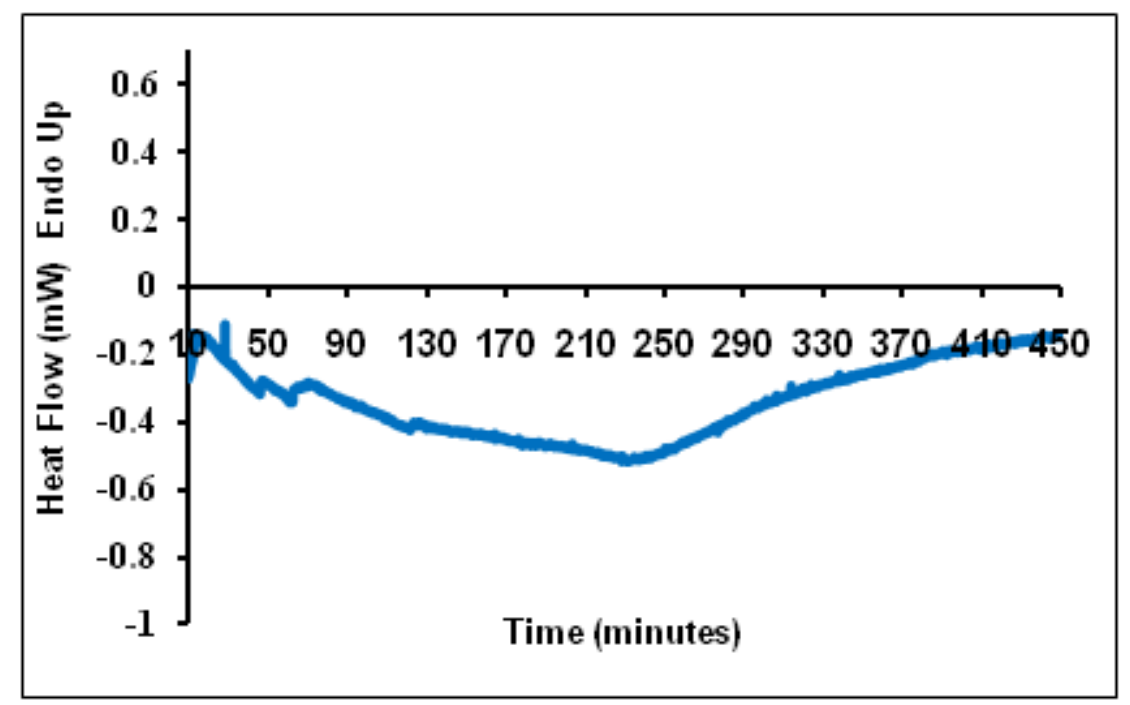

Figure 43: Results from isothermal hold experiment using DSC at $480^{\circ} \mathrm{C}$ for 7.5 hours. 
The results from DSC analysis show no significant formation of large endothermic peaks during the heat treatment experiment. Since the dissolution of secondary phases is an endothermic process, significant dissolution is generally accompanied by endothermic peaks in a plot relating heat flow and time.

Although the resulting heat flow was not completely constant with time, the maximum heat flow variation in Figure 43 was approximately $0.2 \mathrm{~mW}$ within the $250-450$ minute interval. This variation in heat flow was observed to be significantly lower than the $10 \mathrm{~mW}$ exothermic peak associated with the $\mathrm{Al}-\mathrm{Al}_{2} \mathrm{Cu}-\mathrm{Al}_{5} \mathrm{Mg}_{8} \mathrm{Cu}_{2} \mathrm{Si}_{6}$ complex eutectic reaction, shown in Figure 35. This is important since in 319 aluminum alloys, dissolution of $\mathrm{Al}_{2} \mathrm{Cu}$ and $\mathrm{Al}_{5} \mathrm{Mg}_{8} \mathrm{Cu}_{2} \mathrm{Si}_{6}$ allows for effective precipitation hardening following heat treatment. For this reason, this endothermic peak was not significant with regards to dissolution of secondary phases. Therefore, the results suggest that the dissolution of equilibrium secondary phases was did not occur extensively during solution heat treatment. This confirmed that the dissolution of secondary phases is sluggish using this solution heat treatment schedule.

To further investigate the influence of heat treatment on the microstructure at the cylinder bridge of the engine block, the composition of the $\alpha$-Al dendrites was determined. The measurements were performed using wavelength dispersive X-ray spectroscopy (WDS) and are shown in Figure 44. The error bars in Figure 44 represent the 95\% confidence limits of the population mean for the aluminum dendrite composition.

The results obtained from WDS analysis suggest that there was a small increase in the amount of copper and magnesium within the aluminum dendrites at the bottom of the cylinder relative to the top, which was confirmed by ANOVA analysis (Appendicies B5 and B6). Heat treatment and service testing did not significantly change the amount of copper in the aluminum dendrites while the amount of magnesium in the aluminum dendrites changed slightly. The small change in magnesium content, however, points to the sluggish dissolution of $\mathrm{Al}_{5} \mathrm{Mg}_{8} \mathrm{Cu}_{2} \mathrm{Si}_{6}$. Similarly, the relatively small change in copper concentration in the aluminum matrix also confirms the sluggish dissolution of $\mathrm{Al}_{2} \mathrm{Cu}$ during heat treatment. 


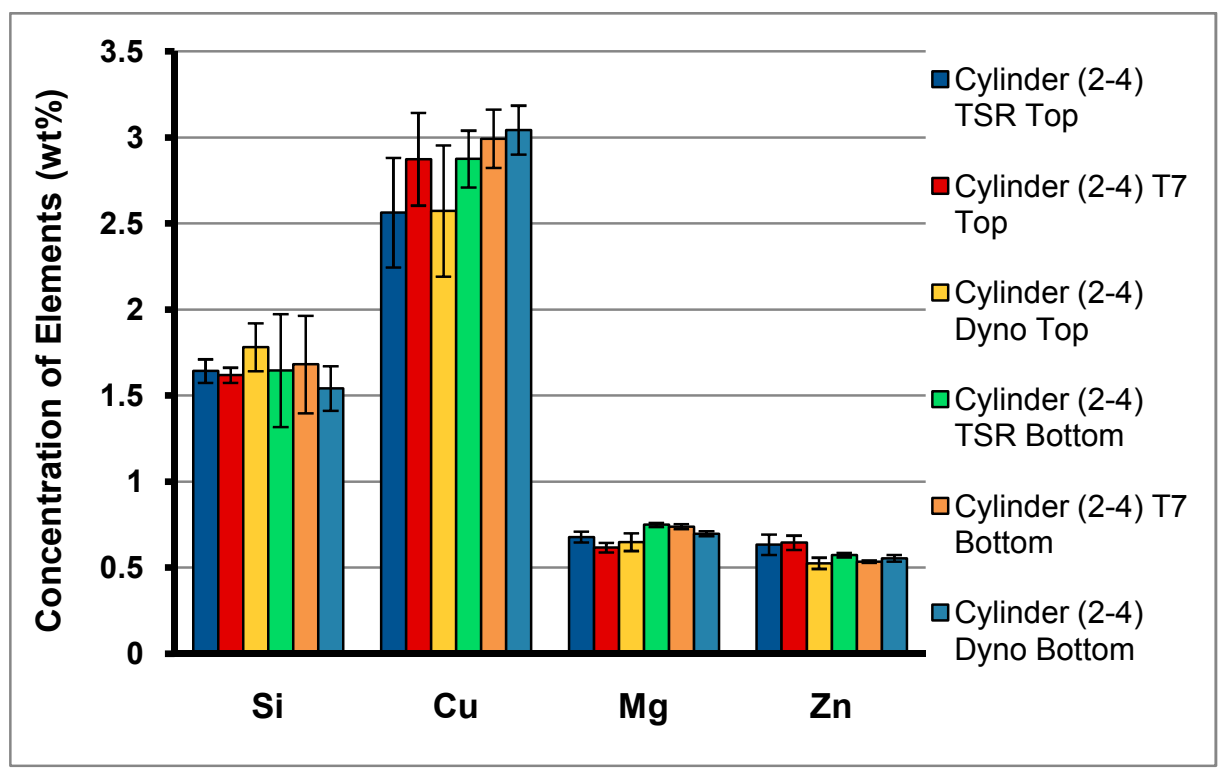

Figure 44: Composition of the aluminum matrix for various treatments for cylinder (2-4) bridge.

The solution heat treatment temperature was likely responsible for the sluggish dissolution of $\mathrm{Al}_{2} \mathrm{Cu}$. It has been documented that a solution temperature of $480{ }^{\circ} \mathrm{C}$ causes sluggish dissolution of $\mathrm{Al}_{2} \mathrm{Cu}[11,23]$. Another reason for the sluggish dissolution of $\mathrm{Al}_{2} \mathrm{Cu}$ may be attributed to the morphology of this phase. For instance, Han et al. [26] found that during heat treatment, blocky $\mathrm{Al}_{2} \mathrm{Cu}$ was more difficult to dissolve than eutectic $\mathrm{Al}_{2} \mathrm{Cu}$. Consequently, since $\mathrm{Al}_{2} \mathrm{Cu}$ mainly exhibited a blocky morphology at the top and bottom of the cylinder bridge, significant dissolution of $\mathrm{Al}_{2} \mathrm{Cu}$ likely did not occur.

The absence of change in microstructure and matrix composition after heat treatment and subsequent in-service testing suggests that the engine blocks are thermally stable. Therefore, service conditions should not result in phase transformations, and it can be expected that the engine blocks will not undergo loss of mechanical properties while in service.

\subsubsection{Secondary Phases within Aluminum Dendrites}

Heat treatable aluminum alloys, such as 319, commonly form metastable age hardening precipitates during aging. These precipitates have been documented to improve the strength of the alloy. For this reason, the secondary phases within the primary aluminum dendrites (FCC crystal structure) were observed using transmission electron microscopy (TEM) in conjunction with EDX analysis. 
The engine blocks in the TSR treatment condition were characterized by sparsely distributed rod-like precipitates, between 300 and $500 \mathrm{~nm}$ in length within the aluminum dendrites, as shown in the bright field TEM image in Figure 45(a). The corresponding selected area diffraction pattern is shown in Figure 45(b). Energy dispersive X-ray spectroscopy (EDX) was carried out on the rod-like particles that were partially removed from the matrix, shown by the red circle in Figure 45(c).
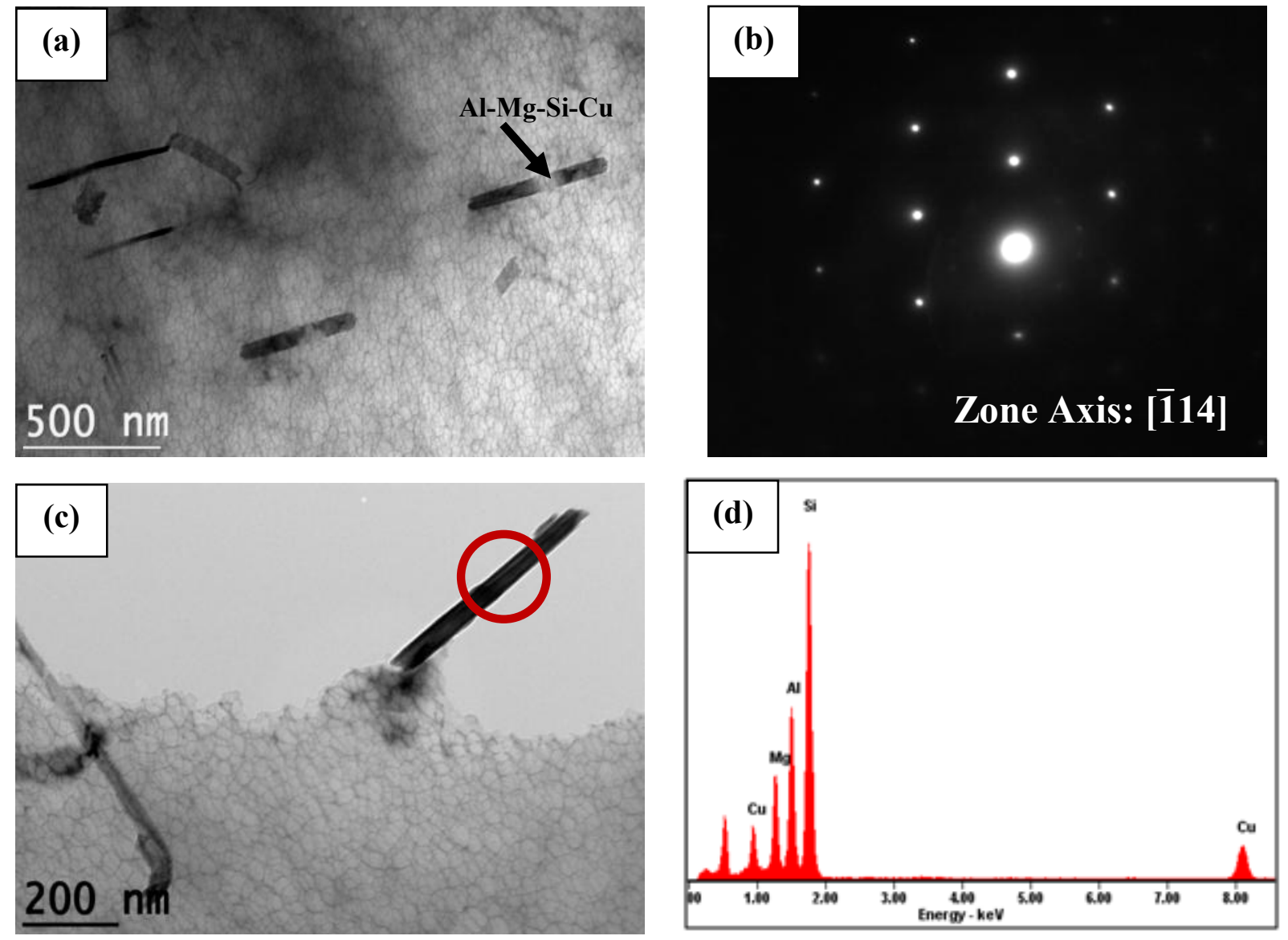

Figure 45: (a) Bright field TEM image of Cylinder (2-4) TSR top (11500x), (b) selected area diffraction pattern of the matrix, (c) bright field TEM image of cylinder (2-4) TSR top (20000x) showing the location where EDX analysis was performed on the rod precipitates, (d) corresponding EDX spectrum for the rod-like precipitate.

The results from EDX, shown in Figure 45 (d), confirmed that these precipitates were Al-Mg-Si-Cu type precipitates. Therefore, the results suggest that the thermal sand reclamation treatment may have caused a redistribution of alloying elements within the aluminum dendrites which subsequently led to the formation of $\mathrm{Al}-\mathrm{Mg}-\mathrm{Si}-\mathrm{Cu}$ type precipitates during cooling to ambient temperature. 
Similarly, TEM analysis was performed on the T7 heat treated and service tested engine blocks. The results obtained during the analysis of the $\mathrm{T} 7$ heat treated engine blocks are shown in the bright field TEM image in Figure 46 (a). The analysis of the $\mathrm{T} 7$ heat treated engine blocks suggests that in addition to the $\mathrm{Al}-\mathrm{Mg}-\mathrm{Si}-\mathrm{Cu}$ precipitates observed in the TSR condition, aging to a $\mathrm{T} 7$ temper resulted in the precipitation of particles amenable to aging. These precipitates appear in the platelet morphology and are approximately $200 \mathrm{~nm}$ long. In addition, EDX analysis in TEM indicates that these precipitates contain mainly aluminum and copper, as shown in Figure 46 (b). This suggests that these precipitates were likely $\mathrm{Al}_{2} \mathrm{Cu}$. The formation of age hardening precipitates likely occurred due to a redistribution of alloying elements already present within the aluminum dendrites. This is likely the case since the solute necessary for the age hardening precipitates to form was not significantly supplied by the dissolution of equilibrium secondary phases. Moreover, the relatively small volume fraction of age hardening precipitates present within the aluminum dendrites relative to that observed by Hwang et al. [31] for a T6 heat treated 319 aluminum alloy, further suggests that a limited amount of solute was present within the aluminum dendrites during aging.

Transmission electron microscopy of the service tested engine block did not show a significant change in the morphology of the $\mathrm{Al}-\mathrm{Cu}$ age hardening precipitates found in the $\mathrm{T} 7$ heat treated condition, as shown in Figure 46 (c). Since service testing caused the engine block to be heated to the approximate aging temperature of the 319 alloy, this suggests that the age hardening precipitates were effectively stabilized by the $\mathrm{T} 7$ treatment. Thus no additional aging was experienced when exposed to service conditions. It is also important to note that the microstructure within the aluminum dendrites was similar at the top and bottom of the cylinder. This confirms that the formation of precipitates within the aluminum dendrites was due to heat treatment rather than solidification since the large variation in cooling rate from top to bottom did not influence the morphology of the precipitates within the aluminum dendrites.

The Al- $\mathrm{Cu}$ age hardening precipitates formed during aging were further analyzed utilizing the selected area diffraction patterns, as shown in Figure 47. The diffraction patterns were formed by placing the selected area aperture around an area encompassing the aluminum matrix and a single cluster of $\mathrm{Al}-\mathrm{Cu}$ age hardening precipitates as shown in the insert in Figure 47 (a). 

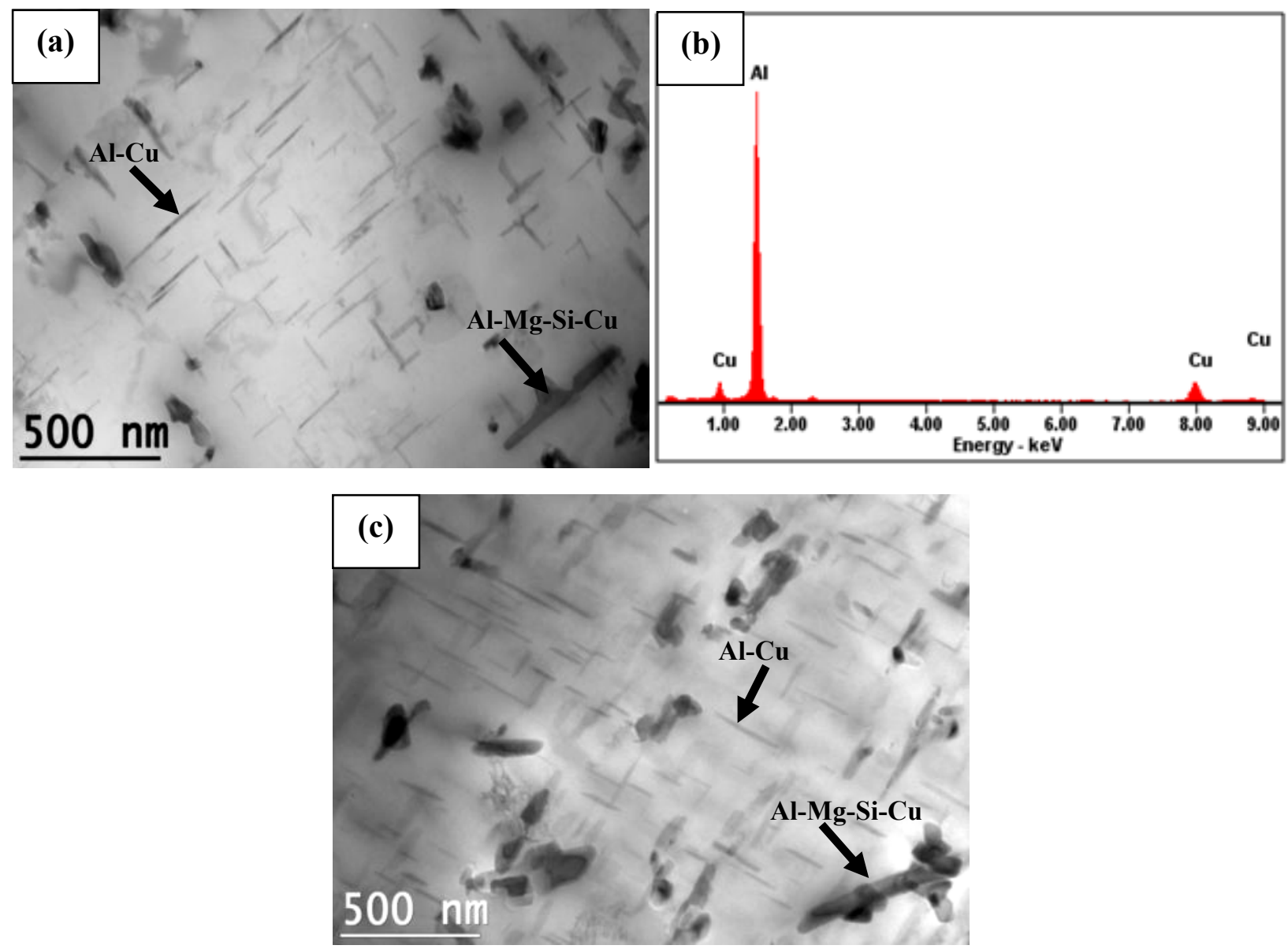

Figure 46: Bright field TEM images of: (a) cylinder (2-4) T7 top (11500x), (b) EDX spectrum for Al-Cu platelet precipitates. (c) cylinder (2-4) Dyno bottom (11500x).
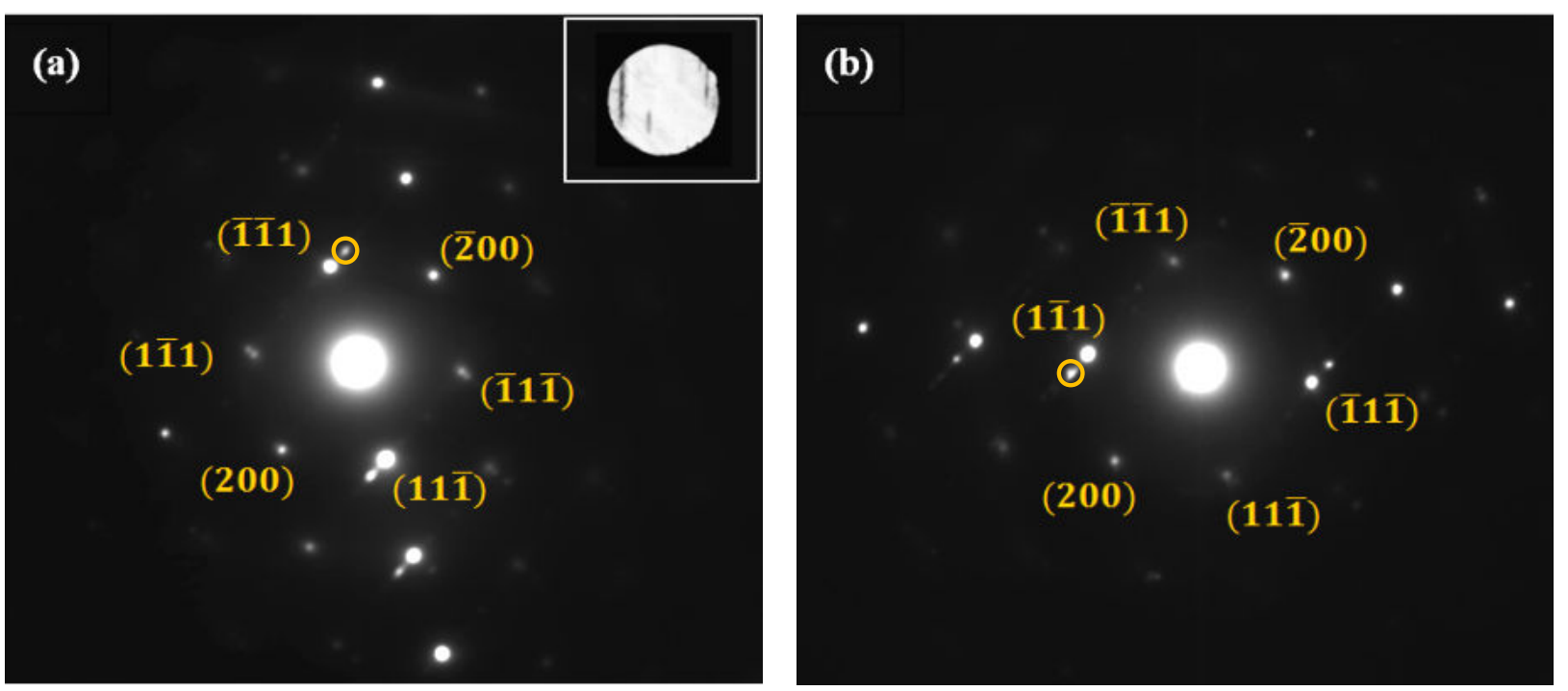

Figure 47: Selected area diffraction patterns for an area encompasssing the matrix and a single cluster of age hardening precipitates for cylinder (2-4) T7 top. (a) [011] zone axis, (b) [011] zone axis with sample tilted. 
The selected area diffraction patterns in Figure 47 were composed of bright spots corresponding to the matrix planes as well as additional spots from the precipitates. Although both diffraction patterns were formed using the [011] zone axis, the slight tilting of the specimen allowed different spots to become visible. The objective aperture was then utilized to isolate the additional spots in the selected area diffraction patterns to form a dark field TEM image of the precipitate. The resulting dark field image (Figure 48) shows bright platelet age hardening precipitates surrounded by a dark matrix phase. Since this image was formed using the additional spots in the selected area diffraction patterns, the dark field image confirms that these additional spots were caused by electron diffraction from the Al-Cu age hardening precipitates.

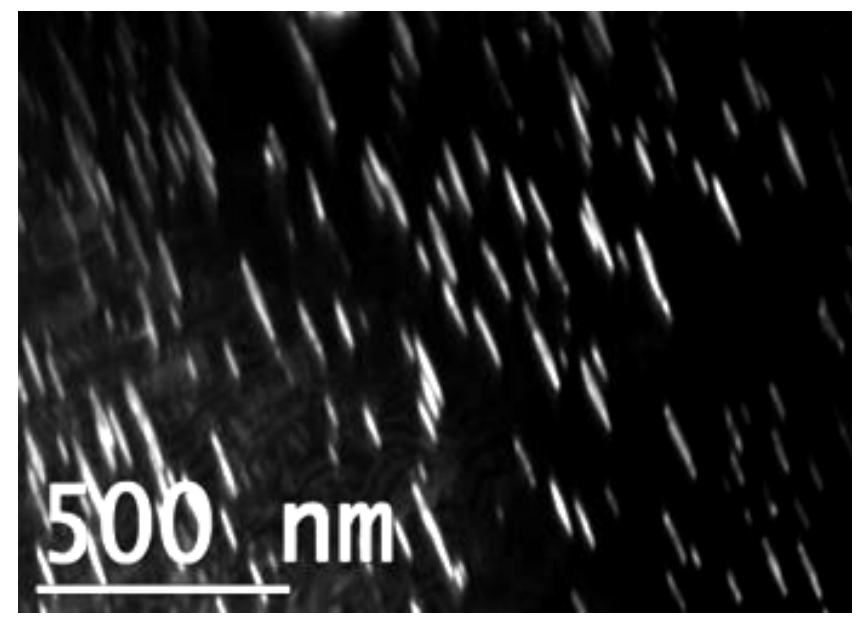

Figure 48: Dark field TEM image corresponding to additional spots outlined by circles in Figure 47.

Further analysis of the selected area diffraction patterns was done to examine the coherency of the age hardening precipitates. For precipitates to be coherent with the matrix, the misfit between the matrix and the precipitates should approach zero. Consequently, the misfit parameter $(\delta)$, which relates the interplanar (d) spacing of the matrix and the precipitates, was used to analyse the interface between the matrix and the $\mathrm{Al}-\mathrm{Cu}$ precipitates [60]. The relationship is shown in Equation 9.

$$
\delta=\frac{d_{\text {precipitate }}-d_{\text {matrix }}}{d_{\text {matrix }}}
$$

Analysis of the diffraction patterns in conjunction with the use of Equation 9 showed that the misfit in $\mathrm{d}$-spacing between the aluminum $\{111\}$ planes and the planes of the Al-Cu precipitates 
was approximately $15 \%$. This significant misfit between the $\{111\}$ matrix planes and these precipitates indicated that the $\mathrm{Al}-\mathrm{Cu}$ precipitates were incoherent with the aluminum matrix since only a limited misfit can be accommodated by elastic strain prior to the formation of an incoherent interface [60]. Furthermore, the presence of $\theta$ ' in the microstructure typically results in extra spots that appear like streaks between matrix spots in the selected area diffraction pattern $[31,61,62]$. However the diffraction patterns in Figure 47 do not show streaking between spots, rather there are additional spots present near the matrix planes. This result supports the observations of Tavitas-Medrano et al. [61] for the diffraction pattern of equilibrium $\theta-\mathrm{Al}_{2} \mathrm{Cu}$, which is incoherent with the aluminum matrix. Therefore, the T7 heat treatment schedule used on the engine blocks likely resulted in the precipitation of equilibrium $\theta-\mathrm{Al}_{2} \mathrm{Cu}$ within the aluminum dendrites.

Similar analysis was performed on the service tested engine block, which revealed that the age hardening precipitates within the aluminum dendrites were also incoherent due to a misfit between the matrix and particles approaching 15\%. Based on these results, the Al-Cu age hardening precipitates were fully stabilized by overaging and thus no additional phase transformations are expected to occur during engine operation. For this reason, cylinder bore distortion was not likely caused by phase transformation induced changes in specific volume of the aluminum alloy even though the engine operating temperature approaches the aging temperature of the 319 alloy.

\subsubsection{Microstructure in the Gray Iron Cylinder Liners}

Microstructural characterization was also performed along the gray cast iron cylinder liners. The microstructure at the top and bottom of the gray iron cylinder liners is shown in Figure 49. The microstructure of the gray iron liners is composed of graphite flakes embedded in an iron matrix. Furthermore, optical micrographs in Figure 49 show no significant change in microstructure of the gray iron liners at the top and bottom of the cylinder. The relative uniformity in microstructure was expected as unlike in the case for the aluminum, the gray iron liners were pre-manufactured and placed in the sand mould prior to pouring of the molten aluminum alloy. Furthermore, heat treatment did not result in any significant change in microstructure of the gray iron liners since the temperatures used were insufficient to result in any significant changes in microstructure. 

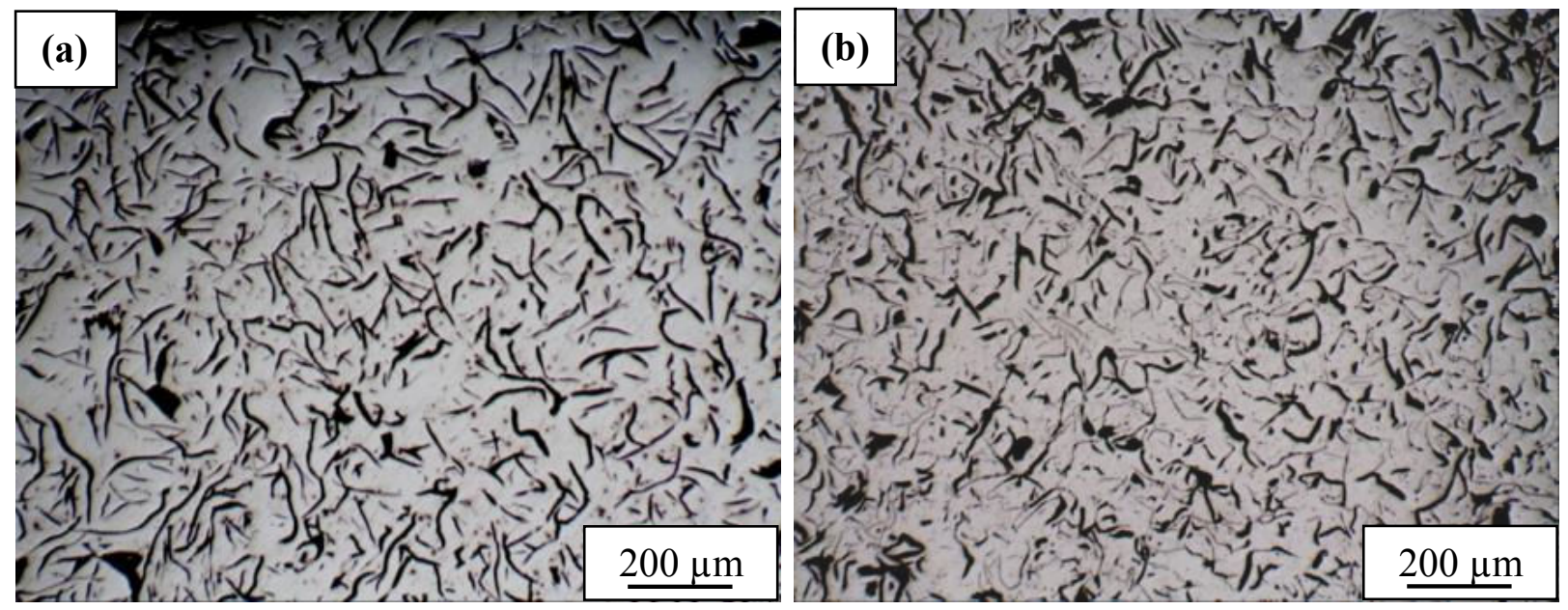

Figure 49: Optical micrographs of: (a) top section of the gray cast iron cylinder liner, (b) bottom section of the gray cast iron cylinder liner

\section{Section Summary}

Analysis of the microstructure along the cylinder bridge revealed a variation in microstructure from top to bottom of the cylinder, which was likely caused by a variation in cooling rate along the cylinder during solidification. The top of the cylinder was characterized by relatively coarse primary aluminum dendrites along with coarse and clustered $\mathrm{Al}_{2} \mathrm{Cu}, \mathrm{Al}_{17} \mathrm{Fe}_{3.2} \mathrm{Mn}_{0.8} \mathrm{Si}_{2}$ and eutectic silicon secondary phases. Conversely, the bottom of the cylinder contained finer aluminum dendrites and secondary phase particles.

The microstructural analysis of heat treated and service tested engine blocks determined that solution heat treatment did not cause a significant change in the amount of secondary phases present in interdendritic regions. This indicated that solution heat treatment was ineffective in the dissolution of equilibrium secondary phases. Aging, however, resulted in the formation of fine $\theta-\mathrm{Al}_{2} \mathrm{Cu}$ platelets within the aluminum dendrites. These precipitates were likely formed using copper solute atoms previously in solution with the aluminum matrix since dissolution of equilibrium secondary phases did not occur to a significant level. In addition, the presence of $\theta-\mathrm{Al}_{2} \mathrm{Cu}$ suggests that the $\mathrm{T} 7$ treatment effectively stabilized the microstructure. Thus, cylinder distortion was not likely caused by thermal growth. 


\subsection{Mechanical Properties}

\subsubsection{Hardness of Microstructural Constituents}

Nanoindentation was performed on the phases in the interdendritic regions as identified from SEM, EDX and XRD at the top and bottom sections of the cylinder for each treatment condition. Based on preliminary experiments, it was determined that the indention size, measured as the distance between the tip and the base of the triangular indent, was less than $1.5 \mu \mathrm{m}$ when indenting the secondary phases. Therefore, hardness measurements were performed on particles larger than $5 \mu \mathrm{m}$ to ensure no matrix influence. However, the hardness of the Al-Mg-Si-Cu phase could not be accurately determined because of its small particle size and volume fraction. The hardness of each analyzed phase in the microstructure was obtained from a load-displacement curve plotted during indentation. A representative load-displacement curve for each phase analyzed is shown in Figure 50.

The load-displacement curves in Figure 50 illustrate the relative hardness of each analyzed phase in the microstructure. The largest displacement was recorded for the indentation of the aluminum dendrites due to the relative softness of this phase. Furthermore, eutectic silicon and $\mathrm{Al}_{17} \mathrm{Fe}_{3.2} \mathrm{Mn}_{0.8} \mathrm{Si}_{2}$ had very similar load-displacement curves, while $\mathrm{Al}_{2} \mathrm{Cu}$ had a displacement in between that of the aluminum dendrites and the other secondary phases. The decreasing indenter displacement for the secondary phases compared to the aluminum-matrix was due to a higher resistance to the applied load indicating higher hardness.

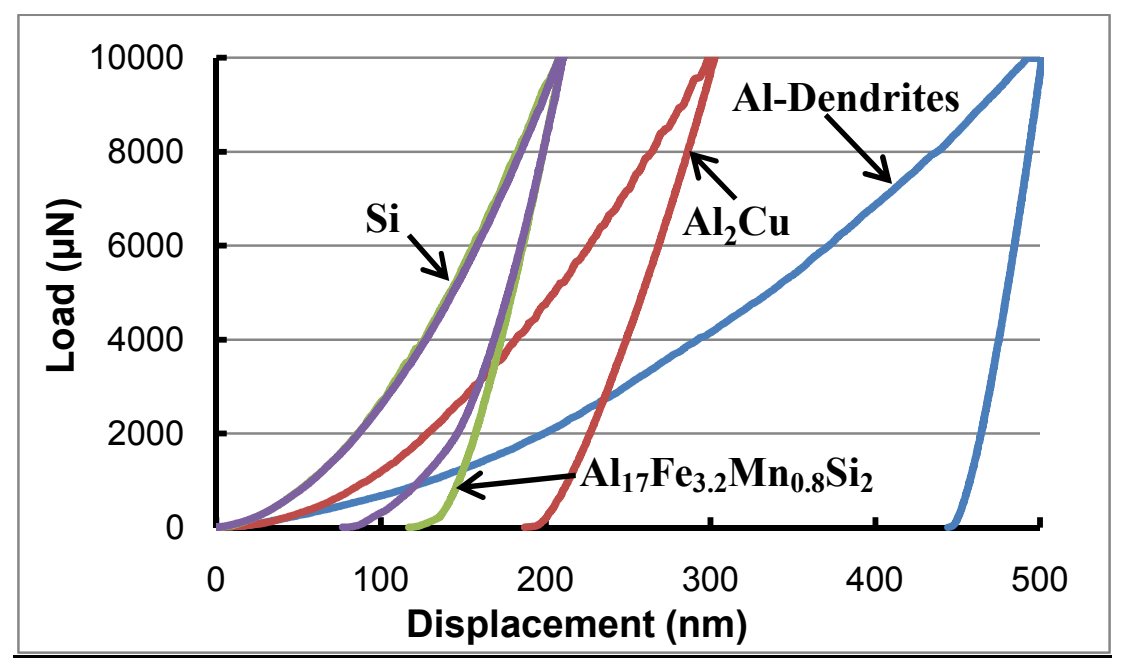

Figure 50: Load-displacement curves for each analyzed phase. 
The average hardness of each phase at the top and bottom sections of the cylinder bridge for each treatment condition is shown in Figure 51. The error bars represent the 95\% confidence limits of the population mean for the hardness of each phase in the microstructure.

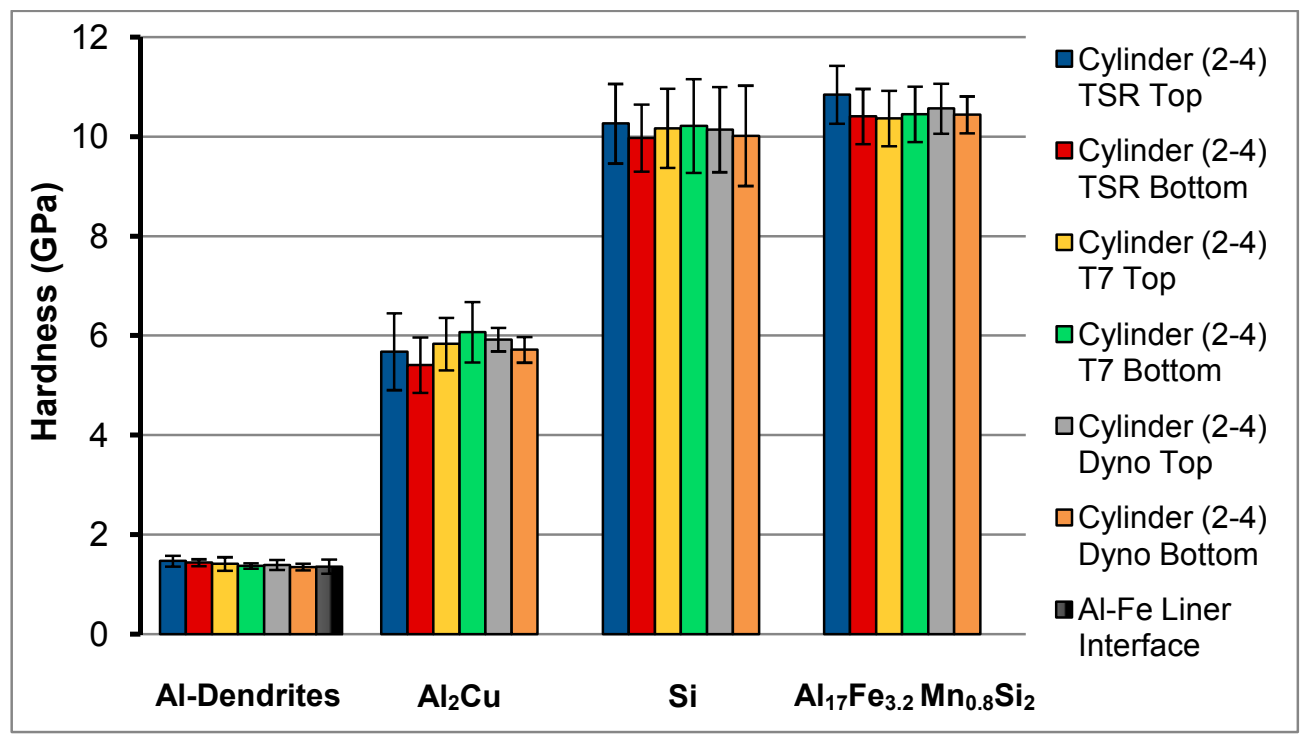

Figure 51: Hardness of each phase for the top and bottom of cylinder (2-4) bridge in each treatment condition.

From the observations of the load-displacement curves, the aluminum dendrites were determined to be the softest phase in the microstructure, followed by $\mathrm{Al}_{2} \mathrm{Cu}, \mathrm{Al}_{17} \mathrm{Fe}_{3.2} \mathrm{Mn}_{0.8} \mathrm{Si}_{2}$ and eutectic silicon, although the latter two phases essentially had the same hardness. The hardness of each phase observed in this study corresponds reasonably well with the results of Chen et al. [63]. In addition, the hardness of the aluminum dendrites within the $100 \mu \mathrm{m}$ band near the Al-Fe liner interface did not have an appreciable change in hardness compared to that of the matrix in the centre of the section. This indicates that despite a segregation of alloying elements to the Al-Fe liner interface, as discussed in Section 4.2.2.3, the increased concentration of alloying elements at the Al-Fe liner interface resulted in a large volume fraction of coarse secondary phases, such as $\mathrm{Al}_{2} \mathrm{Cu}$, rather than increased concentration of alloying elements in solid solution with the aluminum dendrites.

The results from nanoindentation, along with ANOVA analysis (Appendices B7-B10) did not show significant changes in hardness for each phase when comparing the top of the cylinder to the bottom. Although the faster cooling rate at the bottom led to a morphological modification of the secondary phases, the results from EDX, XRD and nanoindentation indicate that similar 
secondary phases are present from top to bottom of the cylinder bridge. The hardness of each analyzed phase also did not change significantly due to heat treatment and service testing. This confirms the observations made from the backscattered electron images and EDX, indicating that heat treatment and service testing does not result in significant dissolution of the phases present in the TSR condition or the precipitation of new secondary phases. Furthermore, a non significant change in hardness of the aluminum dendrites after heat treatment further suggests that the Al-Cu age hardening precipitates within the aluminum dendrites have become incoherent with the aluminum matrix due to overaging.

\subsubsection{Hardness at the Particle-Aluminum Dendrite Interface}

The interface between the particle and the matrix is an important consideration regarding the influence of second phase particles on the mechanical properties of an alloy. Particles that have strong bonding with the primary dendritic phase can greatly improve strength and ductility, while weak bonding with the primary dendrites can lead to cracks at the interface, thus reducing the strength and ductility of the alloy. Using nanoindentation, a hardness distribution was produced by indenting points along a line from the aluminum dendrite phase to the second phase particles. The results, along with atomic force microscopy (AFM) images showing the hardness indentations are shown in Figure 52.
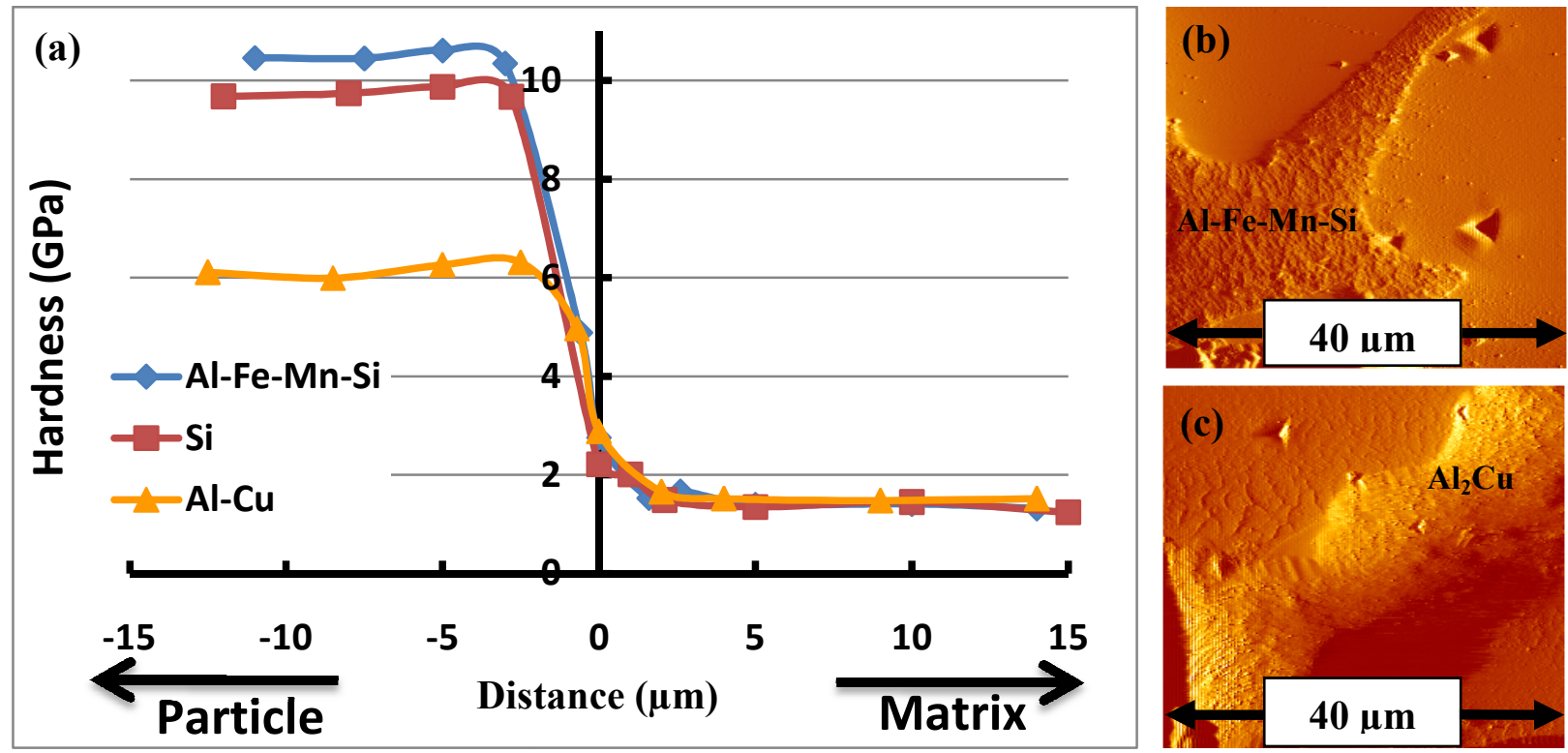

Figure 52: (a) Hardness distribution across the particle-aluminum dendrite interface $($ Distance $=0)$ for each analyzed phase, (b) and (c) AFM images showing the Al-Fe-Mn-Si and $\mathrm{Al}_{2} \mathrm{Cu}$ phases respectively. 
The hardness at the particle-aluminum dendrite interface was higher compared to the hardness of the aluminum dendrites (Figure 52). Further, the hardness distribution for silicon and $\mathrm{Al}_{17} \mathrm{Fe}_{3.2} \mathrm{Mn}_{0.8} \mathrm{Si}_{2}$ indicate that the bonding with the aluminum dendrites was weak for these phases, since there was a large difference in hardness between the particle and the particle-aluminum dendrite interface. However, the results also indicate that bonding between the particles and the aluminum dendrites was stronger for $\mathrm{Al}_{17} \mathrm{Fe}_{3.2} \mathrm{Mn}_{0.8} \mathrm{Si}_{2}$ than that of silicon, as the hardness at the particle-matrix interface was higher for $\mathrm{Al}_{17} \mathrm{Fe}_{3.2} \mathrm{Mn}_{0.8} \mathrm{Si}_{2}$ despite similar particle hardness.

Another important observation is that while the $\mathrm{Al}_{2} \mathrm{Cu}$ particles ( $\left.\sim 6 \mathrm{GPa}\right)$ had a significantly lower hardness than silicon ( $\sim 10 \mathrm{GPa})$ and $\mathrm{Al}_{17} \mathrm{Fe}_{3.2} \mathrm{Mn}_{0.8} \mathrm{Si}_{2}(\sim 10.5 \mathrm{GPa})$, the hardness at the particle-aluminum dendrite interface for $\mathrm{Al}_{2} \mathrm{Cu}(\sim 3 \mathrm{GPa})$ was determined to be higher than that of silicon ( $\sim 2 \mathrm{GPa}$ ) and approximately equal to that of $\mathrm{Al}_{17} \mathrm{Fe}_{3.2} \mathrm{Mn}_{0.8} \mathrm{Si}_{2}$. This indicates that the interfacial bond between $\mathrm{Al}_{2} \mathrm{Cu}$ and the aluminum dendrites may be stronger than the bond between the matrix and the other phases in the microstructure. Geometric effects, such as particle size and shape, may have influenced the hardness at the interface. However, the nanoindentation hardness at interfaces similar to those shown in the AFM images in Figure 52 for many particles of each phase yielded identical confirmatory results. Therefore, due to the higher interfacial strength with the aluminum dendrites, $\mathrm{Al}_{2} \mathrm{Cu}$ is likely a more effective strengthening phase than silicon or the iron bearing phases. This is in agreement with literature as it has been documented that silicon and the iron bearing phases are detrimental to the tensile properties of aluminum alloys $[12,14]$.

\subsubsection{Macrohardness of the Aluminum Cylinder Bridge Region}

Macrohardness (HRE) was used to relate hardness to tensile strength (Figure 53). The error bars represent the 95\% confidence limits of the population mean for the Rockwell hardness of the cylinder bridge. The Rockwell hardness measurements show a small increase in hardness at the bottom of the cylinder relative to the top. Although the change in hardness was small, ANOVA analysis (Appendix B11) confirmed that the hardness increase at the bottom of the cylinder was statistically significant with a 99.9\% confidence level. The increase in Rockwell hardness at the bottom of the cylinder bridge was likely caused by the refinement of the primary aluminum dendrites and the secondary phases. Finer and more evenly distributed intermetallics increase 
alloy hardness due to dispersion strengthening, in which second phase particles restrict dislocation motion [37]. Since there was no appreciable difference in the hardness of the aluminum dendrites, it can be deduced that the small increase in Rockwell hardness was attributed solely to the refinement and increased uniformity of the primary aluminum dendrites and secondary phases.

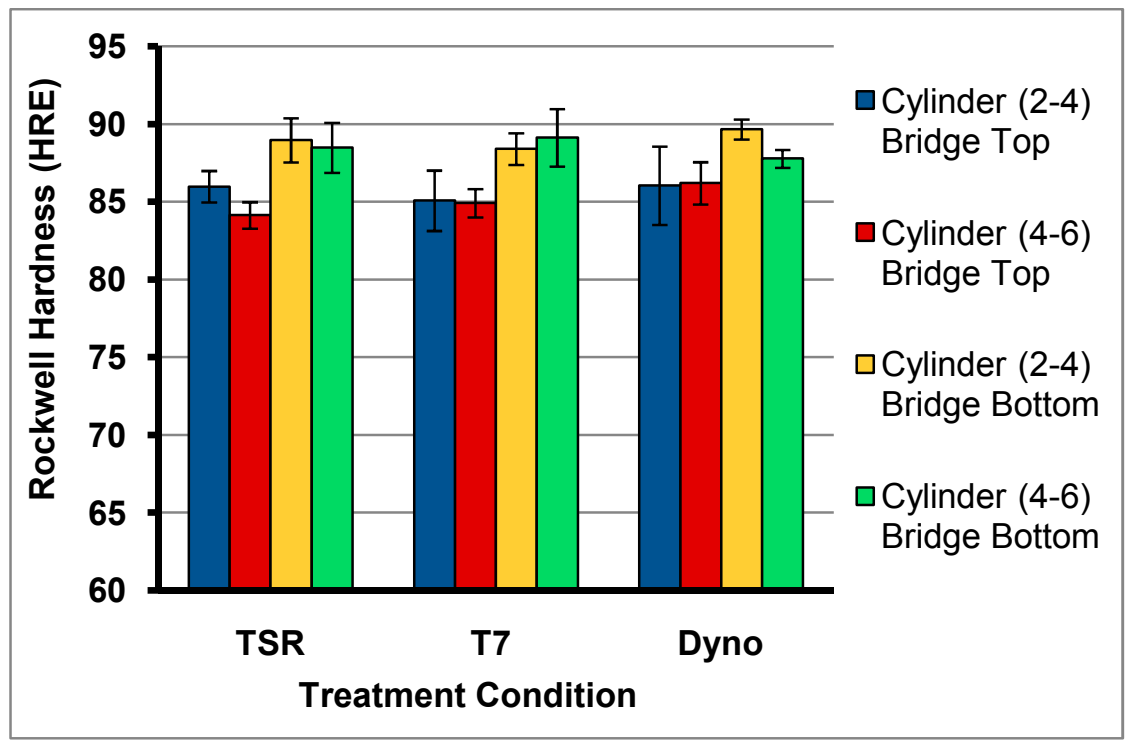

Figure 53: Rockwell hardness for cylinder (2-4) and (4-6) bridge in each treatment condition.

Hardness did not change significantly after heat treatment and service testing. This was expected since there were no appreciable changes in the morphology of secondary phase in interdendritic regions between the TSR, T7 heat treated and service tested engine blocks. Furthermore, the age hardening precipitates observed within the aluminum dendrites in Figure 46 were not coherent with the matrix which likely eliminated any significant hardening effect.

\subsubsection{Tensile Testing}

Tensile testing was carried out at the cylinder bridge of engine blocks in the TSR, T7 and service tested conditions at ambient temperature. The results are shown in Figure 54, where the error bars represent the $95 \%$ confidence limits of the population mean for yield and ultimate tensile strength. The tensile samples were taken at a depth within the cylinder bridge corresponding to the middle of the cylinder bridge. This was done since it was not possible to obtain samples at the top and bottom sections of the cylinder bridge. 


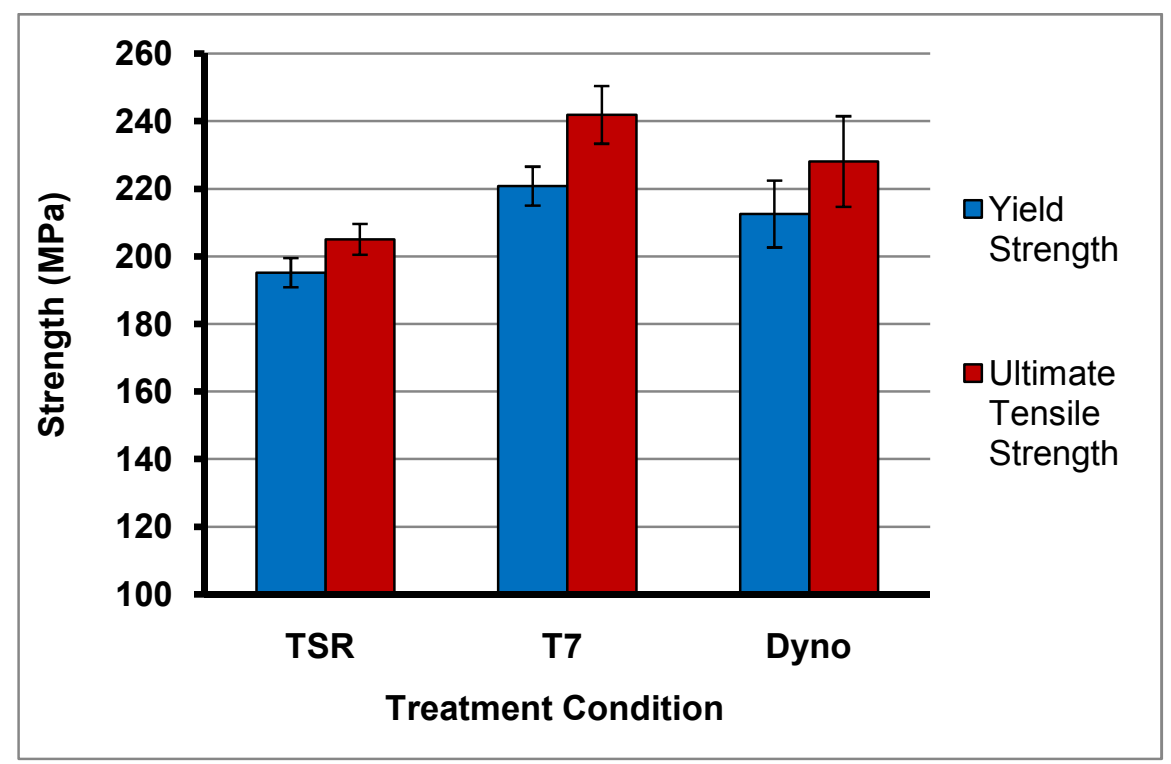

Figure 54: Cylinder bridge tensile strength.

The yield strength (YS) and the ultimate tensile strength (UTS) were found to be approximately 195 and $205 \mathrm{MPa}$, respectively at the cylinder bridge in the TSR condition. Heat treatment to a T7 temper resulted in a small increase in both the YS and UTS to values of approximately 220 and $240 \mathrm{MPa}$, respectively, indicative mainly of precipitation and dispersion hardening. Analysis of Variance (Appendices B12 and B13) confirmed that the increases in YS and UTS with heat treatment were statistically significant with a $99.9 \%$ confidence level. Finally, service testing did not result in a significant change in strength compared to the $\mathrm{T} 7$ heat treated engine blocks. Analysis of the tensile data also revealed a small difference between the YS and UTS, indicating that the alloy was highly brittle. Elongation at fracture was measured in order to quantify the alloy ductility (Figure 55). The error bars in Figure 55 represent the 95\% confidence limits of the population mean for yield and ultimate tensile strength. The results reveal that the elongation at fracture was between 0.7 and $0.8 \%$ for all of the examined treatment conditions, confirming the highly brittle nature of the alloy. The alloy brittleness was likely caused by the large volume fraction of eutectic silicon and $\mathrm{Al}_{17} \mathrm{Fe}_{3.2} \mathrm{Mn}_{0.8} \mathrm{Si}_{2}$ present in the microstructure. These phases are hard, brittle and have poor bonding with the aluminum matrix, as demonstrated by the results from nanoindentation (Figures 50 and 51). 


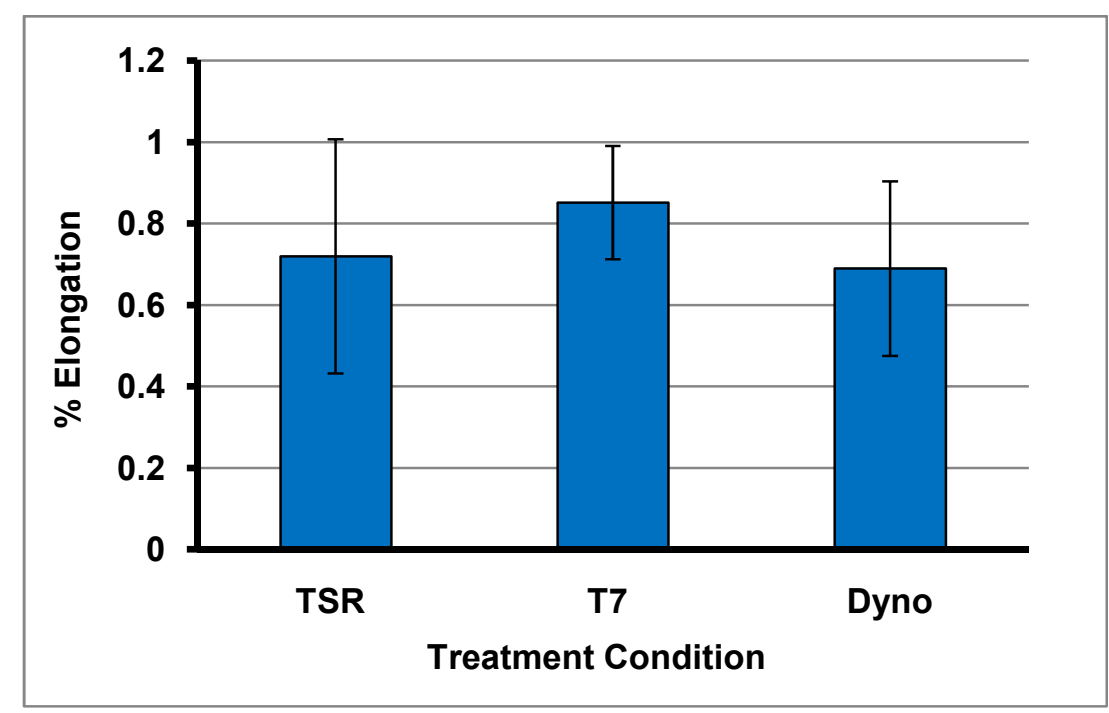

Figure 55: Cylinder bridge fracture elongation.

The increase in YS and UTS in the T7 heat treated condition compared to the TSR condition may be attributed to the formation of fine $\theta-\mathrm{Al}_{2} \mathrm{Cu}$ precipitates within the aluminum dendrites. Analysis using selected area diffraction patterns in TEM showed that the precipitates present in the aluminum dendrites were not coherent with the aluminum matrix due to a mismatch in $\mathrm{d}$ spacing between the matrix and precipitates approaching 15\%. This nullified strengthening due to coherency strains. However, the precipitates in the T7 engine block are finer and more densely distributed as compared to the TSR engine block. Therefore, the reduction in the interparticle spacing within the dendrites of the $\mathrm{T} 7$ heat treated engine block likely increased strength by increasing the resistance to dislocation motion. Furthermore, the tensile properties in the service tested engine blocks did not change significantly compared to the T7 heat treated blocks, which is due to the unappreciable changes in microstructure between these two treatment conditions.

\section{Section Summary}

Mechanical testing revealed that the refinement in microstructure at the bottom of the cylinder bridge resulted in increased hardness at the bottom relative to the top. Furthermore, while the formation of $\theta-\mathrm{Al}_{2} \mathrm{Cu}$ precipitates did not increase the hardness of the aluminum dendrites, the yield strength and ultimate tensile strength increased by a small amount following heat treatment. This was attributed to a more uniform distribution of particles within the aluminum dendrites following heat treatment which decreased the interparticle spacing and may have increased the resistance to dislocation motion. 


\subsection{Residual Strain and Stress Mapping}

\subsubsection{Residual Strain Mapping}

Residual strain mapping was carried out at the cylinder bridge region of the engine block for the aluminum cylinder bridge as well as the gray cast iron cylinder liners. Neutron diffraction was used to measure strain along the cylinder bridge in the hoop, axial and radial orientations for the TSR, T7 heat treated and service tested conditions.

\subsubsection{Aluminum Cylinder Bridge}

The strain profiles along the aluminum cylinder bridge for the engine block in the TSR condition are shown in Figure 56. The error bars represent the uncertainty which arise from the uncertainty of the diffraction angle, obtained using a Gaussian fit of the neutron diffraction data. However, for the engine block in the TSR condition, the uncertainty was negligible relative to the stress magnitude, and therefore no error bars were generated for this condition.

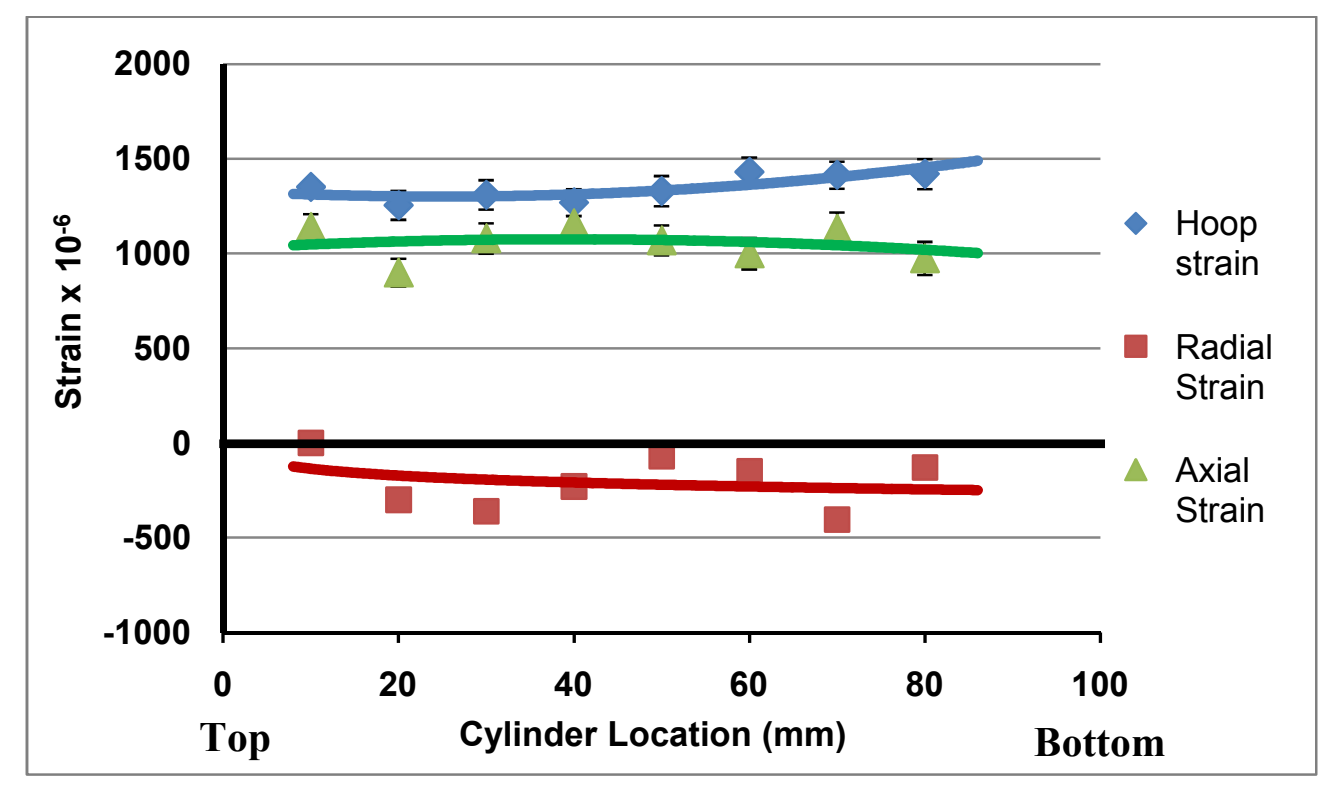

Figure 56: Residual strain profiles along the aluminum cylinder bridge in the TSR condition.

The strain profiles in Figure 56 indicate that the hoop strain is tensile with a slightly increasing magnitude along the cylinder bridge from approximately 1300 to $1500 \times 10^{-6}$. Similarly, the axial strain was also found to be tensile with an approximately constant magnitude of $1000 \times 10^{-6}$ along the cylinder bridge. Conversely, the radial strain component was compressive with 
increasing magnitude from approximately $100 \times 10^{-6}$ near the top of the cylinder bridge to $300 \times 10^{-6}$ at a depth of approximately $80 \mathrm{~mm}$ within the cylinder. Strain profiles could not be plotted for the entire cylinder depth in the TSR condition, however, due to inability to accommodate the component in the equipment.

In order to observe the influence of heat treatment on residual strain, strain measurements were also carried out along the cylinder bridge of a $\mathrm{T} 7$ heat treated engine block. The resulting strain profiles are shown in Figure 57.

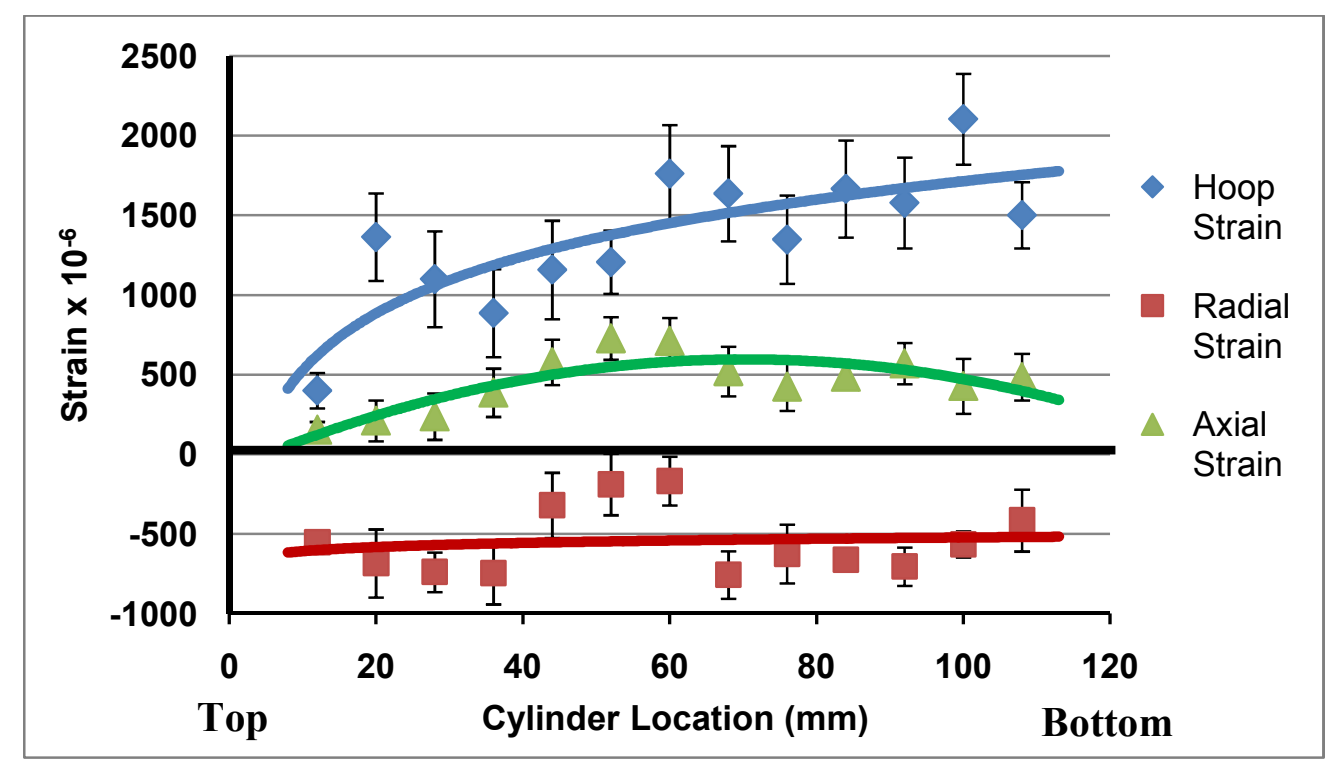

Figure 57: Residual strain profiles along the aluminum cylinder bridge in the $T 7$ condition.

The results in Figure 57 suggest that the hoop strain was tensile with an increasing magnitude from approximately $500 \times 10^{-6}$ near the top of the cylinder to $1800 \times 10^{-6}$ near the bottom. The radial strain on the other hand was compressive with a relatively constant $500 \times 10^{-6}$ along the cylinder. Finally, the axial strain component was slightly tensile at the top of the cylinder and increased to approximately $600 \times 10^{-6}$ at a cylinder depth of approximately $70 \mathrm{~mm}$. The axial strain subsequently decreased to approximately $400 \times 10^{-6}$ near the bottom of the cylinder.

Following the analysis of the T7 heat treated engine block, strain measurements were performed on a service tested engine block to observe the evolution of the residual stress when exposed to the engine operating conditions. The resulting strain profiles along the cylinder bridge of a service tested engine block are shown in Figure 58. 
The strain profiles for the service tested engine block suggest that the hoop strain remained tensile along the cylinder following service testing with a magnitude of approximately $100 \times 10^{-6}$ at the top of the cylinder and $1800 \times 10^{-6}$ at the bottom. The radial strain, on the other hand, was tensile at the top with a magnitude approaching $300 \times 10^{-6}$ and gradually became compressive with increasing cylinder depth, reaching a magnitude of approximately $800 \times 10^{-6}$ at the bottom of the cylinder. The axial component was tensile at the top of the cylinder with a magnitude of $400 \times 10^{-6}$, which increased to approximately $700 \times 10^{-6}$ at a cylinder depth of approximately $70 \mathrm{~mm}$. The axial strain subsequently decreased to approximately $500 \times 10^{-6}$ as the bottom of the cylinder was approached.

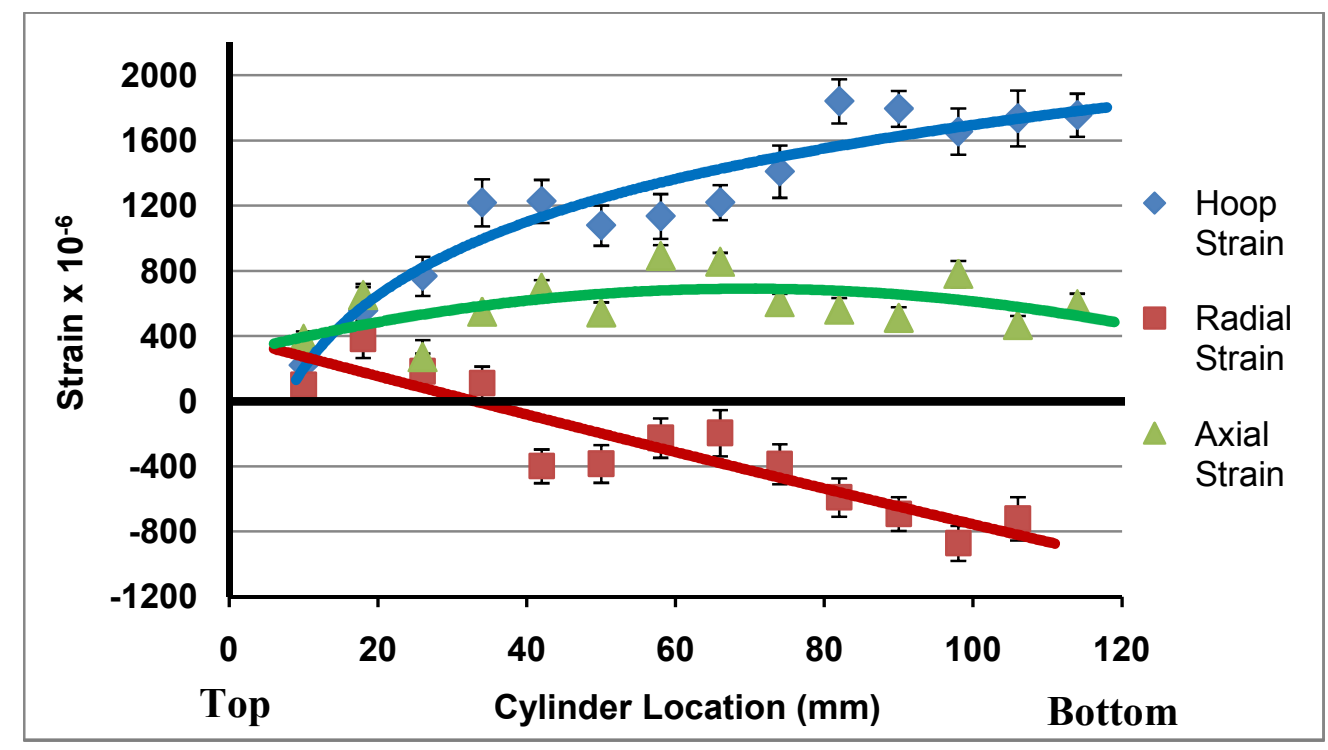

Figure 58: Residual strain profiles along the aluminum cylinder bridge in the service tested condition.

Analysis of the strain profiles for the TSR, T7 heat treated and service tested engine blocks revealed a relatively large difference in strain magnitude between the hoop, radial and axial components. This indicates that the hoop orientation was largely affected by the gray cast iron liners acting as constraints to the free contraction of aluminum during solidification and quenching (after heat treatment). Furthermore, the large tensile strain in the axial component also indicates restriction to free contraction during solidification. This restriction was likely caused by the aluminum solidifying around the iron liner in the axial cylinder direction. The other possible cause of the large tensile axial strain was the non-uniform cooling rate which resulted in the bottom of the cylinder solidifying faster than the top. The solid section at the bottom of the cylinder may have contributed to the restriction to free contraction of the remaining liquid 
aluminum in the cylinder. Conversely, the radial component was influenced to a lesser extent by the liners as evidenced by the smaller strain magnitudes along the cylinder bridge for all treatment conditions.

The direct comparison between the strain profiles in the TSR and T7 heat treated engine blocks suggested that heat treatment relieved residual hoop strain more effectively near the top of the interbore region. Although comparisons could only be made up to a cylinder depth of $80 \mathrm{~mm}$, the hoop strain profiles for both the TSR and T7 conditions appear to become approximately equal as the bottom of the cylinder is approached. The radial orientation, on the other hand, had a slightly more compressive strain magnitude following heat treatment while the axial strain was reduced by approximately $50 \%$ compared to that observed in the TSR engine block with the top of the cylinder experiencing the most significant strain relief.

Analysis of the service tested engine block gave similar strain profiles compared to the $\mathrm{T} 7$ heat treated engine block. For the hoop orientation, the strain profiles for both the T7 heat treated and service tested conditions showed a region of low tensile strain near the top of the cylinder, which increased gradually towards the bottom of the cylinder. Service testing, however, resulted in an approximately $300 \times 10^{-6}$ strain relief at the top of the cylinder, as compared to the $\mathrm{T} 7$ heat treated engine block, while the strain level approaching the bottom of the cylinder was approximately equal to that observed in the TSR and T7 conditions. Similarly, strain relief in the radial orientation also occurred near the top of the cylinder with the bottom of the cylinder having a strain level approximately equal to that of the TSR and T7 heat treated engine blocks. The axial component, on the other hand did not change significantly in the service tested condition compared to the $\mathrm{T} 7$ heat treated condition.

Comparison of the strain profiles for the aluminum interbore regions in the three analyzed conditions illustrate that relief of strain generally occurs more readily near the top of the cylinder during elevated temperature exposure, such as heat treatment and service testing. The top of the cylinder corresponds to the region of coarse microstructure within the cylinder as was discussed in Sections 4.2.1 and 4.2.2. Therefore, the results indicate that microstructural refinement reduces the susceptibility of strain relief at elevated temperature. The reasons for these trends are discussed further in Section 4.3.2. 


\subsubsection{Gray Cast Iron Cylinder Liners}

In order to fully assess the state of strain in the interbore regions of the engine block, neutron diffraction was also carried out to measure the strain in the gray cast iron cylinder liners. The strain profiles along the gray iron liner in cylinder 6 for the engine block in the TSR condition are shown in Figure 59. Although strain mapping was completed for the axial and radial orientations, time constraints prevented detailed strain mapping in the hoop orientation of the cylinder liners in the TSR condition.

The strain profiles for the gray iron liners in the TSR condition suggest high tensile strains in the radial direction with magnitudes ranging between 1200 and $1300 \times 10^{-6}$. The axial strain was also found to be tensile with a decreasing magnitude from approximately $450 \times 10^{-6}$ at the top of the cylinder to $250 \times 10^{-6}$ at a cylinder depth of $80 \mathrm{~mm}$. Finally, the hoop strain, measured only at the top of the cylinder, was tensile with a magnitude of approximately $650 \times 10^{-6}$.

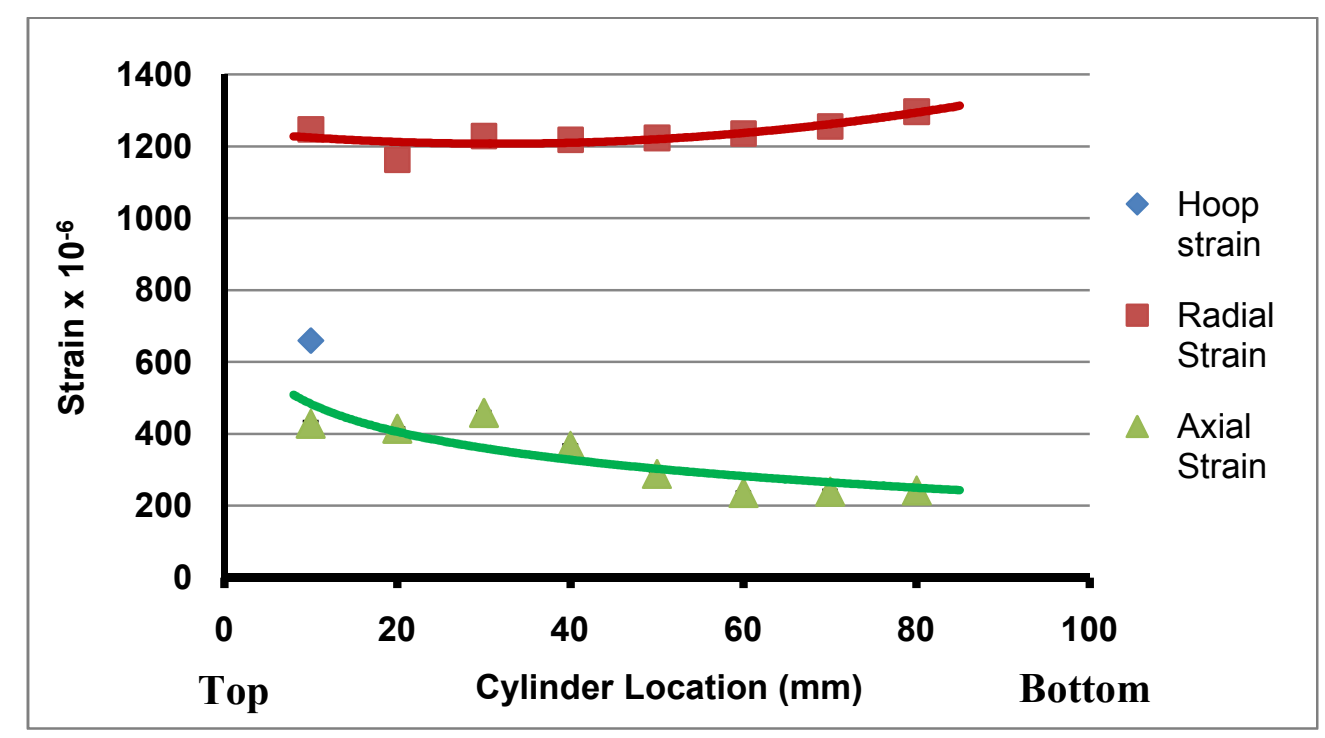

Figure 59: Residual strain profiles along the gray iron cylinder liners in the TSR condition.

Strain profiles were also generated along the gray iron cylinder liners for the T7 heat treated engine block (Figure 60). In contrast to the aluminum section of the cylinder bridge for the T7 condition, the hoop strain in the iron liners was slightly tensile at the top of the cylinder and gradually became compressive at the bottom. The radial strain component in the iron liners also had a strain profile that was opposite to that observed in the aluminum interbore region with a tensile strain magnitude of approximately $300 \times 10^{-6}$. Finally, the axial component of the strain 
had the largest tensile strain magnitude in the cast iron liners for the T7 engine condition. This strain also decreased in magnitude from approximately $800 \times 10^{-6}$ at the top of the cylinder to $600 \times 10^{-6}$ at the bottom.

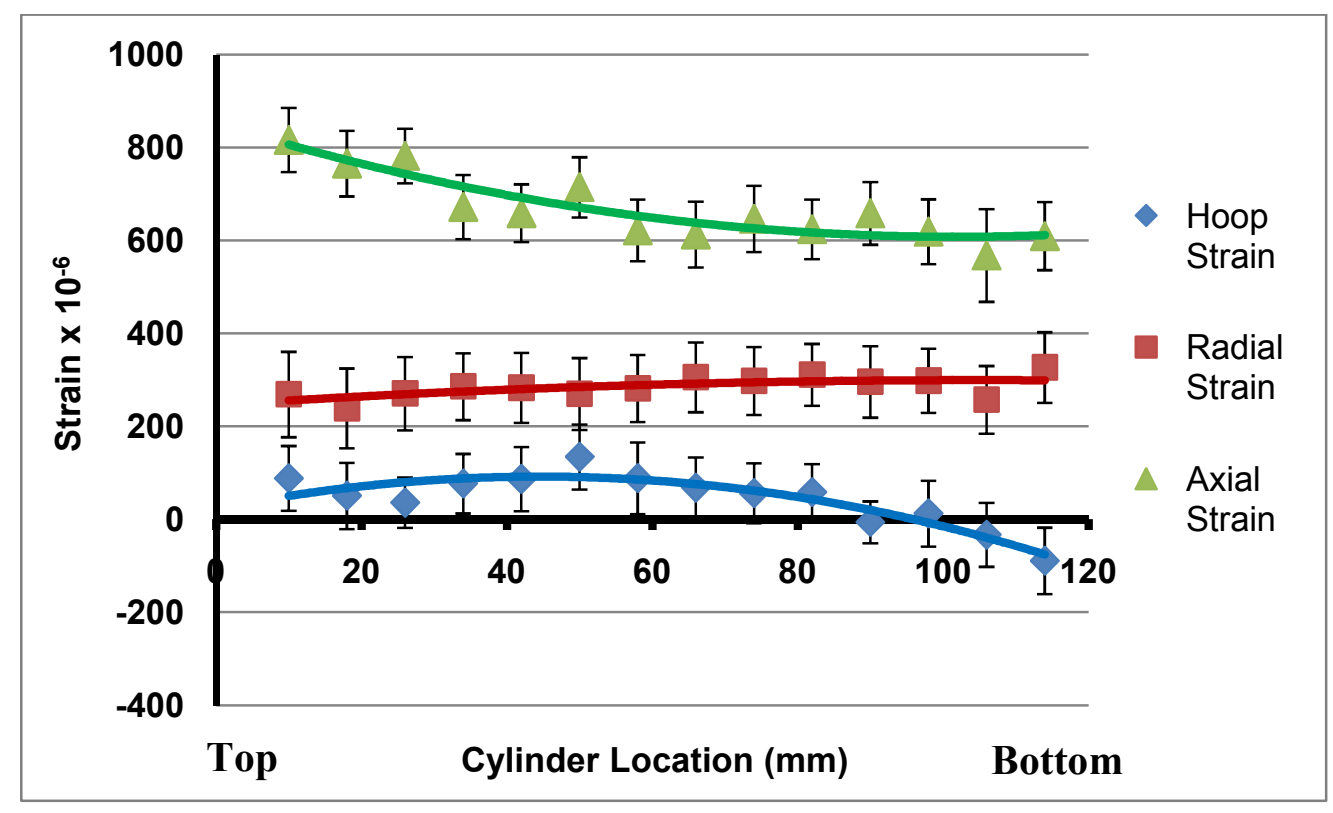

Figure 60: Residual strain profiles along the gray iron cylinder liners in the T7 condition.

Finally, strain profiles were generated for the gray iron cylinder liners for the service tested engine block. The resulting strain profiles are shown in Figure 61. Strain measurements along the gray iron cylinder liners in the hoop, radial and axial orientations for the service tested engine block revealed that the strains were compressive in all orientations. The hoop strain component was compressive at the top of the cylinder with a magnitude of approximately $800 \times 10^{-6}$, which subsequently decreased to $150 \times 10^{-6}$ at the bottom. The radial strain component had a magnitude of approximately zero at the top of the cylinder and gradually became compressive, up to a maximum compressive strain magnitude of $250 \times 10^{-6}$ at the bottom. Finally, the axial strain component was compressive throughout the cylinder length with strain magnitudes ranging between 800 and $1000 \times 10^{-6}$.

The comparison of the strain along the gray iron liners in the TSR and T7 conditions revealed that the strain magnitude in the radial direction was reduced significantly following T7 heat treatment, while the axial strain slightly increased. Service testing and machining of the cylinder bores to service specifications also caused a significant relief of the tensile strains in the cylinder 
liners, resulting in compressive strain profiles in each orientation. An important observation was that the top of the cylinder liner relieved tensile strain more readily in the hoop orientation following machining and service testing, which corresponds to the trends observed for the aluminum cylinder bridge. This was indicated by the large difference in hoop strain magnitude between the $\mathrm{T} 7$ heat treated and service tested engine blocks at the top of the cylinder and the approximately equal strain at the bottom. Conversely, the radial and axial strain components showed a more uniform relief of tensile residual strain following machining and service testing.

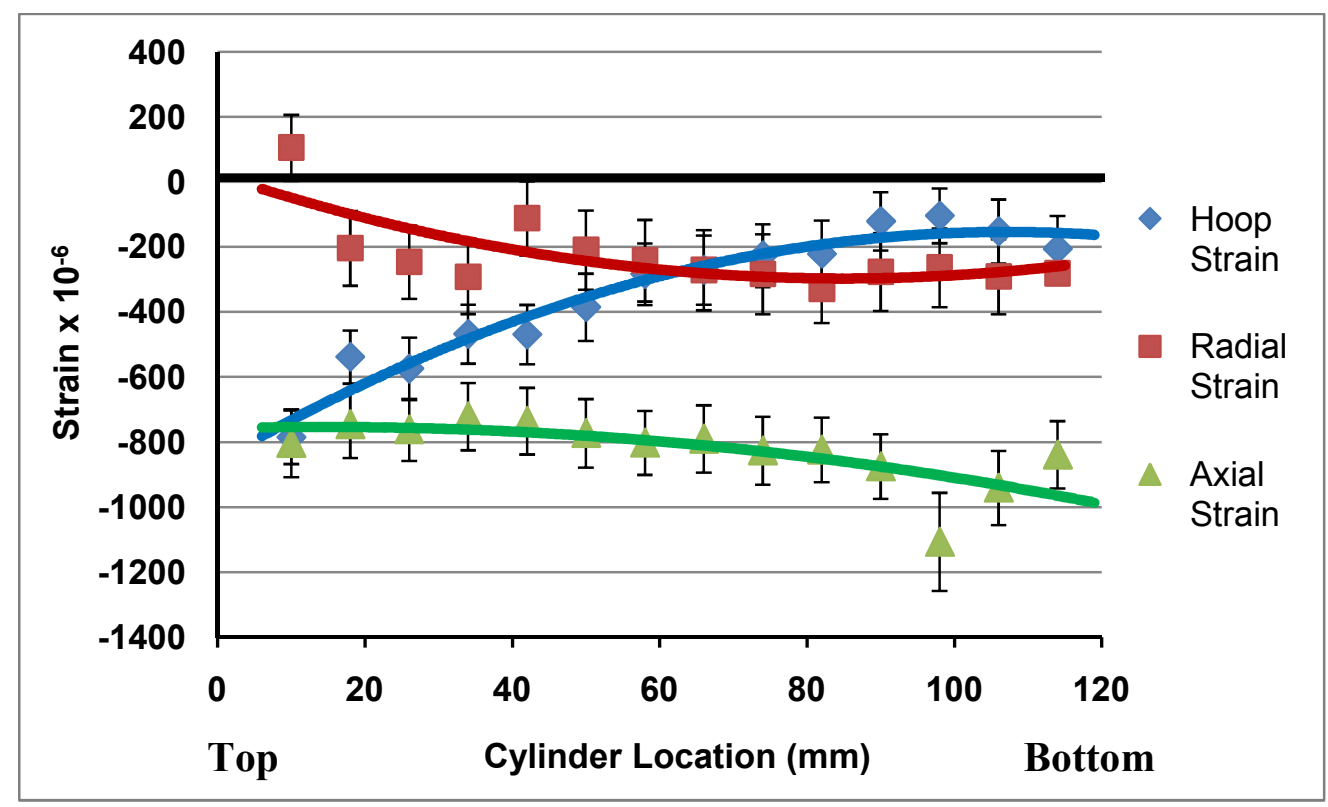

Figure 61: Residual strain profiles along the gray iron cylinder liners in the service tested condition.

Although machining of the cylinder bores prior to service testing likely relieved most of the strain causing compressive residual strain profiles in the cylinder liners, the non-uniform strain profile was likely not caused by machining. Unlike aluminum, the gray iron liners have a relatively uniform microstructure from top to bottom of the cylinder, which should result in constant strain relief along the cylinder. Therefore, the interaction with the aluminum interbore region likely caused the strain to be relieved more readily at the top of the cylinder liner in the service tested engine block to accommodate and partially equilibrate the residual strain in the neighbouring aluminum cylinder bridge.

It is important to note that although there are somewhat contrasting trends between the strain profiles of the aluminum cylinder bridge and the cylinder liners, the strain magnitudes observed 
in aluminum and the gray iron liners do not balance, specifically for the TSR and T7 heat treated engine blocks. This is likely because of the complex geometry of the engine block, which caused equilibration of strain to be accomplished by compressive strains in regions adjacent to the interbore region of the engine block. Conversely, in the service tested engine block, the highly compressive strain profiles along the cylinder liners suggest that equilibration occurred to a greater extent between the aluminum cylinder bridge and the neighbouring gray iron liners.

\subsubsection{Residual Stress Mapping in the Aluminum Cylinder Bridge}

Residual stress profiles were generated along the aluminum cylinder bridge for each analyzed condition by applying generalized Hooke's law to the strain profiles discussed in Section 4.4.1.1. The residual stress profiles in the hoop, radial and axial orientations for the engine block in the TSR condition are shown in Figure 62.

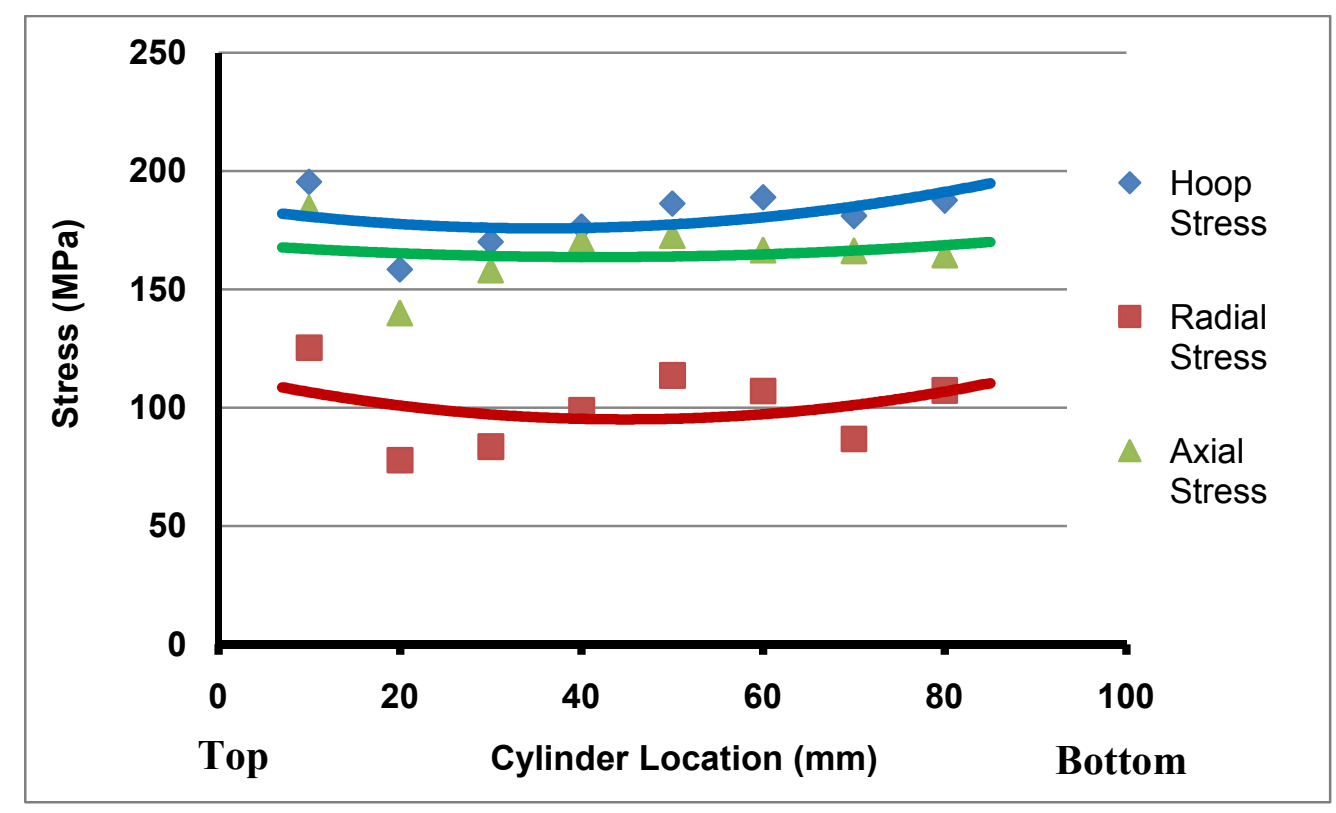

Figure 62: Residual stress profiles along the aluminum cylinder bridge in the TSR condition.

The resulting residual stress profiles indicate that the stress in the hoop, radial and axial orientations were tensile with an approximately constant magnitude of approximately 180, 100 and $160 \mathrm{MPa}$, respectively. Similarly to the strain profiles for the aluminum cylinder bridge, the large tensile residual stresses in the hoop orientation suggest that the presence of the iron cylinder liner caused the largest constraint to the free contraction of the aluminum alloy during 
solidification to be in the hoop direction. Residual stress maps were also generated along the aluminum cylinder bridge for the T7 heat treated engine block (Figure 63).

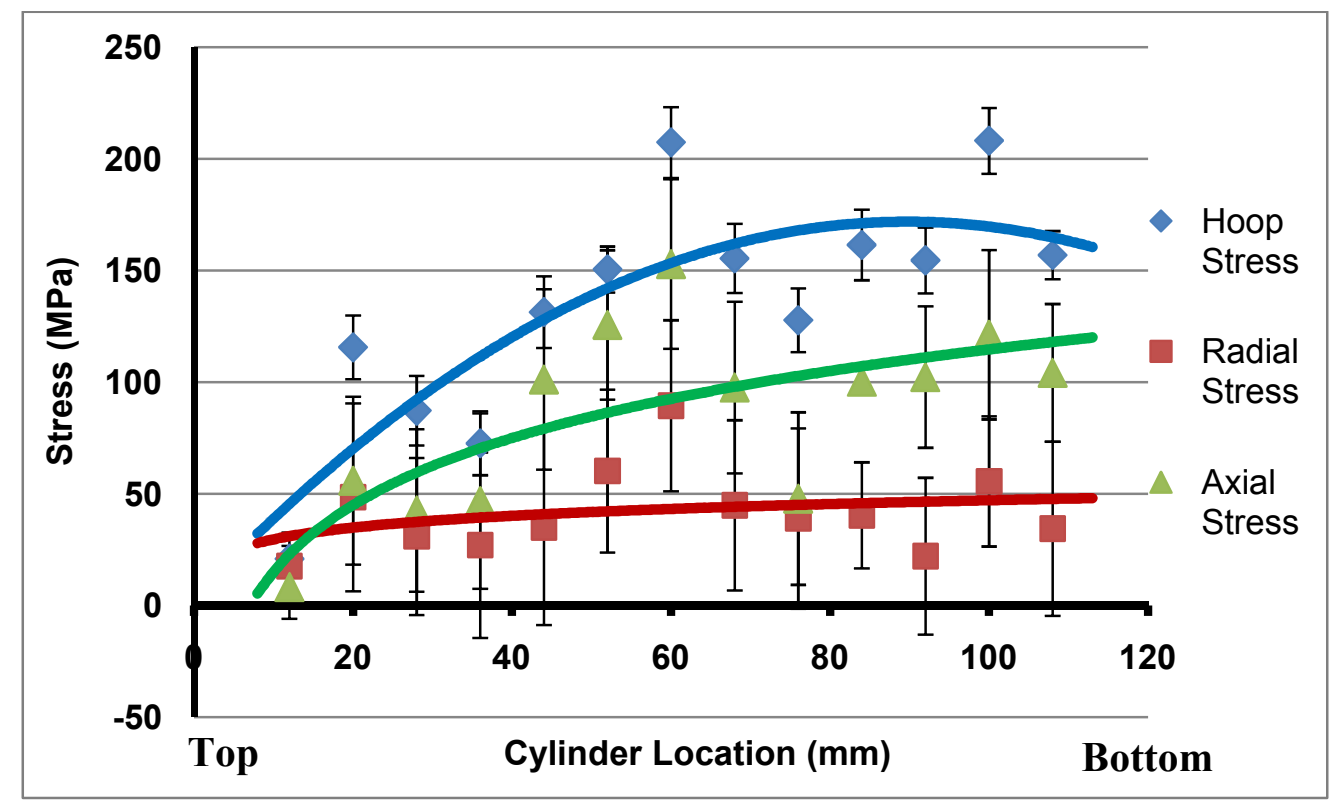

Figure 63: Residual stress profiles along the aluminum cylinder bridge in the $T 7$ condition.

The residual stress profiles for the hoop, radial and axial components were tensile along the aluminum interbore. Similar to the residual strain profiles in aluminum, the hoop stress had the highest magnitude which increased from approximately $40 \mathrm{MPa}$ at the top of the cylinder to approximately $170 \mathrm{MPa}$ at the bottom. The axial component had a similar stress profile to the hoop component with the stress increasing from approximately $5 \mathrm{MPa}$ at the top of the cylinder to $130 \mathrm{MPa}$ at the bottom. The radial stress component had a stress magnitude increasing from approximately $40 \mathrm{MPa}$ at the top of the cylinder to $50 \mathrm{MPa}$ at the bottom. By comparing the stress and strain profiles, it can be stated that stress profiles for the radial and axial stress components were largly influenced by the hoop component since the tensile strain was significantly larger in the hoop direction and the calculation of stress with Hooke's Law involves the use of all measured strain components.

Similar to the TSR and T7 heat treated conditions, residual stress profiles were also generated at the cylinder bridge for a service (dyno) tested engine block. The resulting stress maps are shown in Figure 64. 


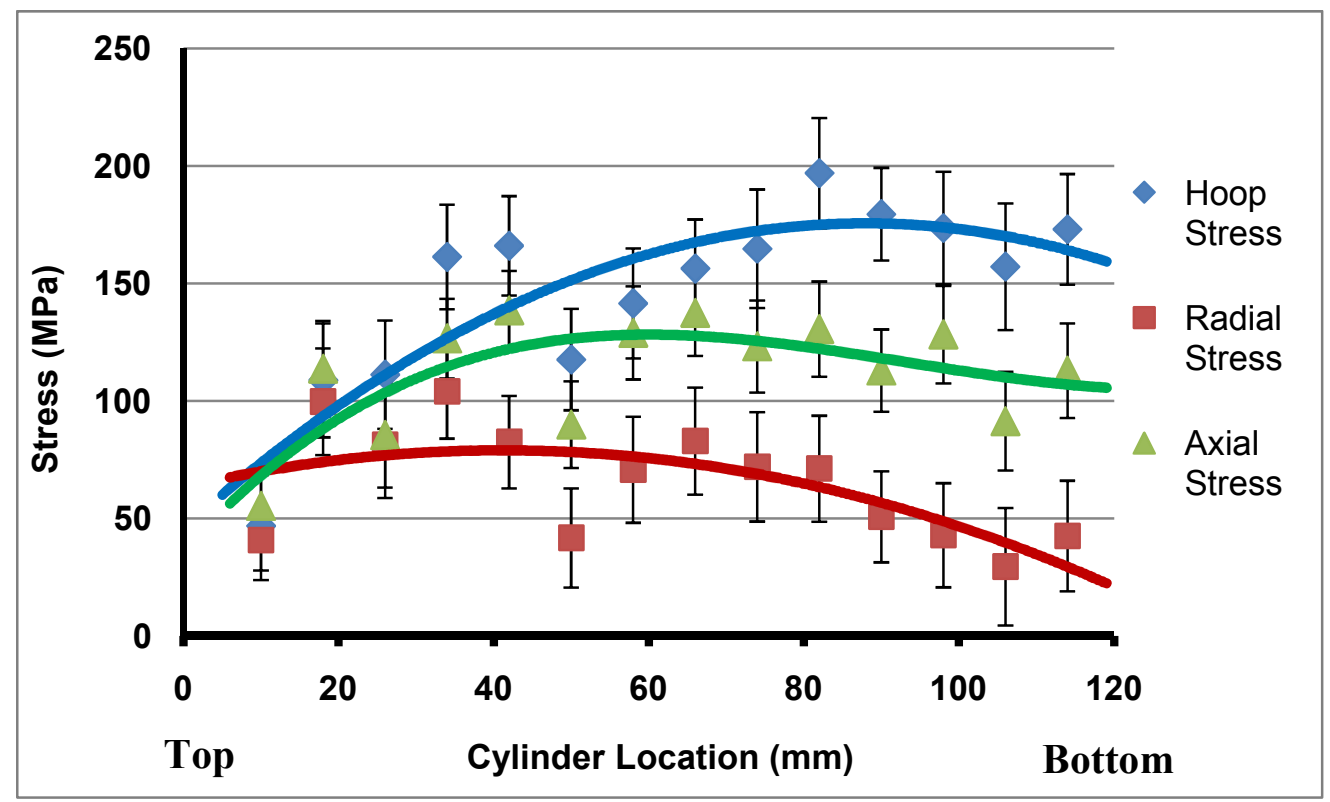

Figure 64: Residual stress profiles along the aluminum cylinder bridge for the engine block in the service tested condition.

The residual stress profiles obtained for the service tested engine block showed similar trends to the T7 heat treated engine block. The hoop stress component was again tensile with a magnitude of $50 \mathrm{MPa}$ at the top of the cylinder, which increased gradually to $170 \mathrm{MPa}$ as the bottom of the cylinder was approached. The axial stress component was also tensile with the stress increasing from $50 \mathrm{MPa}$ at the top of the cylinder to approximately $125 \mathrm{MPa}$ at a depth of $60 \mathrm{~mm}$ within cylinder. This residual stress subsequently decreased to $110 \mathrm{MPa}$ at the bottom of the cylinder bridge. Finally, the radial stress component was tensile with a gradually decreasing stress value from $60 \mathrm{MPa}$ at the top of the cylinder to $40 \mathrm{MPa}$ at the bottom.

The residual stress profiles for the TSR, T7 heat treated and service tested engine blocks were compared in order to determine the influence of heat treatment and exposure to service conditions on residual stress level. The results suggest that $\mathrm{T} 7$ heat treatment led to a $50 \%$ reduction in residual stress in the radial orientation for all locations along the interbore region, compared to the TSR condition. Similarly, T7 heat treatment also significantly reduced the axial stress. However, the stress reduction was more pronounced at the top of the cylinder rather than at the bottom. In the hoop orientation, heat treatment caused a large reduction in residual stress at the top of the cylinder, but did not affect the residual stress magnitude near the bottom of the cylinder. 
Service testing, however, did not significantly influence the residual stress levels in the hoop and axial components while the radial stress increased slightly near the top of the cylinder. This result contrasts the strain profiles since there was a small strain relief in the hoop and radial orientations at the top of the cylinder bridge following service testing. However, the radial strain component was compressive in the TSR and T7 conditions and relief of this strain during service testing caused the strain to become approximately zero at the top. This increased the calculated radial stress at this cylinder location. Furthermore, the small relief in tensile hoop strain was counteracted by the relief of compressive radial strain, thus causing the calculated hoop stress at the top of the cylinder to be approximately equal to that in the $\mathrm{T} 7$ heat treated engine block.

Relief of residual strain and stress has been found to occur when the residual stress magnitude exceeds the yield strength of the material $[49,50,64]$. In this study, the yield strength at ambient temperature in the cylinder bridge was determined as approximately $195 \mathrm{MPa}$ in the TSR condition and between 215 and $220 \mathrm{MPa}$ in the heat treated and service tested conditions. Although the yield strength appears to be higher than the residual stress level, the engine blocks were exposed to elevated temperature during heat treatment and service testing, causing a significant reduction in the yield strength. The significant relief of residual stress, therefore, indicates that the yield strength drops below the residual stress level when exposed to elevated temperatures [49].

In addition, the varying levels of stress relief along the cylinder bridge suggests a variation in alloy yield strength along the cylinder. This was likely due to the top of the cylinder being comprised of a coarse dendritic structure with large and clustered secondary phase particles. In contrast, the bottom of the cylinder had a significantly finer and more evenly distributed microstructure. This likely resulted in the bottom of the cylinder having increased YS and UTS, compared to the top. Increased strength at the bottom of the cylinder relative to the top was also indicated by a higher Rockwell hardnesss at the bottom of the cylinder relative to the top. The increased strength at the bottom of the cylinder may have prevented significant stress relief, since in this section the residual stress likely did not exceed the yield strength by a significant amount compared to the top of the cylinder. For this reason, the results indicate that sections of finer microstructure are less susceptible to rapid residual stress relief at elevated temperature. 
Relief of residual stress has been documented to result in plastic deformation $[49,50]$. Therefore, cylinder bore distortion may have occurred due to the relief of tensile residual stress at the cylinder bore region. The small change in residual stress in the service tested condition, as compared to the $\mathrm{T} 7$ heat treated condition, correlates well with the small measured distortion (maximum roundness of approximately $45 \mu \mathrm{m}$ ) observed in Section 4.1. Furthermore, although CMM measurements were not performed at the bottom of the cylinder, the negligible change in residual stress at this section following heat treatment and service testing suggests that distortion does not occur at the bottom of the cylinder. Therefore, based on the evolution of the residual stress profiles, the large relief of residual stress following $\mathrm{T} 7$ heat treatment and service testing suggests that the top of the cylinder was most susceptible to permanent dimensional distortion when exposed to operating conditions.

\section{Section Summary}

Residual strain measurements and subsequent stress calculations showed that large tensile residual stresses formed during solidification with the hoop orientation having a stress magnitude approaching the ambient temperature yield strength of the 319 aluminum alloy. Similar strain measurements in the $\mathrm{T} 7$ heat treated and service tested engine blocks revealed that a significant strain relief occurred near the top of the aluminum cylinder bridge. The top of the aluminum cylinder bridge corresponds to a region of coarser microstructure, indicating that stress relief and therefore cylinder distortion likely occurs more readily in regions of coarse microstructure.

The gray cast iron cylinder liners also experienced a significant relief of tensile residual strains in the hoop, radial and axial components following heat treatment and service testing. Moreover, the strains in the gray iron liners for the service tested engine block were compressive in all orientations, which was likely due to the machining of the cylinder bores to service specifications prior to dyno testing. However, the tensile hoop strain at the top of the cylinder liner was relieved more readily than the rest of the cylinder as indicated by a larger compressive strain than at the bottom of the cylinder. This result suggests that the interaction between the aluminum cylinder bridge and the iron liners likely led to non-uniform stress relief in the liners. 


\section{Chapter 5: Conclusions}

This research was conducted with a view to relating the microstructure, mechanical properties and measured residual stress level, thus determine the cause of permanent cylinder bore distortion. The following are the conclusions from this study:

\section{Cylinder Distortion}

1. Measurement of the cylinder profiles for each cylinder in the service tested engine block revealed that the maximum radial deviation from the nominal diameter was between 35 and $45 \mu \mathrm{m}$. Leakage of the combustion chamber was found to occur for a minimum distortion of approximately $40 \mu \mathrm{m}$. Therefore, the analyzed service tested engine block is susceptible to loss of engine operating efficiency.

\section{Microstructure}

1. The bottom section of the aluminum cylinder bridge had finer dendrites and a smaller SDAS than the top, due to a variation in cooling rate from top to bottom during solidification. The faster cooling rates at the bottom of the cylinder also caused a refinement and modification in morphology of the $\mathrm{Al}_{2} \mathrm{Cu}, \mathrm{Al}_{17} \mathrm{Fe}_{3.2} \mathrm{Mn}_{0.8} \mathrm{Si}_{2}$ and eutectic silicon secondary phase particles.

2. Microstructural analysis of the gray cast iron cylinder liners determined that the microstructure did not change from top to bottom of the cylinder since the liners were pre-manufactured and subsequently placed in the mould prior to pouring of molten aluminum alloy.

3. Solution heat treatment did not cause significant dissolution of secondary phases, although subsequent aging led to the precipitation of fine $\theta-\mathrm{Al}_{2} \mathrm{Cu}$ platelets within the aluminum dendrites.

4. The stable $\theta-\mathrm{Al}_{2} \mathrm{Cu}$ precipitates were observed in the aluminum dendrites. Thus, the $\theta$ " or $\theta^{\prime}$ phases did not precipitate in the dendrites. This suggests that cylinder bore distortion was not caused by the thermal growth mechanism. 


\section{Mechanical Properties}

1. Hardness of the aluminum dendrites and the secondary phase particles did not change significantly from top to bottom and after heat treatment and service testing.

2. Rockwell hardness was found to increase at the bottom of the cylinder relative to the top which was attributed to the finer and more uniform microstructure at the bottom of the cylinder (matrix grains and intermetallics).

3. Tensile testing at the cylinder bridge revealed that the yield and ultimate tensile strength increased following heat treatment. Service testing did not cause any further strengthening effect. The increased strength was attributed to the formation of fine $\theta-\mathrm{Al}_{2} \mathrm{Cu}$ within the aluminum dendrites following aging.

\section{Residual Stress/Strain Mapping}

1. Strain measurements and subsequent residual stress calculations in the aluminum interbore region, revealed that the hoop, radial and axial stress components were tensile in the TSR condition with residual stress reaching 180,100 and $160 \mathrm{MPa}$, respectively

2. Heat treatment to a T7 temper resulted in a significant relief in hoop and axial stress at the top of the aluminum cylinder bridge with residual stress decreasing to 40 and $5 \mathrm{MPa}$, respectively. Service testing did not significantly change the magnitude of the residual stresses. However, strain measurements confirmed that there was a small relief in tensile hoop strain and compressive radial strain at the top of the cylinder. The small change in residual stress following service testing is in agreement with the small amount of distortion observed using the co-ordinate measuring machine.

3. Hoop, radial and axial stress components changed by a significantly smaller amount at the bottom of the aluminum cylinder bridge compared to the top following heat treatment and service testing. 
4. Residual stress measurements along the gray cast iron liners revealed a large relief of tensile residual stress following service testing. The resulting compressive stresses were likely caused by machining of the cylinder bores. However, the larger compressive strain in the hoop direction at the top of the cylinder indicates that the top of the cylinder relieved stress more readily in the iron liners due to the interaction with the aluminum cylinder bridge.

5. The large relief in residual stress at the top of the aluminum cylinder bridge indicated that regions of coarser microstructure relieve stress more readily and as such were more prone permanent dimensional distortion. Moreover, the larger relief in hoop stress at the top of the gray iron cylinder liners further indicated that the top of the cylinder was prone to distortion due to the relief of hoop stress. 


\section{Chapter 6: Recommendations for Future Work}

1. Microstructural analysis and residual stress measurements of as-cast (pre-TSR) engine blocks.

2. Microstructural analysis and measurement of residual stress of a service tested engine block with heavily distorted cylinder bores.

3. Variation of quench rate following solution heat treatment $\left(20,45,75,100{ }^{\circ} \mathrm{C} / \mathrm{min}\right)$ to observe the influence of quench rate on microstructure and residual stress.

4. Variation of solution heat treatment temperature between $480{ }^{\circ} \mathrm{C}$ to $540{ }^{\circ} \mathrm{C}$ to optimize the dissolution of equilibrium secondary phases, which thereby increases strength following aging.

5. Variation of aging treatment schedule resulting in $\theta^{\prime}$ rather than $\theta$ in the $\mathrm{T} 7$ condition to increase the yield strength which would reduce distortion susceptibility from relief of residual stress.

6. Model externally applied stress on the cylinder bores due to the expansion of the air/fuel mixture during combustion. Relate externally applied stress and measured residual stress to the tensile properties of 319 aluminum alloy at the engine operating temperature.

7. Modelling of various solution heat treatment schedules as well as cooling rates with a view on the impact on microstructure and mechanical properties.

8. Tensile testing at the engine operating temperature $\left(\sim 180{ }^{\circ} \mathrm{C}\right)$ to relate residual stress level to the yield strength of the 319 aluminum alloy in operating conditions. 


\section{Back Matter}

\section{Appendix A: Calculations Pertaining to Confidence Limits of Estimated Mean Values}

Experiments of evaluation were used to estimate the population mean $(\mu)$ pertaining to size and amount of microstructural constituents as well as the mechanical properties of the engine blocks in each treatment condition. In order to observe if heat treatment and service testing significantly influenced the microstructure and mechanical properties of the engine blocks, the $95 \%$ upper and lower confidence limits of the population mean were determined. Since the population standard deviation $(\sigma)$ was unknown during experimentation and the sample size was relatively small $(<\sim 30)$, the confidence limits were determined using the relationships shown in Equations A1 and $\mathrm{A} 2$.

$$
\begin{aligned}
& \mu_{\text {lower }}=\bar{x}-\left(\frac{S t_{\alpha / 2 ; v}}{\sqrt{N}}\right) \\
& \mu_{\text {upper }}=\bar{x}+\left(\frac{S t_{\alpha / 2 ; v}}{\sqrt{N}}\right)
\end{aligned}
$$

Where,

$\mathrm{N}=$ Sample size

$\bar{x}=$ Sample mean

$\mathrm{S}=$ Sample standard deviation

$t_{\alpha / 2 ; v}=$ Student "t" distribution with significance level, $\alpha$, and $v=\mathrm{N}-1$ degrees of freedom

Select results from the calculations of the confidence limits for each measured quantity in this study are shown in Tables A1 through A11. 
Table A1: Calculated 95\% confidence intervals for SDAS measurements in cylinder (2-4) bridge. Calculations performed with $\mathbf{N}=\mathbf{2 5}$.

\begin{tabular}{|c|c|c|c|}
\hline Description of Sample & $\begin{array}{c}\text { SDAS Sample Mean } \\
(\mu \mathrm{m})\end{array}$ & $\begin{array}{c}\text { SDAS Sample Standard } \\
\text { Deviation }(\mu \mathrm{m})\end{array}$ & $\begin{array}{c}\text { 95\% Confidence Limits } \\
(\mu \mathrm{m})\end{array}$ \\
\hline Cylinder (2-4) TSR Top & 37.7 & 6.4 & $\begin{array}{l}\text { Upper: } 40.3 \\
\text { Lower: } 35.0\end{array}$ \\
\hline Cylinder (2-4) T7 Top & 34.4 & 5.9 & $\begin{array}{l}\text { Upper: } 36.8 \\
\text { Lower: } 32.0\end{array}$ \\
\hline Cylinder (2-4) Dyno Top & 36.1 & 6.6 & $\begin{array}{l}\text { Upper: } 38.9 \\
\text { Lower: } 33.4 \\
\end{array}$ \\
\hline $\begin{array}{c}\text { Cylinder (2-4) TSR Upper } \\
\text { Middle }\end{array}$ & 25.9 & 3.4 & $\begin{array}{l}\text { Upper: } 27.3 \\
\text { Lower: } 24.5\end{array}$ \\
\hline $\begin{array}{c}\text { Cylinder (2-4) T7 Upper } \\
\text { Middle }\end{array}$ & 25.0 & 4.1 & $\begin{array}{l}\text { Upper: } 26.7 \\
\text { Lower: } 23.3\end{array}$ \\
\hline $\begin{array}{l}\text { Cylinder (2-4) Dyno } \\
\text { Upper Middle }\end{array}$ & 26.2 & 5.4 & $\begin{array}{l}\text { Upper: } 28.4 \\
\text { Lower: } 24.0 \\
\end{array}$ \\
\hline $\begin{array}{c}\text { Cylinder (2-4) TSR Lower } \\
\text { Middle }\end{array}$ & 19.0 & 3.2 & $\begin{array}{l}\text { Upper: } 20.4 \\
\text { Lower: } 17.7\end{array}$ \\
\hline $\begin{array}{c}\text { Cylinder (2-4) T7 Lower } \\
\text { Middle }\end{array}$ & 19.1 & 3.1 & $\begin{array}{l}\text { Upper: } 20.4 \\
\text { Lower: } 17.8\end{array}$ \\
\hline $\begin{array}{l}\text { Cylinder (2-4) Dyno } \\
\text { Lower Middle }\end{array}$ & 20.2 & 3.2 & $\begin{array}{l}\text { Upper: } 21.6 \\
\text { Lower: } 18.9\end{array}$ \\
\hline $\begin{array}{c}\text { Cylinder (2-4) TSR } \\
\text { Bottom }\end{array}$ & 19.7 & 3.1 & $\begin{array}{l}\text { Upper: } 21.0 \\
\text { Lower: } 19.3\end{array}$ \\
\hline Cylinder (2-4) T7 Bottom & 18.0 & 2.8 & $\begin{array}{l}\text { Upper: } 19.1 \\
\text { Lower: } 16.8 \\
\end{array}$ \\
\hline $\begin{array}{c}\text { Cylinder (2-4) Dyno } \\
\text { Bottom }\end{array}$ & 19.0 & 3.2 & $\begin{array}{l}\text { Upper: } 20.3 \\
\text { Lower: } 17.7\end{array}$ \\
\hline
\end{tabular}

Table A2: Calculated 95\% confidence intervals for $\mathrm{Al}_{2} \mathrm{Cu}$ volume fraction measurements in cylinder (2-4) bridge. Calculations performed with $\mathrm{N}=17$ for the top of the cylinder and $\mathrm{N}=\mathbf{2 5}$ for the bottom

\begin{tabular}{|c|c|c|c|}
\hline Description of Sample & $\begin{array}{c}\mathrm{Al}_{2} \mathrm{Cu} \text { Volume Fraction } \\
\text { Sample Mean (\%) }\end{array}$ & $\begin{array}{c}\mathrm{Al}_{2} \mathrm{Cu} \text { Volume Fraction } \\
\text { Sample Standard Deviation } \\
(\%)\end{array}$ & $\begin{array}{l}\text { 95\% Confidence } \\
\text { Limits (\%) }\end{array}$ \\
\hline Cylinder (2-4) TSR Top & 1.1 & 0.9 & $\begin{array}{l}\text { Upper: } 1.58 \\
\text { Lower: } 0.62\end{array}$ \\
\hline Cylinder (2-4) T7 Top & 1.0 & 0.6 & $\begin{array}{l}\text { Upper: } 1.28 \\
\text { Lower: } 0.63 \\
\end{array}$ \\
\hline Cylinder (2-4) Dyno Top & 1.2 & 1.1 & $\begin{array}{l}\text { Upper: } 1.78 \\
\text { Lower: } 0.57\end{array}$ \\
\hline $\begin{array}{c}\text { Cylinder (2-4) TSR } \\
\text { Bottom }\end{array}$ & 0.3 & 0.2 & $\begin{array}{c}\text { Upper: } 0.4 \\
\text { Lower: } 0.19\end{array}$ \\
\hline Cylinder (2-4) T7 Bottom & 0.3 & 0.2 & $\begin{array}{l}\text { Upper: } 0.32 \\
\text { Lower: } 0.18\end{array}$ \\
\hline $\begin{array}{c}\text { Cylinder (2-4) Dyno } \\
\text { Bottom }\end{array}$ & 0.3 & 0.2 & $\begin{array}{l}\text { Upper: } 0.38 \\
\text { Lower: } 0.25\end{array}$ \\
\hline
\end{tabular}


Table A3: Calculated 95\% confidence intervals for $\mathrm{Al}_{17} \mathrm{Fe}_{3.2} \mathrm{Mn}_{0.8} \mathrm{Si}_{2}$ volume fraction measurements in cylinder (2-4) bridge. Calculations performed with $\mathrm{N}=16$ for the top of the cylinder and $\mathrm{N}=25$ for the bottom.

\begin{tabular}{|c|c|c|c|}
\hline Description of Sample & $\begin{array}{c}\mathrm{Al}_{17} \mathrm{Fe}_{3.2} \mathrm{Mn}_{0.8} \mathrm{Si}_{2} \text { Volume } \\
\text { Fraction Sample Mean (\%) }\end{array}$ & $\begin{array}{c}\mathrm{Al}_{17} \mathrm{Fe}_{3.2} \mathrm{Mn}_{0.8} \mathrm{Si}_{2} \text { Volume } \\
\text { Fraction Sample Standard } \\
\text { Deviation (\%) }\end{array}$ & $\begin{array}{l}\text { 95\% Confidence Limits } \\
\text { (\%) }\end{array}$ \\
\hline Cylinder (2-4) TSR Top & 3.0 & 1.6 & $\begin{array}{l}\text { Upper: } 3.8 \\
\text { Lower: } 2.2\end{array}$ \\
\hline Cylinder (2-4) T7 Top & 2.4 & 1.3 & $\begin{array}{l}\text { Upper: } 3.1 \\
\text { Lower: } 1.7\end{array}$ \\
\hline Cylinder (2-4) Dyno Top & 1.8 & 0.9 & $\begin{array}{l}\text { Upper: } 2.2 \\
\text { Lower: } 1.3\end{array}$ \\
\hline Cylinder (2-4) TSR Bottom & 1.8 & 0.4 & $\begin{array}{l}\text { Upper: } 1.9 \\
\text { Lower: } 1.6\end{array}$ \\
\hline Cylinder (2-4) T7 Bottom & 2.0 & 0.3 & $\begin{array}{l}\text { Upper: } 2.1 \\
\text { Lower: } 1.8\end{array}$ \\
\hline Cylinder (2-4) Dyno Bottom & 2.1 & 0.3 & $\begin{array}{l}\text { Upper: } 2.2 \\
\text { Lower: } 2.0\end{array}$ \\
\hline
\end{tabular}

Table A4: Calculated 95\% confidence intervals for eutectic silicon volume fraction measurements in cylinder (2-4) bridge. Calculations performed with $\mathrm{N}=21$.

\begin{tabular}{|c|c|c|c|}
\hline Description of Sample & $\begin{array}{c}\text { Eutectic Si Volume } \\
\text { Fraction Sample Mean } \\
(\%)\end{array}$ & $\begin{array}{c}\text { Eutectic Si Volume Fraction } \\
\text { Sample Standard Deviation } \\
(\%)\end{array}$ & $\begin{array}{c}\text { 95\% Confidence } \\
\text { Limits (\%) }\end{array}$ \\
\hline Cylinder (2-4) TSR Top & 9.5 & 2.0 & $\begin{array}{c}\text { Upper: } 10.4 \\
\text { Lower: } 8.6\end{array}$ \\
\hline Cylinder (2-4) T7 Top & 9.0 & 1.1 & Upper: 9.5 \\
Lower: 8.5
\end{tabular}


Table A5: Calculated 95\% confidence intervals for composition of the aluminum dendrites for cylinder (2-4) bridge. Calculations performed with $\mathrm{N}=10$.

\begin{tabular}{|c|c|c|c|c|}
\hline $\begin{array}{l}\text { Description of } \\
\text { Sample }\end{array}$ & Element & $\begin{array}{l}\text { Concentration } \\
\text { Sample Mean } \\
\text { (wt.\%) }\end{array}$ & $\begin{array}{c}\text { Concentration } \\
\text { Sample Standard } \\
\text { Deviation (wt.\%) }\end{array}$ & $\begin{array}{l}\text { 95\% Confidence } \\
\text { Limits (wt.\%) }\end{array}$ \\
\hline \multirow{3}{*}{$\begin{array}{c}\text { Cylinder (2-4) TSR } \\
\text { Top }\end{array}$} & $\mathrm{Si}$ & 1.6 & 0.1 & $\begin{array}{l}\text { Upper: } 1.7 \\
\text { Lower: } 1.6\end{array}$ \\
\hline & $\mathrm{Cu}$ & 2.5 & 0.5 & $\begin{array}{l}\text { Upper: } 2.8 \\
\text { Lower: } 2.1\end{array}$ \\
\hline & $\mathrm{Mg}$ & 0.7 & 0.04 & $\begin{array}{l}\text { Upper: } 0.71 \\
\text { Lower: } 0.65\end{array}$ \\
\hline \multirow{3}{*}{ Cylinder (2-4) T7 Top } & $\mathrm{Si}$ & 1.6 & 0.06 & $\begin{array}{l}\text { Upper: } 1.66 \\
\text { Lower: } 1.57\end{array}$ \\
\hline & $\mathrm{Cu}$ & 2.6 & 0.6 & $\begin{array}{l}\text { Upper: } 3.04 \\
\text { Lower: } 2.14\end{array}$ \\
\hline & $\mathrm{Mg}$ & 0.6 & 0.1 & $\begin{array}{l}\text { Upper: } 0.7 \\
\text { Lower: } 0.6\end{array}$ \\
\hline \multirow{3}{*}{$\begin{array}{c}\text { Cylinder (2-4) Dyno } \\
\text { Top }\end{array}$} & $\mathrm{Si}$ & 1.8 & 0.2 & $\begin{array}{l}\text { Upper: } 1.9 \\
\text { Lower: } 1.6\end{array}$ \\
\hline & $\mathrm{Cu}$ & 2.5 & 0.6 & $\begin{array}{l}\text { Upper: } 2.9 \\
\text { Lower: } 2.1\end{array}$ \\
\hline & $\mathrm{Mg}$ & 0.6 & 0.1 & $\begin{array}{l}\text { Upper: } 0.7 \\
\text { Lower: } 0.6\end{array}$ \\
\hline \multirow{3}{*}{$\begin{array}{c}\text { Cylinder (2-4) TSR } \\
\text { Bottom }\end{array}$} & $\mathrm{Si}$ & 1.6 & 0.4 & $\begin{array}{l}\text { Upper: } 2.0 \\
\text { Lower: } 1.3\end{array}$ \\
\hline & $\mathrm{Cu}$ & 2.9 & 0.2 & $\begin{array}{l}\text { Upper: } 3.0 \\
\text { Lower: } 2.7\end{array}$ \\
\hline & $\mathrm{Mg}$ & 0.7 & 0.01 & $\begin{array}{l}\text { Upper: } 0.8 \\
\text { Lower: } 0.7\end{array}$ \\
\hline \multirow{3}{*}{$\begin{array}{c}\text { Cylinder (2-4) T7 } \\
\text { Bottom }\end{array}$} & $\mathrm{Si}$ & 1.7 & 0.4 & $\begin{array}{l}\text { Upper: } 2.0 \\
\text { Lower: } 1.4\end{array}$ \\
\hline & $\mathrm{Cu}$ & 3.0 & 0.2 & $\begin{array}{l}\text { Upper: } 3.2 \\
\text { Lower: } 2.8\end{array}$ \\
\hline & $\mathrm{Mg}$ & 0.7 & 0.02 & $\begin{array}{l}\text { Upper: } 0.8 \\
\text { Lower: } 0.7\end{array}$ \\
\hline \multirow{3}{*}{$\begin{array}{c}\text { Cylinder (2-4) Dyno } \\
\text { Bottom }\end{array}$} & $\mathrm{Si}$ & 1.5 & 0.2 & $\begin{array}{l}\text { Upper: } 1.7 \\
\text { Lower: } 1.4\end{array}$ \\
\hline & $\mathrm{Cu}$ & 3.1 & 0.2 & $\begin{array}{l}\text { Upper: } 3.2 \\
\text { Lower: } 3.0\end{array}$ \\
\hline & $\mathrm{Mg}$ & 0.7 & 0.2 & $\begin{array}{l}\text { Upper: } 0.71 \\
\text { Lower: } 0.68\end{array}$ \\
\hline
\end{tabular}


Table A6: Calculated 95\% confidence intervals for $\mathrm{Al}_{2} \mathrm{Cu}$ volume fraction measurements at the $\mathrm{Al}-\mathrm{Fe}$ liner interface for the bottom of cylinder (2-4) and (4-6) bridge. Calculations performed with $\mathrm{N}=9$.

\begin{tabular}{|c|c|c|c|}
\hline Description of Sample & $\begin{array}{c}\mathbf{A l}_{\mathbf{2}} \text { Cu Volume Fraction } \\
\text { Sample Mean (\%) }\end{array}$ & $\begin{array}{c}\mathbf{A l}_{\mathbf{2}} \text { Cu Volume Fraction } \\
\text { Sample Standard Deviation } \\
(\%)\end{array}$ & $\begin{array}{c}\text { 95\% Confidence } \\
\text { Limits (\%) }\end{array}$ \\
\hline Cylinder (2-4) TSR & 5.8 & 1.8 & $\begin{array}{c}\text { Upper: } 7.2 \\
\text { Lower: } 4.3\end{array}$ \\
\hline Cylinder (2-4) T7 & 8.3 & 2.0 & Lower: 6.7 \\
\hline Cylinder (2-4) Dyno & 6.1 & 1.1 & Upper: 7.0 \\
Lower: 5.2
\end{tabular}

Table A7: Calculated 95\% confidence intervals for Rockwell hardness measurements of cylinder (2-4) bridge. Calculations performed with $\mathrm{N}=5$.

\begin{tabular}{|c|c|c|c|}
\hline Description of Sample & $\begin{array}{c}\text { Rockwell Hardness } \\
\text { Sample Mean (HRE) }\end{array}$ & $\begin{array}{c}\text { Rockwell Hardness Sample } \\
\text { Standard Deviation (HRE) }\end{array}$ & $\begin{array}{c}\text { 95\% Confidence } \\
\text { Limits (HRE) }\end{array}$ \\
\hline Cylinder (2-4) TSR Top & 86.0 & 0.78 & $\begin{array}{c}\text { Upper: } 86.9 \\
\text { Lower: } 85.0\end{array}$ \\
\hline Cylinder (2-4) T7 Top & 85.1 & 1.6 & Upper: 87.0 \\
Lower: 83.1
\end{tabular}


Table A8: Calculated 95\% confidence intervals for hardness of microstructural constituents in cylinder (2-4) bridge. Calculations performed with $\mathrm{N}=7$.

\begin{tabular}{|c|c|c|c|c|}
\hline $\begin{array}{l}\text { Description of } \\
\text { Sample }\end{array}$ & Phase & $\begin{array}{c}\text { Hardness Sample } \\
\text { Mean (GPa) }\end{array}$ & $\begin{array}{c}\text { Hardness Sample } \\
\text { Standard Deviation } \\
\text { (GPa) }\end{array}$ & $\begin{array}{l}\text { 95\% Confidence } \\
\text { Limits (GPa) }\end{array}$ \\
\hline \multirow{4}{*}{$\begin{array}{c}\text { Cylinder (2-4) TSR } \\
\text { Top }\end{array}$} & Al-Dendrites & 1.5 & 0.1 & $\begin{array}{l}\text { Upper: } 1.6 \\
\text { Lower: } 1.4\end{array}$ \\
\hline & $\mathrm{Al}_{2} \mathrm{Cu}$ & 5.7 & 0.6 & $\begin{array}{l}\text { Upper: } 6.3 \\
\text { Lower: } 5.1\end{array}$ \\
\hline & $\mathrm{Si}$ & 10.3 & 0.7 & $\begin{array}{l}\text { Upper: } 11.0 \\
\text { Lower: } 9.5\end{array}$ \\
\hline & $\mathrm{Al}_{17} \mathrm{Fe}_{3.2} \mathrm{Mn}_{0.8} \mathrm{Si}_{2}$ & 10.8 & 0.8 & $\begin{array}{l}\text { Upper: } 11.6 \\
\text { Lower: } 10.0\end{array}$ \\
\hline \multirow{4}{*}{$\begin{array}{c}\text { Cylinder (2-4) Dyno } \\
\text { Top }\end{array}$} & Al-Dendrites & 1.4 & 0.1 & $\begin{array}{l}\text { Upper: } 1.5 \\
\text { Lower: } 1.3\end{array}$ \\
\hline & $\mathrm{Al}_{2} \mathrm{Cu}$ & 5.9 & 0.5 & $\begin{array}{l}\text { Upper: } 6.4 \\
\text { Lower: } 5.4\end{array}$ \\
\hline & $\mathrm{Si}$ & 10.1 & 0.3 & $\begin{array}{l}\text { Upper: } 10.4 \\
\text { Lower: } 9.9\end{array}$ \\
\hline & $\mathrm{Al}_{17} \mathrm{Fe}_{3.2} \mathrm{Mn}_{0.8} \mathrm{Si}_{2}$ & 10.6 & 0.9 & $\begin{array}{l}\text { Upper: } 11.4 \\
\text { Lower: } 9.7\end{array}$ \\
\hline \multirow{4}{*}{$\begin{array}{c}\text { Cylinder (2-4) TSR } \\
\text { Bottom }\end{array}$} & Al-Dendrites & 1.4 & 0.1 & $\begin{array}{l}\text { Upper: } 1.5 \\
\text { Lower: } 1.4\end{array}$ \\
\hline & $\mathrm{Al}_{2} \mathrm{Cu}$ & 5.4 & 0.6 & $\begin{array}{l}\text { Upper: } 6.0 \\
\text { Lower: } 4.9\end{array}$ \\
\hline & $\mathrm{Si}$ & 10.0 & 0.7 & $\begin{array}{l}\text { Upper: } 10.5 \\
\text { Lower: } 9.4\end{array}$ \\
\hline & $\mathrm{Al}_{17} \mathrm{Fe}_{3.2} \mathrm{Mn}_{0.8} \mathrm{Si}_{2}$ & 10.4 & 0.8 & $\begin{array}{l}\text { Upper: } 11.1 \\
\text { Lower: } 9.7\end{array}$ \\
\hline \multirow{4}{*}{$\begin{array}{c}\text { Cylinder (2-4) Dyno } \\
\text { Bottom }\end{array}$} & Al-Dendrites & 1.3 & 0.1 & $\begin{array}{l}\text { Upper: } 1.4 \\
\text { Lower: } 1.3\end{array}$ \\
\hline & $\mathrm{Al}_{2} \mathrm{Cu}$ & 5.7 & 0.4 & $\begin{array}{l}\text { Upper: } 6.1 \\
\text { Lower: } 5.3\end{array}$ \\
\hline & $\mathrm{Si}$ & 10.0 & 0.3 & $\begin{array}{l}\text { Upper: } 10.3 \\
\text { Lower: } 9.8\end{array}$ \\
\hline & $\mathrm{Al}_{17} \mathrm{Fe}_{3.2} \mathrm{Mn}_{0.8} \mathrm{Si}_{2}$ & 10.4 & 1.1 & $\begin{array}{l}\text { Upper: } 11.4 \\
\text { Lower: } 9.4\end{array}$ \\
\hline
\end{tabular}


Table A9: Calculated 95\% confidence intervals for the yield strength in each treatment condition.

Calculations performed with $\mathrm{N}_{\mathrm{TSR}}=10, \mathrm{~N}_{\mathrm{T} 7}=13, \mathrm{~N}_{\mathrm{dyno}}=8$.

\begin{tabular}{|c|c|c|c|}
\hline Description of Sample & $\begin{array}{c}\text { Yield Strength Sample } \\
\text { Mean (MPa) }\end{array}$ & $\begin{array}{c}\text { Yield Strength Sample } \\
\text { Standard Deviation (MPa) }\end{array}$ & $\begin{array}{c}\text { 95\% Confidence } \\
\text { Limits (MPa) }\end{array}$ \\
\hline Cylinder Bridge TSR & 195.2 & 6.0 & $\begin{array}{c}\text { Upper: } 199.5 \\
\text { Lower: } 190.9\end{array}$ \\
\hline Cylinder Bridge T7 & 220.9 & 9.3 & Upper: 226.6 \\
Lower: 215.2
\end{tabular}

Table A10: Calculated 95\% confidence intervals for the ultimate tensile strength in each treatment condition.

Calculations performed with $\mathrm{N}_{\mathrm{TSR}}=10, \mathrm{~N}_{\mathrm{T} 7}=13, \mathrm{~N}_{\mathrm{dyno}}=8$.

\begin{tabular}{|c|c|c|c|}
\hline Description of Sample & $\begin{array}{c}\text { Ultimate Tensile } \\
\text { Strength Sample Mean } \\
\text { (MPa) }\end{array}$ & $\begin{array}{c}\text { Ultimate Tensile Strength } \\
\text { Sample Standard Deviation } \\
\text { (MPa) }\end{array}$ & $\begin{array}{l}\text { 95\% Confidence } \\
\text { Limits (MPa) }\end{array}$ \\
\hline Cylinder Bridge TSR & 205.1 & 6.0 & $\begin{array}{l}\text { Upper: } 209.7 \\
\text { Lower: } 200.5\end{array}$ \\
\hline Cylinder Bridge T7 & 241.9 & 14.2 & $\begin{array}{l}\text { Upper: } 250.5 \\
\text { Lower: } 233.4\end{array}$ \\
\hline Cylinder Bridge Dyno & 228.1 & 16.0 & $\begin{array}{l}\text { Upper: } 241.5 \\
\text { Lower: } 214.7\end{array}$ \\
\hline
\end{tabular}

Table A11: Calculated 95\% confidence intervals for the fracture elongation in each treatment condition. Calculations performed with $\mathrm{N}_{\mathrm{TSR}}=5, \mathrm{~N}_{\mathrm{T} 7}=10, \mathrm{~N}_{\text {dyno }}=5$.

\begin{tabular}{|c|c|c|c|}
\hline Description of Sample & $\begin{array}{c}\text { Fracture Elongation } \\
\text { Sample Mean (\%) }\end{array}$ & $\begin{array}{c}\text { Fracture Elongation Sample } \\
\text { Standard Deviation (\%) }\end{array}$ & $\begin{array}{c}\text { 95\% Confidence } \\
\text { Limits (\%) }\end{array}$ \\
\hline Cylinder Bridge TSR & 0.7 & 0.2 & $\begin{array}{c}\text { Upper: } 1.0 \\
\text { Lower: } 0.4\end{array}$ \\
\hline Cylinder Bridge T7 & 0.9 & 0.2 & Upper: 1.0 \\
Lower: 0.7
\end{tabular}




\section{Appendix B: Analysis of Variance}

\section{B.1 Secondary Dendrite Arm Spacing}

To determine if the secondary dendrite arm spacing (SDAS) changes significantly along the cylinder bridge for each treatment condition, 2-factor ANOVA analysis was applied with the following 3 Null Hypotheses:

$\mathrm{H}_{0}{ }^{(1)}$ : There is no change in SDAS with depth along the cylinder bridge. $\mathrm{H}_{0}{ }^{(2)}$ : There is no change in SDAS due to heat treatment and service testing. $\mathrm{H}_{0}{ }^{(3)}$ : There is no interaction effect between cylinder location and treatment condition on SDAS.

The results from ANOVA analysis are summarized in a 2-factor ANOVA table in Table B1.

Table B1: Results from 2-Factor ANOVA analysis of the SDAS at the cylinder bridge.

\begin{tabular}{ccccc}
\hline Source of Variation & $\begin{array}{c}\text { Sum of } \\
\text { Squares }\end{array}$ & $\begin{array}{c}\text { Degrees of } \\
\text { Freedom }\end{array}$ & $\begin{array}{c}\text { Mean Square } \\
\text { Value }\end{array}$ & $F\left(v_{1}, v_{2}\right)$ \\
\hline Depth Along Cylinder (A) & 14276.475 & 3 & 4758.875 & 246.309 \\
Treatment Condition (B) & 106.672 & 2 & 53.336 & 2.761 \\
Interaction (I) & 59.318 & 6 & 9.886 & 0.512 \\
Residual (R) & 5564.315 & 288 & 19.321 & \\
Total & 20006.780 & 299 & & \\
\hline
\end{tabular}

With respect to $\mathrm{H}_{0}{ }^{(3)}$, set $F_{I}=F_{v_{I} ; v_{R} ; \alpha^{*}}$ to determine $\mathrm{P}_{\alpha \max }$. From the F-distribution, $F_{6 ; 288 ; 0.25}=1.33$, which is significantly greater than $F_{I}$. Therefore $\mathbf{P}_{\text {amax }}<\mathbf{7 5 \%}$. Since $\mathbf{P}_{\text {amax }}<\mathbf{8 5 \%}$, accept $\mathbf{H}_{\mathbf{0}}{ }^{(\mathbf{3})}$. Therefore, there is no interaction effect between cylinder location and treatment condition on SDAS.

With respect to $\mathrm{H}_{0}{ }^{(1)}$, set $F_{A}=F_{v_{A} ; \nu_{R} ; \alpha^{*}}$ to determine $\mathrm{P}_{\alpha \max }=1-\alpha^{*}$. From the F-distribution, $F_{3 ; 288 ; 0.001}=5.42$, which is significantly less than $F_{A}$. Therefore, $P_{a \max }>\mathbf{9 9 . 9 \%}$. Since $\mathbf{P}_{\text {amax }}>\mathbf{9 5 \%}$, reject $\mathbf{H}_{\mathbf{0}}{ }^{(\mathbf{1})}$. Therefore, the SDAS changes significantly along the cylinder bridge.

With respect to $\mathrm{H}_{0}{ }^{(2)}$, set $F_{B}=F_{v_{B} ; v_{R} ; \alpha^{*}}$ to determine $\mathrm{P}_{\alpha \max }=1-\alpha^{*}$. From the F-distribution, with proper interpolation, $\mathbf{P}_{a \max }=\mathbf{9 3 . 1 7 \%}$. Since $85 \% \leq \mathbf{P}_{\text {amax }} \leq \mathbf{9 5 \%}$, no decision possible. Therefore, although a rational and objective decision cannot be made, the data indicates that heat treatment has a significantly lower influence on SDAS than the location within the cylinder bridge. 


\section{B.2 Volume Fraction of $\mathrm{Al}_{2} \mathrm{Cu}$}

To determine if the volume fraction of $\mathrm{Al}_{2} \mathrm{Cu}$ changed significantly along the cylinder bridge for each treatment condition, 2-factor ANOVA analysis was applied with the following 3 Null Hypotheses:

\section{$\mathrm{H}_{0}{ }^{(1)}$ : There is no change in $\mathrm{Al}_{2} \mathrm{Cu}$ volume fraction with depth along the cylinder bridge. $\mathrm{H}_{0}{ }^{(2)}$ : There is no change in $\mathrm{Al}_{2} \mathrm{Cu}$ volume fraction due to heat treatment and service testing. \\ $\mathrm{H}_{0}{ }^{(3)}$ : There is no interaction effect between cylinder location and treatment condition on volume fraction of $\mathrm{Al}_{2} \mathrm{Cu}$.}

The results from ANOVA analysis are summarized in a 2-factor ANOVA table in Table B2.

Table B2: Results from 2-Factor $\mathrm{ANOVA}$ analysis of the $\mathrm{Al}_{2} \mathrm{Cu}$ volume fraction at the cylinder bridge.

\begin{tabular}{ccccc}
\hline Source of Variation & $\begin{array}{c}\text { Sum of } \\
\text { Squares }\end{array}$ & $\begin{array}{c}\text { Degrees of } \\
\text { Freedom }\end{array}$ & $\begin{array}{c}\text { Mean Square } \\
\text { Value }\end{array}$ & $F\left(v_{1}, v_{2}\right)$ \\
\hline Depth Along Cylinder (A) & 16.985 & 1 & 16.985 & 41.262 \\
Treatment Condition (B) & 0.316 & 2 & 0.158 & 0.384 \\
Interaction (I) & 0.223 & 2 & 0.111 & 0.270 \\
Residual (R) & 41.988 & 102 & 0.412 & \\
Total & 59.512 & 107 & & \\
\hline
\end{tabular}

With respect to $\mathrm{H}_{0}^{(3)}$, set $F_{I}=F_{v_{I} ; v_{R} ; \alpha^{*}}$ to determine $\mathrm{P}_{\alpha \max }$. From the F-distribution with appropriate interpolation, $F_{2 ; 102 ; 0.25}=1.406$, which is significantly greater than $\mathrm{F}_{\mathrm{I}}$. Therefore $P_{\text {amax }}<\mathbf{7 5 \%}$. Since $P_{\text {amax }}<\mathbf{8 5 \%}$, accept $\mathbf{H}_{\mathbf{0}}{ }^{(3)}$. Therefore, there is no interaction effect between cylinder location and treatment condition on $\mathrm{Al}_{2} \mathrm{Cu}$ volume fraction.

With respect to $\mathrm{H}_{0}{ }^{(1)}$, set $F_{A}=F_{v_{A} ; v_{R} ; \alpha^{*}}$ to determine $\mathrm{P}_{\alpha \max }=1-\alpha^{*}$. From the F-distribution, with appropriate interpolation, $F_{1 ; 102 ; 0.001}=11.557$, which is significantly less than $F_{A}$. Therefore $\mathbf{P}_{a \max }>\mathbf{9 9 . 9 \%}$. Since $\mathbf{P}_{\text {amax }}>\mathbf{9 5 \%}$, reject $\mathbf{H}_{\mathbf{0}}{ }^{(\mathbf{1})}$. Therefore, the $\mathrm{Al}_{2} \mathrm{Cu}$ volume fraction changes significantly along the cylinder bridge.

With respect to $\mathrm{H}_{0}^{(2)}$, set $F_{B}=F_{v_{B} ; v_{R} ; \alpha^{*}}$ to determine $\mathrm{P}_{\text {amax }}$. From the F-distribution with appropriate interpolation, $F_{1 ; 102 ; 0.25}=1.343$, which is significantly greater than $F_{B}$. Therefore $\mathbf{P}_{\text {amax }}<\mathbf{7 5 \%}$. Since $\mathbf{P}_{\text {amax }}<\mathbf{8 5 \%}$, accept $\mathbf{H}_{\mathbf{0}}{ }^{(2)}$. Therefore, heat treatment has no significant effect on $\mathrm{Al}_{2} \mathrm{Cu}$ volume fraction. 


\section{B.3 Volume Fraction of $\mathrm{Al}_{17} \mathrm{Fe}_{3.2} \mathrm{Mn}_{0.8} \mathrm{Si}_{2}$}

To determine if the volume fraction of $\mathrm{Al}_{17} \mathrm{Fe}_{3.2} \mathrm{Mn}_{0.8} \mathrm{Si}_{2}$ changed significantly along the cylinder bridge for each treatment condition, 2-factor ANOVA analysis was applied with the following 3 Null Hypotheses:

$\mathrm{H}_{0}^{(1)}$ : There is no change in $\mathrm{Al}_{17} \mathrm{Fe}_{3.2} \mathrm{Mn}_{0.8} \mathrm{Si}_{2}$ volume fraction with depth along the cylinder bridge.

$\mathrm{H}_{0}{ }^{(2)}$ : There is no change in $\mathrm{Al}_{17} \mathrm{Fe}_{3.2} \mathrm{Mn}_{0.8} \mathrm{Si}_{2}$ volume fraction due to heat treatment and service testing.

$\mathrm{H}_{0}{ }^{(3)}$ : There is no interaction effect between cylinder location and treatment condition on volume fraction of $\mathrm{Al}_{17} \mathrm{Fe}_{3.2} \mathrm{Mn}_{0.8} \mathrm{Si}_{2}$

The results from ANOVA analysis are summarized in a 2-factor ANOVA table in Table B3.

Table B3: Results from 2-Factor ANOVA analysis of the $\mathrm{Al}_{17} \mathrm{Fe}_{3.2} \mathrm{Mn}_{0.8} \mathrm{Si}_{2}$ volume fraction at the cylinder bridge.

\begin{tabular}{ccccc}
\hline & Sum of & Degrees of & Mean Square & \\
Source of Variation & Squares & Freedom & Value & $F\left(v_{1}, v_{2}\right)$ \\
\hline Depth Along Cylinder (A) & 6.468 & 1 & 6.468 & 7.614 \\
Treatment Condition (B) & 1.492 & 2 & 0.746 & 0.878 \\
Interaction (I) & 5.153 & 2 & 2.576 & 3.033 \\
Residual (R) & 86.643 & 102 & 0.849 & \\
Total & 99.755 & 107 & & \\
\hline
\end{tabular}

With respect to $\mathrm{H}_{0}{ }^{(3)}$, set $F_{I}=F_{\nu_{I} ; v_{R} ; \alpha^{*}}$ to determine $\mathrm{P}_{\text {amax }}$. From the F-distribution with appropriate interpolation, $P_{\alpha \max }=\mathbf{9 4 . 6} \%$. Since $85 \% \leq \mathbf{P}_{\alpha \max } \leq \mathbf{9 5 \%}$, no decision possible.

With respect to $\mathrm{H}_{0}{ }^{(1)}$, set $F_{A}=F_{v_{A} ; v_{R} ; \alpha^{*}}$ to determine $\mathrm{P}_{\alpha \max }=1-\alpha^{*}$. From the F-distribution, with appropriate interpolation $P_{\alpha \max }=\mathbf{9 9 . 1 3 \%}$. Since $\mathbf{P}_{\alpha \max }>\mathbf{9 5 \%}$, reject $\mathbf{H}_{0}{ }^{(1)}$. Therefore, the $\mathrm{Al}_{17} \mathrm{Fe}_{3.2} \mathrm{Mn}_{0.8} \mathrm{Si}_{2}$ volume fraction changes along the depth of the cylinder bridge.

With respect to $\mathrm{H}_{0}^{(2)}$, set $F_{B}=F_{v_{B} ; v_{R} ; \alpha^{*}}$ to determine $\mathrm{P}_{\text {amax }}$. From the F-distribution with appropriate interpolation, $F_{2 ; 102 ; 0.25}=1.406$, which is significantly greater than $F_{B}$. Therefore, $\mathbf{P}_{\boldsymbol{\alpha m a x}}<\mathbf{7 5 \%}$. Since $\mathbf{P}_{\boldsymbol{\alpha m a x}}<\mathbf{8 5 \%}$, accept $\mathbf{H}_{\mathbf{0}}{ }^{(2)}$. Heat treatment and service testing has no significant influence on the $\mathrm{Al}_{17} \mathrm{Fe}_{3.2} \mathrm{Mn}_{0.8} \mathrm{Si}_{2}$ volume fraction. 


\section{B.4 Volume Fraction of Eutectic Silicon}

To determine if the volume fraction of eutectic silicon changed significantly along the cylinder bridge for each treatment condition, 2-factor ANOVA analysis was applied with the following 3 Null Hypotheses:

\section{$\mathrm{H}_{0}{ }^{(1)}$ : There is no change in eutectic silicon volume fraction with depth along the cylinder bridge. \\ $\mathrm{H}_{0}{ }^{(2)}$ : There is no change in eutectic silicon volume fraction due to heat treatment and service testing. \\ $\mathrm{H}_{0}^{(3)}$ : There is no interaction effect between cylinder location and treatment condition on volume fraction of eutectic silicon.}

The results from ANOVA analysis are summarized in a 2-factor ANOVA table in Table B4.

Table B4: Results from 2-Factor ANOVA analysis of the eutectic silicon volume fraction at the cylinder bridge.

\begin{tabular}{ccccc}
\hline & Sum of & Degrees of & Mean Square & \\
Source of Variation & Squares & Freedom & Value & $F\left(v_{1}, v_{2}\right)$ \\
\hline Depth Along Cylinder (A) & 1.905 & 1 & 1.905 & 1.872 \\
Treatment Condition (B) & 4.351 & 2 & 2.175 & 2.138 \\
Interaction (I) & 0.334 & 2 & 0.167 & 0.164 \\
Residual (R) & 122.106 & 120 & 1.018 & \\
Total & 128.696 & 125 & & \\
\hline
\end{tabular}

With respect to $\mathrm{H}_{0}{ }^{(3)}$, set $F_{I}=F_{v_{I} ; v_{R} ; \alpha^{*}}$ to determine $\mathrm{P}_{\alpha \max }$. From the F-distribution, $F_{2 ; 120 ; 0.25}=1.40$, which is significantly greater than $F_{\mathrm{I}}$. Therefore $\mathbf{P}_{\boldsymbol{\alpha m a x}}<\mathbf{7 5 \%}$. Since $\mathbf{P}_{\boldsymbol{\alpha m a x}}<$ $\mathbf{8 5 \%}$, accept $\mathbf{H}_{\mathbf{0}}{ }^{(3)}$. Therefore, there is no interaction effect between cylinder location and treatment condition on the eutectic silicon volume fraction.

With respect to $\mathrm{H}_{0}{ }^{(1)}$, set $F_{A}=F_{v_{A} ; v_{R} ; \alpha^{*}}$ to determine $\mathrm{P}_{\alpha \max }=1-\alpha^{*}$. From the F-distribution, with appropriate interpolation, $P_{\alpha \max }=\mathbf{8 0 . 6 6 \%}$. Since $\mathbf{P}_{\boldsymbol{\alpha m a x}}<\mathbf{8 5 \%}$, accept $\mathbf{H}_{\mathbf{0}}{ }^{(\mathbf{1})}$. Therefore, cylinder location has no significant effect on the eutectic silicon volume fraction.

With respect to $\mathrm{H}_{0}^{(2)}$, set $F_{B}=F_{v_{B} ; v_{R} ; \alpha^{*}}$ to determine $\mathrm{P}_{\text {amax }}$. From the F-distribution with appropriate interpolation, $P_{\alpha \max }=\mathbf{8 3 . 4 9 \%}$. Since $\mathbf{P}_{\boldsymbol{\alpha m a x}}<\mathbf{8 5} \%$, accept $\mathbf{H}_{\mathbf{0}}{ }^{(2)}$. Therefore, heat treatment and service tested do not significantly influence the eutectic silicon volume fraction. 


\section{B.5 Copper Content within the Aluminum Dendrites}

To determine if the copper content in the aluminum dendrites changed significantly along the cylinder bridge for each treatment condition, 2-factor ANOVA analysis was applied with the following 3 Null Hypotheses:

\section{$\mathrm{H}_{0}{ }^{(1)}$ : There is no change in the amount of copper in the aluminum dendrites with depth along the cylinder bridge. \\ $\mathrm{H}_{0}{ }^{(2)}$ : There is no change in the amount of copper in the aluminum dendrites due to heat treatment and service testing. \\ $\mathrm{H}_{0}{ }^{(3)}$ : There is no interaction effect between cylinder location and treatment condition on the amount of copper in the aluminum dendrites.}

The results from ANOVA analysis are summarized in a 2-factor ANOVA table in Table B5.

Table B5: Results from 2-Factor ANOVA analysis of the copper content within the aluminum dendrites.

\begin{tabular}{ccccc}
\hline & & Degrees of & Mean Square & \\
Source of Variation & Sum of Squares & Freedom & Value & $F\left(v_{1}, v_{2}\right)$ \\
\hline Depth Along Cylinder (A) & 1.473 & 1 & 1.473 & 12.119 \\
Treatment Condition (B) & 0.491 & 2 & 0.245 & 2.019 \\
Interaction (I) & 0.360 & 2 & 0.180 & 1.481 \\
Residual (R) & 6.564 & 54 & 0.122 & \\
Total & 8.888 & 59 & & \\
\hline
\end{tabular}

With respect to $\mathrm{H}_{0}{ }^{(3)}$, set $F_{I}=F_{v_{I} ; v_{R} ; \alpha^{*}}$ to determine $\mathrm{P}_{\alpha \max }$. From the F-distribution with appropriate interpolation, $P_{\alpha \max }=\mathbf{7 5 . 8 5} \%$. Since $\mathbf{P}_{\boldsymbol{\alpha m a x}}<\mathbf{8 5} \%$, accept $\mathbf{H}_{\mathbf{0}}{ }^{(3)}$. Therefore, there is no interaction effect between cylinder location and treatment condition on amount of copper within the aluminum dendrites.

With respect to $\mathrm{H}_{0}{ }^{(1)}$, set $F_{A}=F_{v_{A} ; v_{R} ; \alpha^{*}}$ to determine $\mathrm{P}_{\alpha \max }=1-\alpha^{*}$. From the F-distribution, with appropriate interpolation, $P_{\alpha \max }=\mathbf{9 9 . 8 9 \%}$. Since $\mathbf{P}_{\alpha \max }>\mathbf{9 5 \%}$, reject $\mathbf{H}_{\mathbf{0}}{ }^{(\mathbf{1})}$. Therefore, the amount of copper within the aluminum dendrites changes with depth along the cylinder bridge.

With respect to $\mathrm{H}_{0}{ }^{(2)}$, set $F_{B}=F_{v_{B} ; v_{R} ; \alpha^{*}}$ to determine $\mathrm{P}_{\text {amax }}$. From the F-distribution with appropriate interpolation, $\mathbf{P}_{\boldsymbol{\alpha m a x}}=\mathbf{8 4 . 0 8 \%}$. Since $\mathbf{P}_{\boldsymbol{\alpha m a x}}<\mathbf{8 5 \%}$, accept $\mathbf{H}_{\mathbf{0}}{ }^{(2)}$. Therefore, heat treatment and service tested do not significantly influence the amount of copper within the aluminum dendrites. 


\section{B.6 Magnesium Content within the Aluminum Dendrites}

To determine if the magnesium content in the aluminum dendrites changed significantly along the cylinder bridge for each treatment condition, 2-factor ANOVA analysis was applied with the following 3 Null Hypotheses:

\section{$\mathrm{H}_{0}{ }^{(1)}$ : There is no change in the amount of magnesium in the aluminum dendrites with} depth along the cylinder bridge.

$\mathrm{H}_{0}{ }^{(2)}$ : There is no change in the amount of magnesium in the aluminum dendrites due to heat treatment and service testing.

$\mathrm{H}_{0}{ }^{(3)}$ : There is no interaction effect between cylinder location and treatment condition on the amount of magnesium in the aluminum dendrites.

The results from ANOVA analysis are summarized in a 2-factor ANOVA table in Table B6.

Table B6: Results from 2-Factor ANOVA analysis of the magnesium content within the aluminum dendrites.

\begin{tabular}{ccccc}
\hline & Sum of & Degrees of & Mean Square & \\
Source of Variation & Squares & Freedom & Value & $F\left(v_{1}, v_{2}\right)$ \\
\hline Depth Along Cylinder (A) & 0.098 & 1 & 0.098 & 65.194 \\
Treatment Condition (B) & 0.016 & 2 & 0.008 & 5.381 \\
Interaction (I) & 0.008 & 2 & 0.004 & 2.830 \\
Residual (R) & 0.081 & 54 & 0.002 & \\
Total & 0.204 & 59 & & \\
\hline
\end{tabular}

With respect to $\mathrm{H}_{0}{ }^{(3)}$, set $F_{I}=F_{v_{I} ; v_{R} ; \alpha^{*}}$ to determine $\mathrm{P}_{\alpha \max }$. From the F-distribution with appropriate interpolation, $\mathbf{P}_{\alpha \max }=\mathbf{9 2 . 7 6} \%$. Since $85 \% \leq \mathbf{P}_{\alpha \max } \leq \mathbf{9 5 \%}$, no decision possible.

With respect to $\mathrm{H}_{0}{ }^{(1)}$, set $F_{A}=F_{v_{A} ; v_{R} ; \alpha^{*}}$ to determine $\mathrm{P}_{\alpha \max }=1-\alpha^{*}$. From the F-distribution, with appropriate interpolation $F_{1 ; 54 ; 0.001}=12.162$, which is significantly less than $\mathrm{F}_{\mathrm{A}}$. Therefore, $\mathbf{P}_{\boldsymbol{\alpha m a x}}>\mathbf{9 9 . 9 \%}$. Since $\mathbf{P}_{\boldsymbol{\alpha m a x}}>\mathbf{9 5 \%}$, reject $\mathbf{H}_{\mathbf{0}}{ }^{(1)}$. The amount of magnesium within the aluminum dendrites changes with depth along the cylinder bridge.

With respect to $\mathrm{H}_{0}{ }^{(2)}$, set $F_{A}=F_{v_{A} ; v_{R} ; \alpha^{*}}$ to determine $\mathrm{P}_{\alpha \max }=1-\alpha^{*}$. From the F-distribution, with appropriate interpolation, $\mathbf{P}_{\alpha \max }=\mathbf{9 9 . 0 4 \%}$. Since $\mathbf{P}_{\alpha \max }>\mathbf{9 5 \%}$, reject $\mathbf{H}_{\mathbf{0}}{ }^{(2)}$. The amount of magnesium within the aluminum dendrites changes due to heat treatment and service testing. 


\section{B.7 Hardness of the Aluminum Dendrites}

To determine if the hardness of the aluminum dendrites changed significantly along the cylinder bridge for each treatment condition, 2-factor ANOVA analysis was applied with the following 3 Null Hypotheses:

$\mathrm{H}_{0}{ }^{(1)}$ : There is no change in the hardness of the aluminum dendrites with depth along the cylinder bridge.

$\mathrm{H}_{0}^{(2)}$ : There is no change in hardness of the aluminum dendrites due to heat treatment and service testing.

$\mathrm{H}_{0}^{(3)}$ : There is no interaction effect between cylinder location and treatment condition on the hardness of the aluminum dendrites.

The results from ANOVA analysis are summarized in a 2-factor ANOVA table in Table B7.

Table B7: Results from 2-Factor ANOVA analysis of the hardness of the aluminum dendrites.

\begin{tabular}{ccccc}
\hline & $\begin{array}{c}\text { Sum of } \\
\text { Squares }\end{array}$ & $\begin{array}{c}\text { Degrees of } \\
\text { Freedom }\end{array}$ & $\begin{array}{c}\text { Mean Square } \\
\text { Value }\end{array}$ & $F\left(v_{1}, v_{2}\right)$ \\
\hline Source of Variation & 0.012 & 1 & 0.012 & 1.255 \\
Depth Along Cylinder (A) & 0.054 & 2 & 0.026 & 2.736 \\
Treatment Condition (B) & 0.001 & 2 & 0.001 & 0.066 \\
Interaction (I) & 0.354 & 36 & 0.010 & \\
Residual (R) & 0.421 & 41 & & \\
Total &
\end{tabular}

With respect to $\mathrm{H}_{0}^{(3)}$, set $F_{I}=F_{v_{I} ; v_{R} ; \alpha^{*}}$ to determine $\mathrm{P}_{\text {amax }}$. From the F-distribution with appropriate interpolation, $F_{2 ; 36 ; 0.25}=1.444$, which is significantly greater than $\mathrm{F}_{\mathrm{I}}$. Therefore, $\mathbf{P}_{\boldsymbol{\alpha} \max }<75 \%$. Since $\mathbf{P}_{\boldsymbol{\alpha} \max }<\mathbf{8 5} \%$, accept $\mathbf{H}_{\mathbf{0}}{ }^{(3)}$. There is no interaction effect between cylinder location and treatment condition on hardness of the aluminum dendrites.

With respect to $\mathrm{H}_{0}{ }^{(1)}$, set $F_{A}=F_{v_{A} ; v_{R} ; \alpha^{*}}$ to determine $\mathrm{P}_{\alpha \max }=1-\alpha^{*}$. From the F-distribution, with appropriate interpolation $F_{1 ; 36 ; 0.25}=1.368$, which is greater than $F_{\mathrm{A}}$. Therefore, $\mathbf{P}_{\mathbf{\alpha m a x}}<\mathbf{7 5 \%}$. Since $\mathbf{P}_{\boldsymbol{a m a x}}<\mathbf{8 5} \%$, accept $\mathbf{H}_{\mathbf{0}}{ }^{(\mathbf{1})}$. The hardness of the aluminum dendrites does not change significantly with depth along the cylinder bridge.

With respect to $\mathrm{H}_{0}{ }^{(2)}$, set $F_{A}=F_{v_{A} ; v_{R} ; \alpha^{*}}$ to determine $\mathrm{P}_{\alpha \max }=1-\alpha^{*}$. From the F-distribution, with appropriate interpolation, $P_{\alpha \max }=\mathbf{9 1 . 7 1 \%}$. Since $85 \% \leq \mathbf{P}_{\alpha \max } \leq \mathbf{9 5 \%}$, no decision possible. 


\section{B.8 Hardness of $\mathrm{Al}_{2} \mathrm{Cu}$}

To determine if the hardness of $\mathrm{Al}_{2} \mathrm{Cu}$ changed significantly along the cylinder bridge for each treatment condition, 2-factor ANOVA analysis was applied with the following 3 Null Hypotheses:

$\mathrm{H}_{0}{ }^{(1)}$ : There is no change in the hardness of $\mathrm{Al}_{2} \mathrm{Cu}$ with depth along the cylinder bridge. $\mathrm{H}_{0}{ }^{(2)}$ : There is no change in hardness of $\mathrm{Al}_{2} \mathrm{Cu}$ due to heat treatment and service testing. $\mathrm{H}_{0}{ }^{(3)}$ : There is no interaction effect between cylinder location and treatment condition on the hardness of $\mathrm{Al}_{2} \mathrm{Cu}$.

The results from ANOVA analysis are summarized in a 2-factor ANOVA table in Table B8.

Table B8: Results from 2-Factor ANOVA analysis of the hardness of $\mathrm{Al}_{2} \mathrm{Cu}$.

\begin{tabular}{ccccc}
\hline & Sum of & Degrees of & Mean Square & \\
Source of Variation & Squares & Freedom & Value & $F\left(v_{1}, v_{2}\right)$ \\
\hline Depth Along Cylinder (A) & 0.035 & 1 & 0.035 & 0.110 \\
Treatment Condition (B) & 0.856 & 2 & 0.428 & 1.333 \\
Interaction (I) & 0.818 & 2 & 0.409 & 1.274 \\
Residual (R) & 11.561 & 36 & 0.321 & \\
Total & 13.271 & 41 & & \\
\hline
\end{tabular}

With respect to $\mathrm{H}_{0}{ }^{(3)}$, set $F_{I}=F_{v_{I} ; v_{R} ; \alpha^{*}}$ to determine $\mathrm{P}_{\text {amax }}$. From the F-distribution with appropriate interpolation, $F_{2 ; 36 ; 0.25}=1.444$, which is significantly greater than $\mathrm{F}_{\mathrm{I}}$. Therefore, $\mathbf{P}_{\boldsymbol{\alpha} \max }<75 \%$. Since $\mathbf{P}_{\boldsymbol{\alpha} \max }<\mathbf{8 5 \%}$, accept $\mathbf{H}_{\mathbf{0}}{ }^{(3)}$. There is no interaction effect between cylinder location and treatment condition on hardness of $\mathrm{Al}_{2} \mathrm{Cu}$.

With respect to $\mathrm{H}_{0}{ }^{(1)}$, set $F_{A}=F_{v_{A} ; v_{R} ; \alpha^{*}}$ to determine $\mathrm{P}_{\alpha \max }=1-\alpha^{*}$. From the F-distribution, with appropriate interpolation $F_{1 ; 36 ; 0.25}=1.368$, which is greater than $\mathrm{F}_{\mathrm{A}}$. Therefore, $\mathbf{P}_{\mathbf{\alpha m a x}}<\mathbf{7 5 \%}$. Since $\mathbf{P}_{\boldsymbol{\alpha m a x}}<\mathbf{8 5 \%}$, accept $\mathbf{H}_{\mathbf{0}}{ }^{(\mathbf{1})}$. The hardness of $\mathrm{Al}_{2} \mathrm{Cu}$ does not change significantly with depth along the cylinder bridge.

With respect to $\mathrm{H}_{0}{ }^{(2)}$, set $F_{B}=F_{v_{B} ; v_{R} ; \alpha^{*}}$ to determine $\mathrm{P}_{\alpha \max }=1-\alpha^{*}$. From the F-distribution, with appropriate interpolation $F_{2 ; 36 ; 0.25}=1.444$, which is greater than $F_{B}$. Therefore, $\mathbf{P}_{\boldsymbol{\alpha m a x}}<\mathbf{7 5 \%}$. Since $\mathbf{P}_{\boldsymbol{\alpha m a x}}<\mathbf{8 5 \%}$, accept $\mathbf{H}_{\mathbf{0}}{ }^{(2)}$. The hardness of $\mathrm{Al}_{2} \mathrm{Cu}$ does not change significantly due to heat treatment and service testing. 


\section{B.9 Hardness of $\mathrm{Al}_{17} \mathrm{Fe}_{3.2} \mathrm{Mn}_{0.8} \mathrm{Si}_{2}$}

To determine if the hardness of $\mathrm{Al}_{17} \mathrm{Fe}_{3.2} \mathrm{Mn}_{0.8} \mathrm{Si}_{2}$ changed significantly along the cylinder bridge for each treatment condition, 2-factor ANOVA analysis was applied with the following 3 Null Hypotheses:

\section{$\mathrm{H}_{0}{ }^{(1)}$ : There is no change in the hardness of $\mathrm{Al}_{17} \mathrm{Fe}_{3.2} \mathrm{Mn}_{0.8} \mathrm{Si}_{2}$ with depth along the cylinder bridge.}

$\mathrm{H}_{0}{ }^{(2)}$ : There is no change in hardness of $\mathrm{Al}_{17} \mathrm{Fe}_{3.2} \mathrm{Mn}_{0.8} \mathrm{Si}_{2}$ due to heat treatment and service testing.

\section{$\mathrm{H}_{0}{ }^{(3)}$ : There is no interaction effect between cylinder location and treatment condition on the hardness of $\mathrm{Al}_{17} \mathrm{Fe}_{3.2} \mathrm{Mn}_{0.8} \mathrm{Si}_{2}$.}

The results from ANOVA analysis are summarized in a 2-factor ANOVA table in Table B9.

Table B9: Results from 2-Factor ANOVA analysis of the hardness of $\mathrm{Al}_{17} \mathrm{Fe}_{3.2} \mathrm{Mn}_{0.8} \mathrm{Si}_{2}$.

\begin{tabular}{ccccc}
\hline & Sum of & $\begin{array}{c}\text { Degrees of } \\
\text { Freedom }\end{array}$ & $\begin{array}{c}\text { Mean Square } \\
\text { Value }\end{array}$ & $F\left(v_{1}, v_{2}\right)$ \\
\hline Source of Variation & Squares & 1 & 0.133 & 0.164 \\
Depth Along Cylinder (A) & 0.133 & 2 & 0.115 & 0.143 \\
Treatment Condition (B) & 0.230 & 2 & 0.103 & 0.127 \\
Interaction (I) & 0.206 & 36 & 0.808 & \\
Residual (R) & 29.090 & 41 & & \\
Total & 29.659 & & & \\
\hline
\end{tabular}

With respect to $\mathrm{H}_{0}{ }^{(3)}$, set $F_{I}=F_{v_{I} ; v_{R} ; \alpha^{*}}$ to determine $\mathrm{P}_{\text {amax }}$. From the F-distribution with appropriate interpolation, $F_{2 ; 36 ; 0.25}=1.444$, which is significantly greater than $\mathrm{F}_{\mathrm{I}}$. Therefore, $\mathbf{P}_{\boldsymbol{\alpha} \text { max }}<75 \%$. Since $\mathbf{P}_{\boldsymbol{\alpha} \text { max }}<\mathbf{8 5 \%}$, accept $\mathbf{H}_{\mathbf{0}}{ }^{(3)}$. There is no interaction effect between cylinder location and treatment condition on hardness of $\mathrm{Al}_{17} \mathrm{Fe}_{3.2} \mathrm{Mn}_{0.8} \mathrm{Si}_{2}$.

With respect to $\mathrm{H}_{0}{ }^{(1)}$, set $F_{A}=F_{v_{A} ; v_{R} ; \alpha^{*}}$ to determine $\mathrm{P}_{\alpha \max }=1-\alpha^{*}$. From the F-distribution, with appropriate interpolation $F_{1 ; 36 ; 0.25}=1.368$, which is greater than $\mathrm{F}_{\mathrm{A}}$. Therefore, $\mathbf{P}_{\mathbf{\alpha m a x}}<\mathbf{7 5 \%}$. Since $\mathbf{P}_{\boldsymbol{\alpha m a x}}<\mathbf{8 5 \%}$, accept $\mathbf{H}_{\mathbf{0}}{ }^{(\mathbf{1})}$. The hardness of $\mathrm{Al}_{17} \mathrm{Fe}_{3.2} \mathrm{Mn}_{0.8} \mathrm{Si}_{2}$ does not change significantly with depth along the cylinder bridge.

With respect to $\mathrm{H}_{0}{ }^{(2)}$, set $F_{B}=F_{v_{B} ; v_{R} ; \alpha^{*}}$ to determine $\mathrm{P}_{\alpha \max }=1-\alpha^{*}$. From the F-distribution, with appropriate interpolation $F_{2 ; 36 ; 0.25}=1.444$, which is greater than $F_{B}$. Therefore, $\mathbf{P}_{\boldsymbol{\alpha m a x}}<\mathbf{7 5 \%}$. Since $\mathbf{P}_{\boldsymbol{\alpha m a x}}<\mathbf{8 5 \%}$, accept $\mathbf{H}_{\mathbf{0}}{ }^{(2)}$. The hardness of $\mathrm{Al}_{17} \mathrm{Fe}_{3.2} \mathrm{Mn}_{0.8} \mathrm{Si}_{2}$ does not change significantly due to heat treatment and service testing. 


\section{B.10 Hardness of Eutectic Silicon}

To determine if the hardness of eutectic silicon changed significantly along the cylinder bridge for each treatment condition, 2-factor ANOVA analysis was applied with the following 3 Null Hypotheses:

\section{$\mathrm{H}_{0}{ }^{(1)}$ : There is no change in the hardness of eutectic silicon with depth along the cylinder bridge.}
$\mathrm{H}_{0}{ }^{(2)}$ : There is no change in hardness of eutectic silicon due to heat treatment and service testing.
$\mathrm{H}_{0}^{(3)}$ : There is no interaction effect between cylinder location and treatment condition on the hardness of eutectic silicon.

The results from ANOVA analysis are summarized in a 2-factor ANOVA table in Table B10.

Table B10: Results from 2-Factor ANOVA analysis of the hardness of eutectic silicon.

\begin{tabular}{ccccc}
\hline & Sum of & Degrees of & Mean Square & \\
Source of Variation & Squares & Freedom & Value & $F_{\left(v_{1}, v_{2}\right)}$ \\
\hline Depth Along Cylinder (A) & 0.073 & 1 & 0.073 & 0.241 \\
Treatment Condition (B) & 0.122 & 2 & 0.061 & 0.202 \\
Interaction (I) & 0.030 & 2 & 0.015 & 0.050 \\
Residual (R) & 10.901 & 36 & 0.303 & \\
Total & 11.126 & 41 & & \\
\hline
\end{tabular}

With respect to $\mathrm{H}_{0}{ }^{(3)}$, set $F_{I}=F_{v_{I} ; v_{R} ; \alpha^{*}}$ to determine $\mathrm{P}_{\alpha \max }$. From the F-distribution with appropriate interpolation, $F_{2 ; 36 ; 0.25}=1.444$, which is significantly greater than $\mathrm{F}_{\mathrm{I}}$. Therefore, $\mathbf{P}_{\boldsymbol{\alpha m a x}}<75 \%$. Since $\mathbf{P}_{\boldsymbol{\alpha m a x}}<\mathbf{8 5} \%$, accept $\mathbf{H}_{\mathbf{0}}{ }^{(3)}$. There is no interaction effect between cylinder location and treatment condition on hardness of eutectic silicon.

With respect to $\mathrm{H}_{0}{ }^{(1)}$, set $F_{A}=F_{v_{A} ; v_{R} ; \alpha^{*}}$ to determine $\mathrm{P}_{\alpha \max }=1-\alpha^{*}$. From the F-distribution, with appropriate interpolation $F_{1 ; 36 ; 0.25}=1.368$, which is greater than $\mathrm{F}_{\mathrm{A}}$. Therefore, $\mathbf{P}_{\mathbf{\alpha m a x}}<\mathbf{7 5 \%}$. Since $\mathbf{P}_{\boldsymbol{\alpha m a x}}<\mathbf{8 5 \%}$, accept $\mathbf{H}_{\mathbf{0}}{ }^{(\mathbf{1})}$. The hardness of eutectic silicon does not change significantly with depth along the cylinder bridge.

With respect to $\mathrm{H}_{0}{ }^{(2)}$, set $F_{B}=F_{v_{B} ; v_{R} ; \alpha^{*}}$ to determine $\mathrm{P}_{\alpha \max }=1-\alpha^{*}$. From the F-distribution, with appropriate interpolation $F_{2 ; 36 ; 0.25}=1.444$, which is greater than $F_{B}$. Therefore, $\mathbf{P}_{\boldsymbol{\alpha m a x}}<\mathbf{7 5 \%}$. Since $\mathbf{P}_{\boldsymbol{\alpha m a x}}<\mathbf{8 5} \%$, accept $\mathbf{H}_{\mathbf{0}}{ }^{(2)}$. The hardness of eutectic silicon does not change significantly due to heat treatment and service testing. 


\section{B.11 Rockwell Hardness}

To determine if the Rockwell hardness changed significantly along the cylinder bridge for each treatment condition, 2-factor ANOVA analysis was applied with the following 3 Null Hypotheses:

$\mathrm{H}_{0}{ }^{(1)}$ : There is no change in Rockwell hardness with depth along the cylinder bridge. $\mathrm{H}_{0}{ }^{(2)}$ : There is no change Rockwell hardness due to heat treatment and service testing. $\mathrm{H}_{0}{ }^{(3)}$ : There is no interaction effect between cylinder location and treatment condition on Rockwell hardness.

The results from ANOVA analysis are summarized in a 2-factor ANOVA table in Table B11.

Table B11: Results from 2-Factor ANOVA analysis of Rockwell hardness.

\begin{tabular}{ccccc}
\hline Source of Variation & Sum of Squares & $\begin{array}{c}\text { Degrees of } \\
\text { Freedom }\end{array}$ & $\begin{array}{c}\text { Mean Square } \\
\text { Value }\end{array}$ & $F\left(v_{1}, v_{2}\right)$ \\
\hline Depth Along Cylinder (A) & 168.003 & 1 & 168.003 & 110.144 \\
Treatment Condition (B) & 3.825 & 2 & 1.913 & 1.254 \\
Interaction (I) & 4.185 & 2 & 2.093 & 1.372 \\
Residual (R) & 82.366 & 54 & 1.525 & \\
Total & 258.379 & 59 & & \\
\hline
\end{tabular}

With respect to $\mathrm{H}_{0}^{(3)}$, set $F_{I}=F_{v_{I} ; v_{R} ; \alpha^{*}}$ to determine $\mathrm{P}_{\alpha \max }$. From the F-distribution with appropriate interpolation, $F_{2 ; 54 ; 0.25}=1.426$, which is significantly greater than $\mathrm{F}_{\mathrm{I}}$. Therefore, $\mathbf{P}_{\boldsymbol{a m a x}}<\mathbf{7 5 \%}$. Since $\mathbf{P}_{\boldsymbol{a m a x}}<\mathbf{8 5 \%}$, accept $\mathbf{H}_{\mathbf{0}}{ }^{(3)}$. There is no interaction effect between cylinder location and treatment condition on Rockwell hardness.

With respect to $\mathrm{H}_{0}{ }^{(1)}$, set $F_{A}=F_{v_{A} ; v_{R} ; \alpha^{*}}$ to determine $\mathrm{P}_{\alpha \max }=1-\alpha^{*}$. From the F-distribution, with appropriate interpolation $F_{1 ; 54 ; 0.001}=12.162$, which is significantly less than $\mathrm{F}_{\mathrm{A}}$. Therefore, $\mathbf{P}_{\text {amax }}>\mathbf{9 9 . 9 \%}$. Since $\mathbf{P}_{\text {amax }}>\mathbf{9 5 \%}$, reject $\mathbf{H}_{\mathbf{0}}{ }^{(\mathbf{1})}$. The Rockwell hardness changes significantly with depth along the cylinder bridge.

With respect to $\mathrm{H}_{0}{ }^{(2)}$, set $F_{B}=F_{v_{B} ; v_{R} ; \alpha^{*}}$ to determine $\mathrm{P}_{\alpha \max }=1-\alpha^{*}$. From the F-distribution, with appropriate interpolation $F_{2 ; 54 ; 0.25}=1.426$, which is greater than $\mathrm{F}_{\mathrm{B}}$. Therefore, $\mathbf{P}_{\boldsymbol{a m a x}}<\mathbf{7 5 \%}$. Since $\mathbf{P}_{\boldsymbol{a m a x}}<\mathbf{8 5 \%}$, accept $\mathbf{H}_{\mathbf{0}}{ }^{(2)}$. The Rockwell hardness does not change significantly due to heat treatment and service testing. 


\section{B.12 Yield Strength}

To determine if the yield strength changed significantly due to heat treatment and service testing, 1-factor ANOVA analysis was applied with the following Null Hypothesis:

\section{$\mathrm{H}_{0}$ : There is no change in yield strength due to heat treatment and service testing.}

The results from ANOVA analysis are summarized in a 1-factor ANOVA table in Table B12.

Table B12: Results from 1-Factor ANOVA analysis on the yield strength.

\begin{tabular}{ccccc}
\hline & Sum of & Degrees of & Mean Square & \\
Source of Variation & Squares & Freedom & Value & $F\left(v_{1}, v_{2}\right)$ \\
\hline Treatment Condition (A) & 3924.044 & 2 & 1962.022 & 25.014 \\
Residual (R) & 2117.826 & 27 & 78.438 & \\
Total & 6041.870 & 29 & & \\
\hline
\end{tabular}

To determine $\mathrm{P}_{\alpha \max }$, set $F_{A}=F_{v_{A} ; v_{R} ; \alpha^{*}}$. From the F-distribution $F_{2 ; 27 ; 0.001}=9.02$, which is significantly less than $F_{A}$. Therefore, $P_{\alpha \max }>\mathbf{9 9 . 9 \%}$. Since $\mathbf{P}_{\alpha \max }>\mathbf{9 5 \%}$, reject $\mathbf{H}_{0}$. The yield strength changes significantly due to heat treatment.

\section{B.13 Ultimate Tensile Strength}

To determine if the ultimate tensile strength changes significantly due to heat treatment and service testing, 1-factor ANOVA analysis is applied with the following Null Hypothesis:

\section{$\mathrm{H}_{0}$ : There is no change in ultimate tensile strength due to heat treatment and service testing.}

The results from ANOVA analysis are summarized in a 1-factor ANOVA table in Table B13.

Table B13: Results from 1-Factor ANOVA analysis on the ultimate tensile strength.

\begin{tabular}{ccccc}
\hline & Sum of & Degrees of & Mean Square & \\
Source of Variation & Squares & Freedom & Value & $F_{\left(v_{1}, v_{2}\right)}$ \\
\hline Treatment Condition (A) & 8621.696 & 2 & 4310.848 & 33.212 \\
Residual (R) & 3374.772 & 26 & 129.799 & \\
Total & 11996.47 & 28 & & \\
\hline
\end{tabular}

To determine $\mathrm{P}_{\alpha \max }$, set $F_{A}=F_{v_{A} ; v_{R} ; \alpha^{*}}$. From the F-distribution $F_{2 ; 26 ; 0.001}=9.12$, which is significantly less than $F_{A}$. Therefore, $P_{\alpha \max }>\mathbf{9 9 . 9 \%}$. Since $\mathbf{P}_{\boldsymbol{\alpha m a x}}>\mathbf{9 5 \%}$, reject $\mathbf{H}_{0}$. The ultimate tensile strength changes significantly due to heat treatment. 


\section{B.14 Elongation at Fracture}

To determine if the elongation at fracture changed significantly due to heat treatment and service testing, 1-factor ANOVA analysis was applied with the following Null Hypothesis:

\section{$\mathrm{H}_{0}$ : There is no change in elongation at fracture due to heat treatment and service testing.}

The results from ANOVA analysis are summarized in a 1-factor ANOVA table in Table B14.

Table B14: Results from 1-Factor ANOVA analysis on the elongation at fracture

\begin{tabular}{ccccc}
\hline & $\begin{array}{c}\text { Sum of } \\
\text { Source of Variation }\end{array}$ & $\begin{array}{c}\text { Degrees of } \\
\text { Freedom }\end{array}$ & $\begin{array}{c}\text { Mean Square } \\
\text { Value }\end{array}$ & $F\left(v_{1}, v_{2}\right)$ \\
\hline Treatment Condition (A) & 0.102 & 2 & 0.051 & 1.305 \\
Residual (R) & 0.625 & 16 & 0.039 & \\
Total & 0.727 & 18 & & \\
\hline
\end{tabular}

To determine $\mathrm{P}_{\alpha \max }$, set $F_{A}=F_{v_{A} ; v_{R} ; \alpha^{*}}$. From the F-distribution $F_{2 ; 16 ; 0.25}=1.514$, which is greater than $\mathrm{F}_{\mathrm{A}}$. Therefore, $\mathbf{P}_{\boldsymbol{\alpha m a x}}<\mathbf{7 5 \%}$. Since $\mathbf{P}_{\boldsymbol{\alpha m a x}}<\mathbf{8 5 \%}$, accept $\mathbf{H}_{\mathbf{0}}$. The elongation at fracture does not change significantly due to heat treatment. 


\section{Appendix C: Phase Diagrams}

C.1 Aluminum-Silicon-Copper Ternary Phase Diagram

$\mathrm{Cu}$

liquidus projection

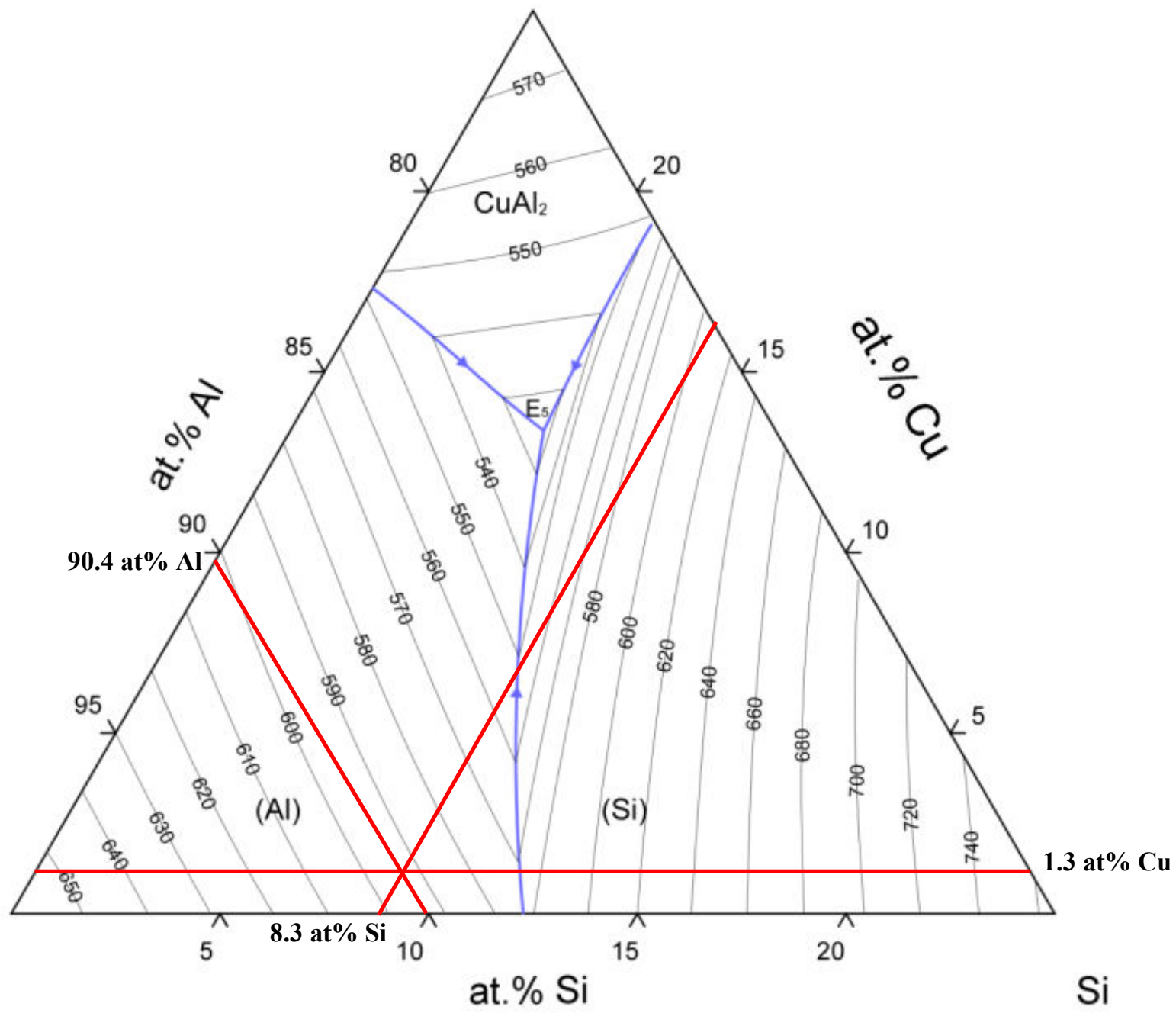

Figure C1: Aluminum-silicon-copper ternary phase diagram [65]. 
C.1 Aluminum-Silicon Binary Phase Diagram

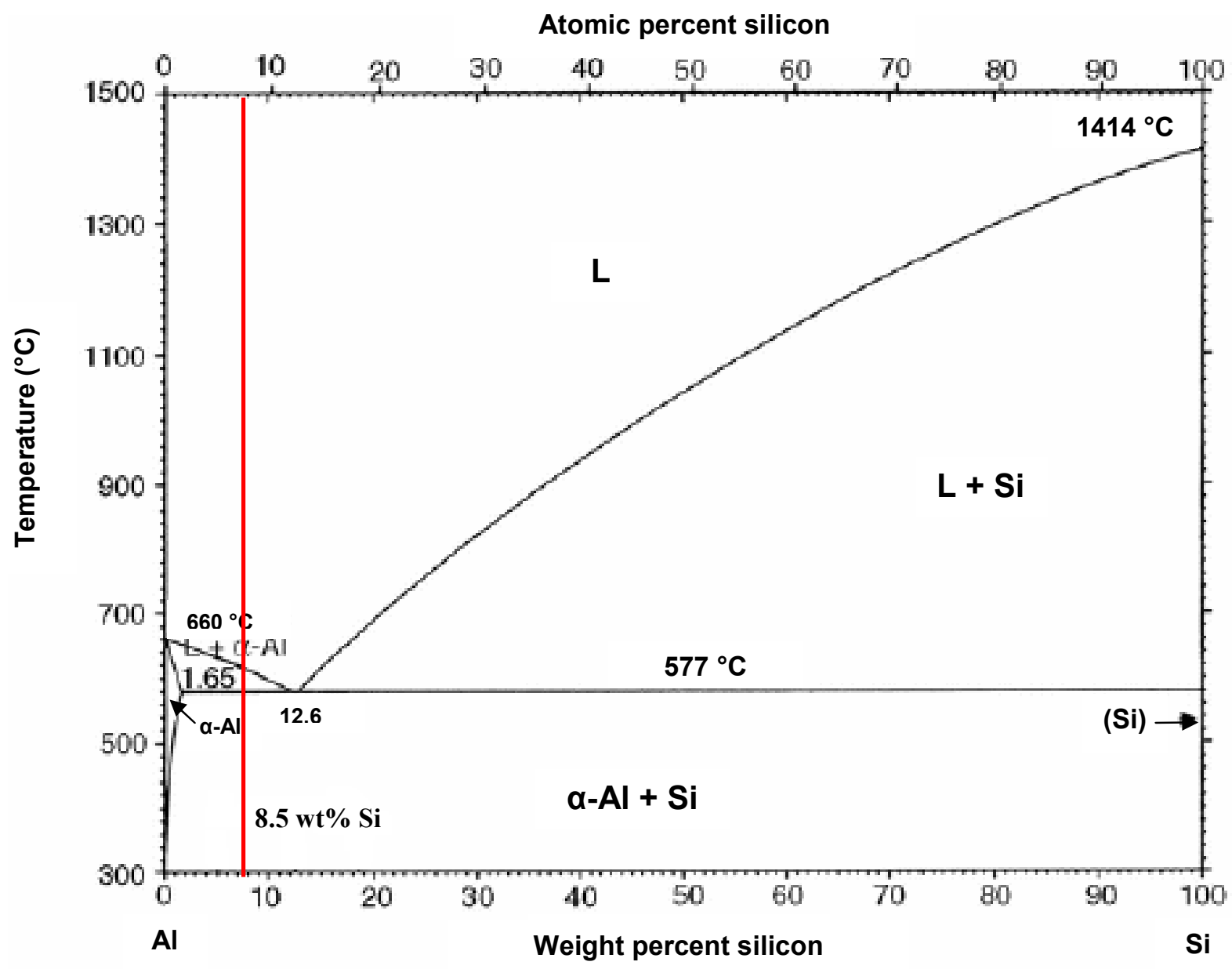

Figure C2: Aluminum-silicon binary phase diagram [1]. 
Appendix D: List of Achievements

\section{Academic Achievements}

1. 2011 Alexander Graham Bell Canada Graduate Scholarship - Doctoral (CGS-D)

2. Best Paper Award $-\mathbf{2 3}^{\text {rd }}$ Canadian Materials Science Conference (CMSC), Kelowna, British Columbia, Canada (2011): "Variation in Microstructure and Mechanical Properties along Cylinder Bore Regions of Modified 319 Al Alloy Engine Blocks with Cast-in Gray Iron Liners" (Lombardi, A., D’Elia, F., Machin, A., Ravindran, C., MacKay, R.).

3. 2011 AUTO21 HQP Poster Competition ( $5^{\text {th }}$ Prize)

4. 2010 CGS Michael Smith Foreign Study Supplement (CGS-MSFSS)

5. Best Paper Award $-4^{\text {th }}$ International Symposium for Research Scholars (ISRS), Chennai, India (2010): "Characterization of Microstructure and Mechanical Properties along Cylinder Bore Regions of Modified 319 Al Alloy Engine Blocks" (Lombardi, A., D’Elia, F., Ravindran, C., Murty, B.S., MacKay, R.).

6. 2010 Ontario Graduate Scholarship (OGS)

7. 2010 AUTO21 HQP Poster Competition ( $4^{\text {th }}$ Prize)

8. 2009 Alexander Graham Bell Canada Graduate Scholarship - Masters (CGS-M)

9. 2009 AFS-Ontario Scholarship

10. 2008 and 2009 NSERC Undergraduate Student Research Award

11. 2008 J. L. Beaton Award

12. 2008 George Wong Achievement Award

13. 2007 Jeld-Wen Achievement Award

\section{Publications}

Journal

Lombardi, A., D’Elia, F., Machin, A., Ravindran, C., MacKay, R., "Variation in Microstructure and Mechanical Properties Along the Cylinder Bores of a Modified 319 Type Al Alloy Engine Block with Cast-in Iron Liners" AFS Transactions, Vol. 119, pp. 229-238 (2011).

Lombardi, A., D’Elia, F., Ravindran, C., Murty, B.S., MacKay, R., “Analysis of the Secondary Phases in the Microstructure of 319 Type Al Alloy Engine Blocks using Electron Microscopy and Nanoindentation", Transactions of the Indian Institute of Metals, Vol. 64, pp. 7-11 (2011).

Sediako, D., D’Elia, F., Lombardi, A., Machin, A., Ravindran, C., Hubbard, C., MacKay, R., "Analysis of Residual Stress Profiles in the Cylinder Web Region of an As-Cast V6 Al Engine Block with Cast-In Fe Liners Using Neutron Diffraction", SAE International Journal of Materials and Manufacturing, Vol. 4, pp. 138-151 (2011). 
Lombardi, A., Lun Sin, S., Ravindran, C., "Influence of Silicon on the Microstructure and Mechanical Properties of Lost Foam cast AE42 Magnesium Alloy”, AFS Transactions, Vol. 118, pp. 331-338 (2010).

Lun Sin, S., Lombardi, A., Ravindran, C., " Influence of Calcium on the Castability, Microstructure, Castability and Mechanical Properties of Lost Foam cast AE42 Magnesium Alloy", AFS Transactions, Vol. 117, pp. 651-658 (2009).

\section{Conference Proceedings}

Sediako, D., D’Elia, F., Lombardi, A., Machin, A., Ravindran, C., Hubbard, C., MacKay, R., "Application of Neutron Diffraction in Analysis of Residual Stress Profiles in the Cylinder Web Region of an As-cast V6 Al Engine Block with Cast-in Fe Liners", TMS Annual Meeting, February 27 - March 3, 2011, San Diego, CA.

Sediako, D., Lombardi, A., D’Elia, F., Ravindran, C., Machin, A., Rogge, R.B., MacKay, R., "Residual Stress Mapping in the Interbore Region of a Heat Treated Aluminum Engine Block", COM 2011 Conference Proceedings, October 2-5, 2011, Montreal, Canada. (accepted).

\section{Posters}

Lombardi, A.,*, D’Elia, F., Ravindran, C., Sediako, D., Murty, B.S., and MacKay, R., "Cylinder Bore Distortion in V6 Al Engine Blocks", " AUTO21 Highly Qualified Personnel (HQP) Poster Competition, Ottawa, Ontario, May 25-27, 2011. (Within top five across all themes. National poster competition with over 60 posters from universities across Canada)

Lombardi, A.,*, D’Elia, F., Ravindran, C., and MacKay, R., "Dimensional Distortions of A319 Al Engine Blocks with Cast-in Cylinder Liners" AUTO21 Highly Qualified Personnel (HQP) Poster Competition, Windsor, Ontario, June 7-10, 2010. ( $1^{\text {st }}$ Prize in Theme. Within top five across all themes National poster competition with over 60 posters from universities across Canada)

Lombardi, A.,*, Lun Sin, S., and Ravindran, C., (2009) Influence of Calcium on the Microstructure and Mechanical Properties of Lost Foam Cast AE42 Magnesium Alloy, ASM International Poster Competition, Toronto, Ontario, March 8, 2009. (1 ${ }^{\text {st }}$ Prize) 


\section{References}

1. Davis, J.R., "ASM Specialty Handbook: Aluminum and Aluminum Alloys", ASM International, Materials Park, OH (1993).

2. Campbell, J., "Castings", Butterworth-Heinemann, London (1991).

3. Moran, M.J., Shapiro, H.N., "Fundamentals of Engineering Thermodynamics", 5 ${ }^{\text {th }}$ Edition, John Wiley \& Sons, New Jersey, NY (2004).

4. Swift, K., Booker, J., "Process Selection: From Design to Manufacture", ButterworthHeinemann, Burlington, MA (2003).

5. Kaufman, J., Rooy, R., "Aluminum Alloy Castings: Properties, Processes and Applications”, ASM International, Materials Park, OH, (2004).

6. Chakrabarti, A., "Casting Technology and Cast Alloys", Prentice-Hall of India, New Delhi (2005).

7. Busby, A., Archibald, J., "Expanded Opportunities for Precision Sand Casting Utilizing Coldbox Binders", AFS Transactions, Vol. 113, pp. 344-355 (2005).

8. Byczynski, G., MacKay, R., "The Nemak Cosworth Casting Process-Innovation”, Shape Casting: $3^{\text {rd }}$ International Symposium, pp. 199-206 (2009).

9. Gesing, A., "Assuring the Continued Recycling of Light Metals in End-of-Life Vehicles: A Global Perspective", JOM, Vol. 56, pp. 18-27 (2004).

10. Hegde, S., Prahbu, K., "Modification of Eutectic Silicon in Al-Si Alloys", Journal of Materials Science, Vol. 43, pp. 3009-3027 (2008).

11. Li, Z., Samuel, A.M., Samuel, F.H., Ravindran, C., Valtierra, S., "Effect of Alloying Elements on the Segregation and Dissolution of $\mathrm{CuAl}_{2}$ Phase in Al-Si-Cu 319 Alloys", Journal of Materials Science, Vol. 38, pp. 1203-1218 (2003).

12. Apelian, D., Sigworth, G., Whaler, K., "Assessment of Grain Refinement and Modification of Al-Si Foundry Alloys by Thermal Analysis", AFS Transactions, Vol. 92, pp. 297-307 (1984).

13. Fatahalla, N., Hafiz, M., Abdulkhalek, M., "Effect of Microstructure on the Mechanical Properties and Fracture of Commercial Hypoeutectic Al-Si Alloy Modified with Na, Sb and Sr", Journal of Materials Science, Vol. 34, pp. 3555-3564 (1999).

14. Narayanan, L., Samuel, F.H., Gruzleski, J.E., "Crystallization Behavior of IronContaining Intermetallic Compounds in 319 Aluminum Alloy”, Metallurgical and Materials Transactions A, Vol. 25, pp. 1761-1773 (1994).

15. Hwang, J., Doty, H.W., Kaufman, M., "Crystallographic Studies on the Iron-Containing Intermetallic Phases in the 319-type Aluminum Casting Alloys", Philosophical Magazine, Vol. 88, pp. 607-619 (2008).

16. Hwang, J., Doty, H.W., Kaufman, M., "The Effects of Mn Additions on the Microstructure and Mechanical Properties of Al-Si-Cu Casting Alloys", Materials Science and Engineering A, Vol. 488, pp. 496-504 (2008). 
17. Albonetti, R., "Porosity and Intermetallic Formation in Lost Foam Casting of 356 Alloy", M.E.Sc. Thesis, University of Western Ontario, London, Ontario, Canada (1997).

18. Lasa, L., Rodriguez-Ibabe, J., "Evolution of the Main Intermetallic Phases in Al-Si-Cu-Mg Casting Alloys during Solution Heat Treatment", Journal of Materials Science, Vol. 39, pp. 1343-1355 (2004).

19. Samuel, F.H., Ouellete, P., Samuel, A.M., Doty, H.W., "Effect of Mg and Sr Additions on the Formation of Intermetallics in Al-6 wt pet Si- 3.5 wt pet $\mathrm{Cu}-(0.45)$ to $(0.8)$ wt pet Fe 319-type Alloys", Metallurgical and Materials Transactions A, Vol. 29, pp. 2871-2884 (1998).

20. Rajan, T.V., Sharma, C.P., Sharma, A., "Heat Treatment Principles and Techniques", Prentice-Hall of India, New Delhi (1999).

21. Sharma, R.C., "Phase Transformations in Materials", CBS Publishers and Distributors, New Delhi (2002).

22. Ashby, M., Shercliff, H., Cebon, D., "Materials: Engineering, Science, Processing and Design", $2^{\text {nd }}$ Edition, Butterworth-Heinemann, Oxford (2007).

23. Samuel, A.M., Gauthier, J., Samuel, F.H., "Microstructural Aspects of the Dissolution and Melting of $\mathrm{Al}_{2} \mathrm{Cu}$ Phase in Al-Si Alloys During Solution Heat Treatment", Metallurgical and Materials Transactions A, Vol. 27, pp. 1785-1798 (1996).

24. Samuel F.H., "Incipient melting of $\mathrm{Al}_{5} \mathrm{Mg}_{8} \mathrm{Si}_{6} \mathrm{Cu}_{2}$ and $\mathrm{Al}_{2} \mathrm{Cu}$ Intermetallics in Unmodified and Strontium-modified Al-Si-Cu-Mg (319) Alloys during Solution Heat Treatment", Journal of Materials Science, Vol. 33, pp. 2283-2297 (1998).

25. Garcia-Garcia, G., Espinoza-Cuadra, J., Mancha-Molinar, H., "Copper Content and Cooling Rate Effects over Second Phase Particles Behavior in Industrial Aluminum-Silicon Alloy 319", Materials \& Design, Vol. 28, pp. 428-433 (2007).

26. Han, Y.M., Samuel, A.M., Samuel, F.H., Valtierra, S., Doty, H.W., "Effect of Solution Heat Treatment type on the Dissolution of Copper Phases in Al-Si-Cu-Mg type Alloys", AFS Transactions, Vol. 116, pp. 79-90 (2008).

27. Li, M., Vijayaraghavan, R., Wolverton, C., Allison, J., "Simulation of Local Microstructures and Thermal Growth of a Cast 319 Aluminum Alloy Component", $I^{\text {st }}$ International Symposium on Metallurgical Modelling for Aluminum Alloys, Pittsburgh, U.S.A., October 13-15 (2003).

28. Tiryakioglu, M., Totten, G., "Quenching Aluminum Components in Water: Problems and Alternatives", Heat Treating: Proceedings of the $18^{\text {th }}$ Conference, October $12^{\text {th }}-15^{\text {th }}$ (1998).

29. MacKenzie, D., Lambert, D., "Effect of Quenching Variables on Distortion and Residual Stress", Proceedings of the $22^{\text {nd }}$ Heat Treating Society Conference and the $2^{\text {nd }}$ International Surface Engineering Congress, Indianapolis, U.S.A., September 15-17 (2003). 
30. Polmear, I., "Light Alloys, Metallurgy of the Light Metals", $3^{\text {rd }}$ Edition, Butterworth-Heinemann, Melbourne (1995).

31. Hwang, J., Banerjee, R., Doty, H.W., Kaufman, M., "The Effect of Mg on the Structure and Properties of Type 319 Aluminum Casting Alloys", Acta Materialia, Vol. 57, pp. 1308-1317 (2009).

32. Wang, G., Bian, X., Qiao, J., Zhang, J., "Effect of Be on the Aging Behavior of an Al-Si-Cu-Mg Cast Alloy", Journal of Materials Engineering and Performance, Vol. 13, pp. 99-102 (2004).

33. Kang, H.G., Kida, M., Miyahara, H., Ogi, K., "Age-Hardening Characteristics of Al-Si-Cu-Base Cast Alloys" AFS Transactions Vol. 107, pp. 507-515 (1999).

34. Li, Y.J., Brusethaug, S., Olsen, A., "Influence of $\mathrm{Cu}$ on the Mechanical Properties and Precipitation Behavior of AlSi7Mg0.5 Alloy during Aging Treatment", Scripta Materialia, Vol. 54, pp. 99-103 (2006).

35. Dahata, N., "Fillability, Microstructure and Mechanical Properties in Lost Foam Casting of B206 Aluminum-Copper Alloy", M.A.Sc. Thesis, Ryerson University, Toronto, Ontario, Canada (2007).

36. Gerold, V., "Precipitation Hardening. In: Nabarro, F.R.N. (Ed.), Dislocations in Solids" North-Holland Publishing Company, Amsterdam, pp. 222 (1979).

37. Dieter, G., "Mechanical Metallurgy", $2^{\text {nd }}$ Edition, McGraw-Hill International, London, pp. 211-219 (1981).

38. Withers, P., Bhadeshia, D., "Residual Stress Part 1 - Measurement Techniques", Materials Science and Technology, Vol. 17, pp. 355-365 (2004).

39. Withers, P., Bhadeshia, D., "Residual Stress Part 2 - Nature and Origins", Materials Science and Technology, Vol. 17, pp. 356-375 (2004).

40. Carrera, E., Rodriguez, A., Talamantes, J., Valtierra, S., Colas, R., "Measurement of Residual Stresses in Cast Aluminum Engine Blocks", Journal of Materials Processing Technology, Vol. 189, pp. 206-210 (2007).

41. Sekar, C.K., "Effect of Heat Treatment Method in Minimizing the Residual Stress Level in Cold Drawn Welded Tubes" (2007), Retrieved December 14, 2010 from http://www.tubenet.org.uk/technical/technical article SRA.shtml

42. Barson, J., Rolfe, S., "Fracture and Fatigue Control in Structures: Applications of Fracture Mechanics", ASTM International, West Conshohocken, PA (1999).

43. Boley, B., Weiner, J., "Theory of Thermal Stresses", John Wiley and Sons., New York, NY (1960).

44. Shen, Y., "Constrained Deformation of Materials: Devices, Heterogeneous Structures and Thermo-Mechanical Modelling", Springer Science + Business Media (2010).

45. Totten, G., MacKenzie, D.S., "Handbook of Aluminum: Physical Metallurgy and Processes", Taylor \& Francis Group, Boca Raton, FL (2003). 
46. Su, X., Jan, J., Lasecki, J., Allison, J., "Thermal and Residual Stress Analysis of an Engine Block with Cast-in Liners", $1^{\text {st }}$ International Symposium on Metallurgical Modelling for Aluminum Alloys, Pittsburgh, U.S.A., October 13-15 (2003).

47. Hutchings, M., Krawitz, A., "Measurement of Residual and Applied Stress using Neutron Diffraction", NATO Advanced Research Workshop on Measurement of Residual and Applied Stress using Neutron Diffraction, Oxford, England, March 18 -22 (1991).

48. Skold, K., Price, D., "Methods of Experimental Physics: Neutron Scattering, Vol. 23, part-C, Academic Press Inc., London (1987).

49. Totten, G., "Handbook of Residual Stress and Deformation of Steel", ASM International, Materials Park, OH (2002).

50. Robinson, J.S., Tanner, D.A., "The Magnitude of Heat Treatment Induced Residual Stresses and the Thermal Relief of Aluminum Alloys", Materials Science Forum, Vol. 404-407, pp. 355-360 (2002).

51. Morales, F., Talamantes-Silva, J., "Cast-In Hypereutectic Aluminum Liners for Engine-Blocks", Journal of Manufacturing Science and Engineering, Vol. 131, pp. 145021-145024 (2009).

52. Gloria, D., Hernandez, F., Valtierra, S., Cisneros, M.A., "Dimensional Changes during Heat Treating of an Automotive 319 Alloy", 20 $0^{\text {th }}$ ASM Heat Treating Conference, St. Louis, MO, October 9 -12 (2000).

53. Hunsicker, H.Y., "Dimensional Changes in Heat Treating Aluminum Alloys", Metallurgical Transactions A., Vol. 11, pp. 759-773 (1980).

54. Boileau, J.M., Cloutier, C.A., Godlewski, L.A., Reeber-Symanksi, P.A., Wolverton, C., Allison, J.E., "The Dimensional Stability of Cast 319 Aluminum", SAE Transactions, Vol. 112, pp. 385-395 (2003).

55. ASTM B557, "Standard Test Methods for Tension Testing Wrought and Cast Aluminum and Magnesium Alloy Products", ASTM International, West Conshohocken, PA (2006).

56. Simpson, R., "The Use of Chills as a Means of Influencing Solidification in Lost Foam Cast Aluminum Alloy 356", M.E.Sc. Thesis, University of Western Ontario, London, Ontario, Canada (1997).

57. Vazquez-Lopez, C., Calderone, A., Rodriguez, M.E., Velasco, E., Cano, S., Colas, R., Valtierra, S., "Influence of Dendrite Arm Spacing on the Thermal Conductivity of an Aluminum-Silicon Casting Alloy", Journal of Materials Research, Vol. 15, pp. 85-91 (2000).

58. Mandal, A., Maiti, R., Chakraborty, M., Murty, B.S., "Effect of $\mathrm{TiB}_{2}$ Particles on Aging Response of Al-4Cu Alloy", Materials Science and Engineering A, Vol. 386, pp. 296-300 (2004).

59. Unlu, N., "Preparation of High Quality Al TEM Specimens via a Double-jet Electropolishing Technique”, Materials Characterization, Vol. 59, pp. 547-553 (2008).

60. Porter. D., Easterling, K., "Phase Transformations in Metals and Alloys", $2^{\text {nd }}$ Edition, Chapman \& Hall, London (1992). 
61. Tavitas-Medrano, F.J., Valtierra, S., Gruzleski, J.E., Samuel, F.H., Doty, H.W., “A TEM Study of the Aging Behavior of 319 type Alloys", AFS Transactions, Vol. 116, pp. 99114 (2008).

62. Skrotzki, B., Shiflet, G.J., Starke, E.A., "On the Effect of Stress on Nucleation and Growth of Precipitates in an Al-Cu-Mg-Ag Alloy", Metallurgical and Materials Transactions A, Vol. 27, pp. 3431-3444 (1996).

63. Chen, C.L., Richter, A., Thomson, R.C., "Mechanical Properties of Intermetallic Phases in Multi-component Al-Si alloys using Nanoindentation", Intermetallics, Vol. 17, pp. 634-641, (2009).

64. Bichler, L., "Phenomenological Studies of Hot Tearing during Solidification of Magnesium Alloys", Ph.D. Thesis, Ryerson University, Toronto, Ontario, Canada (2009).

65. Lukas, H.L., “Aluminum-Silicon-Copper”, Ternary Alloys, Vol. 5, pp. 11-21 (1992). 